\title{
Clinical and biomarker correlates of genetic risk factors for Alzheimer's disease
}

Citation for published version (APA):

Elias-Sonnenschein, L. S. (2013). Clinical and biomarker correlates of genetic risk factors for Alzheimer's disease. [Doctoral Thesis, Maastricht University]. Maastricht University.

https://doi.org/10.26481/dis.20130424le

Document status and date:

Published: 01/01/2013

DOI:

10.26481/dis.20130424le

Document Version:

Publisher's PDF, also known as Version of record

\section{Please check the document version of this publication:}

- A submitted manuscript is the version of the article upon submission and before peer-review. There can be important differences between the submitted version and the official published version of record.

People interested in the research are advised to contact the author for the final version of the publication, or visit the DOI to the publisher's website.

- The final author version and the galley proof are versions of the publication after peer review.

- The final published version features the final layout of the paper including the volume, issue and page numbers.

Link to publication

\footnotetext{
General rights rights.

- You may freely distribute the URL identifying the publication in the public portal. please follow below link for the End User Agreement:

www.umlib.nl/taverne-license

Take down policy

If you believe that this document breaches copyright please contact us at:

repository@maastrichtuniversity.nl

providing details and we will investigate your claim.
}

Copyright and moral rights for the publications made accessible in the public portal are retained by the authors and/or other copyright owners and it is a condition of accessing publications that users recognise and abide by the legal requirements associated with these

- Users may download and print one copy of any publication from the public portal for the purpose of private study or research.

- You may not further distribute the material or use it for any profit-making activity or commercial gain

If the publication is distributed under the terms of Article $25 \mathrm{fa}$ of the Dutch Copyright Act, indicated by the "Taverne" license above, 
Clinical and Biomarker Correlates

\section{of Genetic Risk Factors}

for Alzheimer's Disease 
ISBN/EAN: 978-94-6108-423-1

Graphic design and layout: GAZmedia

Illustrations: Anita Salemink

Print and production: Gildeprint Drukkerijen-Enschede

\section{(c) Copyright LS Elias-Sonnenschein, Maastricht 2013}

All rights reserved. No part of this dissertation may be reproduced, stored or transmitted in any way or by any means without the prior permission of the author or, when applicable, of the publishers of the publications. 


\title{
Clinical and Biomarker Correlates of Genetic Risk Factors for Alzheimer's Disease
}

\author{
DISSERTATION \\ To obtain the degree of Doctor at Maastricht University, \\ on the authority of the Rectus Magnificus, Prof. dr. L.L.G. Soete \\ in accordance with the decision of the Board of Deans, \\ to be defended in public on \\ Wednesday, the 24 th of April 2013 at 14:00 hrs
}

by

Lyzel Samaniego Elias-Sonnenschein 


\section{Supervisor:}

Prof. dr. Frans RJ Verhey

\section{Co-supervisor:}

Dr. Pieter Jelle Visser

\section{Assessment Committee:}

Prof. dr. Marc De Baets, chair

Prof. dr. Christine EM de Die-Smulders

Prof. dr. Cornelia van Duijn-Marja (Erasmus Medical Center, Rotterdam)

Dr. Gunter Kenis

Dr. Bart Rutten

The research described in this dissertation was performed tat the Alzheimer Centrum Limburg of the the Department of Psychiatry and Psychology, School for Mental Health and Neuroscience, Maastricht University, The Netherlands; and at the Institute of Clinical Medicine-Neurology, University of Eastern Finland, Kuopio, Finland.

Financial support for the publication of this dissertation was provided by Alzheimer Nederland, the Internationale Stichting Alzheimer Onderzoek (ISAO), AEGON Nederland NV, Nutricia Advanced Medical Nutrition, Danone ResearchCentre for Specialised Nutrition, Lundbeck and DiaGenic ASA, Norway. GAZmedia sponsored the graphic design and layout.

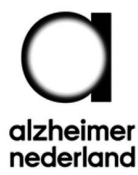




\section{CONTENTS}

$\begin{array}{lll}\text { Chapter } 1 \text { General introduction } & 7\end{array}$

Chapter 2 Predictive value of $A P O E \varepsilon 4$ allele for progression from $\mathrm{MCl} \quad 21$ to AD-type dementia: a meta-analysis Journal of Neurology, Neurosurgery and Psychiatry, 2011

Chapter 3 Cochrane diagnostic test accuracy protocols: Addendum to 63 Chapter 2

APOE $\varepsilon 4$ allele for the diagnosis of Alzheimer's disease and other dementia disorders in people with $\mathrm{MCl}$ in a primary care setting

Revision submitted to the Cochrane Collaboration

Chapter 4 Neuropsychiatric symptoms related to the APOE \&4 allele in individuals with mild cognitive impairment in the DESCRIPA and ADNI cohorts

Submitted

Chapter 5 Relationship between genetic risk factors and markers for 115 Alzheimer's disease pathology Biomarkers in Medicine, 2012

Chapter 6 Biomarker and cognitive correlates of AD risk genes in 161 nondemented individuals with cognitive impairment Under review

Chapter 7 Genetic variants associated with Alzheimer's disease and 191 cerebrospinal fluid biomarkers in a Finnish case-control study PLOS ONE 2013 (In press)

Chapter 8 Effects of $M S_{4} A$ variants on cerebrospinal fluid $A \beta_{1-42}$ in the EDAR cohort

Submitted

Chapter 9 General discussion 233

Summary 278

Samenvatting 281

Acknowledgments 285

Curriculum vitae 292

Publications 294 
Alzheimer's disease (AD) is multifaceted and influenced by many factors. The goal of our research is to better understand how genetic risk factors may influence the pathophysiology and clinical presentation of $A D$. 


\section{CHAPTER 1}

General introduction 


\section{ALZHEIMER'S DISEASE}

Alzheimer's disease (AD) is the most common cause of dementia. ${ }^{1}$ It is characterized by progressive neuronal death, memory loss, behavioral and affective changes, and impairments in activities of daily living. It culminates in dementia. The global prevalence of dementia in 2012 has been estimated at 35.6 million, which is expected to double by 2030 and more than triple by $2050^{2}$ because of advancing age in the population. The global socio-economic costs of dementia are enormous, with estimates at US $\$ 604$ billion in 2010. ${ }^{2}$

There is currently no cure for AD-type dementia. Available treatments are aimed at slowing the progression of the disease and address its associated symptoms. Often, treatment is sought when the disease is already at an advanced phase because only then do clinical symptoms become evident. Early diagnosis of $A D$ is important, as drugs with disease-delaying potentials are most effective at the predementia stage. Identifying those who are at risk is equally important for prognostic purposes. Individuals with mild cognitive impairment (MCl) have been reported to have an increased risk of developing AD. About $10-30 \%$ of $\mathrm{MCl}$ cases have been reported to progress to AD.3.4

Early detection of $A D$ entails understanding the complex relationship between risk factors and $A D$ pathophysiology. In order to further clarify this relationship, we investigated in the thesis the relation between genetic risk factors, and biomarkers and clinical correlates of $A D$. We focused on single nucleotide polymorphisms (SNPs), which are specific variations in the gene; and on sporadic $A D$ with no obvious familial aggregation, which represents the majority of AD cases.

Genetic risk factors do not directly cause the disease but are associated with increased risk for developing the disease. Until recently, the only established genetic risk factor for sporadic $A D$ has been the apolipoprotein $\mathrm{E}(A P O E) \varepsilon 4$ allele. ${ }^{5-7}$ With the development of highthroughput techniques in the past years, other variants that predispose individuals to develop AD have been identified in genome-wide association studies (GWAS) with clinical diagnosis of AD as outcome (for a review, see ${ }^{8}$ ) and with biomarkers as outcome. ${ }^{9-11}$ Candidate gene studies, in turn, have reported how other potential AD risk genes affect pathways or biomarkers in AD. Compared to APOE, these SNPs exert 
only small risk effects but when taken in combination with other risk variants or non-genetic risk factors may have a considerable role in the development of AD.

Biomarkers are objectively quantifiable measures that could be used as indicators of pathogenic processes in AD. The pathological hallmarks of $A D$ are neuritic plaques, which are mainly composed of aggregated amyloid- $\beta(A \beta)$, and neurofibrillary tangles consisting of hyperphosphorylated tau (p-tau) proteins. ${ }^{1}$ There are many isoforms of $A \beta$, but $A \beta_{1-42}$ has been shown to be more prone to aggregate. ${ }^{12} A \beta$ and tau concentrations can be measured in vivo in cerebrospinal fluid (CSF) and through positron emission tomography (PET) imaging. Changes in $A \beta$ and tau levels years before the onset of dementia have been reported. ${ }^{13,14}$ As neuritic plaques and tangles build up, the brain shrinks. The hippocampus in the medial temporal lobe is one of the earliest structures to be affected in AD. ${ }^{5,16}$ Hippocampal volume loss has been reported in the early stage of the disease. ${ }^{17}$ In the thesis, we focused on the biomarkers CSF A $\beta_{1-42}$ and tau, and hippocampal volume as measured by magnetic resonance imaging (MRI).

With respect to clinical correlates, cognitive decline is a key feature of $A D$ and is already present in the predementia stage. Significant impairment in episodic memory is a core diagnostic criterion for probable AD. ${ }^{18-20}$ Changes in episodic memory have been reported in nondemented elderly ${ }^{21}$ and in individuals with cognitive impairment. ${ }^{22}$ Meanwhile, neuropsychiatric symptoms are common in predementia. ${ }^{23,}{ }^{24}$ Depression, apathy, agitation and aggression are prevalent symptoms that have been reported in both $\mathrm{MCl}$ and $A D .{ }^{25-27}$ We examined in the thesis the effects of $A D$ risk genes on delayed memory and on 12 neuropsychiatric symptoms: delusions, hallucination, agitation, depression, anxiety, euphoria, apathy, disinhibition, irritability, aberrant motor behavior, nighttime behavior, and appetite/eating abnormalities.

\section{PURPOSE OF THE THESIS}

The goal of our research is to gain better insight on how genetic risk factors influence the pathophysiology and clinical presentation of AD. We strived to attain our goal by investigating the influence of $A D$ risk genes on the clinical and biomarker correlates of AD. Herewith we hope 
to contribute to the development of early diagnostic markers for $A D$ and eventually treatment strategies.

The thesis has three aims that serve as main research questions:

1. To evaluate the predictive and diagnostic value of $A D$ risk genes for $A D$

2. To identify correlations between $A D$ risk variants and clinical markers of $A D$

3. To investigate the relationship between $A D$ risk variants and biomarkers of AD pathology

Related to these aims, we had the following objectives:

Objectives related to aim 1:

1.1 To test the predictive accuracy of the APOE \&4 allele for progression from $\mathrm{MCl}$ to $\mathrm{AD}$

1.2 To test the predictive accuracy of AlzGene top loci for progression to AD in nondemented individuals with cognitive impairments

1.3 To test the association of a selection of candidate genes with the diagnosis of clinical $A D$

Objectives related to aim 2:

2.1 To test the correlation between the APOE \&4 allele and neuropsychiatric symptoms in individuals with $\mathrm{MCl}$

2.2 To test the correlation between top AlzGene loci and memory function in $\mathrm{MCl}$

Objectives related to aim 3 :

3.1 To test the relation between genetic risk factors, and amyloid and tau markers through a literature review

3.2 To test the correlation between AlzGene top loci and CSF markers in $\mathrm{MCl}$

3.3 To test the correlation between AlzGene top loci, and a selection of other GWAS and candidate gene loci, and CSF markers in AD

3.4 To test the correlation between a selection of $A D$ risk genes and CSF markers in non-AD type dementia, $A D, M C l$ and control subjects

3.5 To test the correlation between AlzGene top loci and hippocampal volume markers in $\mathrm{MCl}$ 


\section{APPROACH}

Three main approaches were employed to respond to our aims and objectives. These are described below.

\section{Gene selection}

We first selected genes based on their reported association with $A D$ or effect on $A \beta$ and tau. Next, we classified the genes into one of the four categories below. A summary over the selected genes is shown in Table 1.

1. AlzGene 10 'top results' loci

AlzGene is an online database that provides meta-analyses of published genetic association studies for AD for all polymorphisms with a minor allele frequency of more than $1 \%$ in healthy controls and for which genotype data for the same polymorphism is available in at least four case-control studies. 'T The ranking of 'top results' is according to the interim criteria of the Human Genome Epidemiology Network (HuGENet). ${ }^{28}$ We selected SNPs from the 10 genes that had the strongest association with clinical AD.

2. GWAS with clinical AD as outcome

GWAS is a relatively hypothesis-free approach to determine genotypes of hundreds of thousands of SNPs on a genome-wide scale testing affected vs. controls. This is followed by statistical analyses to investigate differences in allele or genotype frequencies between affected and controls. Due to the multiple tests performed, a strict statistical level, usually $P<5 \times 10^{-8}$, is required to be declared as genome-wide significant. ${ }^{29}$ The outcome is clinical diagnosis of AD. We selected a number of SNPs from genes that were identified in GWAS but were not included in the AlzGene top 10 results.

3. GWAS with biomarkers as outcome

The outcome we specifically looked for were $A \beta$ and tau in CSF, plaques or tangles. The GWAS may be performed in the context of a population study with healthy controls, or in other settings with $A D, M C l$ or controls.

4. Candidate genes

These are genes identified through preconceived hypotheses about the gene's functions. This candidate gene approach allows investigation of complex genetic traits and is a potent approach for direct gene discovery. ${ }^{30}$ We selected SNPs that previously showed a relation with markers for amyloid or tau pathology. 


\section{Review and meta-analysis}

\section{Relation $A P O E \varepsilon_{4}$ allele and progression to $A D$}

We performed an exhaustive search of published literature of prospective cohort studies testing the APOE \&4 allele as predictor for progression from $\mathrm{MCl}$ to $A D$-type dementia. The study was later on elaborated to determine the diagnostic test accuracy of $A P O E-\varepsilon_{4}$ for $A D$ and other dementia in the primary, secondary and community settings. Since outcomes may differ in different settings, we have written three parallel protocols. The protocol for the diagnostic test accuracy in the primary care setting is presented in the thesis as an addendum. The protocols for the secondary care and community settings are found in the Cochrane Collaboration Archie site.

\section{Relation SNPs and biomarkers}

We carried out a systematic review of published literature in which a number of high-risk genetic variants have been studied in relation to $A \beta$ and tau.

\section{Multicenter studies}

We investigated the relation between different SNPs and cognition, neuropsychiatric symptoms, biomarkers and clinical diagnosis in a range of cohorts and diagnostic groups. We used datasets from three different multicenter European cohorts that had DNA for genetic analysis and one dataset from a US-based multicenter study.

\section{DESCRIPA}

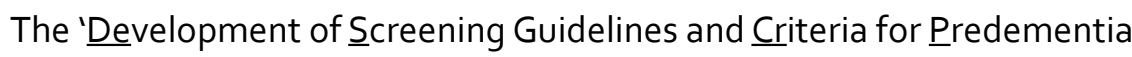
Alzheimer's Disease' (DESCRIPA) multicenter prospective cohort study is part of the European AD Consortium (a general description is found at www.descripa.eu). Its task is to develop screening guidelines and clinical criteria for the diagnosis of predementia AD. DESCRIPA included participants with $\mathrm{MCl}$ and subjective cognitive impairment $(\mathrm{SCl})$, who were followed up for a period of five years. The participants were recruited from 20 memory clinics across Europe. MRI scans and CSF samples were available for a subset of participants. 


\section{FINN-AD}

The Finnish-AD is a collaboration of research institutions and academic hospital in Kuopio, Oulu and Tampere in Finland. It is a multicenter case-control cohort comprised of 890 AD patients from a clinical setting and 701 age-matched healthy controls from a population setting. All patients were diagnosed with probable AD according to NINCDSADRDA $^{18}$ criteria. Control subjects had no symptoms of cognitive impairment based on clinical interview and neuropsychological examination. CSF samples were available for a subset of the cohort.

\section{ADNI}

The Alzheimer's Disease Neuroimaging Initiative is a longitudinal multicenter US-based study whose primary goal has been to test whether MRI, positron emission tomography (PET) and other biological markers, and clinical and neuropsychological assessments can be combined to measure the progression of $\mathrm{MCl}$ and early AD. ADNI recruited participants from 50 centers across the US and Canada. It included at baseline individuals aged 55 to go years clinically diagnosed with probable AD according to NINCDS-ADRDA ${ }^{18}$ criteria, $\mathrm{MCl}$ or normal cognition. The participants underwent routine physical, neurological and neuropsychological assessment. They were followed up for up to three years (for details, see adni.loni.ucla.edu and www.adni-info.org). ADNI has available clinical, imaging and biochemical biomarker data.

\section{EDAR}

The 'beta amyloid oligomers in the early diagnosis of $\underline{A D}$ and as marker for treatment response' (EDAR) is a European multicenter prospective cohort study (for general information, see www.edarstudy.eu) with 15 partners across Europe. Its goal is to develop new diagnostic markers for $A D$ that can be used for the early diagnosis and for the monitoring of treatment response in drug trials. The project focuses on beta amyloid oligomers in CSF, serum and plasma, and the effect of genes involved in beta amyloid processing on these oligomers. EDAR recruited participants with $\mathrm{MCl}, \mathrm{AD}$-type dementia, non- $\mathrm{AD}$ dementia and cognitively healthy controls from memory centers. Participants 
underwent clinical, neurological, neuropsychiatric, neuropsychological and functional assessments up to 18 months. EDAR has available clinical, neuropsychiatric, neuropsychological, imaging and CSF data.

\section{THESIS OUTLINE}

The main research questions, the chapters where we tackled these and the approach used are shown in Figure 1.

In Chapter 2, we performed a meta-analysis to assess the usefulness of $A P O E$ genotyping in predicting progression to $A D$ among patients with $\mathrm{MCl}$, and in selecting subjects for clinical trials aimed at preventing progression to dementia.

Chapter 3 is closely related to Chapter 2. It shows the protocol for the diagnostic test accuracy of APOE for dementia in the primary care setting. The protocol is written for the Cochrane Collaboration, is meant to serve as guide for similar reviews, and is a prerequisite for the conduct of full reviews.

Chapter 4 reports on the relation between neuropsychiatric symptoms and the APOE \&4 allele in $\mathrm{MCl}$ in the DESCRIPA and ADNI cohorts. Analyses were first performed separately for each cohort, and afterwards in the pooled cohort.

Chapter 5 is a qualitative literature review of the possible role of $A D$ genetic risk variants on $A \beta$ and tau measured in vivo in CSF or by positron emission tomography, or upon neuropathological examination.

Chapter 6 is an exploratory study of the correlation between the top 10 AlzGene loci and key markers of AD pathology in CSF, MRI and cognition in nondemented individuals with cognitive impairment in the DESCRIPA study.

Chapter 7 presents the findings of a case-control genetic association study of 25 SNPs, and correlational study of 36 SNPs with CSF biomarkers in the FINN-AD cohort. The research was performed at the University of Eastern Finland in Kuopio.

Chapter 8 further investigates the effects of variants in the $M S_{4} A$ gene cluster on CSF A $\beta$, following findings in Chapter 7. The study was performed in a cohort consisting of patients with $A D, M C l$ and cognitively healthy individuals from the EDAR study. 
Finally, we present in Chapter 9 an overall discussion of the main findings of the studies presented in thesis in the context of current knowledge, relate these to genes in AD pathophysiology, their implications and methodological considerations. We conclude by offering suggestions for future research.

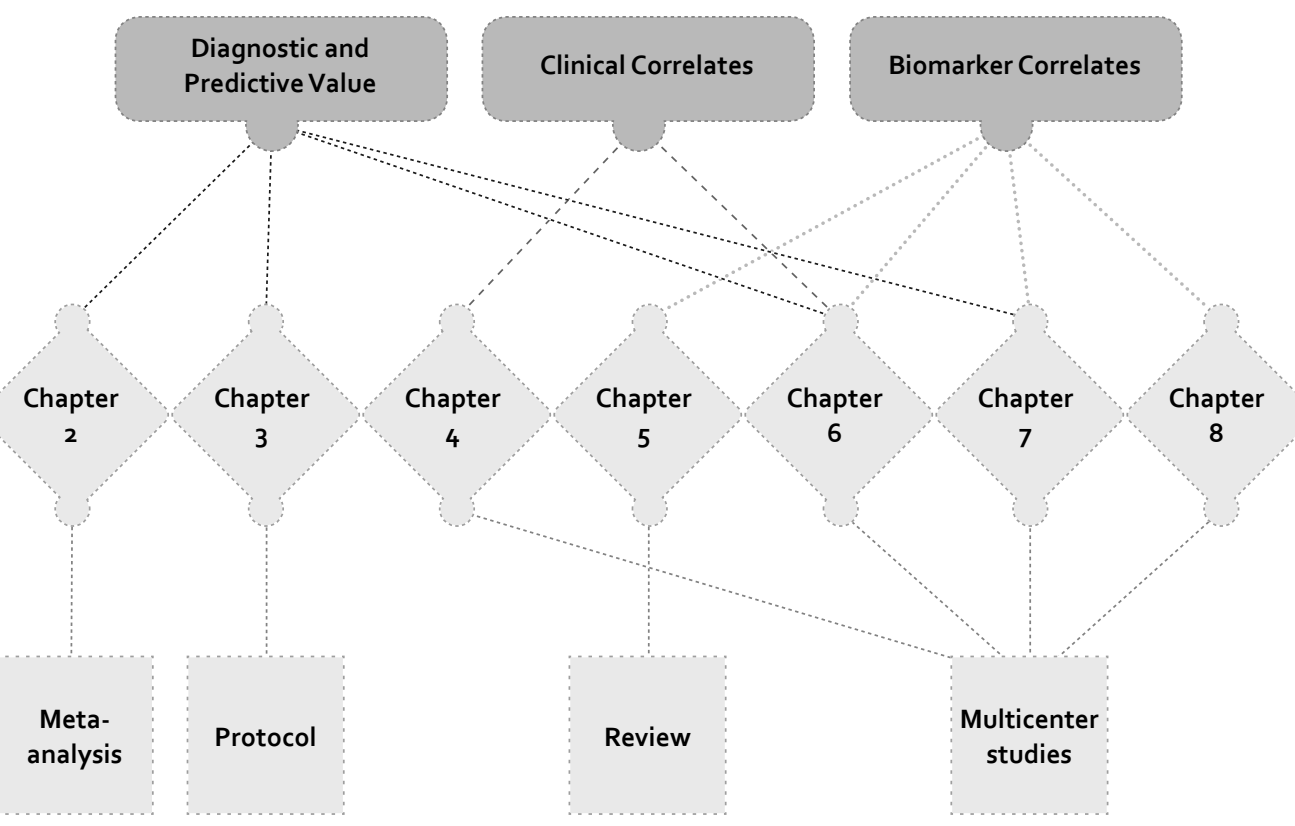

Figure 1 Main research questions and approaches used 
Table 1 List of genes in the thesis

\begin{tabular}{|c|c|c|c|c|c|c|c|}
\hline Gene & Chap2 & Chap3 & Chap4 & Chap5 & Chap6 & Chap7 & Chap8 \\
\hline \multicolumn{8}{|l|}{ Top AlzGene } \\
\hline$A P O E$ & $\sqrt{ }$ & $\sqrt{ }$ & $\sqrt{ }$ & $\sqrt{ }$ & $\sqrt{ }$ & $\sqrt{ }$ & $\sqrt{ }$ \\
\hline$A B C A 7$ & & & & & $\sqrt{ }$ & $\sqrt{ }$ & \\
\hline$B / N_{1}$ & & & & & $\sqrt{ }$ & $\sqrt{ }$ & \\
\hline$C D_{2} A P$ & & & & & $\sqrt{ }$ & $\sqrt{ }$ & \\
\hline$C D_{33}$ & & & & & $\sqrt{ }$ & $\sqrt{ }$ & \\
\hline CLU & & & & & $\sqrt{ }$ & $\sqrt{ }$ & \\
\hline$C R 1$ & & & & $\sqrt{ }$ & $\sqrt{ }$ & $\sqrt{ }$ & \\
\hline$M S_{4} A_{4} E$ & & & & & $\sqrt{ }$ & $\sqrt{ }$ & $\sqrt{ }$ \\
\hline$M S_{4} A 6 A$ & & & & & $\sqrt{ }$ & $\sqrt{ }$ & $\sqrt{ }$ \\
\hline PICALM & & & & $\sqrt{ }$ & $\sqrt{ }$ & $\sqrt{ }$ & \\
\hline \multicolumn{8}{|c|}{ Selection GWAS not in top 10 AlzGene } \\
\hline $\mathrm{EXOC}_{3} \mathrm{~L} 2$ & & & & & & $\sqrt{ }$ & \\
\hline$M S_{4} A_{4} A$ & & & & & & $\sqrt{ }$ & $\sqrt{ }$ \\
\hline MTHFD1L & & & & & & $\sqrt{ }$ & \\
\hline \multicolumn{8}{|c|}{ GWAS with biomarkers as outcome } \\
\hline$A D R A 1$ & & & & $\sqrt{ }$ & & & \\
\hline$A R L_{5} B$ & & & & $\sqrt{ }$ & & & \\
\hline $\mathrm{CDH}_{4}$ & & & & $\sqrt{ }$ & & & \\
\hline $\mathrm{CHN}_{2}$ & & & & $\sqrt{ }$ & & & \\
\hline CYP19A & & & & $\sqrt{ }$ & & $\sqrt{ }$ & \\
\hline$C_{1} Q T N F_{1}$ & & & & $\sqrt{ }$ & & & \\
\hline$E P C_{2}$ & & & & & & $\sqrt{ }$ & \\
\hline$F L J_{21511}$ & & & & $\sqrt{ }$ & & & \\
\hline MSRA & & & & $\sqrt{ }$ & & & \\
\hline MTUS1 & & & & $\sqrt{ }$ & & & \\
\hline NCAM2 & & & & $\sqrt{ }$ & & & \\
\hline RBBP6 & & & & $\sqrt{ }$ & & & \\
\hline RELN & & & & $\sqrt{ }$ & & $\sqrt{ }$ & \\
\hline TMEM65 & & & & $\sqrt{ }$ & & & \\
\hline TMPRSS2 & & & & $\sqrt{ }$ & & & \\
\hline$T_{O M M} \mathrm{M}^{\circ}$ & & & & $\sqrt{ }$ & & $\sqrt{ }$ & \\
\hline$U N C_{5} C$ & & & & $\sqrt{ }$ & & & \\
\hline$U P P_{2}$ & & & & $\sqrt{ }$ & & & \\
\hline \multicolumn{8}{|c|}{ Other candidate genes } \\
\hline$A C E$ & & & & $\sqrt{ }$ & & $\sqrt{ }$ & \\
\hline$B D N F$ & & & & & & $\sqrt{ }$ & \\
\hline CYP46A1 & & & & & & $\sqrt{ }$ & \\
\hline IDE & & & & & & $\sqrt{ }$ & \\
\hline MAPT & & & & $\sqrt{ }$ & & $\sqrt{ }$ & \\
\hline MAPT $\mathrm{H}_{1} / \mathrm{H}_{2}$ & & & & $\sqrt{ }$ & & & \\
\hline$P P P_{3} R_{1}$ & & & & & & $\sqrt{ }$ & \\
\hline SORL1 & & & & $\sqrt{ }$ & & $\sqrt{ }$ & \\
\hline$T F$ & & & & & & $\sqrt{ }$ & \\
\hline$T O M M_{4} 0^{\mathrm{a}}$ & & & & $\sqrt{ }$ & & $\sqrt{ }$ & \\
\hline
\end{tabular}

Abbreviations: Chap=chapter; GWAS=genome-wide association study

a Different single nucleotide polymorphisms from those identified in GWAS with biomarker as outcome. 


\section{Gene names}

$A B C A 7$

$A C E$

$A D R A 1$

$A R L 5 B$

APOE

$B / N_{1}$

$B D N F$

$C D_{2} A P$

$C D_{33}$

$\mathrm{CDH}_{4}$

$\mathrm{CHN}_{2}$

CLU

CR1

CYP19A

CYP46A

$C_{1} Q_{T N F}$

$E P C 2$

$\mathrm{EXOC}_{3} \mathrm{~L}_{2}$

FLJ21511

IDE

MAPT

$M_{4} A_{4} A$

$M S_{4} A 4 E$

$M S_{4} A 6 A$

MSRA

MTHFD $1 L$

MTUS1

NCAM2

PICALM

$P P_{3} R_{1}$

RELN

RBBP6

SORL1

TF

TMEM65

TMPRSS2

$T_{O M M} \mathrm{O}$

$U \mathrm{NC}_{5} \mathrm{C}$

$U P P_{2}$
ATP-binding cassette, subfamily A, member 7

angiotensin I converting enzyme 1

adrenoceptor alpha $1 \mathrm{~B}$

ADP-ribosylation factor-like $5 \mathrm{~B}$

apolipoprotein $\mathrm{E}$

bridging integrator 1

brain-derived neurotrophic factor

$\mathrm{CD}$ 2-associated protein

$\mathrm{CD} 33$ molecule

cadherin 4, type 1, R-cadherin

chimerin 2

clusterin

complement component receptor 1

cytochrome $\mathrm{P} 450$, family 19 , subfamily a, polypeptide 1

cytochrome $\mathrm{P} 450$, family 46 , subfamily $A$, polypeptide

$\mathrm{C}_{1} \mathrm{q}$ and tumor necrosis factor related protein 1

enhancer of polycomb homolog 2

exocyst complex component 3 -like 2

similar to hypothetical protein $\mathrm{FL} 21511$

insulin-degrading enzyme

microtubule-associated protein tau

membrane-spanning 4-domains, subfamily $A$, member $4 \mathrm{~A}$

membrane-spanning 4-domains, subfamily $A$, member $4 \mathrm{E}$

membrane-spanning 4-domains, subfamily $A$, member $6 \mathrm{~A}$

methionine sulfoxide reductase $\mathrm{A}$

methylenetetrahydrofolate dehydrogenase 1-like

microtubule associated tumor suppressor 1

neural cell adhesion molecule 2

phosphatidylinositol binding clathrin assembly protein

protein phosphatase 3, regulatory subunit B, alpha

reelin

retinoblastoma binding protein 6

sortilin-related receptor

transferrin

transmembrane protein 65

transmembrane protease, serine 2

translocase of outer mitochondrial membrane 40 homolog

unc-5 homolog $\mathrm{C}$

uridine phosphorylase 2 


\section{REFERENCES}

1. Blennow K, de Leon MJ, Zetterberg H. Alzheimer's disease. Lancet 2006; 368(9533): 387-403.

2. WHO. Dementia: A Public Health Priority. Geneva, Switzerland: World Health Organization; 2012.

3. Bennet $D$, Wilson RS, Schneider JA. Natural history of mild cognitive impairment in older persons. Neurology 2002; 59: 198-205.

4. Petersen RC, Smith GE, Waring SC, Ivnik RJ, Tangalos EG, Kokmen E. Mild cognitive impairment: clinical characterization and outcome. Arch Neurol 1999; 56(3): 303-8.

5. Strittmatter WJ, Saunders AM, Schmechel D, Pericak-Vance M, Enghild J, Salvesen GS, et al. Apolipoprotein $\mathrm{E}$ : high-avidity binding to beta-amyloid and increased frequency of type 4 allele in late-onset familial Alzheimer disease. Proc Natl Acad SciU S A 1993; 90(5): 1977-81.

6. Farrer LA, Cupples LA, Haines JL, Hyman B, Kukull WA, Mayeux R, et al. Effects of age, sex, and ethnicity on the association between apolipoprotein $\mathrm{E}$ genotype and Alzheimer disease. $\mathrm{A}$ meta-analysis. APOE and Alzheimer Disease Meta Analysis Consortium. JAMA 1997; 278(16): 1349-56.

7. Bertram L, McQueen MB, Mullin K, Blacker D, Tanzi RE. Systematic meta-analyses of Alzheimer disease genetic association studies: the AlzGene database. Nat Genet 2007; 39(1): 17-23.

8. Bertram L, Tanzi RE. Genome-wide association studies in Alzheimer's disease. Hum Mol Genet 2009; 18(R2): R137-45.

9. Kim S, Swaminathan S, Shen L, Risacher SL, Nho K, Foroud T, et al. Genome-wide association study of CSF biomarkers Abeta1-42, t-tau, and p-tau181p in the ADNI cohort. Neurology 2011; 76(1): 69-79.

10. Han MR, Schellenberg GD, Wang LS. Genome-wide association reveals genetic effects on human Abeta 42 and tau protein levels in cerebrospinal fluids: a case control study. BMC Neurol 2010; 10: 90.

11. Kramer PL, Xu H, Woltjer RL, Westaway SK, Clark D, Erten-Lyons D, et al. Alzheimer disease pathology in cognitively healthy elderly: a genome-wide study. Neurobiol Aging 2011; 32(12): 2113-22.

12. Bu G. Apolipoprotein $E$ and its receptors in Alzheimer's disease: pathways, pathogenesis and therapy. Nat Rev Neurosci 2009; 10(5): 333-44.

13. Hansson O, Zetterberg H, Buchhave P, Londos E, Blennow K, Minthon L. Association between CSF biomarkers and incipient Alzheimer's disease in patients with mild cognitive impairment: a follow-up study. Lancet Neurol 2006; 5(3): 228-34.

14. Buchhave $P$, Minthon $L$, Zetterberg $H$, Wallin AK, Blennow $K$, Hansson O. Cerebrospinal fluid levels of beta-amyloid 1-42, but not of tau, are fully changed already 5 to 10 years before the onset of Alzheimer dementia. Arch Gen Psychiatry 2012; 69(1): 98-106.

15. Chupin M, Gerardin E, Cuingnet R, Boutet C, Lemieux L, Lehericy S, et al. Fully automatic hip- 
pocampus segmentation and classification in Alzheimer's disease and mild cognitive impairment applied on data from ADNI. Hippocampus 2009; 19(6): 579-87.

16. Padurariu M, Ciobica A, Mavroudis I, Fotiou D, Baloyannis S. Hippocampal neuronal loss in the $C_{1}$ and $C A 3$ areas of Alzheimer's disease patients. Psychiatr Danub 2012; 24(2): 152-8.

17. Sabuncu MR, Desikan RS, Sepulcre J, Yeo BT, Liu H, Schmansky NJ, et al. The dynamics of cortical and hippocampal atrophy in Alzheimer disease. Arch Neurol 2011; 68(8): 1040-8.

18. McKhann G, Drachman D, Folstein M, Katzman R, Price D, Stadlan EM. Clinical diagnosis of Alzheimer's disease: report of the NINCDS-ADRDA Work Group under the auspices of Department of Health and Human Services Task Force on Alzheimer's Disease. Neurology 1984; 34(7): 939-44.

19. Dubois B, Feldman HH, Jacova C, Dekosky ST, Barberger-Gateau P, Cummings J, et al. Research criteria for the diagnosis of Alzheimer's disease: revising the NINCDS-ADRDA criteria. Lancet Neurol 2007; 6(8): 734-46.

20. APA. Diagnostic and statistical manual of mental disorders (4th edition) (DSM-IV). Washington, DC: American Psychiatric Association; 1994.

21. Bondi MW, Salmon DP, Monsch AU, Galasko D, Butters N, Klauber MR, et al. Episodic memory changes are associated with the APOE-epsilon 4 allele in nondemented older adults. Neurology 1995; 45(12): 2203-6.

22. Dik MG, Jonker C, Bouter LM, Geerlings MI, van Kamp GJ, Deeg DJ. APOE-epsilon 4 is associated with memory decline in cognitively impaired elderly. Neurology 2000; 54(7): 1492-7.

23. Apostolova LG, Cummings JL. Neuropsychiatric manifestations in mild cognitive impairment: a systematic review of the literature. Dement Geriatr Cogn Disord 2008; 25(2): 115-26.

24. Monastero R, Mangialasche F, Camarda C, Ercolani S, Camarda R. A systematic review of neuropsychiatric symptoms in mild cognitive impairment. J Alzheimers Dis 2009; 18(1): 11-30.

25. Feldman $H$, Scheltens $P$, Scarpini E, Hermann N, Mesenbrink P, Mancione $L$, et al. Behavioral symptoms in mild cognitive impairment. Neurology 2004; 62(7): 1199-201.

26. Lyketsos CG, Lopez O, Jones B, Fitzpatrick AL, Breitner J, DeKosky S. Prevalence of neuropsychiatric symptoms in dementia and mild cognitive impairment: results from the cardiovascular health study. JAMA 2002; 288(12): 1475-83.

27. Sierksma AS, van den Hove DL, Steinbusch HW, Prickaerts J. Major depression, cognitive dysfunction and Alzheimer's disease: is there a link? Eur J Pharmacol 2010; 626(1): 72-82.

28. Ioannidis JP, Boffetta P, Little J, O'Brien TR, Uitterlinden AG, Vineis P, et al. Assessment of cumulative evidence on genetic associations: interim guidelines. Int J Epidemiol 2008; 37(1): 120-32.

29. Bertram L, Lill CM, Tanzi RE. The genetics of Alzheimer disease: back to the future. Neuron 2010; 68(2): 270-81.

30. Zhu M, Zhao S. Candidate gene identification approach: progress and challenges. Int J Biol Sci 2007; 3(7): 420-7. 
$A P O E-\varepsilon_{4}$ is by far the strongest known genetic risk factor for $A D$. By combining data from a large number of studies, we assessed the clinical utility of APOE-E4 for people with mild cognitive impairment. 
LS Elias-Sonnenschein, W Viechtbauer, IHGB Ramakers, FRJ Verhey, PJ Visser Journal of Neurology, Neurosurgery \& Psychiatry. 2011; 82 (10):1149-56

\section{CHAPTER 2}

Predictive value of $A P O E \varepsilon_{4}$ allele for progression from $\mathrm{MCl}$ to $A D$-type dementia: a meta-analysis 


\section{ABSTRACT}

Background: The identification of subjects with mild cognitive impairment $(\mathrm{MCl})$ at high risk for Alzheimer's disease (AD) is important for prognosis and early intervention. The APOE \&4 allele is the strongest known genetic risk factor for $A D$. We performed a meta-analysis to establish the predictive accuracy of the APOE 84 allele for progression from $\mathrm{MCl}$ to AD-type dementia.

Methods: We included 35 prospective cohort studies of subjects with $\mathrm{MCl}$, including 6095 subjects, of whom 1236 progressed to AD-type dementia after 2.9 years of follow-up. Pooled estimates of the odds ratio (OR), sensitivity, specificity, positive and negative predictive values (PPV and NPV), and positive and negative likelihood ratios ( $L R+$ and LR-) were obtained using random-effects models.

Results: The OR for subjects with $\mathrm{MCl}$ who are carriers of the APOE 84 allele to progress to $A D$-type dementia was 2.29 ( $95 \% \mathrm{Cl} 1.88$ to 2.80 ), the sensitivity was $0.53(95 \% \mathrm{Cl} 0.46$ to 0.61$)$, the specificity was 0.67 ( $95 \% \mathrm{Cl} 0.62$ to 0.71$)$, the PPV was $0.57(95 \% \mathrm{Cl} 0.48$ to 0.66$)$, the NPV was 0.75 ( $95 \% \mathrm{Cl} 0.70$ to 0.80$)$, the LR+ was 1.60 ( $95 \% \mathrm{Cl} 1.48$ to 1.72$)$, and the LR-was 0.75 ( $95 \% \mathrm{Cl} 0.67$ to 0.82$)$. Meta-regression showed that sensitivity, specificity, and NPV were dependent on age, APOE 84 allele background prevalence, or follow-up length.

Conclusions: The APOE \&4 allele is associated with a moderately increased risk for progression from $\mathrm{MCl}$ to $\mathrm{AD}$-type dementia. The low sensitivity and PPV makes genotyping of limited value for predicting $A D$-type dementia in clinical practice. For trials aiming to prevent progression from $\mathrm{MCl}$ to $\mathrm{AD}$-type dementia, APOE genotyping may be of value as it helps to select subjects with a higher risk for progression to AD-type dementia.

Keywords: APOE, Alzheimer, mild cognitive impairment, meta-analysis, predictive value, sensitivity, specificity, meta-regression 


\section{INTRODUCTION}

Subjects with mild cognitive impairment $(\mathrm{MCl})$ have an increased risk for Alzheimer's disease (AD), but not all subjects will eventually become demented. ${ }^{1}$ Identifying subjects with $\mathrm{MCl}$ at high risk for $\mathrm{AD}$ is important in order to give these subjects a prognosis. Drugs with the potential to modify the disease progression are suggested to be most effective in the predementia stage of $A D$.

The apolipoprotein $E(A P O E) \& 4$ allele is the strongest known genetic risk factor for $A D$. It is supposed to alter beta amyloid processing, a key pathological event in $A D$, or to modify the response to AD pathology. ${ }^{2}$ Although APOE genotyping is not recommended for the diagnosis of $A D,{ }^{3}$ its role in predicting $A D$-type dementia in subjects with $\mathrm{MCl}$ is unclear. Previous studies yielded conflicting results, with odds ratios ranging from 0.58 to $16.7^{4,5}$ and with estimates for sensitivity, specificity, and positive predictive value often missing.

We used a meta-analysis approach to establish the predictive value of the $A P O E \& 4$ allele in the progression from $M C I$ to $A D$-type dementia. We also investigated study characteristics that may explain the variability of results between studies using meta-regression analysis. Study characteristics tested included age, background prevalence of the APOE $\& 4$ allele in the population from which subjects were selected, Mini-Mental State Examination (MMSE) score, ${ }^{6}$ length of follow-up, study setting, and type of $\mathrm{MCl}$ definition.

\section{METHODS}

\section{Search strategy}

We searched the PubMed database for publications from 1995 to 2008 on prospective cohort studies of subjects with $\mathrm{MCl}$ or related concepts in which the $A P O E \& 4$ allele was tested as predictor of progression to AD-type dementia. The search terms used were "human" and "amnestic", "amnestic syndrome", "memory impairment", "mild cognitive decline", "mild cognitive impairment", "MCl", "age-associated cognitive decline", "AACD", "age-associated memory impairment", "AAMI", "cognitive impairment no dementia", "CIND", "memory clinic", "memory disorders clinic", or "dementia clinic". APOE 84 was not included in the search terms because this would exclude studies 
that did not contain the term "APOE $\varepsilon_{4}$ " in their abstracts yet provided information on $A P O E$ genotyping in the main text. The search resulted in 17,233 hits. Two authors reviewed the titles and abstracts, and all relevant studies were retrieved. Additional studies were identified from the reference list of retrieved publications.

\section{Study selection}

Studies were included in the analyses if they had data on APOE genotype, defined $\mathrm{MCl}$ as impairment on a cognitive test or as decline in activities of daily function with an overall Clinical Dementia Rating scale score of 0.5 or based on an equivalent measure, ${ }^{7}$ and defined possible or probable $A D$ at follow-up according to any of the following criteria: National Institute of Neurological and Communicative Disorders and Stroke and the Alzheimer's Disease and Related Disorders Association (NINCDS-ADRDA), ${ }^{8}$ Diagnostic and Statistical Manual of Mental Disorders $4^{\text {th }}$ edition (DSM IV),$^{9}$ DSM $3^{\text {rd }}$ edition, ${ }^{10}$ or the International Statistical Classification of Diseases and Related Health Problems $10^{\text {th }}$ Revision. ${ }^{11}$

Of the 17,233 abstracts reviewed, we retrieved 95 full articles in English that were relevant for our study. Of the 95 studies, 6 were excluded because the subjects were already demented at baseline, 3 did not distinguish MCI from $A D, 8$ had as outcome $A D /$ dementia but not conversion from $\mathrm{MCl}$ to $\mathrm{AD}$-type dementia, 6 had as outcome dementia instead of $A D, 1$ did not distinguish CIND from dementia, 7 were not cohort studies, 1 used weighted inclusion, 2 had unclear $A P O E$ genotyping data, 15 had no APOE data, and 11 referred to the same cohort. In the case wherein data from the same study had been reported in multiple papers, we used the paper in which the follow-up was longest, or if that was not different, in which the sample size was largest. Thirty-five studies with AD-type dementia as outcome were finally included in the meta-analysis (Figure 1). ${ }^{12}$

\section{Data extraction}

Three authors independently completed a data extraction form for each study. Studies were classified according to setting in (1) clinical studies, wherein only patients presenting with cognitive impairments 
at a health care facility were included, (2) population-based studies, wherein a random sample of the general population was included, or (3) other studies, wherein subjects were recruited from both clinical and population settings, or through advertisements. $\mathrm{MCl}$ definitions were recorded as measured by (1) objective tests and (2) assessment of functional impairment. Definitions based on objective test performance were subdivided in studies that used amnestic $\mathrm{MCl}(\mathrm{aMCl})$ as inclusion criterion or studies that included both subjects with $\mathrm{aMCl}$ and nonamnestic $\mathrm{MCl}$.

Data on the APOE \&4 allele and outcome were summarized in a $2 \times 3$ table, which specified the number of subjects who were APOE 84 allele carriers and noncarriers who remained stable, progressed to ADtype dementia, or progressed to other types of dementia. We did not subdivide outcome according to number of APOE 84 alleles as only few studies reported data on all APOE genotypes.

Authors were contacted in case of incomplete data. For one study that included data from a drug trial, we included only data from placebo-treated subjects. ${ }^{13}$ For two trials that did not report separate data for placebo-controlled subjects, we included all subjects. ${ }^{14,15}$ In both trials, the drug was not associated with progression to AD-type dementia.

\section{Assessment of methodological quality}

Two authors rated each study using 17 items for subject sampling, reference diagnosis, and test description selected from rating scales for methodological quality of diagnostic and prognostic studies (Supplementary tables 1, 2). ${ }^{16,17}$ In case of discrepancies between scores, a third rater reviewed the paper and a consensus was reached.

\section{Statistical analysis}

Random-effects models were used for the meta-analysis. Egger's regression test was conducted to test for funnel plot asymmetry. An asymmetrical funnel plot and a significant $P$-value could indicate publication bias. The outcome measures were the pooled odds ratio $(\mathrm{OR})$, sensitivity, specificity, positive and negative predictive values (PPV and NPV) and positive and negative likelihood ratios (LR+ and 
LR-). The heterogeneity was assessed by a $\chi^{2}$ test and is designated as $Q$. The amount of heterogeneity for each outcome measure was calculated using DerSimonian-Laird, with $\tau$ as an estimate for the standard deviation of the underlying true outcomes across studies. The proportion of variation due to heterogeneity was likewise computed and expressed as $l^{2}$.

Mixed-effects meta-regression analyses using restricted maximum likelihood (REML) estimation were conducted to examine the influence of average age and MMSE score of the sample, the setting, definition of $\mathrm{MCl}$, length of follow-up, and background $A P O E$ 84 allele frequency in the population in which the study was performed. Information on the background $A P O E \& 4$ allele prevalence in the population from which subjects were recruited was obtained from published data on the prevalence of the APOE $\& 4$ allele in the general population. ${ }^{18,19}$ The Hardy-Weinberg equilibrium was tested using $\chi^{2}$ test in studies that reported the APOE alleles and frequencies. The $A P O E$ alleles are assumed to be in Hardy-Weinberg equilibrium if the $P$-value obtained is greater than 0.05. Average age and MMSE score, follow-up length, and background $A P O E \& 4$ allele prevalence were included as continuous variables.

Analyses were performed using Stata/SE 9.2 for Mac OSX (Stata Corporation, Texas, USA). R was used to create the figures. ${ }^{20}$ In the main analyses, the outcome was dichotomized as nondemented versus $A D$-type dementia at follow-up because not all studies provided data on non-AD dementia at follow-up. In secondary analyses, which included all studies that provided outcome data on non-AD dementia, the outcome was dichotomized as no AD (combining subjects without dementia and subjects with non-AD type dementia) and AD-type dementia. One study presented data on subjects without dementia and subjects with non-AD type dementia as one group. ${ }^{13}$ We included these subjects in the non-dementia group in the main analysis. Analyses were first performed for all studies combined, and then separately for clinical, population-based, and other studies. 


\section{FINDINGS}

\section{Study characteristics}

We included 21 clinical, 6 population, and 8 other studies (Table 1 ).

The studies represented 7322 cases with $\mathrm{MCl}$, of whom $56 \%(n=4092)$ were females. The majority of the subjects were from population studies $(53 \%, n=3914) ; 23 \%(n=1668)$ were from clinical studies, and $24 \%(n=1740)$, from other studies. The pooled average baseline characteristics were as follows: age 72.1 (range 61-87) years, followup period 2.9 (1-8) years, MMSE score 27 (24-29), and education 11.6 (5-16) years.

Subjects with $\mathrm{MCl}$ from the population studies were older and were followed up for a longer period compared with those in the clinical and other studies (age 77.6 versus 70.1 and $73.4 ;$ follow-up length 4.7 versus 2.4 and 3.1 ) but these differences did not reach statistical significance $(P>0.05)$.

APOE genotyping was available for 6095 subjects (Table 2). Of these, 4170 were $A P O E \& 4$ allele noncarriers and 1925 (32\%) were carriers of at least one $A P O E \& 4$ allele. Among APOE 84 allele carriers, 658 (34\%) progressed to AD-type dementia, 32 (1.7\%) developed non-AD type dementias, and the rest were not demented. Of the noncarriers, 578 (14\%) developed AD-type dementia and 56 (1.3\%) developed non-AD type dementias.

Data on zygosity were available for nine studies, representing 794 subjects with $\mathrm{MCl}$ of whom 256 (32\%) progressed to AD-type dementia. The $A P O E$ allele distribution was in Hardy-Weinberg equilibrium in the six studies ( $P>0.05 ; N=762$ cases of $\mathrm{MCl}$ ) that provided the data to allow the calculation of this equilibrium.

\section{Meta-analysis}

Visual inspection of the funnel plot for the OR did not reveal any marked asymmetry and Egger's regression test was not significant $(P=0.94$; Supplementary figure 1 ). This indicates that the obtained results are not likely to be owing to publication bias. A significant overall outcome was obtained for all measures of predictive accuracy (Supplementary table 3). In the presence of at least 1 APOE 84 allele, the pooled OR for AD-type dementia in all studies was $2.29(95 \% \mathrm{Cl} 1.88$ to 2.80 ; Figure 
2), the sensitivity $0.53(95 \% \mathrm{Cl} 0.46$ to 0.61$)$, the specificity $0.67(95 \% \mathrm{Cl}$ 0.62 to 0.71$)$, the PPV $0.43(95 \% \mathrm{Cl} 0.48$ to 0.66$)$, the NPV $0.75(95 \% \mathrm{Cl}$ 0.70 to 0.80$)$, the $L R+1.60(95 \% \mathrm{Cl} 1.48$ to 1.72$)$ and the $L R-0.74(95 \%$ $\mathrm{Cl} 0.67$ to 0.82 ; Supplementary figures 2 a to $2 f$, Table 3). The OR (3.94, $95 \% \mathrm{Cl} 2.09$ to 7.33$)$, specificity (0.93, 95\% Cl 0.90 to 097 ) and LR+ (3.01, $95 \% \mathrm{Cl} 2.11$ to 4.30 ) were higher, and the sensitivity was lower (0.21, $95 \% \mathrm{Cl} 0.10$ to 0.33 ) among $A P O E-\varepsilon 4$ homozygotes (Table 3). Overall effect and heterogeneity across studies $\left(Q, I^{2}\right.$ and $\tau$ values) are shown in Supplementary table 3.

There were some differences in measures of predictive accuracy between settings, but these differences were not statistically significant $(P>0.10)$. Likewise, the type of $\mathrm{MCl}$ definition was not associated with predictive accuracy $(P>0.20)$.

\section{Assessment of methodological quality}

Use of blinding procedures was the only item that could not be rated in more than $70 \%$ of the studies. Based on items that could be scored, $76 \%$ of the clinical studies and $50 \%$ of population-based and other studies had a positive score on at least $80 \%$ of the items.

Meta-regression results showed that studies with a score below $80 \%$ of the items did not differ in any outcome measure from studies that scored positive on at least $80 \%$ of the items. The results were similar when items that could not be scored were rated as a negative score.

\section{Effect of age, background APOE \&4 allele prevalence, MMSE score, and length of follow-up on the predictive accuracy}

Increasing average study age was associated with decreased sensitivity $(P=0.001)$, increased specificity $(P=0.017)$, and decreased NPV $(P=0.003)$ (Figure 3a). Increasing background $A P O E \& 4$ allele prevalence in the population from which subjects were selected significantly increased sensitivity ( $P=0.014)$ and decreased specificity ( $P=0.004$, Figure $3 b)$. An increase in average length of follow-up was associated with decreased sensitivity $(P=0.025)$ and NPV $(P=0.031$, Figure $3 c)$. The average MMSE score was not associated with any outcome measure. The strength of the associations was similar when analyses were performed in 
clinical, population-based, and other studies separately, although some associations were no longer statistically significant (data not shown).

\section{Non-AD type dementia}

Twenty-six studies presented APOE 84 allele data on subjects who progressed to non-AD type dementia. Analyses with outcome AD $(n=771)$ versus no $A D$ ( $n=4049$, including 3961 subjects without dementia and 88 subjects with non-AD type dementia at follow-up), yielded similar measures of predictive accuracy compared to analyses with outcome AD versus no dementia (Supplementary table 4).

\section{DISCUSSION}

\section{Meta-analysis}

Our results showed that the presence of at least one APOE $\& 4$ allele is associated with a moderately high increased risk of progression from $\mathrm{MCl}$ to AD-type dementia. The estimates for sensitivity, specificity, PPV, NPV, LR+, and LR- were low to moderately high. Meta-regression showed that part of the variability between studies could be partly explained by age, background $A P O E \& 4$ allele prevalence, and length of follow-up.

APOE- 44 homozygotes had a four-fold risk of progression to ADtype dementia. The specificity and LR+ were higher and the LR- lower compared to APOE \&4 heterozygotes. However, the sensitivity was lower which could result in a high number of false negatives.

The OR we obtained in the presence of at least 1 APOE $\varepsilon_{4}$ allele and in the presence of two $A P O E \& 4$ alleles were lower than the $O R$ reported in a meta-analysis of cross-sectional studies that compared the prevalence of the APOE 84 allele in subjects with AD-type dementia relative to healthy controls. ${ }^{52,53} \mathrm{~A}$ possible explanation for the lower $\mathrm{OR}$ in our meta-analysis is that not all subjects with $\mathrm{MCl}$ and an $A P O E \& 4$ allele who are destined to progress to AD-type dementia would develop $A D$ during an average follow-up of 3 years. This could have resulted in a higher number of false positives compared to studies that included healthy controls and subjects with AD-type dementia.

It is also worth noting that although we only included subjects from whom APOE data had been collected, a substantial number of 
subjects within these studies did not have APOE data available. This may have caused a bias, but this could not be ascertained.

\section{Meta-regression}

We noted a number of associations between study characteristics and predictive accuracy. With increasing age, the $A P O E \varepsilon_{4}$ allele became less sensitive and more specific for the prediction of $A D$. This suggests that with increasing age, the number of $A P O E \varepsilon_{4}$ allele carriers decreases, which was indeed observed in our data. This could mean that $A P O E \varepsilon 4$ allele carriers may either progress to AD-type dementia at a younger age, or die earlier. ${ }^{54}$ The decrease in sensitivity and negative predictive value with age suggests that with increasing age, subjects with $\mathrm{MCl}$ who progress to AD-type dementia are more likely to be noncarriers of the APOE 84 allele, which is consistent with previous studies..$^{53}$

As would be expected, the NPV decreased with follow-up length. The decrease in sensitivity with follow-up length suggests that subjects without the $A P O E \& 4$ allele progress slower to AD-type dementia than subjects with the $A P O E \& 4$ allele.

A higher background prevalence of the APOE $\& 4$ allele increased sensitivity and decreased specificity, which would be expected. Remarkably, neither the PPV nor the OR depended on the background prevalence, which suggests that the risk of progression to AD-type dementia is similar in populations with different $A P O E \& 4$ allele background prevalence.

A number of study characteristics were not associated with predictive accuracy. Setting was not associated with any outcome measure, although previous studies have shown that progression rates from $\mathrm{MCl}$ to $\mathrm{AD}$-type dementia was higher in clinical settings than in the general population. ${ }^{55}$ Still, we observed relatively large differences in sensitivity and specificity between population-based studies and clinical studies, which may not have reached statistical significance as only six population-based studies were included in the meta-analysis.

Although MMSE score is associated with risk for $A D$, the average study MMSE score did not modify the relation between the APOE $\varepsilon_{4}$ allele and AD-type dementia. It is possible that the spread of MMSE scores in the studies was too small to detect an effect. 
The relation between $A P O E$ genotype and risk for AD-type dementia was also not dependent on the definition of $\mathrm{MCl}$ used. This could be attributed to overlap in $\mathrm{MCl}$ definitions. Definitions based on objective tests could include subjects with mild functional impairment and vice versa. 56,57

\section{Methodological quality of studies}

The scores of methodological quality were moderate. We may have underestimated these scores as they were only based on information provided in the paper. Information on whether clinicians were blinded to the APOE genotype when the follow-up diagnosis was made was often missing. This incomplete reporting was probably because the $A P O E$ genotype was not the main predictor in most studies. Still, we cannot exclude the possibility that the diagnostic accuracy may have been overestimated because clinicians who made the follow-up diagnosis had access to the APOE genotype. However, it should be noted that criteria for the diagnosis of $A D$ refer to clinical information only, not to any biomarker. Our meta-regression analyses showed that methodological quality had no significant effect on measures of predictive accuracy.

\section{Limitations}

Our study has several limitations. First is the significant heterogeneity between studies. We modeled the heterogeneity by means of a random-effects model. With meta-regression, we found possible explanations for this heterogeneity but other factors that contribute to the heterogeneity remain to be identified. Second, the definition of $\mathrm{MCl}$ varied between studies but this effect may have been limited as discussed above. Third, meta-regression was performed with average study scores, which may lead to an under- or overestimation of the relation between the variables tested in the meta-regression and measures of predictive accuracy.

\section{Implications}

The APOE \&4 allele is a moderately strong predictor of progression from $\mathrm{MCl}$ to $\mathrm{AD}$-type dementia. The risk is twice as high for $A P O E-\varepsilon 4$ heterozygotes and four times as high for $A P O E-\varepsilon 4$ homozygotes 
compared with noncarriers. The effect of the APOE 84 allele is consistent. In spite of this, the low sensitivity and PPV makes genotyping of limited value for predicting AD-type dementia in clinical practice since half of the subjects who progressed to AD-type dementia had no APOE 84 allele while $40 \%$ of those with an APOE 84 allele did not progress to $A D$-type dementia over a 3-year period. The background prevalence of the APOE 84 allele in the population should be taken into account when interpreting the sensitivity and specificity of the APOE 84 allele for the prediction of AD-type dementia. APOE genotyping may be of value in selecting subjects for trials that aim to prevent progression to dementia, as it helps select subjects with a higher risk for progression to AD-type dementia. For example, with an annual progression rate of $15 \%$ in subjects with $\mathrm{MCl}$ and $19 \%$ of subjects with $\mathrm{MCl}$ and at least one $A P O E \varepsilon 4$ allele (conversion rate based on the meta-analysis of clinical studies), the number of subjects needed in a 3-year placebo-controlled trial with $50 \%$ on active treatment designed to detect a relative decrease in conversion rate to AD-type dementia of $20 \%$ (assuming a power of $90 \%$, a 2 -sided alpha of $5 \%$, and a drop-out rate of $30 \%$ ) would be 1720 if subjects with $\mathrm{MCl}$ were included, and 1113 if subjects with $\mathrm{MCl}$ and at least one $A P O E \varepsilon_{4}$ allele were included. However, in order to select $1113 \mathrm{MCI}$ APOE \&4 allele carriers, 2572 subjects with $\mathrm{MCl}$ would be needed for screening, which could be a limitation.

\section{FUTURE PERSPECTIVES}

The APOE $\& 4$ allele is thus far the strongest known genetic risk factor for AD. ${ }^{8}$ Interaction with other genes may increase the predictive accuracy. Notably the translocase of outer mitochondrial membrane 40 homolog ( $T O M M_{40}$ ) could interact with the effect of the APOE $\varepsilon 4$ allele on the development of AD. ${ }^{58,59}$ TOMM4O and the apoE protein are both located on chromosome 19, and are both associated with an increased risk for AD. ${ }^{59}$ How strong this interaction will be requires further investigation. In addition, the $A P O E$ genotype may interact with the predictive accuracy of other markers for $A D$, typically markers related to beta amyloid metabolism, such as Pittsburg Compound-B (PIB) and beta amyloid in cerebrospinal fluid (CSF). ${ }^{60}$ Apart from selecting subjects at an increased risk for $A D, A P O E$ genotyping might be useful to select or 
stratify subjects for trials with drugs for which the mode of action of profile of side effects may be dependent on the APOE genotype. ${ }^{61}$

\begin{abstract}
Acknowledgments: The authors acknowledge S Artero (INSERM, France), WM van der Flier and FH Bouwman (Alzheimercentrum VU University Medical Center, Netherlands), T Gabryelewicz (Mossakowski Medical Research Centre Polish Academy of Sciences, Poland), SK Herukka (University of Kuopio, Finland), L deToledo-Morell (Rush University, USA), H Soininen (Kuopio University Hospital, Finland), and D Erten-Lyons (Oregon Layton Aging \& Alzheimer's Disease Center and the Oregon Brain Aging Study, Oregon Health \& Science University, USA) for providing additional data.
\end{abstract}

\title{
REFERENCES
}

1. Bennett $D$, Wilson RS, Schneider JA, et al. Natural history of mild cognitive impairment in older persons. Neurology 2002;59:198-205.

2. Bu G. Apolipoprotein E and its receptors in Alzheimer's disease: pathways, pathogenesis and therapy. Nat Rev Neurosci 2009;10:333-44.

3. American College of Medical Genetics/American Society of Human Genetics Working Group on ApoE and Alzheimer disease. Statement on use of apolipoprotein E testing for Alzheimer disease. JAMA 1995;274:1627-9.

4. Erten-Lyons $\mathrm{D}$, Howieson $\mathrm{D}$, Moore $\mathrm{MM}$, et al. Brain volume loss in $\mathrm{MCl}$ predicts dementia. Neurology 2006;66:233-5.

5. Coria F RI, Bayon C, Cuadrado N, et al. Apolipoprotein E allelic variants predict dementia in elderly patients ith memory impairment. European Journal of Neurology 1995;2:191-3.

6. Folstein MF, Folstein SE, McHugh PR. "Mini-mental state". A practical method for grading the cognitive state of patients for the clinician. J Psychiatr Res 1975;12:189-98.

7. Morris JC, Storandt M, Miller JP, et al. Mild cognitive impairment represents early-stage Alzheimer disease. Arch Neurol 2001;58:397-405.

8. McKhann G, Drachman D, Folstein M, et al. Clinical diagnosis of Alzheimer's disease: report of the NINCDS-ADRDA Work Group under the auspices of Department of Health and Human Services Task Force on Alzheimer's Disease. Neurology 1984;34:939-44. 
9. American Psychiatric Association. Diagnostic and statistical manual of mental disorders (4th edition) (DSM-IV). Washington, DC: APA 1994.

10. American Psychiatric Association. Diagnostic and statistical manual of mental disorders, 3rd ed. rev. Washington, DC: APA 1987.

11. World Health Organization. International Statistical Classification of Diseases and Related Health Problems 1oth revision. WHO, 1993.

12. Moher D, Liberati A, Tetzlaff J, et al. Preferred reporting items for systematic reviews and meta-analyses: the PRISMA statement. PLoS Med, 2009:6:e1000097.

13. Feldman $\mathrm{HH}$, Ferris $\mathrm{S}$, Winblad $\mathrm{B}$, et al. Effect of rivastigmine on delay to diagnosis of Alzheimer's disease from mild cognitive impairment: the InDDEx study. Lancet Neurol 2007;6:501-12.

14. Amieva $\mathrm{H}$, Letenneur $\mathrm{L}$, Dartigues JF, et al. Annual rate and predictors of conversion to dementia in subjects presenting mild cognitive impairment criteria defined according to a population-based study. Dement Geriatr Cogn Disord 2004;18:87-93.

15. Fleisher AS, Sowell BB, Taylor C, et al. Clinical predictors of progression to Alzheimer disease in amnestic mild cognitive impairment. Neurology 2007;68:1588-95.

16. Altman DG. Systematic reviews of evaluations of prognostic variables. BMJ 2001;323:224-8.

17. Deeks JJ. Systematic reviews in health care: systematic reviews of evaluations of diagnostic and screening tests. $B M J$ 2001;323:157-62.

18. Corbo RM, Scacchi R. Apolipoprotein $\mathrm{E}(A P O E)$ allele distribution in the world. Is $A P O{ }^{*} 4 \mathrm{a}$ 'thrifty' allele? Ann Hum Genet 1999;63:301-10.

19. Tsai MS, Tangalos EG, Petersen RC, et al. Apolipoprotein E: risk factor for Alzheimer disease. Am J Hum Genet 1994;54:643-9.

20. R Development Core Team. R: A Language and Environment for Statistical Computing. Vienna, Austria: R Foundation for Statistical Computing, 2009.

21. Tierney MC, Szalai JP, Snow WG, et al. Neurology 1996; 46: 149-54. A prospective study of the clinical utility of ApoE genotype in the prediction of outcome in patients with memory impairment. Neurology 1996;46:149-54.

22. Visser PJ, Jolles J, Jonker C. Course of minimal dementia and predictors of outcome. Int J Geriatr Psychiatry 2002;17:835-41.

23. Korf ES, Wahlund LO, Visser PJ, et al. Medial temporal lobe atrophy on MRI predicts dementia in patients with mild cognitive impairment. Neurology 2004;63:94-100.

24. Maruyama M, Matsui T, Tanji $\mathrm{H}$, et al. Cerebrospinal Fluid Tau Protein and Periventricular White Matter Lesions in Patients with Mild Cognitive Impairment. Archives of Neurology 2004;61:716-20.

25. Mosconi L, Perani D, Sorbi S, et al. MCI conversion to dementia and the APOE genotype: a 
prediction study with FDG-PET. Neurology 2004;63:2332-40.

26. Drzezga A, GrimmerT, Riemenschneider $M$, et al. Prediction of individual clinical outcome in $\mathrm{MCl}$ by means of genetic assessment and (18)F-FDG PET. J Nucl Med 2005;46:1625-32.

27. Hansson $\mathrm{O}$, Zetterberg $\mathrm{H}$, Buchhave $\mathrm{P}$, et al. Association between CSF biomarkers and incipient Alzheimer's disease in patients with mild cognitive impairment: a follow-up study. Lancet Neurol 2006;5:228-34.

28. Wang PN, Lirng JF, Lin KN, et al. Prediction of Alzheimer's disease in mild cognitive impairment: a prospective study in Taiwan. Neurobiol Aging 2006;27:1797-806.

29. Barabash A, Marcos A, Ancin I, et al. APOE, ACT and CHRNA7 genes in the conversion from amnestic mild cognitive impairment to Alzheimer's disease. Neurobiol Aging 2007.

30. Bouwman FH, Schoonenboom SN, van der Flier WM, et al. CSF biomarkers and medial temporal lobe atrophy predict dementia in mild cognitive impairment. Neurobiol Aging 2007;28:1070-4.

31. Devanand DP, Pradhaban G, Liu X, et al. Hippocampal and entorhinal atrophy in mild cognitive impairment: prediction of Alzheimer disease. Neurology 2007;68:828-36.

32. Ewers M, Buerger K, Teipel SJ, et al. Multicenter assessment of CSF-phosphorylated tau for the prediction of conversion of $\mathrm{MCl}$. Neurology 2007;69:2205-12.

33. Gabryelewicz T, Styczynska M, Luczywek E, et al. The rate of conversion of mild cognitive impairment to dementia: predictive role of depression. Int J Geriatr Psychiatry 2007;22:5637.

34. Liu HC, Wang PN, Wang HC, et al. Conversion to dementia from questionable dementia in an ethnic Chinese population. J Geriatr Psychiatry Neurol 2007;20:76-83.

35. Rozzini L, Chilovi BV, Conti M, et al. Conversion of amnestic Mild Cognitive Impairment to dementia of Alzheimer type is independent to memory deterioration. Int J Geriatr Psychiatry 2007;22:1217-22.

36. Caroli A, Testa C, Geroldi C, et al. Cerebral perfusion correlates of conversion to Alzheimer's disease in amnestic mild cognitive impairment. J Neurol 2007;254:1698-707.

37. Gavrilova SI, Fedorova YB, Roshchina IF, et al. Prognosis of mild cognitive impairment syndrome: data from a two-year clinical follow-up study. Neurosci Behav Physiol 2008;38:129-34.

38. Forsberg A, Engler $\mathrm{H}$, Almkvist $\mathrm{O}$, et al. PET imaging of amyloid deposition in patients with mild cognitive impairment. Neurobiol Aging 2008;29:1456-65.

39. Nobili F, Salmaso D, Morbelli S, et al. Principal component analysis of FDG PET in amnestic $\mathrm{MCl}$. Eur J Nucl Med Mol Imaging 2008;35:2191-202.

40. Touchon J, Ritchie K. Prodromal cognitive disorder in Alzheimer's disease. Int J Geriatr Psychiatry 1999;14:556-63. 
41. Hsiung GY, Sadovnick AD, Feldman H. Apolipoprotein E epsilon4 genotype as a risk factor for cognitive decline and dementia: data from the Canadian Study of Health and Aging. Cmaj 2004;171:863-7.

42. Aggarwal NT, Wilson RS, Beck TL, et al. The apolipoprotein E epsilon 4 allele and incident Alzheimer's disease in persons with mild cognitive impairment. Neurocase 2005;11:3-7.

43. Tapiola T, Pennanen C, Tapiola M, et al. MRI of hippocampus and entorhinal cortex in mild cognitive impairment: a follow-up study. Neurobiol Aging 2008;29:31-8.

44. Artero $S$, Ancelin ML, Portet F, et al. Risk profiles for mild cognitive impairment and progression to dementia are gender specific. J Neurol Neurosurg Psychiatry 2008;79:979-84.

45. Jack CR Jr, Petersen RC, XuYC, et al. Prediction of AD with MRI-based hippocampal volume in mild cognitive impairment. Neurology 1999;52:1397-403.

46. Albert MS, Moss MB, Tanzi R, et al. Preclinical prediction of AD using neuropsychological tests. J Int Neuropsychol Soc 2001;7:631-9.

47. Stoub TR, Bulgakova M, Leurgans $S$, et al. MRI predictors of risk of incident Alzheimer disease: a longitudinal study. Neurology 2005;64:1520-4.

48. Griffith HR, Netson KL, Harrell LE, et al. Amnestic mild cognitive impairment: diagnostic outcomes and clinical prediction over a two-year time period. J Int Neuropsychol Soc 2006;12:166-75.

49. Lee DY, Youn JC, Choo IH, et al. Combination of clinical and neuropsychologic information as a better predictor of the progression to Alzheimer disease in questionable dementia individuals. Am J Geriatr Psychiatry 2006;14:130-8.

50. Herukka SK, Helisalmi S, Hallikainen M, et al. CSF Abeta42, Tau and phosphorylated Tau, APOE epsilon 4 allele and $\mathrm{MCl}$ type in progressive $\mathrm{MCl}$. Neurobiol Aging 2007;28:507-14.

51. The ${ }_{3} C$ Study Group. Vascular factors and risk of dementia: design of the Three-City Study and baseline characteristics of the study population. Neuroepidemiology 2003;22:316-325.

52. Rubinsztein DC, Easton, D.F. Apolipoprotein E Genetic Variation and Alzheimer's Disease: A Meta-Analysis. Dement Geriatr Cog Disord 1999;10:199-209.

53. Farrer LA, Cupples LA, Haines JL, et al. Effects of age, sex, and ethnicity on the association between apolipoprotein $\mathrm{E}$ genotype and Alzheimer disease. A meta-analysis. APOE and Alzheimer Disease Meta Analysis Consortium. JAMA 1997;278:1349-56.

54. Tilvis RS, Kahonen-Vare MH, Jolkkonen J, et al. Predictors of cognitive decline and mortality of aged people over a 10-year period. J Gerontol A Biol Sci Med Sci 2004;59(3):268-74.

55. Visser PJ, Kester A, Jolles J, et al. Ten-year risk of dementia in subjects with mild cognitive impairment. Neurology 2006;67:1201-7.

56. Visser PJ, Verhey FR. Mild cognitive impairment as predictor for Alzheimer's disease in clinical practice: effect of age and diagnostic criteria. Psychol Med 2008;38:113-22. 
57. Saxton J, Snitz BE, Lopez OL, et al. Functional and cognitive criteria produce different rates of mild cognitive impairment and conversion to dementia. J Neurol Neurosurg Psychiatry 2009;80:737-43.

58. Bekris LM, Galloway NM, Montine TJ, et al. APOE mRNA and protein expression in postmortem brain are modulated by an extended haplotype structure. Am J Med Genet Part B 2009.

59. Roses AD, Lutz MW, Amrine-Madsen $\mathrm{H}$, et al. A TOMM40 variable-length polymorphism predicts the age of late-onset Alzheimer's disease. Pharmacogenomics J 2009:1-10.

6o. Visser PJ, Knopman, D.S. Amyloid imaging in the prediction of Alzheimer-type dementia in subjects with amnestic MCl. Neurology 2009;73:744-5.

61. Salloway S, Sperling R, Gilman S, et al. A phase 2 multiple ascending dose trial of bapineuzumab in mild to moderate Alzheimer disease. Neurology 2009;73:2061-70. 
Table 1 Characteristics of studies included in the meta-analysis

\begin{tabular}{|c|c|c|c|c|}
\hline Study & & $\begin{array}{l}\text { MCl defini- } \\
\text { tion }\end{array}$ & Exclusion criteria & $\begin{array}{l}\text { Sample } \\
\text { size, base- } \\
\text { line ( } \% \text { FU) }\end{array}$ \\
\hline \multicolumn{5}{|c|}{ Clinical studies } \\
\hline 1995 & Coria [5] & $\mathrm{aMCl}$ & DCCD & $56(100)$ \\
\hline 1996 & Tierney [21] & MFI & DCCD & $178(80)$ \\
\hline 2002 & Visser [22] & $\mathrm{aMCl}$ & $D C C D$, age $<40 y$ & $74(85)$ \\
\hline \multirow[t]{4}{*}{2004} & Amieva [14] & $\mathrm{MCl}$ & $D C C D$, age $50-85 y$ & $104(87)$ \\
\hline & Korf [23] & $\mathrm{MCl}$ & $D C C D$, age $<40$ y, FU $<6$ mo & $75(100)^{b}$ \\
\hline & Maruyama [24] & $\mathrm{aMCl}$ & Depression & $57(100)$ \\
\hline & Mosconi [25] & $\mathrm{aMCl}$ & DCCD & $37(100)$ \\
\hline 2005 & Drzezga [26] & $\mathrm{aMCl}$ & DCCD & $30(100)$ \\
\hline \multirow[t]{2}{*}{2006} & Hansson [27] & $\mathrm{aMCl}$ & $D C C D$ & $137(98)$ \\
\hline & Wang [28] & $\mathrm{aMCl}$ & DCCD & $58(100)$ \\
\hline \multirow[t]{8}{*}{2007} & Barabash [29] & $\mathrm{aMCl}$ & DCCD, MMSE $<25$ & $89(100)$ \\
\hline & Bouwman [30] & $\mathrm{MCl}$ & DCCD & $64(92)$ \\
\hline & Devanand [31] & MCI/MFI & DCCD & $139(100)$ \\
\hline & Ewers [32] & $\mathrm{MCl}$ & DCCD & $88(100)^{b}$ \\
\hline & Gabryelewicz [33] & $\mathrm{aMCl}$ & DCCD & $105(100)^{b}$ \\
\hline & Liu [34] & MFI & $D C C D,<65 y$ & $124(90)$ \\
\hline & Rozzini [35] & $\mathrm{aMCl}$ & - & $119(100)$ \\
\hline & Caroli [36] & $\mathrm{aMCl}$ & $\mathrm{DCCD}, \mathrm{MMSE}<24$, age $>$ go y & $28(86)$ \\
\hline \multirow[t]{3}{*}{2008} & Gavrilova [37] & $\mathrm{MCl}$ & $D C C D,<50 y$ & $40(90)$ \\
\hline & Forsberg [38] & $\mathrm{aMCl}$ & - & $21(100)$ \\
\hline & Nobili [39] & $\mathrm{aMCl}$ & DCCD & $36(92)$ \\
\hline \multicolumn{5}{|c|}{ Population-based studies } \\
\hline 1999 & Touchon [40] & MFI & age $<60$ y & $397(50)$ \\
\hline 2004 & Hsiung [41] & $\mathrm{MCI} / \mathrm{MFI}$ & age $<65 y$ & $296(88)$ \\
\hline 2005 & Aggarwal [42] & $\mathrm{MCl}$ & $D C C D$, age $<65 y$ & $242(75)$ \\
\hline 2006 & Erten-Lyons [4] & MFI & $D C C D$, age $<65 y$ & $37(100)^{b}$ \\
\hline \multirow[t]{2}{*}{2008} & Tapiola [43] & $\mathrm{MCl}$ & - & $60(100)$ \\
\hline & Artero [44] & $\mathrm{MCl}$ & age $<65 y$ & $2882(100)^{b}$ \\
\hline \multicolumn{5}{|c|}{ Other studies } \\
\hline 1999 & Jack [45] & $\mathrm{aMCl}$ & $\mathrm{DCCD}$, age $<60 \mathrm{y}$ and $>90 \mathrm{y}$ & $80(96)$ \\
\hline 2001 & Albert [46] & MFI & $D C C D$, age $<65 y$ & $123(99)$ \\
\hline
\end{tabular}




\section{Mean} age, y
Mean educa- MMSE tion, y
Follow-up, y score
Converters to dementia (\% AD)

\begin{tabular}{|c|c|c|c|c|}
\hline 71.2 & - & - & 3 & $30(100)$ \\
\hline 72.3 & 13.9 & 27.6 & 2 & $29(97)^{a}$ \\
\hline 61.1 & 10.5 & 27.7 & 3.7 & $19(100)$ \\
\hline 70.2 & - & 27.7 & 2 & $29(100)$ \\
\hline 62.9 & 10.2 & 26.9 & 2.8 & $37(92)$ \\
\hline 73.9 & 11.6 & 25.6 & 2 & $17(100)$ \\
\hline 67.1 & 9.6 & 28.0 & 1 & $8(100)$ \\
\hline 70.0 & 11.6 & 26.9 & 1.3 & $12(100)$ \\
\hline 71.0 & - & 27.0 & 5.2 & 78 (73) \\
\hline 76.3 & 11.8 & 25.9 & 3 & $19(100)$ \\
\hline 75.0 & - & - & 4.1 & $62(100)^{a}$ \\
\hline 69.6 & - & 25.9 & 1.6 & 33(91) \\
\hline 66.8 & 15.2 & 27.5 & 4.2 & $37(100)$ \\
\hline 70.9 & - & 27.0 & 1.8 & $43(100)$ \\
\hline 69.3 & - & 27.2 & 3.1 & $23(87)$ \\
\hline 74.7 & 10.3 & 25.2 & 1.7 & $42(100)$ \\
\hline 70.6 & 7.8 & 26.9 & 1 & $40(100)$ \\
\hline 70.2 & 9.7 & 26.9 & 1.6 & $10(90)^{a}$ \\
\hline 69.3 & - & 27.5 & 2 & $5(100)$ \\
\hline 63.6 & 12.7 & 28.2 & 0.7 & $7(100)$ \\
\hline $75 \cdot 5$ & 8.7 & 27.5 & 1.1 & $12(92)$ \\
\hline 74.7 & - & 26.9 & 3 & $48(46)$ \\
\hline 77.8 & 9.2 & - & 5 & $147(48)^{a}$ \\
\hline 78.7 & 17.8 & 27.4 & $5 \cdot 7$ & $82(96)^{a}$ \\
\hline 86.9 & 13.8 & 27.3 & 7.6 & $23(96)$ \\
\hline 72.7 & 6.7 & 23.9 & 2.8 & $13(77)$ \\
\hline 74.6 & - & $27.2 \mathrm{C}$ & 4 & $145(77)$ \\
\hline $77 \cdot 7$ & 13.1 & 26.4 & 2.7 & $27(100)$ \\
\hline 72.2 & 14.9 & 29.1 & 3 & $26(88)^{a}$ \\
\hline
\end{tabular}


Table 1 Characteristics of studies included in the meta-analysis Continued

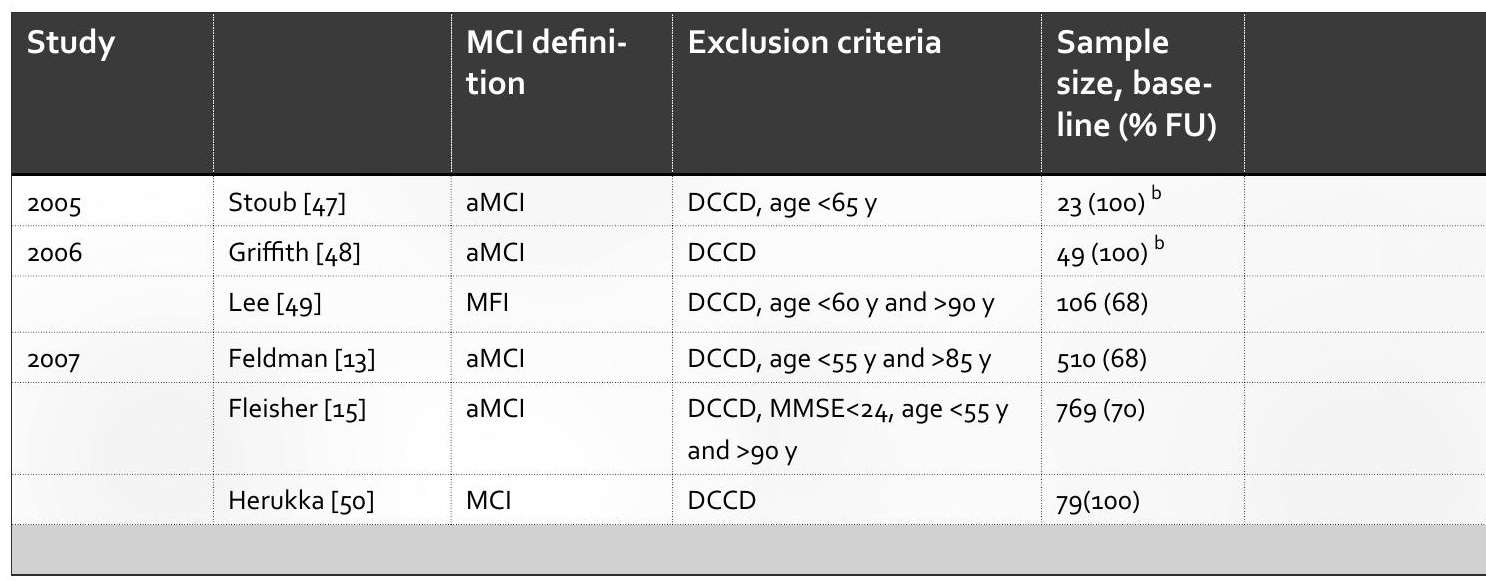

Abbreviations: $\mathrm{MCl}=$ mild cognitive impairment, $\mathrm{y}=\mathrm{years} ; \mathrm{FU}=$ follow-up length; $\mathrm{MMSE}=\mathrm{Mini}$-Mental State Examination; $\mathrm{AD}=$ Alzheimer-type dementia; aMCl=amnestic mild cognitive impairment; $\mathrm{MFI}=\mathrm{mild}$ functional impairment that interferes with daily living; $D C C D=$ disorders causing cognitive decline; - = not specified/no data

a Study did not provide APOE data on subjects with non-AD type dementia.

b Only completed cases reported.

c Obtained from The 3C Study Group (2003).[51]

Table 2 Number of subjects with at least 1 APOE $\varepsilon_{4}$ allele according to outcome and setting

\begin{tabular}{|c|c|c|c|c|}
\hline & Baseline & \multicolumn{3}{|c|}{ Outcome at follow-up } \\
\hline & & Not demented & AD-type dementia & Non-AD type dementia \\
\hline \multicolumn{5}{|c|}{ All studies } \\
\hline$\varepsilon 4^{+}$ & 1925 & 1235 & 658 & 32 \\
\hline$\varepsilon_{4-}^{-}$ & 4170 & 3536 & 578 & 56 \\
\hline \multicolumn{5}{|c|}{ Clinical studies } \\
\hline$\varepsilon 4^{+}$ & 618 & 314 & 293 & 11 \\
\hline$\varepsilon 4^{-}$ & 862 & 615 & 228 & 19 \\
\hline \multicolumn{5}{|c|}{ Population-based studies } \\
\hline$\varepsilon 4^{+}$ & 731 & 601 & 110 & 20 \\
\hline$\varepsilon_{4-}$ & 2702 & 2436 & 229 & 37 \\
\hline \multicolumn{5}{|c|}{ Other studies } \\
\hline$\varepsilon 4^{+}$ & 576 & 320 & 255 & 1 \\
\hline$\varepsilon 4^{-}$ & 606 & 485 & 121 & 0 \\
\hline
\end{tabular}

Abbreviations: $\varepsilon_{4^{+}=} A P O E \varepsilon_{4}$ allele carriers; $\varepsilon_{4}=A P O E \varepsilon_{4}$ allele noncarriers 


\begin{tabular}{|c|c|c|c|c|}
\hline $\begin{array}{l}\text { Mean } \\
\text { age, y }\end{array}$ & $\begin{array}{l}\text { Mean educa- } \\
\text { tion, y }\end{array}$ & $\begin{array}{l}\text { MMSE } \\
\text { score }\end{array}$ & Follow-up, y & $\begin{array}{l}\text { Converters to dementia } \\
\text { (\% AD) }\end{array}$ \\
\hline 82.1 & 16 & 27 & 3.6 & $11(100)$ \\
\hline 68.5 & 13.4 & 28.4 & 1.3 & $13(100)$ \\
\hline 73.1 & 5.2 & - & 3 & $17(82)^{a}$ \\
\hline 70.6 & 11.1 & 26.9 & 4 & $109(100)$ \\
\hline 72.8 & 14.8 & - & 3 & $212(99)^{a}$ \\
\hline 70.4 & - & 24.0 & 4.1 & $33(97)$ \\
\hline
\end{tabular}

Table 3 Measures of predictive accuracy

\begin{tabular}{|c|c|c|c|c|c|c|c|}
\hline $\begin{array}{l}\text { Cat- } \\
\text { egory }\end{array}$ & $\begin{array}{l}\text { OR } \\
(95 \% \mathrm{CI})\end{array}$ & $\begin{array}{l}\text { Sensi- } \\
\text { tivity } \\
(95 \% \mathrm{Cl})\end{array}$ & $\begin{array}{l}\text { Speci- } \\
\text { ficity } \\
(95 \% \mathrm{Cl})\end{array}$ & $\begin{array}{l}\text { PPV } \\
(95 \% \mathrm{CI})\end{array}$ & $\begin{array}{l}\text { NPV } \\
(95 \% \mathrm{Cl})\end{array}$ & $\begin{array}{l}\text { LR+ } \\
(95 \% \mathrm{CI})\end{array}$ & $\begin{array}{l}\text { LR- } \\
(95 \% \mathrm{Cl})\end{array}$ \\
\hline \multicolumn{8}{|c|}{ At least $1 \varepsilon_{4}$ allele versus no $\varepsilon_{4}$ allele } \\
\hline $\begin{array}{l}\text { All studies } \\
(\mathrm{N}=35)\end{array}$ & $\begin{array}{l}2.29 \\
(1.88-2.80)\end{array}$ & $\begin{array}{l}0.53 \\
(0.46-0.61)\end{array}$ & $\begin{array}{l}0.67 \\
(0.62-0.71)\end{array}$ & $\begin{array}{l}0.43 \\
(0.34-0.52)\end{array}$ & $\begin{array}{l}0.75 \\
(0.70-0.80)\end{array}$ & $\begin{array}{l}1.60 \\
(1.48-1.78)\end{array}$ & $\begin{array}{l}0.74 \\
(0.67-0.82)\end{array}$ \\
\hline $\begin{array}{l}\text { Clinical } \\
\text { studies } \\
(n=21)\end{array}$ & $\begin{array}{l}2.36 \\
(1.81-3.07)\end{array}$ & $\begin{array}{l}0.5^{8} \\
(0.49-0.66)\end{array}$ & $\begin{array}{l}0.65 \\
(0.60-0.70)\end{array}$ & $\begin{array}{l}0.46 \\
(0.38-0.54)\end{array}$ & $\begin{array}{l}0.74 \\
(0.69-0.80)\end{array}$ & $\begin{array}{l}1.56 \\
(1.39-1.76)\end{array}$ & $\begin{array}{l}0.73 \\
(0.63-0.83)\end{array}$ \\
\hline $\begin{array}{l}\text { Popula- } \\
\text { tion-based } \\
\text { studies } \\
(n=6)\end{array}$ & $\begin{array}{l}1.83 \\
(1.39-2.40)\end{array}$ & $\begin{array}{l}0.31 \\
(0.23-0.39)\end{array}$ & $\begin{array}{l}0.78 \\
(0.72-0.84)\end{array}$ & $\begin{array}{l}0.34 \\
(0.12-0.55)\end{array}$ & $\begin{array}{l}0.73 \\
(0.56-0.89)\end{array}$ & $\begin{array}{l}1.54 \\
(1.28-1.86)\end{array}$ & $\begin{array}{l}0.86 \\
(0.80-0.94)\end{array}$ \\
\hline $\begin{array}{l}\text { Other } \\
\text { studies } \\
(n=8)\end{array}$ & $\begin{array}{l}2.64 \\
(1.58-4 \cdot 42)\end{array}$ & $\begin{array}{l}0.60 \\
(0.49-0.71)\end{array}$ & $\begin{array}{l}0.64 \\
(0.57-0.70)\end{array}$ & $\begin{array}{l}0.42 \\
(0.29-0.54)\end{array}$ & $\begin{array}{l}0.81 \\
(0.75-0.86)\end{array}$ & $\begin{array}{l}1.61 \\
(1.29-2.02)\end{array}$ & $\begin{array}{l}0.63 \\
(0.47-0.85)\end{array}$ \\
\hline \multicolumn{8}{|c|}{$A P O E-\varepsilon_{4}$ homozygotes versus no $\varepsilon_{4}$ allele } \\
\hline $\begin{array}{l}\text { All studies } \\
(\mathrm{N}=9)\end{array}$ & $\begin{array}{l}3.94 \\
(2.09-7.33)\end{array}$ & $\begin{array}{l}0.21 \\
(0.10-0.33)\end{array}$ & $\begin{array}{l}0.93 \\
(0.90-0.97)\end{array}$ & $\begin{array}{l}0.59 \\
(0.50-0.68)\end{array}$ & $\begin{array}{l}0.69 \\
(0.60-0.79)\end{array}$ & $\begin{array}{l}3.01 \\
(2.11-4 \cdot 30)\end{array}$ & $\begin{array}{l}0.89 \\
(0.79-0.99)\end{array}$ \\
\hline
\end{tabular}

Abbreviations: $\mathrm{OR}=$ odds ratio; $\mathrm{PPV}=$ positive predictive value; $\mathrm{NPV}=$ negative predictive value; $\mathrm{LR+=positive} \mathrm{likelihood} \mathrm{ratio;} \mathrm{LR-=negative} \mathrm{likelihood} \mathrm{ratio}$ 
Figure 1 Flow diagram of study selection ${ }^{a}$

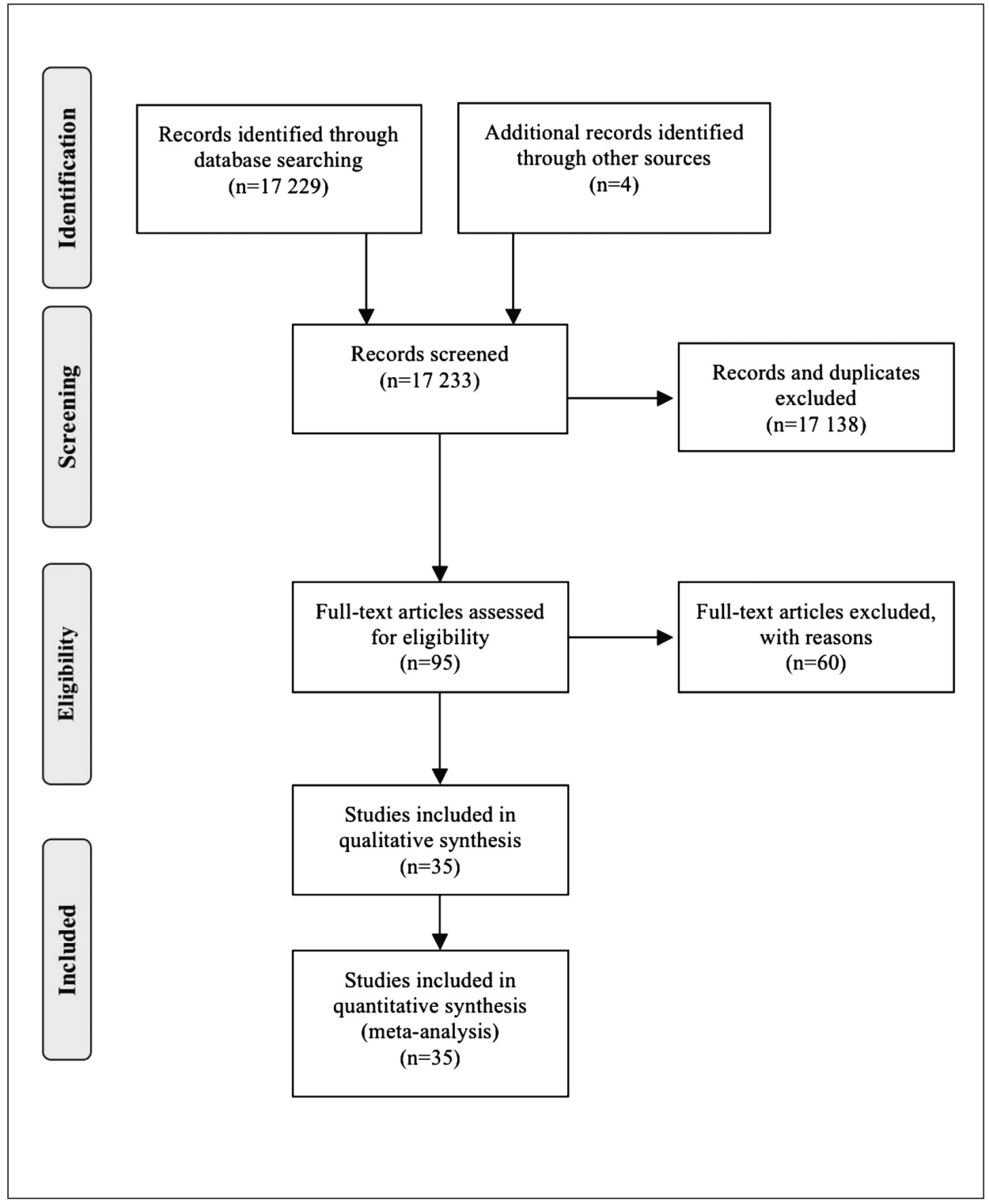

${ }^{\text {a }}$ Flow diagram adapted from Moher D, Liberati A, Tetzlaff J, Altman DG, The PRISMA Group (2009). [12] 
Figure 2 Forest plot odds ratio

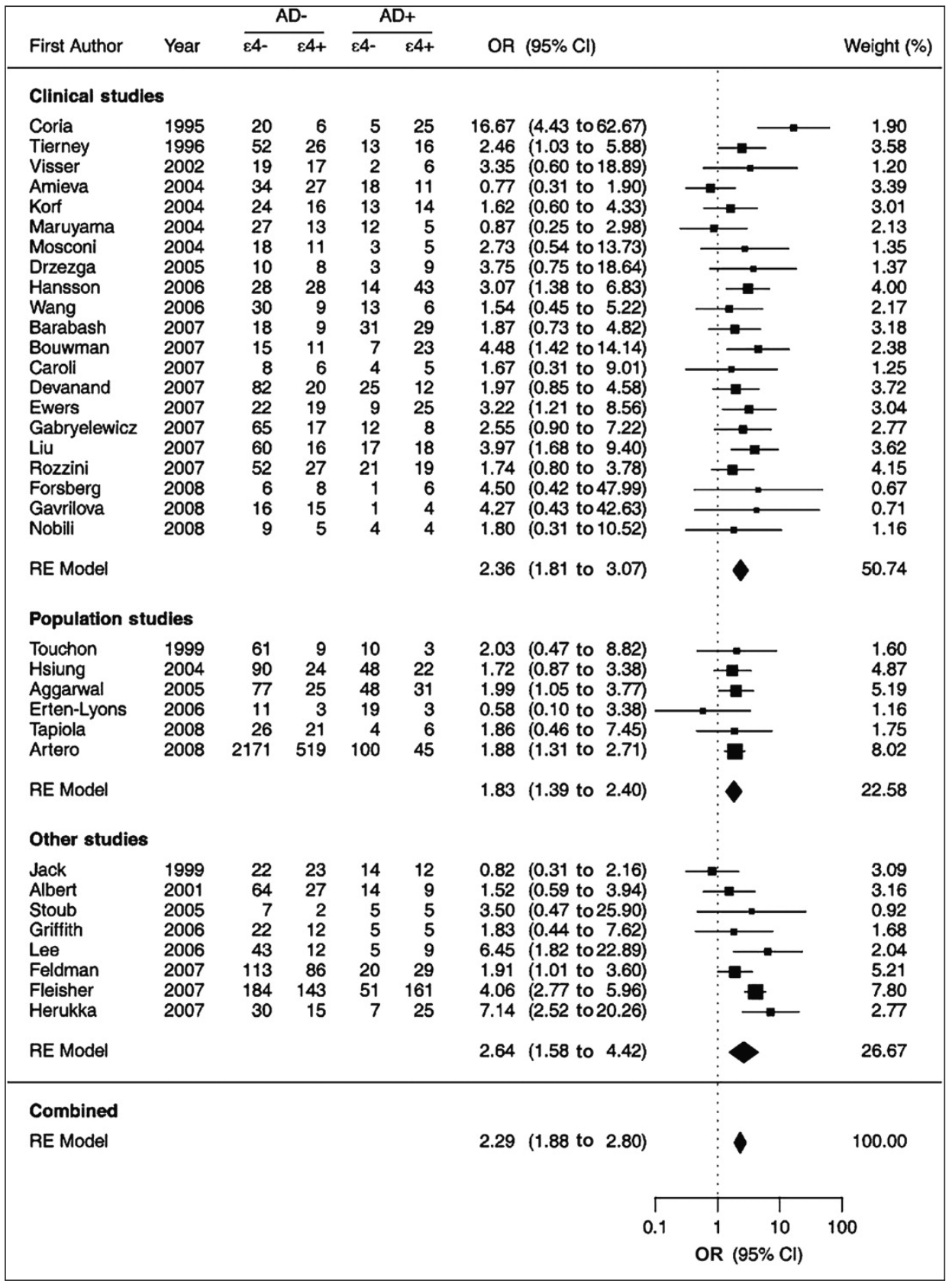

$A D-=$ no dementia; $A D+=$ with Alzheimer-type dementia; $\varepsilon 4-=A P O E-\varepsilon 4$ allele noncarriers; $\varepsilon 4^{+}=A P O E-\varepsilon 4$ allele carriers; $\mathrm{OR}=$ odds ratio; $\mathrm{Cl}=$ confidence interval; $\mathrm{RE}=$ random effects.

The squares represent the weight of the particular study in the overall analysis. The horizontal line across the square shows the confidence interval. The diamond represents the overall effect. 
Figure 3 Meta-regression results

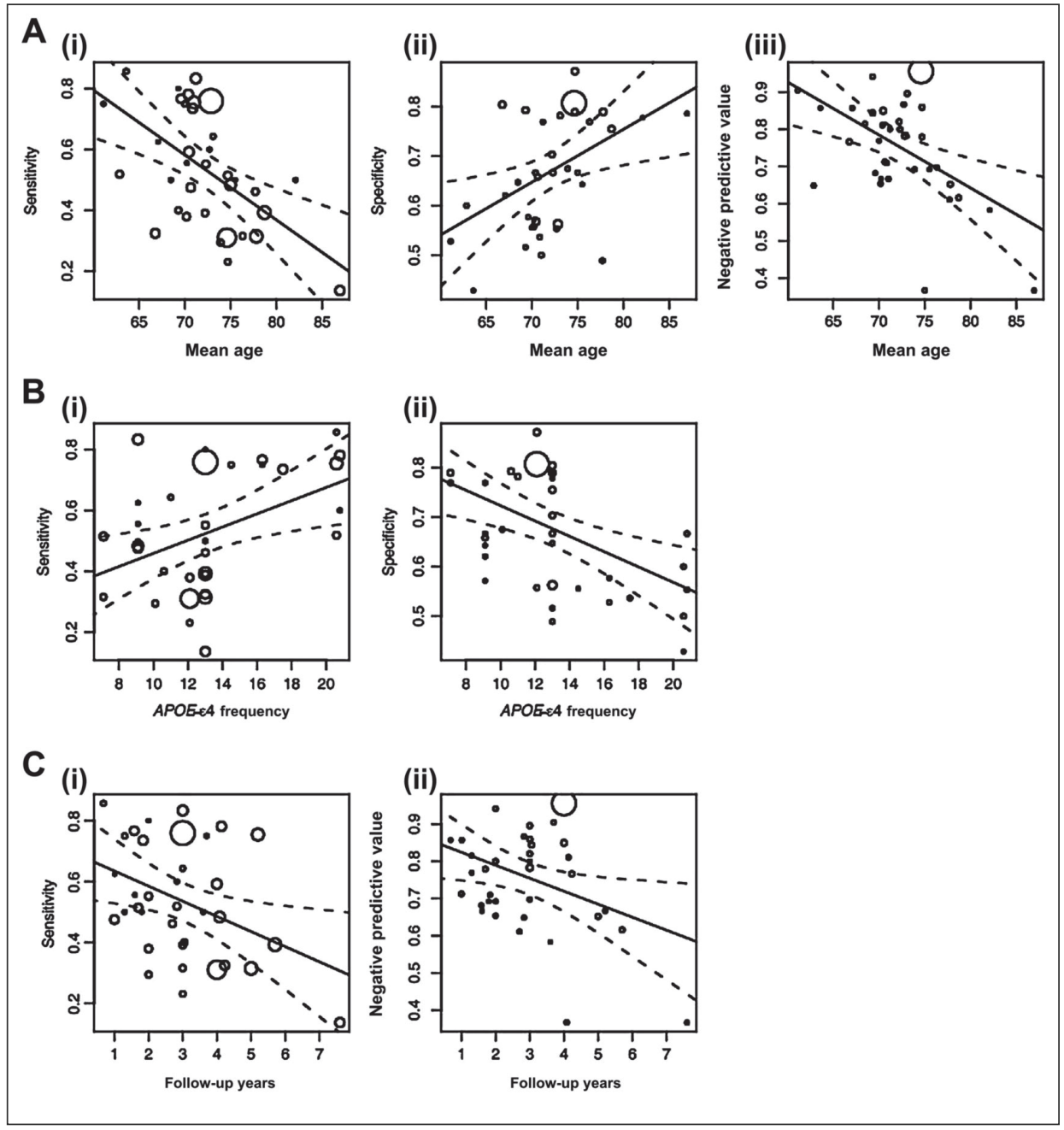

Shown are variables that have a statistically significant association with outcome in the metaregression analysis. The size of the data markers indicates weight of the study.

Supplementary Table 1 Methodological quality rating*

\begin{tabular}{|l|l|}
\hline Item & Criterion \\
\hline 1. Sampling of subjects & \\
\hline 1.1 Random or consecutive selection & $\begin{array}{l}\text { Indication that consecutive subjects or randomly } \\
\text { selected subjects were included }\end{array}$ \\
\hline $\begin{array}{l}1.2 \text { Recruited as single cohort unclassified by } \\
\text { disease state }\end{array}$ & Indication that all patient were included as a single \\
\hline
\end{tabular}


Supplementary Table 1 Methodological quality rating* Continued

\begin{tabular}{|c|c|}
\hline Item & Criterion \\
\hline $\begin{array}{l}\text { 1.3 Recruited from a clinical setting where test } \\
\text { would be used }\end{array}$ & $\begin{array}{l}\text { Study performed in a first-line, second-line or } \\
\text { third-line health care facility. Only scored for clinical } \\
\text { studies }\end{array}$ \\
\hline $\begin{array}{l}\text { 1.4 Recruited at the time point in the diagnostic } \\
\text { process where the test would be used }\end{array}$ & $\begin{array}{l}\text { Subjects enrolled at time baseline visit. Only scored } \\
\text { for clinical studies }\end{array}$ \\
\hline $\begin{array}{l}\text { 1.5 Selection and referral processes fully de- } \\
\text { scribed }\end{array}$ & $\begin{array}{l}\text { Description of sampling method and the inclusion } \\
\text { and exclusion criteria; and (for clinical studies only), } \\
\text { full description of referral pattern }\end{array}$ \\
\hline $\begin{array}{l}\text { 1.6 Clinical and demographic characteristics fully } \\
\text { described }\end{array}$ & $\begin{array}{l}\text { Data on age, gender, educational level, and score for } \\
\text { the MMSE or equivalent cognitive screening test }\end{array}$ \\
\hline 1.7 Complete & $\begin{array}{l}\text { APOE genotype available for all eligible subjects; if } \\
\text { available for subgroup only description of differences } \\
\text { in baseline characteristics between subjects with and } \\
\text { without data on the APOE genotype. }\end{array}$ \\
\hline 1.8 Large sample size & Baseline sample of at least 50 subjects \\
\hline \multicolumn{2}{|l|}{ 2. Reference diagnosis } \\
\hline 2.1 Methods and tests described in detail & $\begin{array}{l}\text { Description of person who made the diagnosis and } \\
\text { of data used for diagnosis }\end{array}$ \\
\hline $\begin{array}{l}\text { 2.2 Positive and negative diagnoses clearly } \\
\text { described }\end{array}$ & Description of dementia criteria used \\
\hline 2.3 Diagnosis likely to be close to truth & This item was scored present for all studies \\
\hline 2.4 Available for all subjects & Follow-up rate of at least $85 \%$ \\
\hline $\begin{array}{l}\text { 2.5 Based on the same tests and same informa- } \\
\text { tion in all subjects }\end{array}$ & $\begin{array}{l}\text { Description that diagnostic procedure at follow-up } \\
\text { did not differ for subjects }\end{array}$ \\
\hline $\begin{array}{l}\text { 2.6 Blinding procedures used to prevent knowl- } \\
\text { edge of } A P O E \text { genotype when follow-up diagno- } \\
\text { sis was made (i.e. verification bias) }\end{array}$ & $\begin{array}{l}\text { Indication that the person who made the diagnosis } \\
\text { at follow-up was blinded for the APOE genotype }\end{array}$ \\
\hline \multicolumn{2}{|l|}{ 3. Experimental test } \\
\hline 3.1 Description of test described in detail & $\begin{array}{l}\text { Description of method of } A P O E \text { genotyping such } \\
\text { that it could be reproduced }\end{array}$ \\
\hline 3.2 Positive and negative test results described & This item was scored present for all studies \\
\hline 3.3 All results described & $\begin{array}{l}\text { Although none of the studies reported data on the } \\
\text { failure rate of the APOE test, this item was scored } \\
\text { present for all studies }\end{array}$ \\
\hline
\end{tabular}

Abbreviations: $\mathrm{MMSE}=$ Mini-Mental State examination; $A P O E=$ Apolipoprotein $\mathrm{E}$ *Items were selected from rating scales of methodological quality of diagnostic and prognostic studies as described in Altman DG, Systematic reviews of evaluations of prognostic variables, $B M J$ 2001;323:224-8; and Deeks JJ, Systematic reviews in health care: Systematic reviews of evaluations of diagnostic and screening tests. BMJ 2001;323:157-62. 
Supplementary Table 2 Meta-analysis of observational studies in epidemiology (MOOSE) statement

\begin{tabular}{|c|c|c|}
\hline \multicolumn{2}{|c|}{ Checklist item } & $\begin{array}{l}\text { Brief description of how the criteria were } \\
\text { handled in the review }\end{array}$ \\
\hline \multicolumn{3}{|c|}{ Reporting of background } \\
\hline 1 & Problem definition & $\begin{array}{l}\text { To establish the predictive accuracy of the } A P O E-\varepsilon 4 \\
\text { allele for conversion from mild cognitive impairment } \\
(\mathrm{MCl}) \text { to Alzheimer's disease (AD) }\end{array}$ \\
\hline 2 & Hypothesis statement & $\begin{array}{l}\text { The presence of the } A P O E-\varepsilon 4 \text { allele increases the risk } \\
\text { for } A D\end{array}$ \\
\hline 3 & Description of study outcomes & $\begin{array}{l}\text { The outcome is conversion from } \mathrm{MCI} \text { to AD. The meas- } \\
\text { ures of predictive accuracy are the pooled odds ratio, } \\
\text { sensitivity, specificity, positive and negative predictive } \\
\text { value, and positive and negative likelihood ratio. }\end{array}$ \\
\hline 4 & Type of exposure & Carrier or non-carrier of $A P O E-\varepsilon 4$ allele \\
\hline 5 & Type of study designs used & $\begin{array}{l}\text { Prospective cohort studies of subjects with } \mathrm{MCl} \text { or re- } \\
\text { lated concepts in which the } A P O E-\varepsilon 4 \text { allele was tested } \\
\text { as predictor of conversion to } A D\end{array}$ \\
\hline 6 & Study population & Subjects with $\mathrm{MCl}$ \\
\hline \multicolumn{3}{|c|}{ Reporting of search strategy should include } \\
\hline 7 & Qualifications of searchers & LS Elias-Sonnenschein, MA, MSc; PJ Visser, MD, PhD \\
\hline 8 & $\begin{array}{l}\text { Search strategy, including time period } \\
\text { included in the synthesis and keywords }\end{array}$ & $\begin{array}{l}\text { Time period: January } 1995 \text { to December } 2008 \\
\text { Keywords: } \\
\text { "human" and "amnestic", "amnestic syndrome", } \\
\text { "memory impairment", "mild cognitive decline", } \\
\text { "mild cognitive impairment", "MCl", "age-associated } \\
\text { cognitive decline", "AACD", "age-associated memory } \\
\text { impairment", "AAMI", "cognitive impairment no de- } \\
\text { mentia", "CIND", "memory clinic", "memory disorders } \\
\text { clinic", or "dementia clinic }\end{array}$ \\
\hline 9 & $\begin{array}{l}\text { Effort to include all available studies, } \\
\text { including contact with authors }\end{array}$ & $\begin{array}{l}\text { Efforts were made to include all available studies. } \\
\text { Authors of studies with unclear outcome measures } \\
\text { were contacted. }\end{array}$ \\
\hline \multirow[t]{2}{*}{10} & Databases and registries searched & PubMed \\
\hline & (Supplementary Table 2 continued) & \\
\hline 11 & $\begin{array}{l}\text { Search software used, name and version, } \\
\text { including special features }\end{array}$ & ExLibris MetaLib was used to search PubMed. \\
\hline 12 & Use of hand searching & $\begin{array}{l}\text { Additional studies were identified from the reference } \\
\text { list of retrieved publications. }\end{array}$ \\
\hline
\end{tabular}




\section{Supplementary Table 2 Continued}

\begin{tabular}{|c|c|c|}
\hline \multicolumn{2}{|c|}{ Checklist item } & $\begin{array}{l}\text { Brief description of how the criteria were } \\
\text { handled in the review }\end{array}$ \\
\hline 13 & $\begin{array}{l}\text { List of citations located and those ex- } \\
\text { cluded, including justifications }\end{array}$ & $\begin{array}{l}\text { Of the } 17,233 \text { abstracts reviewed, we retrieved } 95 \text { full } \\
\text { articles in English that were relevant for our study. Of } \\
\text { the } 95 \text { studies, } 6 \text { were excluded because the subjects } \\
\text { were already demented at baseline, } 3 \text { did not distin- } \\
\text { guish } M C I \text { from } A D, 11 \text { referred to the same cohort, } 8 \\
\text { had as outcome AD/dementia but not conversion from } \\
M C I \text { to } A D, 6 \text { had as outcome dementia instead of } \\
A D, 1 \text { did not distinguish CIND from dementia, } 7 \text { were } \\
\text { not cohort studies, } 1 \text { used weighted inclusion, } 2 \text { had } \\
\text { unclear } A P O E \text { genotyping data, and } 15 \text { had no APOE } \\
\text { data (Figure 1). }\end{array}$ \\
\hline 14 & $\begin{array}{l}\text { Method of addressing articles published } \\
\text { in languages other than English }\end{array}$ & Only publications in English were included. \\
\hline 15 & $\begin{array}{l}\text { Method of handling abstracts and un- } \\
\text { published studies }\end{array}$ & No searching of the grey literature was performed. \\
\hline 16 & Description of any contact with authors & Authors were contacted in case of incomplete data. \\
\hline \multicolumn{3}{|c|}{ Reporting of methods should include } \\
\hline 17 & $\begin{array}{l}\text { Description of relevance or appropriate- } \\
\text { ness of studies assembled for assessing } \\
\text { the hypothesis to be tested }\end{array}$ & Table of included studies (Table 1 ) \\
\hline 18 & $\begin{array}{l}\text { Rationale for the selection and coding } \\
\text { of data }\end{array}$ & $\begin{array}{l}\text { To assess the effect of a priori variables on the meas- } \\
\text { ures of predictive accuracy. }\end{array}$ \\
\hline 19 & $\begin{array}{l}\text { Documentation of how data were classi- } \\
\text { fied and coded }\end{array}$ & $\begin{array}{l}\text { Three authors independently completed a data } \\
\text { extraction form for each study. Data on the } A P O E-\varepsilon 4 \\
\text { allele and outcome were summarized in a } 2 \times 3 \text { table, } \\
\text { which specified the number of subjects who were } \\
A P O E \varepsilon_{4} \text { allele carriers and noncarriers who remained } \\
\text { stable, progressed to } A D \text {, or progressed to other types } \\
\text { of dementia. }\end{array}$ \\
\hline 20 & Assessment of confounding & $\begin{array}{l}\text { Meta-regression was conducted to examine the influ- } \\
\text { ence of average age and MMSE score of the sample, } \\
\text { the setting, definition of } \mathrm{MCl} \text {, length of follow-up, and } \\
\text { background } A P O E \varepsilon_{4} \text { allele frequency in the popula- } \\
\text { tion in which the study was performed. }\end{array}$ \\
\hline
\end{tabular}


Supplementary Table 2 Continued

\begin{tabular}{|c|c|c|}
\hline \multicolumn{2}{|c|}{ Checklist item } & $\begin{array}{l}\text { Brief description of how the criteria were } \\
\text { handled in the review }\end{array}$ \\
\hline 21 & $\begin{array}{l}\text { Assessment of study quality, including } \\
\text { blinding of quality assessors; stratifica- } \\
\text { tion or regression on possible predictors } \\
\text { of study results }\end{array}$ & $\begin{array}{l}\text { Two authors rated each study using } 17 \text { items for } \\
\text { subject sampling, reference diagnosis, and test } \\
\text { description selected from rating scales for methodo- } \\
\text { logical quality of diagnostic and prognostic studies } \\
\text { (Supplementary table } 1 \text { ). In case of discrepancies } \\
\text { between scores, a third rater reviewed the paper and a } \\
\text { consensus was reached. }\end{array}$ \\
\hline 22 & Assessment of heterogeneity & $\begin{array}{l}\text { Heterogeneity was assessed by a chi-square test, } \\
\text { Q. The amount of heterogeneity for each outcome } \\
\text { measure was calculated using DerSimonian-Laird, } \\
\text { with t as an estimate for the standard deviation of the } \\
\text { underlying true outcomes across studies. The } \\
\text { proportion of variation due to heterogeneity, was } \\
\text { likewise computed and expressed as I2. }\end{array}$ \\
\hline 23 & $\begin{array}{l}\text { Description of statistical methods in suf- } \\
\text { ficient detail to be replicated }\end{array}$ & $\begin{array}{l}\text { We used random-effects models for the meta-analysis } \\
\text { and performed mixed-effects meta-regression analy- } \\
\text { ses using restricted maximum likelihood estimation. } \\
\text { Analyses were performed using Stata/SE 9.2 for Mac } \\
\text { OSX. }\end{array}$ \\
\hline 24 & $\begin{array}{l}\text { Provision of appropriate tables and } \\
\text { graphics }\end{array}$ & $\begin{array}{l}\text { Appropriate tables and figures are presented. R was } \\
\text { used to create the figures. }\end{array}$ \\
\hline \multicolumn{3}{|c|}{ Reporting of results should include } \\
\hline 25 & $\begin{array}{l}\text { Graph summarizing individual study } \\
\text { estimates and overall estimate }\end{array}$ & $\begin{array}{l}\text { A forest plot for the odds ratio is presented as figure } 2 \text {. } \\
\text { The forest plots for sensitivity, specificity, positive and } \\
\text { negative predictive values, and positive and negative } \\
\text { likelihood ratios are presented in the supplementary } \\
\text { data (Supplementary figures } 2 \text { a to } 2 \text { f). }\end{array}$ \\
\hline 26 & $\begin{array}{l}\text { Table giving descriptive information for } \\
\text { each study included }\end{array}$ & The study characteristics are shown in Table 1. \\
\hline 27 & Results of sensitivity testing & $\begin{array}{l}\text { Use of blinding procedures was the only item that } \\
\text { could not be rated in more than } 70 \% \text { of the studies. } \\
\text { Based on items that could be scored, } 76 \% \text { of the clini- } \\
\text { cal studies and } 50 \% \text { of population-based and other } \\
\text { studies had a positive score on at least } 80 \% \text { of the } \\
\text { items. }\end{array}$ \\
\hline 28 & $\begin{array}{l}\text { Indication of statistical uncertainty of } \\
\text { findings }\end{array}$ & $\begin{array}{l}95 \% \text { confidence intervals were presented with all } \\
\text { summary estimates (table } 3 \text { ), t values (table } 3 \text { ), results } \\
\text { of methodological quality assessment, and result of } \\
\text { funnel plot asymmetry test. }\end{array}$ \\
\hline
\end{tabular}


Supplementary Table 2 Continued

\begin{tabular}{|c|c|c|}
\hline \multicolumn{2}{|c|}{ Checklist item } & $\begin{array}{l}\text { Brief description of how the criteria were } \\
\text { handled in the review }\end{array}$ \\
\hline \multicolumn{3}{|c|}{ Reporting of discussion should include } \\
\hline 29 & Quantitative assessment of bias & $\begin{array}{l}\text { We addressed the heterogeneity between studies by } \\
\text { using a random-effects model. }\end{array}$ \\
\hline 30 & Justification for exclusion & $\begin{array}{l}\text { All studies were excluded based on the pre-defined } \\
\text { inclusion criteria. }\end{array}$ \\
\hline 31 & $\begin{array}{l}\text { Assessment of quality of included stud- } \\
\text { ies }\end{array}$ & $\begin{array}{l}\text { The scores of methodological quality were relatively } \\
\text { low. We may have underestimated these scores as } \\
\text { they were only based on information provided in the } \\
\text { paper. Our meta-regression analyses showed that } \\
\text { methodological quality had no significant effect on } \\
\text { measures of predictive accuracy. }\end{array}$ \\
\hline 32 & $\begin{array}{l}\text { Consideration of alternative explana- } \\
\text { tions for observed results }\end{array}$ & $\begin{array}{l}\text { The meta-regression was performed with average } \\
\text { study scores, which may lead to an under- or overes- } \\
\text { timation of the relation between the variables tested } \\
\text { in the meta-regression and measures of predictive ac- } \\
\text { curacy. Alternative explanations are further discussed } \\
\text { in the manuscript. }\end{array}$ \\
\hline 33 & Generalization of the conclusions & $\begin{array}{l}\text { Discussed in the context of the results of the cohort } \\
\text { study. }\end{array}$ \\
\hline 34 & Guidelines for future research & $\begin{array}{l}\text { Interaction with other genes and biomarkers may } \\
\text { increase the predictive accuracy of the } A P O E-\varepsilon 4 \text { allele } \\
\text { for the conversion from } \mathrm{MCl} \text { to } \mathrm{AD} \text {. This is further } \\
\text { discussed in the manuscript. }\end{array}$ \\
\hline 35 & Disclosure of funding source & We have nothing to disclose. \\
\hline
\end{tabular}

Adapted from: Stroup DF, Berlin JA, Morton SC, Olkin I, Williamson GD, Rennie D, Moher D, Becker BJ, Sipe TA, Thaker SB.

Meta-analysis of observational studies in epidemiology: a proposal for reporting. JAMA 2000;283:2008-2012. 
Supplementary Table 3 Measures of overall effect and heterogeneity

\begin{tabular}{|c|c|c|c|}
\hline Category & OR & Sensitivity & Specificity \\
\hline \multicolumn{4}{|c|}{ At least $1 \varepsilon_{4}$ allele versus no $\varepsilon_{4}$ allele } \\
\hline \multicolumn{4}{|l|}{ All studies $(\mathrm{N}=35)$} \\
\hline Effect $(95 \% \mathrm{Cl})$ & $\begin{array}{l}2.29 \\
(1.88-2.80)\end{array}$ & $\begin{array}{l}0.53 \\
(0.46-0.61)\end{array}$ & $\begin{array}{l}0.67 \\
(0.62-0.71)\end{array}$ \\
\hline Test for overall effect & $\begin{array}{l}z=8.11 \\
P<0.001\end{array}$ & $\begin{array}{l}z=14.08 \\
P<0.001\end{array}$ & $\begin{array}{l}z=29.72 \\
P<0.001\end{array}$ \\
\hline Test for heterogeneity & $\begin{array}{l}Q=49.31 \\
P=0.043 \\
\mathrm{t}=0.31 \\
I^{2}=31.04 \%\end{array}$ & $\begin{array}{l}Q=252.29 \\
P<0.001 \\
\mathrm{t}=0.20 \\
I^{2}=86.52 \%\end{array}$ & $\begin{array}{l}Q=237.36 \\
P<0.001 \\
\mathrm{t}=0.11 \\
I^{2}=85.68 \%\end{array}$ \\
\hline \multicolumn{4}{|l|}{ Clinical studies $(n=21)$} \\
\hline Effect $(95 \% \mathrm{Cl})$ & $\begin{array}{l}2.36 \\
(1.81-3.07)\end{array}$ & $\begin{array}{l}0.5^{8} \\
(0.49-0.66)\end{array}$ & $\begin{array}{l}0.65 \\
(0.60-0.70)\end{array}$ \\
\hline Test for overall effect & $\begin{array}{l}z=6.32 \\
P<0.001\end{array}$ & $\begin{array}{l}z=13.70 \\
P<0.001\end{array}$ & $\begin{array}{l}z=24.88 \\
P<0.001\end{array}$ \\
\hline Test for heterogeneity & $\begin{array}{l}Q=23.56, \\
P=0.262 \\
\mathrm{t}=0.24 \\
I^{2}=15.10 \%\end{array}$ & $\begin{array}{l}Q=79.09 \\
P<0.001 \\
\mathrm{t}=0.16 \\
I^{2}=74.71 \%\end{array}$ & $\begin{array}{l}Q=54.10 \\
P<0.001 \\
\mathrm{t}=0.09 \\
I^{2}=63.03 \%\end{array}$ \\
\hline \multicolumn{4}{|c|}{ Population-based studies $(n=6)$} \\
\hline Effect $(95 \% \mathrm{Cl})$ & $\begin{array}{l}1.83 \\
(1.39-2.40)\end{array}$ & $\begin{array}{l}0.31 \\
(0.23-0.39)\end{array}$ & $\begin{array}{l}0.78 \\
(0.72-0.84)\end{array}$ \\
\hline Test for overall effect & $\begin{array}{l}z=4.33 \\
P<0.001\end{array}$ & $\begin{array}{l}z=7.22 \\
P<0.001\end{array}$ & $\begin{array}{l}z=26.94 \\
P<0.001\end{array}$ \\
\hline Test for heterogeneity & $\begin{array}{l}Q=1.78 \\
P=0.879 \\
\mathrm{t}=0 \\
I^{2}=0 \%\end{array}$ & $\begin{array}{l}Q=11.85 \\
P=0.04 \\
\mathrm{t}=0.08 \\
I^{2}=57.80 \%\end{array}$ & $\begin{array}{l}Q=16.46 \\
P=0.006 \\
\mathrm{t}=0.05 \\
I^{2}=69.63 \%\end{array}$ \\
\hline \multicolumn{4}{|l|}{ Other studies $(n=8)$} \\
\hline Effect $(95 \% \mathrm{Cl})$ & $\begin{array}{l}2.64 \\
\left(1.5^{8}-4.42\right)\end{array}$ & $\begin{array}{l}0.60 \\
(0.49-0.71)\end{array}$ & $\begin{array}{l}0.64 \\
(0.57-0.70)\end{array}$ \\
\hline Test for overall effect & $\begin{array}{l}\mathrm{z}=3.70 \\
P<0.001\end{array}$ & $\begin{array}{l}z=10.37 \\
P<0.001\end{array}$ & $\begin{array}{l}z=18.28 \\
P<0.001\end{array}$ \\
\hline Test for heterogeneity & $\begin{array}{l}Q=17.76 \\
P=0.013 \\
\mathrm{t}=0.54 \\
I^{2}=60.59 \%\end{array}$ & $\begin{array}{l}Q=26.18 \\
P<0.001 \\
\mathrm{t}=0.13 \\
I^{2}=73.26 \%\end{array}$ & $\begin{array}{l}Q=22.69 \\
P=0.002 \\
\mathrm{t}=0.08 \\
I^{2}=69.15 \%\end{array}$ \\
\hline
\end{tabular}




\section{LR-}

\begin{tabular}{l|l|l|l}
0.43 & 0.75 & 1.60 & 0.74 \\
$(0.34-0.52)$ & $(0.70-0.80)$ & $(1.48-1.78)$ & $(0.67-0.82)$ \\
$\mathrm{z}=9.30$ & $\mathrm{z}=27.49$ & $\mathrm{z}=12.23$ & $\mathrm{z}=-5.85$ \\
$P<0.001$ & $P<0.001$ & $P<0.001$ & $P<0.001$ \\
\hline$Q=625.81$ & $Q=461.22$ & $Q=32.73$ & $Q=70.90$ \\
$P<0.001$ & $P<0.001$ & $P=0.530$ & $P<0.001$ \\
$\mathrm{t}=0.26$ & $\mathrm{t}=0.14$ & $\mathrm{t}=0$ & $\mathrm{t}=0.19$ \\
$I^{2}=94.57 \%$ & $I^{2}=92.63 \%$ & $I^{2}=0 \%$ & $I^{2}=52.04 \%$
\end{tabular}

\subsection{6}

(0.38-0.54)

$\mathrm{z}=11.43$

$P<0.001$

$Q=86.64$

$P<0.001$

$\mathrm{t}=0.16$

$I^{2}=76.37 \%$

\subsection{4}

(0.69-0.80)

$z=27.31$

$P<0.001$

$Q=65.50$

$P<0.001$

$\mathrm{t}=0.10$

$I^{2}=69.47 \%$

\begin{tabular}{l|l}
1.56 & 0.73 \\
$(1.39-1.76)$ & $(0.63-0.83)$ \\
$\mathrm{z}=7.39$ & $\mathrm{z}=-4.67$ \\
$P<0.001$ & $P<0.001$ \\
$Q=16.20$ & $Q=29.454$ \\
$P=0.704$ & $P=0.079$ \\
$\mathrm{t}=0$ & $\mathrm{t}=0.17$ \\
$I^{2}=0 \%$ & $I^{2}=32.10 \%$
\end{tabular}

0.34

(0.12-0.55)

$z=3.05$

$P=0.002$

$Q=83.38$

$P<0.001$

$\mathrm{t}=0.25$

$l^{2}=94.00 \%$

\begin{tabular}{l|l}
0.42 & 0.81
\end{tabular}

(0.29-0.54)

$\mathrm{z}=6.62$

$P<0.001$

$Q=49.56$

$P<0.001$

$\mathrm{t}=0.15$

$l^{2}=85.88 \%$

\subsection{3}

(0.56-0.89)

$z=8.76$

$P<0.001$

$Q=164.82$

$P<0.001$

$\mathrm{t}=0.20$

$I^{2}=96.97 \%$

0.81

(0.75 - 0.86$)$

$z=31.00$

$P<0.001$

$Q=14.98$

$P=0.036$

$\mathrm{t}=0.04$

$l^{2}=53.28 \%$

\begin{tabular}{|l|l}
\hline 1.54 & 0.86 \\
$(1.28-1.86)$ & $(0.80-0.94)$ \\
$\mathrm{z}=4.56$ & $\mathrm{z}=-3.58$ \\
$P<0.001$ & $P<0.001$ \\
$Q Q=1.846$ & $Q=2.87$ \\
$P=0.870$ & $P=0.721$ \\
$\mathrm{t}=0$ & $\mathrm{t}=0$ \\
$I^{2}=0 \%$ & $I^{2}=0 \%$ \\
& \\
\hline 1.61 & 0.63 \\
$(1.29-2.02)$ & $(0.47-0.85)$ \\
$\mathrm{z}=4.24$ & $\mathrm{z}=-3.01$ \\
$P<0.001$ & $P=0.003$ \\
\hline$Q=15.06$ & $Q=22.35$ \\
$P=0.050$ & $P=0.002$ \\
$\mathrm{t}=0.21$ & $\mathrm{t}=0.34$ \\
$I^{2}=50.22 \%$ & $I^{2}=68.68 \%$ \\
&
\end{tabular}


Supplementary Table 3 Measures of overall effect and heterogeneity Continued

\begin{tabular}{|c|c|c|c|}
\hline Category & OR & Sensitivity & Specificity \\
\hline \multicolumn{4}{|c|}{$A P O E-\varepsilon_{4}$ homozygotes versus no $\varepsilon_{4}$ allele } \\
\hline \multicolumn{4}{|l|}{ All studies $(\mathrm{N}=9)$} \\
\hline Effect $(95 \% \mathrm{Cl})$ & $\begin{array}{l}3.94 \\
(2.09-7.33)\end{array}$ & $\begin{array}{l}0.21 \\
(0.10-0.33)\end{array}$ & $\begin{array}{l}0.93 \\
(0.90-097)\end{array}$ \\
\hline Test for overall effect & $\begin{array}{l}z=4.28 \\
P<0.001\end{array}$ & $\begin{array}{l}z=3.79 \\
P<0.001\end{array}$ & $\begin{array}{l}z=50.16 \\
P<0.001\end{array}$ \\
\hline Test for heterogeneity & $\begin{array}{l}Q=10.83 \\
P=0.21 \\
\mathrm{t}=0.47 \\
I^{2}=26.12 \%\end{array}$ & $\begin{array}{l}Q=66.94 \\
P<0.001 \\
\mathrm{t}=0.15 \\
I^{2}=88.05 \%\end{array}$ & $\begin{array}{l}Q=23.11 \\
P=0.003 \\
\mathrm{t}=0.045 \\
I^{2}=65.38 \%\end{array}$ \\
\hline
\end{tabular}

Abbreviations: $\mathrm{OR}=$ odds ratio; $\mathrm{PPV}=$ positive predictive value; $\mathrm{NPV}=$ negative predictive value; $\mathrm{LR}+=$ positive likelihood ratio; $\mathrm{LR}=$ =negative likelihood ratio; $z=$ standardized distribution; $Q=$ chisquare test for heterogeneity; $\tau=$ estimated standard deviation of between study variance; $l^{2}=$ proportion of variation due to heterogeneity

Supplementary Table 4 Measures of predictive accuracy for AD in studies that provided APOE data for subjects progressing to non-AD type dementia

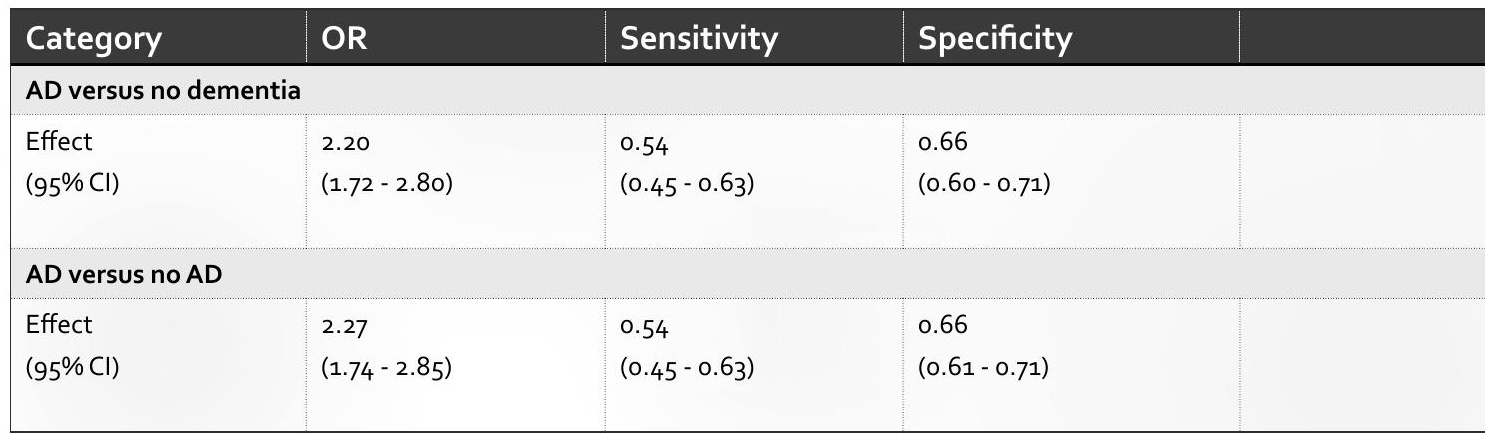

Abbreviations: $\mathrm{AD}=\mathrm{Alzheimer-type} \mathrm{dementia;} \mathrm{OR}=$ odds ratio; $\mathrm{PPV}=$ positive predictive value; $\mathrm{NPV}=$ negative predictive value; $\mathrm{LR+=}$ positive likelihood ratio; $\mathrm{LR}-=$ negative likelihood ratio; $\mathrm{Cl}=$ confidence interval

Note: Included were 4818 subjects from 26 studies with AD at follow-up ( $n=801)$, no dementia $(n=3873)$, and other types of dementia $(n=144)$. The analysis AD versus no dementia is similar to that reported in the main paper but now for the selection of studies that provided data on the $A P O E$ genotype in subjects with non-AD dementia at follow-up. In the analysis AD versus no $A D$, subjects without dementia and subjects with non-AD type dementia at follow-up are included in the no AD group. 


\section{PPV}

NPV

LR+

LR-

\begin{tabular}{|l|l|l|l}
\hline 0.59 & 0.69 & 3.01 & 0.89 \\
$(0.50-0.68)$ & $(0.60-0.79)$ & $(2.11-4.30)$ & $(0.79-0.99)$ \\
\hline $\mathrm{z}=12.72$ & $\mathrm{z}=14.31$ & $\mathrm{z}=6.06$ & $\mathrm{z}=-2.00$ \\
$P<0.001$ & $P<0.001$ & $P<0.001$ & $P=0.045$ \\
\hline$Q=6.56$ & $Q=61.98$ & $Q=8.10$ & $Q=24.57$ \\
$P=0.585$ & $P<0.001$ & $P=0.424$ & $P=0.002$ \\
$\mathrm{t}=0.16$ & $\mathrm{t}=0.13$ & $\mathrm{t}=0.71$ & $\mathrm{t}=0.13$ \\
$P^{2}=0 \%$ & $P^{2}=44.11 \%$ & $P^{2}=1.17 \%$ & $P^{2}=67.43 \%$ \\
\hline
\end{tabular}

\section{PPV}

NPV

LR+

LR-

0.42

0.76

$(0.31-0.52)$

$(0.70-0.82)$

1.53

0.77

(1.39- 1.69)

$(0.69-0.86)$

\begin{tabular}{l|l|l|l}
0.41 & 0.76 & 1.55 & 0.76 \\
$(0.31-0.51)$ & $(0.71-0.82)$ & $(1.40-1.71)$ & $(0.68-0.85)$
\end{tabular}


Supplementary Figure 1 Funnel plot for visual assessment of publication bias

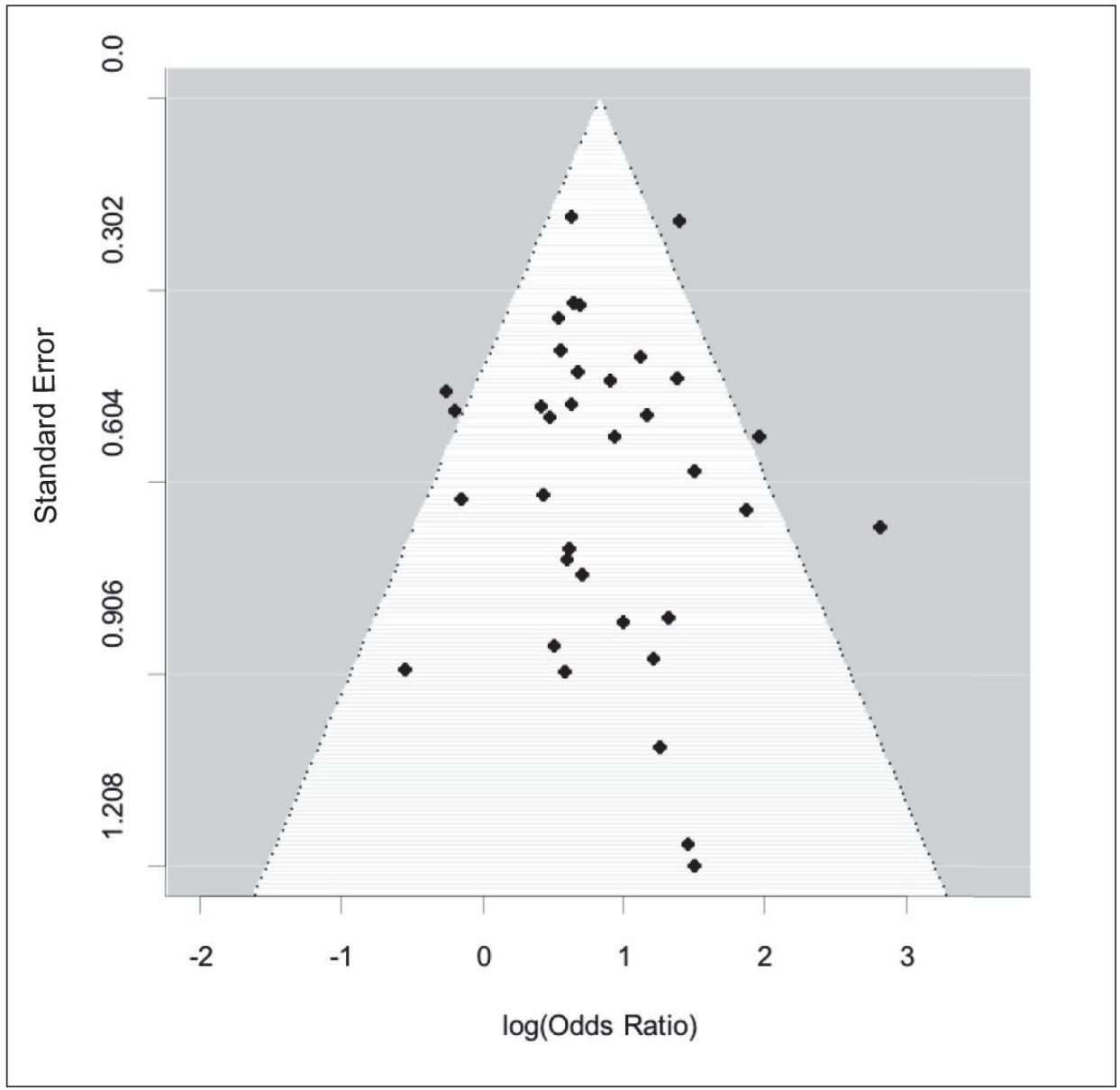

The dots represent the studies included in the meta-analysis 
Supplementary Figure 2a Forest plot sensitivity

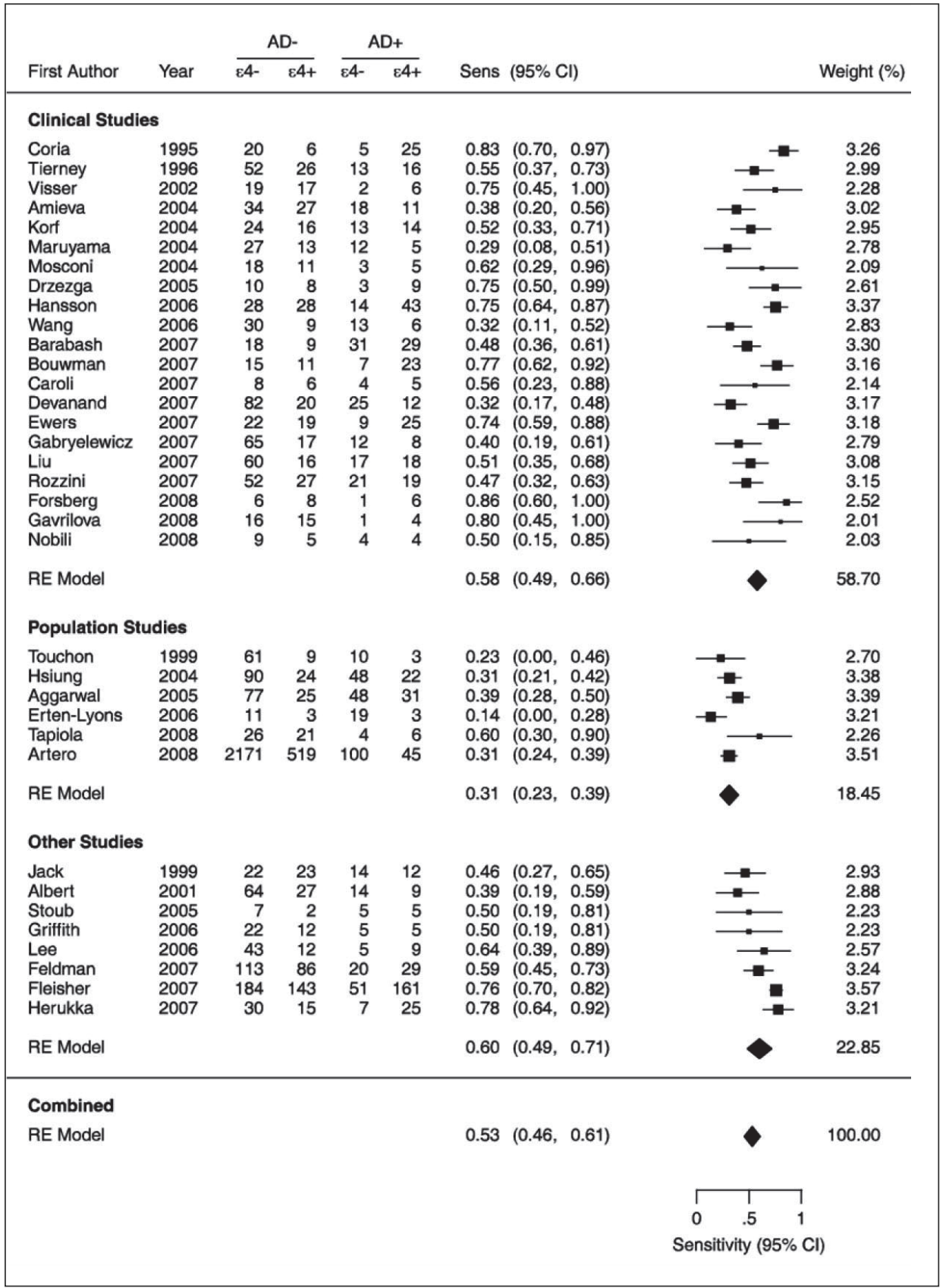

$A D-=$ no dementia; $A D+=$ with Alzheimer-type dementia; $\varepsilon_{4}-=A P O E-\varepsilon 4$ allele noncarriers; $\varepsilon 4^{+}=A P O E-\varepsilon 4$ allele carriers; $\mathrm{OR}=$ odds ratio; $\mathrm{Cl}=$ confidence interval; $\mathrm{RE}=$ random effects.

The squares represent the weight of the particular study in the overall analysis. The horizontal line across the square shows the confidence interval. The diamond represents the overall effect. 
Supplementary Figure $\mathbf{2 b}$ Forest plot specificity

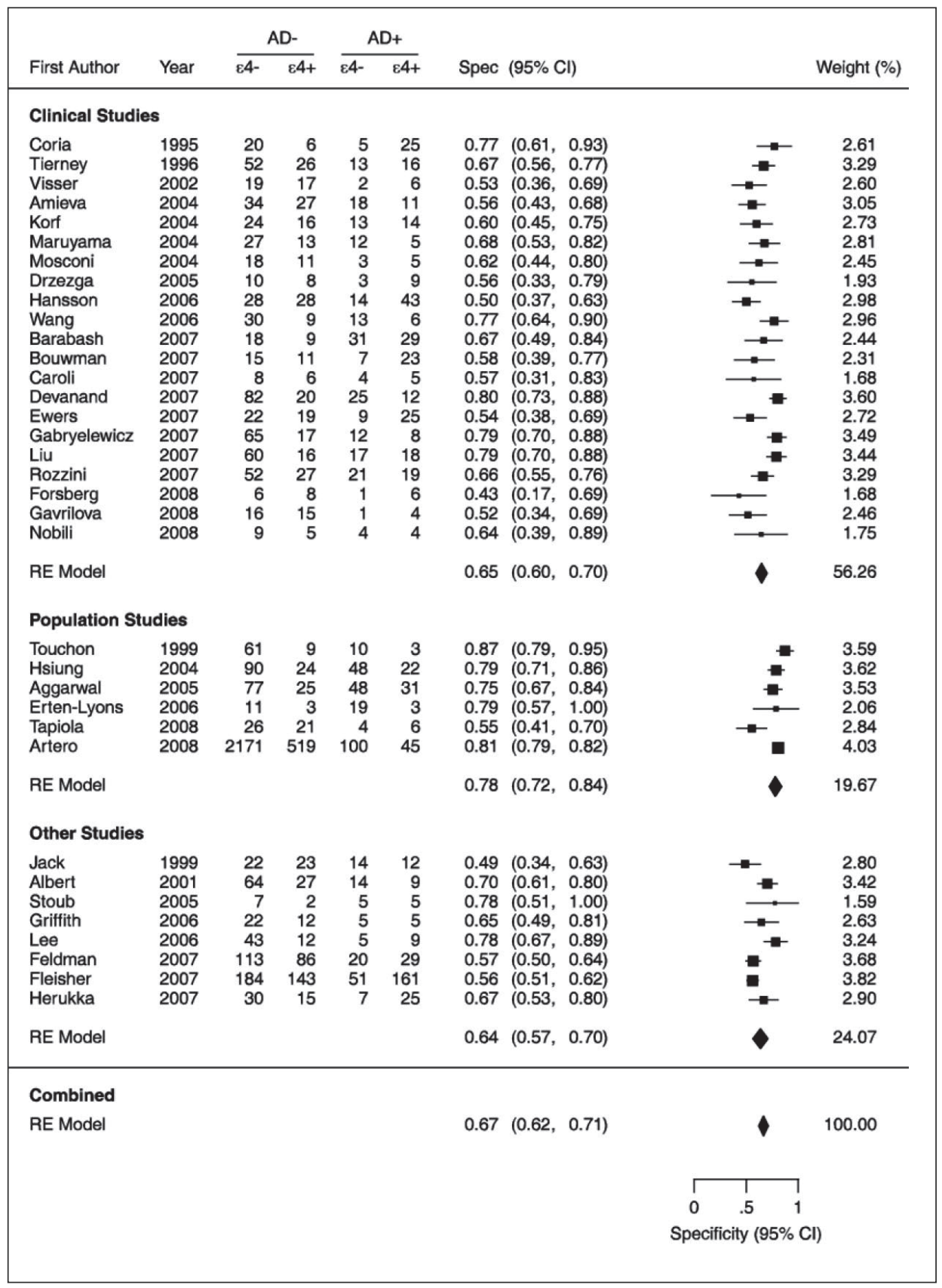

$A D-=$ no dementia; $A D+=$ with Alzheimer-type dementia; $\varepsilon_{4}-=A P O E-\varepsilon_{4}$ allele noncarriers; $\varepsilon_{4}+=A P O E-\varepsilon 4$ allele carriers; $\mathrm{OR}=$ odds ratio; $\mathrm{Cl}=$ confidence interval; $\mathrm{RE}=$ random effects.

The squares represent the weight of the particular study in the overall analysis. The horizontal line across the square shows the confidence interval. The diamond represents the overall effect. 
Supplementary Figure $\mathbf{2 c}$ Forest plot positive predictive value

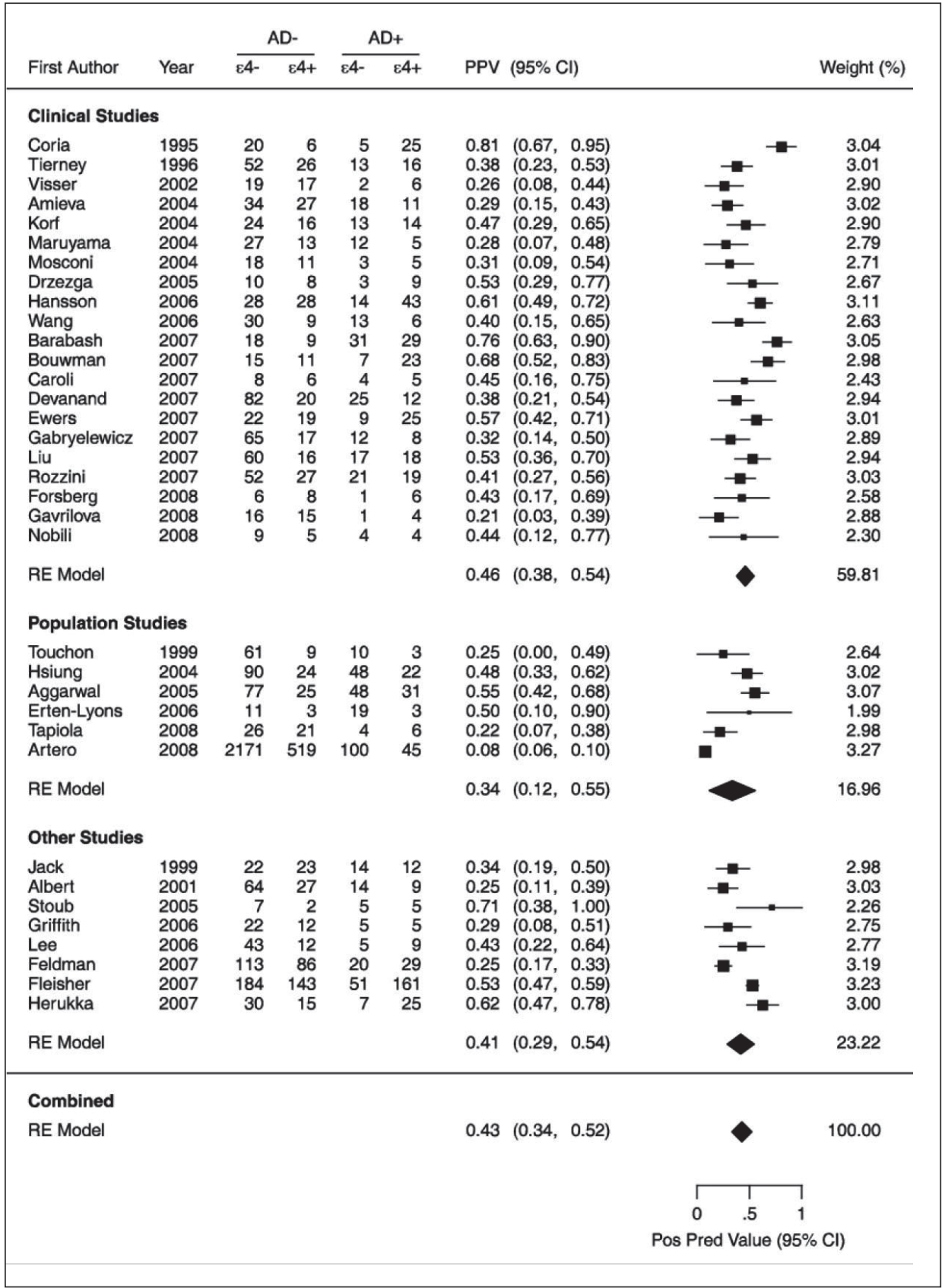

$A D-=$ no dementia; $A D+=$ with Alzheimer-type dementia; $\varepsilon_{4}-=A P O E-\varepsilon 4$ allele noncarriers; $\varepsilon 4^{+}=A P O E-\varepsilon 4$ allele carriers; $\mathrm{OR}=$ odds ratio; $\mathrm{Cl}=$ confidence interval; $\mathrm{RE}=$ random effects.

The squares represent the weight of the particular study in the overall analysis. The horizontal line across the square shows the confidence interval. The diamond represents the overall effect. 
Supplementary Figure 2d Forest plot negative predictive value

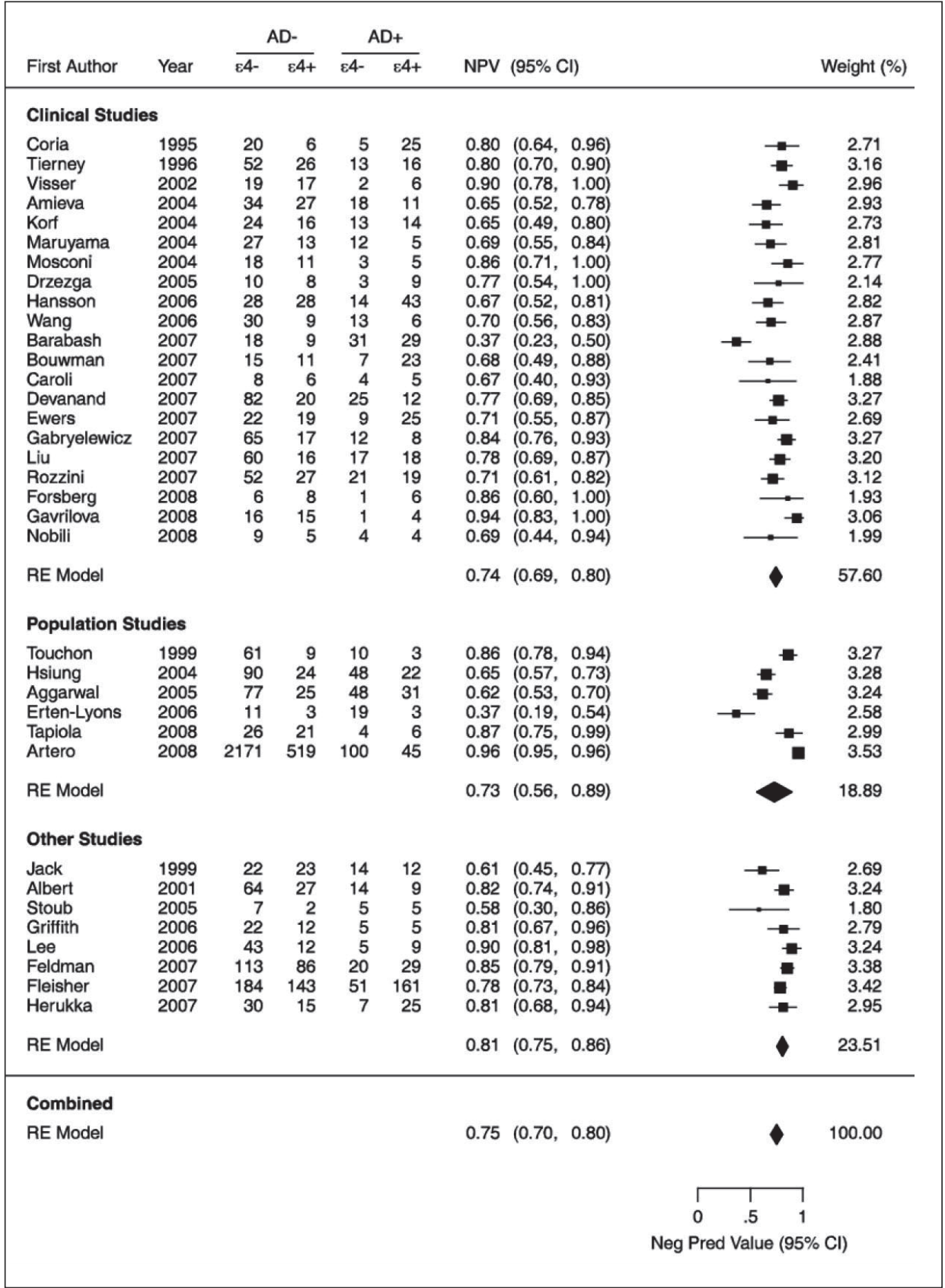

$\mathrm{AD}-=$ no dementia; $\mathrm{AD}+=$ with Alzheimer-type dementia; $\varepsilon_{4}-=A P O E-\varepsilon 4$ allele noncarriers; $\varepsilon 4^{+}=A P O E-\varepsilon 4$ allele carriers; $\mathrm{OR}=$ odds ratio; $\mathrm{Cl}=$ confidence interval; $\mathrm{RE}=$ random effects.

The squares represent the weight of the particular study in the overall analysis. The horizontal line across the square shows the confidence interval. The diamond represents the overall effect. 
Supplementary Figure 2e Forest plot positive likelihood ratio

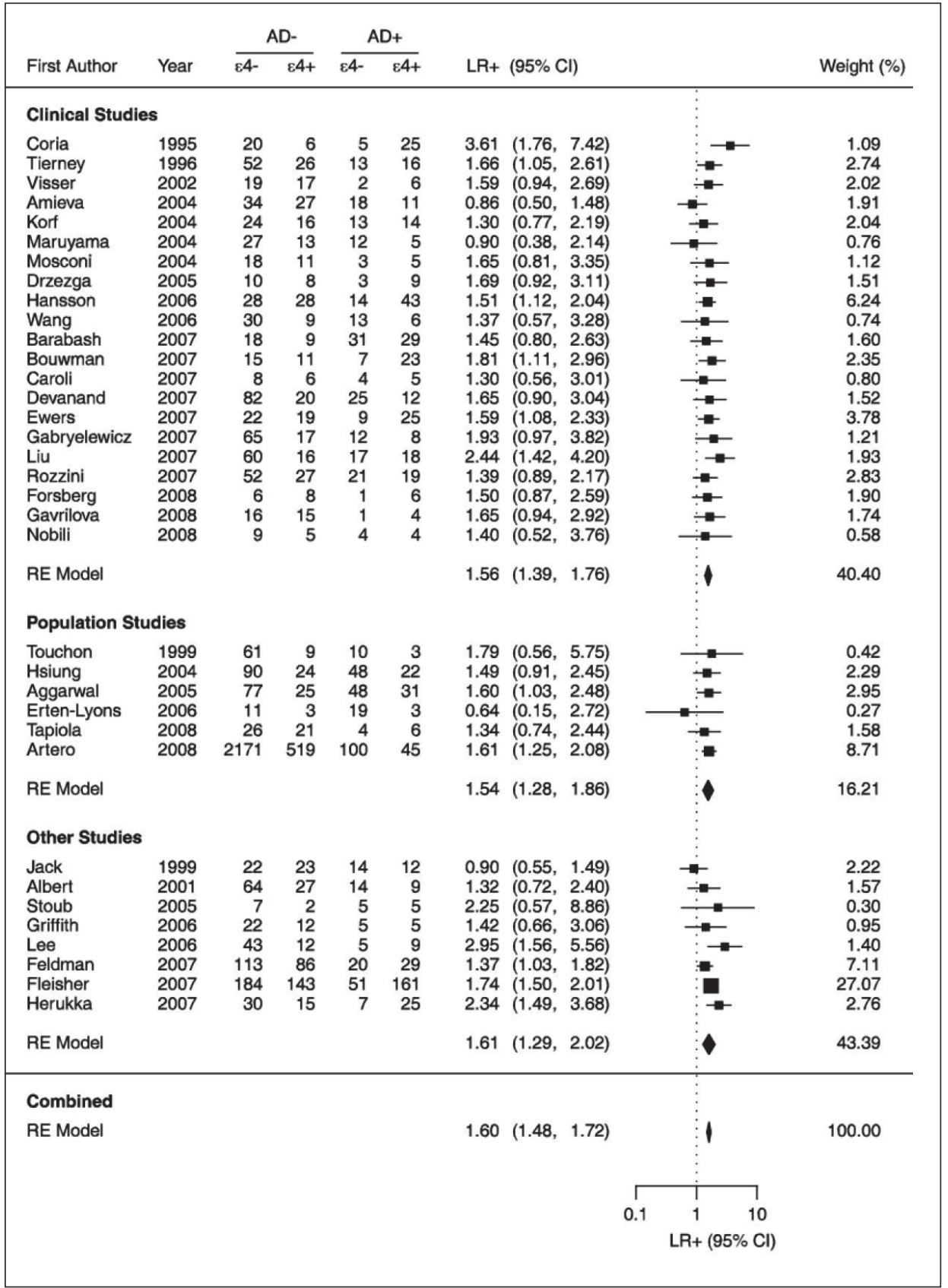

$A D-=$ no dementia; $A D+=$ with Alzheimer-type dementia; $\varepsilon_{4}-=A P O E-\varepsilon 4$ allele noncarriers; $\varepsilon 4^{+}=A P O E-\varepsilon 4$ allele carriers; $\mathrm{OR}=$ odds ratio; $\mathrm{Cl}=$ confidence interval; $\mathrm{RE}=$ random effects.

The squares represent the weight of the particular study in the overall analysis. The horizontal line across the square shows the confidence interval. The diamond represents the overall effect. 
Supplementary Figure $\mathbf{2 f}$ Forest plot negative likelihood ratio

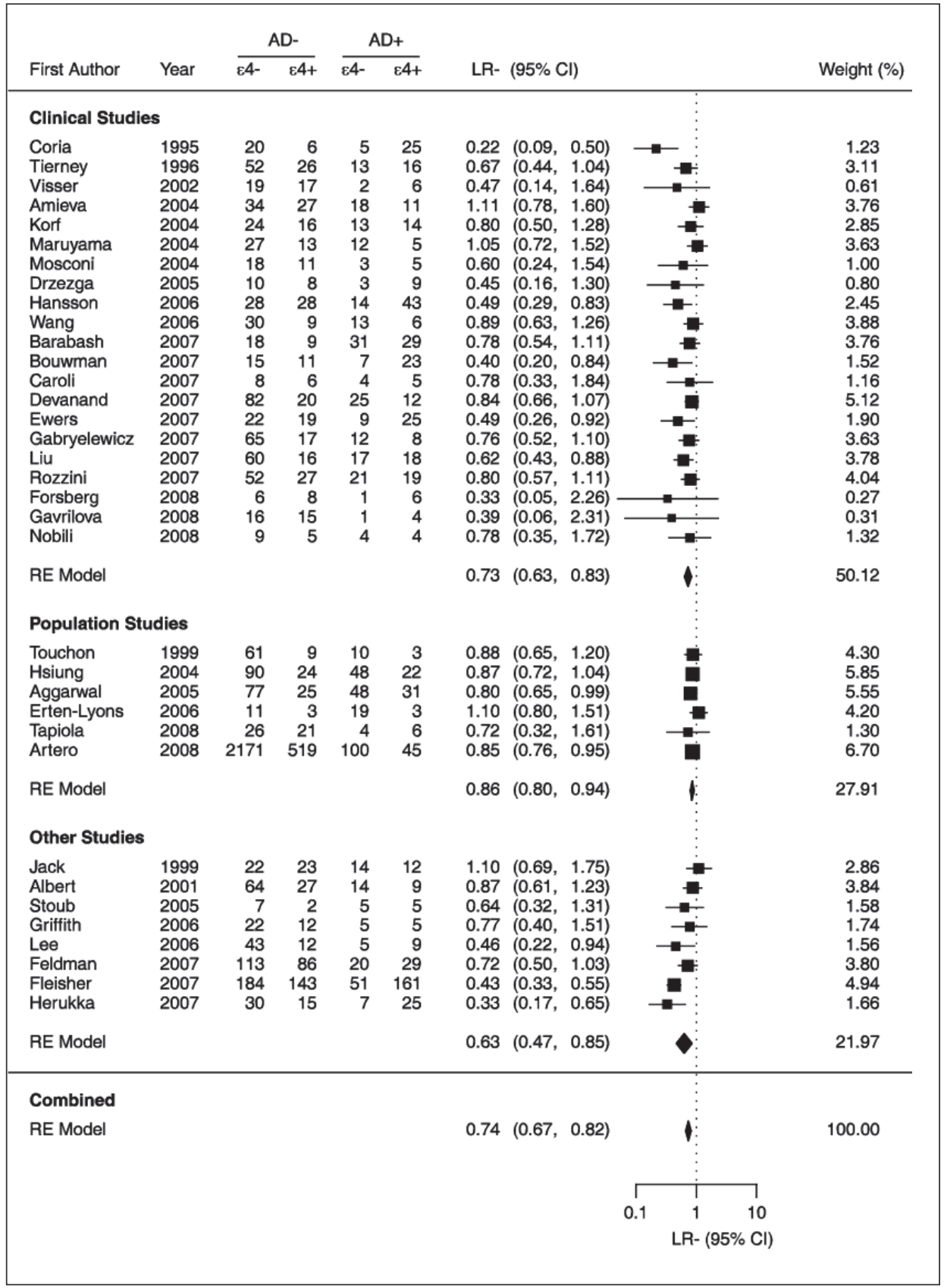

$\mathrm{AD}-=$ no dementia; $\mathrm{AD}+=$ with Alzheimer-type dementia; $\varepsilon_{4}-=A P O E-\varepsilon_{4}$ allele noncarriers; $\varepsilon 4^{+}=A P O E-\varepsilon 4$ allele carriers; $\mathrm{OR}=$ odds ratio; $\mathrm{Cl}=$ confidence interval; $\mathrm{RE}=$ random effects. The squares represent the weight of the particular study in the overall analysis. The horizontal line across the square shows the confidence interval. The diamond represents the overall effect. 
APOE META-ANALYSIS AND META-REGRESSION 
The review protocol for $A P O E-\varepsilon_{4}$ that we drafted in this chapter is meant to ensure that subsequent reviews are performed in a consistent and systematic manner. 
LS Elias-Sonnenschein, W Viechtbauer, IHGB Ramakers, FRJ Verhey, PJ Visser Cochrane Diagnostic Test Accuracy Protocol

Revisions submitted to the Cochrane Collaboration

\section{CHAPTER 3}

\section{APOE $\varepsilon 4$ allele for the diagnosis of Alzheimer's and other dementia disorders in people with $\mathrm{MCl}$ in a primary care setting}




\section{BACKGROUND}

Mild cognitive impairment $(\mathrm{MCl})$ refers to cognitive impairment without dementia (Morris 2001). It is a heterogeneous condition that has been operationalised in several ways. Matthews (Matthews 2008) has categorised $\mathrm{MCl}$ into age-related cognitive change, pathological decline, category systems, and the Mayo Clinic criteria. Under agerelated cognitive change are age-consistent memory impairment $(A C M I)$ and age-related cognitive decline (ARCD). Pathological decline encompasses the conditions of cognitive impairment no dementia (CIND), age-associated memory impairment (AAMI), age-associated cognitive decline $(A A C D)$, mild cognitive disorder $(M C D)$, questionable dementia (OD), minimal dementia (MD), mild neurocognitive disorder (MNCD), limited cognitive disturbance (LCD), and benign senescent forgetfulness (BSF). The category systems cover subjective memory complaint (SMC) and $\mathrm{MCl}$ defined as a score of 22 to 26 on the 30 -item Mini-Mental State Examination. The Mayo Clinic criteria differentiate $\mathrm{MCl}$ into three subtypes: non-amnestic $\mathrm{MCl}(\mathrm{N}-\mathrm{MCl})$, amnestic $\mathrm{MCl}$ (A-MCl), multiple $\mathrm{MCl}(\mathrm{M}-\mathrm{MCl})$. A-MCI refers to objective memory impairment with generally preserved cognitive functioning, or subjective memory complaints corroborated by an informant (Petersen 2004).

Throughout this review, we will use the term "MCl" to refer to any of the abovementioned conditions. In addition, we will be including in our definition of $\mathrm{MCl}$ impairment on a cognitive test with an overall Clinical Dementia Rating (CDR) score of 0.5 or based on an equivalent measure (Morris 2001).

People with $\mathrm{MCl}$ are at an increased risk for Alzheimer's disease (AD). About 35 percent of those with $\mathrm{MCl}$ have been reported to progress to $A D$ over a follow-up period of 4.5 years, with a rate of progression that was thrice faster compared to cognitively healthy individuals (Bennett 2002). AD is a neurodegenerative disorder characterized pathologically by neuritic plaques and neurofibrillary tangles; and clinically by progressive memory loss, impairments in activities of daily living, and behavioral and neuropsychiatric symptoms. $A D$ is the most common cause of dementia (Blennow 2006) and accounts for the majority of dementia cases worldwide (World Health Organization 2012). 
There is currently no cure for AD dementia, although previous studies have shown some benefits of drug treatments in delaying cognitive decline and slowing disease progression (Rountree 2012; Peters 2012). Identifying those who are at an increased risk of developing $A D$ dementia is therefore important for prognosis purposes and early intervention, when and if a treatment for reducing incident $A D$ dementia is found.

Among the known risk factors for AD dementia is the $\varepsilon_{4}$ allele of the apolipoprotein gene. The APOE gene transports cholesterol and lipids in the brain, and is involved in neuronal repair ( $B \cup$ 2009). APOE has three polymorphic alleles $\left(\varepsilon 2, \varepsilon 3\right.$ and $\left.\varepsilon_{4}\right)$, the combinations of which result in six genotypes: $\varepsilon 2 \varepsilon 2, \varepsilon 2 \varepsilon 3, \varepsilon 2 \varepsilon_{4}, \varepsilon 3 \varepsilon_{3}, \varepsilon 3 \varepsilon_{4}$ and $\varepsilon_{4} \varepsilon 4$ (Leoni 2011). The APOE $\varepsilon 4$ allele has been shown to have high-avidity binding to amyloid beta (Strittmatter 1993), which is the main constituent of neuritic plaques.

About $15 \%$ of the general population has been reported to be $A P O E \varepsilon_{4}$ allele carriers (Bu 2009). In Europe, $A P O E-\varepsilon_{4}$ prevalence has been reported to follow a north-south gradient, which was highest in northern Europe ( $60 \%)$, followed by midden Europe ( 40\%) and southern Europe ( $30 \%$ ) (Norberg 2011). An estimated $40 \%$ of those with $A D$ dementia in the general population carry the $\varepsilon_{4}$ allele (Bu 2009). APOE- $\varepsilon 4$ has been associated with a $~ 3.7$-fold increased risk for AD dementia in case-control studies (Bertram 2007), while carriership of two $\varepsilon_{4}$ alleles has been reported to increase the risk to as high as $\sim 15^{-}$ fold (Farrer 1997). Although other genetic risk factors for AD dementia have been identified in genome-wide association studies in recent years, these genes usually show a much weaker effect (odds ratio of $<1.5)$ compared to $A P O E-\varepsilon 4$. In a meta-analysis, we found the APOE $\varepsilon 4$ allele to be a moderately strong predictor of progression from $\mathrm{MCl}$ to AD dementia (odds ratio of $~ 2.3$ ) (Elias-Sonnenschein 2011).

The purpose of the current review is to (1) assess through meta-analysis the diagnostic accuracy of the APOE $\varepsilon_{4}$ allele for identifying $A D$ and predicting progression to $A D$ dementia and other dementia among people with $\mathrm{MCl}$; and (2) update and expand our previous meta-analysis.It differs from our earlier study in the following aspects. First, the period that will be covered is from 1993, when the 
first publication on the relationship between the APOE $\varepsilon_{4}$ allele and AD appeared (Strittmatter 1993), to 2012. Second, the definition of $\mathrm{MCl}$ will include the concepts of Matthews (Matthews 2008). Third, the methodological quality of the studies that will be included in the review will be assessed using the revised quality assessment of diagnostic accuracy studies (QUADAS-2)(Whiting 2011). Fourth, in the statistical analyses, we will be taking into account correlations between outcome measures, which is ideally assessed using a bivariate model. Fifth, no language restriction will be imposed on the search for relevant literature for the review. And sixth, as the diagnostic accuracy of the $A P O E$ \& 4 allele in one setting may be different from other settings, we will be including in this review only studies in a primary care setting. We have prepared a similar review for studies in secondary care and in community settings.

We will be evaluating the accuracy of the APOE $\varepsilon 4$ allele at baseline in relation to (1) progression from $\mathrm{MCl}$ to $\mathrm{AD}$ dementia; and (2) progression from $\mathrm{MCl}$ to other forms of dementia.

\section{Target condition being diagnosed}

There are two target conditions in this review: (1) AD dementia and (2) other forms of dementia, which will be assessed at follow-up.

We will be comparing the results of the index test obtained at baseline with the results of the reference standards at follow-up (delayed verification).

\section{Index test(s)}

The index test is the $A P O E$ genotype, in particular, carriership of the $A P O E \varepsilon_{4}$ allele as assessed by genotyping.

\section{Clinical pathway}

Dementia develops over several years. There is a presumed period when people are asymptomatic, and when pathology is accumulating. Individuals or their relatives may then notice subtle impairments of recent memory. Gradually, more cognitive domains become involved, and difficulty in planning complex tasks becomes increasingly apparent. In the Netherlands, people usually present to their general practitioner, 
who may administer a cognitive screening test and refer the person to a hospital memory clinic. However, many people with dementia do not present until much later in the disorder and will follow a different pathway to diagnosis, for example being identified during an admission to general hospital for a physical illness. Thus, the pathway influences the accuracy of the diagnostic test. The accuracy of the test will vary with the experience of the administrator, and the accuracy of the subsequent diagnosis will vary with the history of referrals to the particular healthcare setting. Diagnostic assessment pathways may vary in other countries and diagnoses may be made by a variety of specialists including neurologists and geriatricians.

Standard assessment of dementia includes history taking, clinical examination (including neurological, mental state, and cognitive examinations), and informant interview. Prior to diagnosis of dementia, the clinician normally rules out, and if possible treats, other physical or mental conditions that may be causing the cognitive impairment. Neuroimaging (computed tomography or magnetic resonance imaging) is recommended in most recent guidelines (McKhann 2011; NICE 2006). Most neuroimaging tests, and also recently cerebrospinal fluid sampling, are performed after a cognitive deficit is noted. However, individuals with abnormalities on brain imaging, which may be performed for any number of reasons, are more likely to be tested subsequently for cognitive impairment. $A P O E$ is currently not part of the standard assessment procedure for dementia.

Dementia as diagnosed is defined by a deficit in more than two cognitive domains of sufficient degree to impair functional activities of daily living. The different dignostic criteria for dementia are presented hereunder in the 'Reference standards' section and in Appendix 1.

\section{Rationale}

An increasing number of studies suggest genetic susceptibility to $A D$ dementia (Hollingworth 2011; Naj 2011; Seshadri 2010; Lambert 2009). The $A P O E \varepsilon_{4}$ allele is the strongest known genetic risk factor for $A D$ dementia. As a diagnostic tool, APOE genotyping might aid in: 
- identifying individuals with $\mathrm{MCl}$ at high risk of developing $\mathrm{AD}$ dementia

- increasing the accuracy of dementia diagnostics in addition to the reference standards

- $\quad$ selecting candidates for trials with drugs that aim to slow down the progression of AD dementia

Particular advantages of $A P O E$ genotyping is that it is safe and relatively inexpensive to perform.

\section{Objectives}

To determine the diagnostic accuracy of the APOE $\varepsilon 4$ allele in detecting $A D$ dementia and other forms of dementia in people with $\mathrm{MCl}$ in a primary care setting.

\section{Secondary objectives}

To investigate heterogeneity of test accuracy in the included studies.

To highlight the quality and quantity of research evidence available about the effectiveness of $A P O E$ as an index test in people with $\mathrm{MCl}$ in a primary care setting.

\section{METHODS}

\section{Criteria for considering studies for this review Types of studies}

We will be including longitudinal cohort studies in a primary care setting of people with $\mathrm{MCl}$ in which APOE was genotyped at baseline and the reference standard results were obtained at follow-up. These studies necessarily employed delayed verification of progression to dementia and are sometimes labelled as 'delayed verification cross-sectional studies' (Bossuyt 2008).

Case-control studies will be included if they incorporate a delayed verification design. As these can only occur in the context of a cohort study, these studies are invariably diagnostic nested case-control studies.

\section{Participants}

Participants with $\mathrm{MCl}$ will be included in this review. $\mathrm{MCl}$ will be defined according to the criteria of Matthews, Petersen or Morris (Matthews 
2008; Petersen 2004; Morris 2001), as described above. These criteria include a CDR score of 0.5 , memory impairment confirmed by neuropsychological assessment, subjective memory complaints corroborated by an informant, generally preserved cognitive functions, no or minimal impairment of activities of daily living, absence of dementia.

The participants for this review are those in a primary care setting. By primary care, we mean all generalist office-based practices, including general practice and family physician. An office-based neurology, psychiatry, gerontology or other specialist memory service will not be included. Subjects in this category may have presented with subjective memory problems or be part of a "screening" program.

We will exclude participants with cognitive impairment due to alcohol or substance abuse, head injury, major depression or other neuropsychiatric disorders, Parkinson's disease or other neurological disorders, somatic disorders, or endocrine disorders.

Studies that have more than $20 \%$ drop-out will be considered separately. The causes for the drop-out will be noted down. If this information is missing, the reliability of the conclusions must be questioned.

\section{Index tests}

Participants genotyped for APOE will be classified as $\varepsilon_{4}$ allele carriers or noncarriers; heterozygote carriers or homozygote carriers. We will record the genotypes for the other $A P O E$ alleles, which may then be the subject of subgroup analyses.

\section{Target conditions}

There are two target conditions in this review:

1. AD dementia (conversion from $\mathrm{MCl}$ to $\mathrm{AD}$ dementia)

2. Any other forms of dementia (conversion from $\mathrm{MCl}$ to any other forms of dementia)

\section{Reference standards}

Several definitions of AD dementia are acceptable for the purposes of this review. 
Post-morten diagnosis is the 'gold standard'. Pathological confirmation of $A D$ according to the Braak, the Consortium to Establish a Registry for Alzheimer's Disease (CERAD), or the National Institute for Aging and Ronald and Nancy Reagan Institute for the Alzheimer's Association (NIA-RIA) criteria are based on the density and distribution of neurofibrillary tangles (NFTs) or neuritic plaques (NP) (Murayama 2004; Appendix 1).

The acceptable clinical reference standards for diagnosing $A D$ dementia include that of the National Institute of Neurological and Communicative Disorders and Stroke and the Alzheimer's Disease and Related Disorders Association (NINCDS-ADRDA) criteria (McKhann 1984); the International Statistical Classification of Diseases and Related Health Problems 1oth Revision (ICD-10) (World Health Organization 1993); the Diagnostic and Statistical Manual of Mental Disorders $4^{\text {th }}$ edition text revised (DSM-IV-TR) (American Psychiatric Association 2000); DSM $4^{\text {th }}$ editon (DSM-IV) (American Psychiatric Association 1994); and DSM $3^{\text {rd }}$ revised edition (DSM-III-R) (American Psychiatric Association 1987).

NINCDS-ADRDA differentiates between probable and possible $A D$. A diagnosis of probable $A D$ is supported by abnormal biomarkers, whereas possible AD mainly has a clinical presentation. Details of the criteria are shown in Appendix 1. If sufficient data is available, subgroup analyses for probable and for possible AD will be performed.

Recently, the NINCDS-ADRDA criteria has been revised to include as key diagnostic feature early episodic memory impairment, the presence of abnormal biomarkers, namely medial temporal lobe atrophy, abnormal cerebrospinal fluid markers, specific metabolic pattern on neuroimaging methods, and familial genetic mutations (Dubois 2007). Studies that used this revised criteria will be included in the review.

The key distinction in all clinical criteria is extent of social and occupational functional impairment. The different iterations of these clinical criteria may not be directly comparable over time, and the validity of the diagnoses may vary depending on how they were operationalised. We will take these issues into consideration in interpreting results, assessing sources of heterogeneity and performing 
sensitivity analyses, as appropriate.

With regard to other dementia, the reference standard for Lewy Body Dementia is the McKeith criteria (McKeith 2005); for frontotemporal dementia, the Lund criteria (The Lund and Manchester Groups 1994), Boxer criteria (Boxer 2005), DSM and ICD; and for vascular dementia, the National Institute of Neurological Disorders and Stroke and Association Internationale pour la Recherche et I'Enseignement en Neurosciences (NINDS-AIREN) criteria (Roman 1993), DSM and ICD.

In this review, we will perform separate analyses for $A D$ dementia diagnosis based on pathological criteria and on clinical criteria. The reference standards used will be included in the investigation of sources of heterogeneity.

\section{Search methods for identification of studies}

\section{Electronic searches}

We will search ALOIS, the Cochrane Dementia and Cognitive Improvement Group's specialised register, MEDLINE (Ovid SP), EMBASE (Ovid SP), BIOSIS Previews (Ovid SP), Science Citation Index (ISI Web of Knowledge), PsycINFO (Ovid SP), and LILACS (Bireme). See Appendix 2 for a proposed draft strategy to be run in MEDLINE (Ovid SP) plus additional narrative on the search process. Similarly structured search strategies will be designed using search terms appropriate for each database listed above. We will also request a search of the Cochrane Register of Diagnostic Test Accuracy Studies (maintained by the Cochrane Renal Group).

There will be no restriction based on language of the study report. Translation services will be used, as necessary.

Initial searches will be performed by a single researcher with extensive experience of systematic review.

\section{Searching other resources}

- Grey literature: Chosen electronic databases will include assessments of conference proceedings.

- Handsearching: We will not perform handsearching as there is little published evidence of the benefits of handsearching for reports of DTA studies (Glanville 2010). 
- Reference lists: Reference lists of all eligible studies and reviews in the field will be scanned for further possible titles and the process repeated until no new titles are found (Horsley 2011; Greenhalgh 2005). The citation tracking and "related articles" will be checked to identify studies that could be included in the review.

\section{Data collection and analysis}

\section{Selection of studies}

One researcher will screen all titles generated by electronic database searches for relevance. The results of these electronic searches will receive an initial screen, including de-duplication, by a team of experienced assessors (predominantly senior medical students). This group has previously been shown to have good inter-rater reliability results.

Two review authors with content expertise will perform a second level of screening and identify studies for inclusion in the review. In case of differences in opinion on whether or not to include a particular study, a third author will serve as arbiter. When multiple publications are based on the same cohort, the study with the largest sample will be selected. The PRISMA flowchart will be used to illustrate the selection process.

\section{Data extraction and management}

Two review authors will independently complete a data extraction form for each study (see Appendix 3 ). The data extraction form includes information on the baseline characteristics of the population, $A P O E$ genotyping, outcomes at follow-up, $\mathrm{MCl}$ definition of the study, study duration, and inclusion and exclusion criteria.

Data on $A P O E \varepsilon_{4}$ allele and outcome will be summarized in a $2 \times 2$ table. In this table, the number of people who are carriers of at least $1 A P O E \varepsilon 4$ allele and number of noncarriers who remained stable or progressed to $A D$ will be specified. Information on the specific $A P O E$ genotype and type of dementia at follow-up will be summarised in another table. The data will be cross-checked for consistency. Authors will be contacted in case of incomplete data. Excel, Endnote and RevMan will be used to manage the data. 


\section{Assessment of methodological quality}

We will assess the methodological quality of each study using QUADAS-2 tool (Whiting 2011), as recommended by the Cochrane Collaboration. The tool consists of four domains: Patient selection; Index test; Reference standard; and Patient flow. Each domain is assessed in terms of risk of bias, with the first three domains also considered in terms of applicability (http://www.bris.ac.uk/quadas/ quadas-2 Appendix 3 ). The components of each of these domains and a rubric that details how judgements concerning risk of bias are made are detailed in Appendix 4. Certain key areas important to qualify assessment are participant selection, blinding and missing data. We recognise that QUADAS-2 may still develop and that as yet standard RevMan software does not incorporate QUADAS-2 functionality.

We will pilot QUADAS-2 assessment on 2 papers. If agreement is poor, we will refine the questions. QUADAS-2 data will not be used to form a summary quality score. We will produce a narrative summary describing numbers of studies that found high/low/unclear risk of bias as well as concerns regarding applicability, which we will assess using Appendix 5 .

\section{Statistical analysis and data synthesis}

We will apply the DTA framework for the analysis of a single test and extract the data from a study into a $2 \times 2$ table, showing the binary test results cross-classified with the binary reference standard and ignoring any censoring that might have occurred. We acknowledge that such a reduction in the data may represent a significant oversimplification. We will therefore adopt an intention to diagnose (ITD) approach as well. If possible, we would present what the result would be if all dropouts would have developed dementia, and if all dropouts would not have developed dementia. We may also need to assume that the proportion of positive and negative test results is the same in the unknown as the known participants in order to do this.

We will use data from the $2 \times 2$ tables abstracted from the included studies (true positive $=T P$, false negative $=F N$, false positive $=F P$, true negative $=T N$ ) and entered into RevMAN to calculate the sensitivities, specificities and their $95 \%$ confidence intervals. We will 
also present individual study results graphically by plotting estimates of sensitivities and specificities in both a forest plot and a receiver operating characteristic (ROC) space. If more than one threshold is published in primary studies, we will report accuracy estimates for all thresholds.

If there are sufficient data, we will meta-analyse the pairs of sensitivity and specificity. The preferred approach would be the hierarchical summary ROC curve (HSROC) method proposed by Rutter and Gatsonis (Cochrane Handbook for Systematic Reviews of Diagnostic Test Accuracy, chapter 10) (Macaskill 2010) because implicit thresholds are expected in primary studies. We will conduct these analyses in Stata, R and RevMan software (Stata Corporation 2011; R Core Team 2012; Review Manager 2012) with support from the UK DTA Support Unit. If there are common thresholds across included studies, we will also consider the bivariate random effects approach (Reitsma 2005). When a primary study reports more than one threshold result, we will only select the threshold nearer to the upper left point of the ROC curve for the meta-analysis. We are aware that this data-driven method for threshold selection could lead to an overestimation of diagnostic accuracy (Leeflang 2008).

We will explore the implications of any summary accuracy estimates not affected by heterogeneity emerging by considering the numbers of false positive and false negatives in populations with different prevalence of $\mathrm{MCl}$ and by presenting the results as natural frequencies and using alternative metrics such as likelihood ratios and predictive values.

We will prepare a summary of results table irrespectively.

\section{Investigations of heterogeneity}

The potential sources of heterogeneity, which will be used as framework for investigating heterogeneity, include:

- Spectrum of patients (mean age, gender, Mini-Mental State Examination (MMSE) score)

- Background prevalence of $A P O E \varepsilon_{4}$ allele

- Definition of $\mathrm{MCl}$ 
- Length of follow-up

- Reference standards used

- Exclusion criteria of the study

For diagnostic odds ratios, heterogeneity will be assessed by the Chi-square test, $Q$. The amount of heterogeneity for each outcome measure will be calculated using DerSimonian-Laird, with Tau as an estimate for the standard deviation of the underlying true outcomes across studies. The proportion of variation due to heterogeneity will likewise be computed and expressed as I-square.

As heterogeneity may also be a result of correlation between outcomes (e.g. high sensitivity is correlated with low specificity), a bivariate model will be used and results presented in ROC space. Descriptive analysis will be done by visual examination of the forest plot of sensitivity and specificity, and the ROC plot. Subgroup analyses will be performed if there are sufficient number of studies included. Further analysis will be done by including the potential sources of heterogeneity as covariates in the HSROC model.

\section{Sensitivity analyses}

We will visually inspect the forest plots for outliers and investigate the influence of study quality on the overall diagnostic accuracy of the index test. Studies at high risk of bias as assessed using QUADAS- 2 and the Standards for Reporting Diagnostic Accuracy (STARD) (Bossuyt 2003; Appendix 4; Appendix 6) will be systematically excluded, and the analyses repeated with every exclusion of a study to test if the results would be consistent.

A separate sensitivity analysis will be performed by excluding data-driven threshold selection studies to evaluate their effects on the overall diagnostic accuracy of the index test.

\section{Assessment of reporting bias}

Reporting bias will not be investigated because of current uncertainty about how it operates in test accuracy studies and the interpretation of existing analytical tools such as funnel plots. 


\section{REFERENCES}

American Psychiatric Association 1987

American Psychiatric Association. Diagnostic and statistical manual of mental disorders (DSM III-R). Third revised edition. Washington, DC: APA, 1987.

\section{American Psychiatric Association 1994}

American Psychiatric Association. Diagnostic and statistical manual of mental disorders (DSM-IV). Fourth edition. Washington, DC: APA, 1994.

American Psychiatric Association 2000

American Psychiatric Association. Diagnostic and statistical manual of mental disorders (DSM IV-TR). Fourth edition text revised. Washington: APA, 2000.

\section{Bennett 2002}

Bennett D, Wilson RS, Schneider JA, Evans DA, Beckett LA, Aggarwal NT, et al. Natural history of mild cognitive impairment in older persons. Neurology 2002;59:198-205.

\section{Bertram 2007}

Bertram L, McQueen MB, Mullin K, Blacker D, Tanzi RE. Systematic meta-analyses of Alzheimer disease genetic association studies: the AlzGene database. Nature Genetics 2007;39(1):17-23. [Other: http://www.alzgene.org]

\section{Blennow 2006}

Blennow K, Leon MJ, Zetterberg H. Alzheimer's disease. Lancet 2006;368(9533):387-403. Bossuyt 2003

Bossuyt PM, Reitsma JB, Bruns DE, Gatsonis PP, Glasziou PP, Irwig LM, et al. Standards for reporting of diagnostic accuracy. Toward complete and accurate reporting of studies of diagnostic accuracy: the STARD initiative. British Medical Journal 2003;326:41-4.

Bossuyt 2008

Bossuyt PM, Leeflang MM. Chapter 6: Developing criteria for including studies. In: Cochrane handbook of systematic reviews of diagnostic test accuracy. Version 0.4 edition. The Cochrane Collaboration, 2008.

\section{Boxer 2005}

Boxer AL, Miller BL. Clinical features of frontotemporal dementia. Alzheimer Disease and Associated Disorders 2005;Oct-Dec(19):Suppl 1:S3-6.

Bu 2009

Bu G. Apolipoprotein E and its receptors in Alzheimer's disease: pathways, pathogenesis and therapy. Nature Reviews Neuroscience 2009;10:333-344.

Dubois 2007

Dubois B, Feldman HH, Jacova C, DeKosky ST, Barberger-Gateau P, Cummings J, et al. Research criteria for the diagnosis of Alzheimer's disease: revising the NINCDS-ADRDA 
criteria. Lancet Neurology 2007;6:734-46.

Elias-Sonnenschein 2011

Elias-Sonnenschein LS, Viechtbauer W, Ramakers IHGB, Verhey RJ, Visser PJ. Predictive value of $A P O E-\varepsilon 4$ allele for conversion from $\mathrm{MCl}$ to $\mathrm{AD}$-type dementia: a meta-analysis. Journal of Neurology, Neurosurgery and Psychiatry 2011;10:1149-56.

Farrer 1997

Farrer LA, Cupples LA, Haines JL, Hyman B, Kukull WA, Mayeux R, et al. Effects of age, sex, and ethnicity on the association between apolipoprotein $\mathrm{E}$ genotype and Alzheimer disease: a meta-analysis. Journal of the American Medical Association 1997;278(16):1349-56.

Geslani 2005

Geslani DM, Tierney MC, Herrmann N. Mild Cognitive Impairment: An operational definition and its conversion rate to Alzheimer's disease. Dementia and Geriatric Cognitive Disorders 2005;19:383-9.

Glanville 2010

Glanville JM, Cikalo M, Crawford F, Dozier M,Lowson P. Handsearching for reports of diagnostic test accuracy studies: adding to the evidence base. Cochrane Database of Systematic Reviews, Supplement 2010;CDooooo2:48.

Greenhalgh 2005

Greenhalgh T, Peacock R. Effectiveness and efficiency of search methods in systematic reviews of complex evidence: audit of primary sources. BMJ 2005;331:1064-5.

Hollingworth 2011

Hollingworth $P$, Harold D, Sims R, Gerrish A, Lambert JC, Carrasquillo MM, et al. Common variants at $A B C A 7, M S_{4} A 6 A / M S_{4} A_{4} E_{1} E P H A_{1}, C D_{33}$ and $C D_{2} A P$ are associated with Alzheimer's disease. Nature Genetics 2011;43(5):429-35.

Horsley 2011

Horsley T, Dingwall O, Sampson M. Checking reference lists to find additional studies for systematic reviews. Cochrane Database of Systematic Reviews 2011, Issue 8. Art. No.:

MRoooo26. DOI: 10.1002/14651858.MRoooo26.pub2.

\section{Lambert 2009}

Lambert JC, Heath S, Even G, Campion D, Sleegers K, Hiltunen M, et al. Genome-wide association study identifies variants at CLU and CR1 associated with Alzheimer's disease. Nature Genetics 2009;41(10):1094-9.

Leeflang 2008

Leeflang MGM, Moons KGM, Reitsma JB, Zwinderman AH. Bias in sensitivity and specificity caused by data-driven selection of optimal cutoff values: mechanisms, magnitude, and solutions. Clinical Chemistry 2008;54(4):729-737. 


\section{Leoni 2011}

Leoni V. The Effect of apolipoprotein E (ApoE) genotype on biomarkers of amyloidogenesis, tau pathology and neurodegeneration in Alzheimer's disease. Clinical Chemistry and Laboratory Medicine 2011;49(3):375-83.

\section{Macaskill 2010}

Macaskill P, Gatsonis C, Deeks JJ, Harbord rM, TakwoingiY. Chapter 10: Analysing and presenting results. In: Cochrane handbook for systematic reviews of diagnostic test accuracy. verion 1.0 edition. The Cochrane Collaboration, 2010. [Other: http://srdta.cochrane.org]

\section{Matthews 2008}

Matthews FE, Stephan BCM, McKeith IG, Bond J, Brayne C, and the Medical Research Council Cognitive Function and Ageing Study. Two-year progression from mild cognitive impairment to dementia: to what extent do different definitions agree? Journal of American Geriatric Society 2008;56(8):1424-33.

McKeith 2005

McKeith IG, Dickson DW, Lowe J, Emre M, O'Brien JT, Feldman H, et al. Diagnosis and management of dementia with Lewy bodies: third report of the DLB consortium. Neurology 2005;65(12):1863-72.

\section{McKhann 1984}

McKhann G, Drachman D, Folstein M, Katzman R, Price D, Stadlan EM. Clinical diagnosis of Alzheimer's disease: report of the NINCDS-ADRDA Work Group under the auspices of Department of Health and Human Services Task Force on Alzheimer's Disease. Neurology 1984;34(7):939-44.

\section{McKhann 2011}

McKhann GM, Knopman DS, Chertkow H, Hyman BT, Jack CR Jr, Kawas CH, et al. The diagnosis of dementia due to Alzheimer's disease: recommendations from the National Institute on Aging-Alzheimer's Association workgroups on diagnostic guidelines for Alzheimer's disease. Alzheimer's \& Dementia 2011;7:263-9.

\section{Morris 2001}

Morris JC, Storandt M, Miller JP, McKeel DW, Price JL, Rubin EH, et al. Mild cognitive impairment represents early stage Alzheimer's disease. Archives of Neurology 2001;58(3):397-405.

\section{Murayama 2004}

Murayama S, Saito Y. Neuropathological diagnostic criteria for Alzheimer's disease. Neuropathology 2004;24:254-260.

Naj 2011

Naj AC, Jun G, Beecham GW, Wang LS, Vardarajan BN, Buros J, et al. Common variants at $\mathrm{MS}_{4} \mathrm{~A}_{4} \mathrm{~A} / \mathrm{MS}_{4} \mathrm{~A} 6 \mathrm{E}_{1}, \mathrm{CD}_{2} \mathrm{AP}, \mathrm{CD}_{33}$ and EPHA1 are associated with late-onset Alzheimer's disease. Nature Genetics 2011;43(5):436-41. 
NICE 2006

National Institute for Health and Clinical Excellence. Dementia: supporting people with dementia and their careers in health and social care. Clinical Guideline 42. 2006.

Norberg 2011

Norberg J, Graff C, Almkvist O, Ewers M, Frisoni GB, Frölich L, et al. Regional differences in effects of $A P O E \varepsilon_{4}$ on cognitive impairment in non-demented subjects. Dementia and Geriatric Cognitive Disorders 2011;32:135-142.

Okello 2009

Okello A, Koivunen J, Edison P, Archer HA, Turkheimer FE, Någren K, et al. Conversion of amyloid positive and negative $\mathrm{MCl}$ to $\mathrm{AD}$ over 3 years. An 11C-PIB PET study. Neurology 2009;73(10):754-60.

Peters 2012

Peters O, Lorenz D, Fesche A, Schmidtke K, Hüll M, Perneczky R, et al. A combination of galantamine and memantine modifies cognitive function in subjects with amnestic $\mathrm{MCl}$. The Journal of Nutrition, Health \& Aging 2012;16(6):544-548.

Petersen 2004

Petersen RC. Mild cognitive impairment as a diagnostic entity. Journal of Internal Medicine 2004; 256:183-194.

R Core Team 2012

R: a language and environment for statistical computing [Computer program]. R Core Team. Vienna: R Foundation for Statistical Computing, 2012.

Reitsma 2005

Reitsma JB, Glas AS, Rutjes AW, Scholten RJ, Bossuyt PM, Zwinderman AH. Bivariate analysis of sensitivity and specificity produces informative summary measures in diagnostic reviews. Journal of Clinical Epidemiology 2005;58(10):982-90.

Review Manager 2012

Review Manager (RevMan) [Computer program]. Version 5.2. Copenhagen: The Nordic Cochrane Centre, The Cochrane Collaboration, 2012.

Roman 1993

Roman GC, Tatemichi TK, Erkinjuntti T, Cummings JL, Masdeu JC, Garcia JH, et al.. Vascular dementia: diagnostic criteria for research studies. Report of the NINDS-AIREN International Workshop. Neurology 1993;43(2):250-60.

Rountree 2012

Rountree SD, Atri A, Lopez OL, Doody RS. Effectiveness of Antidementia Drugs in delaying Alzheimer Disease Progression. Alzheimer's \& Dementia 2012;24:1-8. [DOI: doi: 10.1016/j. alz.2012.01.002] 


\section{Seshadri 2010}

Seshadri S, Fitzpatrick AL, Ikram MA, DeStefano AL, Gudnason V, Boada M, et al. Genomewide analysis of genetic loci associate with Alzheimer disease. Journal of the American Medical Association 2010;303(18):1832-40.

\section{Stata Corporation 2011}

Stata/MP 11.2 for Macintosh [Computer program]. College Station, Texas: Stata Corporation, 2011.

\section{Strittmatter 1993}

Strittmatter WJ, Saunders AM, Schnechel D. Apolipoprotein E: High-avidity binding to bamyloid and increased frequency of type 4 allele in late-onset familial Alzheimer disease. In: Proceedings of the National Academy of Sciences. Vol. 90. 1993:1977-1981.

The Lund and Manchester Groups 1994

The Lund and Manchester Groups. Clinical and neuropathological criteria for frontotemporal dementia. Journal of Neurology, Neurosurgery, and Psychiatry 1994;57:416-418.

Visser 2006

Visser PJ, Kester A, Jolles J, Verhey F. Ten-year risk of dementia in subjectswith mild cognitive impairment. Neurology 2006;67:1201-1207.

Whiting 2011

Whiting P, Rutjes A, Westwood M, Mallett S, Deeks J, Reitsma J, et al. QUADAS-2: a revised tool for the quality assessment of diagnostic accuracy studies. Annals of Internal Medicine 2011;155:529-536.

World Health Organization 1993

World Health Organization. International Statistical Classification of Diseases and Related Health Problems. 10th edition. WHO, 1993.

World Health Organization 2012

World Health Organization. Dementia a public health priority. Geneva, Switzerland: World Health Organization, 2012. 


\section{APPENDICES}

Appendix 1 Reference standards for the diagnosis of AD dementia

\section{Pathological criteria}

Braak stage I/II indicates normal condition; stage III/IV, cognitive impairment; and stage V/VI, dementia (Murayama 2004). The CERAD differentiates between neuritic and diffuse plaques, classifies neocortical NP as $\mathrm{O}, \mathrm{A}, \mathrm{B}$, and $\mathrm{C}$, and in addition uses clinical information in making the diagnosis. A CERAD stage $C$ means abundant NP and corresponds to dementia in the elderly. The NIA-RIA categorises dementia in terms of likelihood and combines the Braak and CERAD criteria. Braak stage $\mathrm{I} / \mathrm{II}$ and CERAD NP stage $A$ corresponds to low probability of $A D$; stage III/IV and $B$ indicates middle probability of $A D$; and stage $V / V I$ and $C$ is regarded as high probability of $A D$ (Murayama 2004).

\section{Clinical criteria}

The NINCDS-ADRDA key features for the diagnosis of probable $A D$ are impairment in at least two cognitive domains, progressive impairment in memory and other cognitive functions not owing to other physical or neurological conditions, normal consciousness, with age of onset between 40 and 90 years of age (McKhann 1984). The supportive features are progressive worsening of specific cognitive functions, such as language, goal-oriented activity, and perception, which is also confirmed by the patients' family; and abnormal results of electroencephalogram (EEG), computed tomography (CT) or magnetic resonance imaging (MRI), or cerebrospinal fluid (CSF) examination (McKhann 1984). Possible AD refers to dementia, based on clinical examination and MMSE or comparable tests score. It course has a clinical presentation. A diagnosis of possible AD is made in the absence of other neurological, psychiatric or general physical impairment that could be causing the dementia; or in the presence of a general physical impairment of brain disorder that could result in dementia but is, in this case, not the cause of the dementia; or in the presence of a confirmed single gradually progressive serious cognitive impairment without other cause (McKhann 1984). 
Appendix 2 Medline search strategy

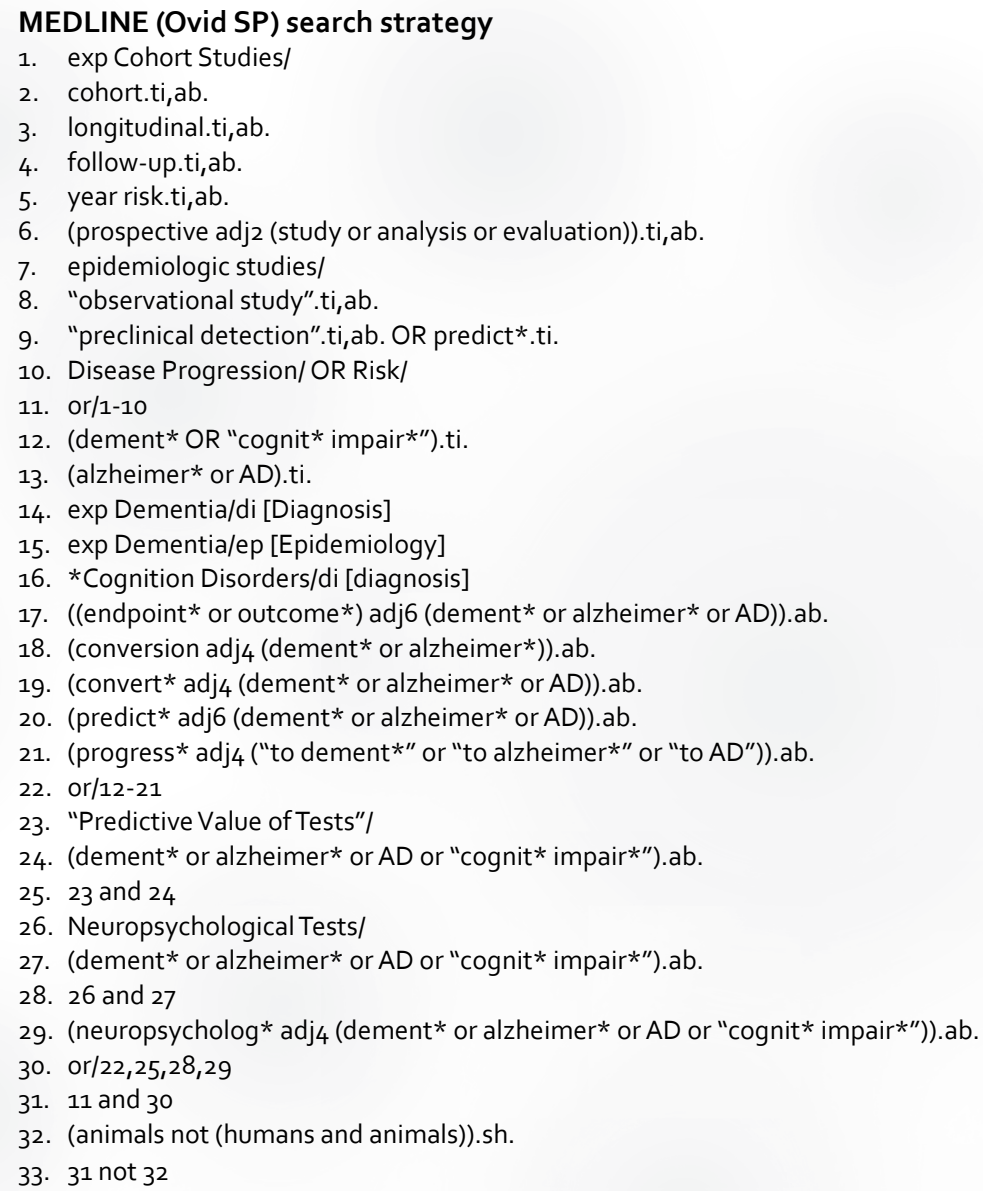

Search narrative: This search strategy (above) has been kept deliberately very broad - utilizing only two main concepts: time (concept A) and the dementia aspect/outcome (concept B). APOE-e4 will not be included in the search terms because this allows the search to be more sensitive to studies that do not contain the term $A P O E-e_{4}$ in their abstracts yet provide information on $A P O E$ genotyping in the main text.

Potential studies for inclusion were initially identified from published non-Cochrane reviews and background literature. This generated a reference set of 35 potential (and probable) studies for inclusion to use to test the search strategy detailed above. All 35 studies are identified by the above strategy. We then further tested the strategy against a set of potential studies that had been identified through an index-test-based search. The yield from the above strategy will be very high. However, a significant proportion of references retrieved will not need to be screened as they will have already been screened from the monthly search detailed below.

Parallel to running non-index test based searches in the databases listed in the search methods section, the offline version of the Cochrane Dementia and Cognitive Improvement Group's specialized register, 


\section{Appendix 2 Medline search strategy Continued}

ALOIS, will be searched for all longitudinal studies in which the presence of APOE \& 4 allele was measured. ALOIS is made up of both intervention and diagnostic test accuracy (DTA) studies. The DTA side of ALOIS is still under development and is not $100 \%$ comprehensive but the MEDLINE search used to identify diagnostic tests (in both longitudinal and normal cross-sectional studies) in any setting, is run and screened every month.

\section{The MEDLINE (Ovid SP) strategy for ALOIS is:}

1. "word recall".ti,ab.

2. "7-minute screen".ti,ab.

3. "6 item cognitive impairment test".ti,ab.

4. "6CIT".ti,ab.

5. "AB cognitive screen".ti, ab.

6. "abbreviated mental test".ti,ab.

7. "ADAS-cog".ti,ab.

8. AD8.ti,ab.

9. "inform* interview".ti,ab.

10. "animal fluency test".ti,ab.

11. "brief alzheimer* screen".ti,ab.

12. "brief cognitive scale".ti,ab.

13. "clinical dementia rating scale".ti,ab.

14. "clinical dementia test".ti, ab.

15. "community screening interview for dementia".ti,ab.

16. "cognitive abilities screening instrument".ti,ab.

17. "cognitive assessment screening test".ti,ab.

18. "cognitive capacity screening examination".ti,ab.

19. "clock drawing test".ti,ab.

20. "deterioration cognitive observee".ti,ab.

21. "Dem Tect".ti,ab.

22. "fuld object memory evaluation".ti,ab.

23. "IOCODE".ti,ab.

24. "mattis dementia rating scale".ti,ab.

25. "memory impairment screen".ti, ab.

26. "minnesota cognitive acuity screen".ti,ab.

27. "mini-cog".ti,ab.

28. "mini-mental state exam*".ti,ab.

29. "mmse".ti,ab.

30. "modified mini-mental state exam".ti,ab.

31. "3MS".ti, ab.

32. "neurobehavioural cognitive status exam*".ti,ab.

33. "cognistat".ti,ab.

34. "quick cognitive screening test".ti, ab.

35. "OCST".ti, ab.

36. "rapid dementia screening test".ti,ab.

37. "RDST".ti,ab.

38. "repeatable battery for the assessment of neuropsychological status".ti,ab.

39. "RBANS".ti,ab.

40. "rowland universal dementia assessment scale".ti,ab.

41. "rudas".ti, ab.

42. "self-administered gerocognitive exam*".ti,ab.

43. ("self-administered" and "SAGE").ti,ab.

44. "self-administered computerized screening test for dementia".ti,ab. 


\section{Appendix 2 Medline search strategy Continued}

45. "short and sweet screening instrument".ti,ab.

46. "sassi".ti,ab.

47. "short cognitive performance test".ti,ab.

48. "syndrome kurztest".ti,ab.

49. "six item screener".ti,ab.

50. "short memory questionnaire".ti,ab.

51. ("short memory questionnaire" and "SMQ").ti,ab.

52. "short orientation memory concentration test".ti,ab.

53. "s-omc".ti,ab.

54. "short blessed test".ti,ab.

55. "short portable mental status questionnaire".ti,ab.

56. "spmsq".ti,ab.

57. "short test of mental status".ti, ab.

58. "telephone interview of cognitive status modified".ti,ab.

59. "tics-m".ti,ab.

6o. "trail making test".ti, ab.

61. "verbal fluency categories".ti,ab.

62. "WORLD test".ti, ab.

63. "general practitioner assessment of cognition".ti,ab.

64. "GPCOG".ti,ab.

65. "Hopkins verbal learning test".ti,ab.

66. "HVLT".ti,ab.

67. "time and change test".ti,ab.

68. "modified world test".ti, ab.

69. "symptoms of dementia screener".ti,ab.

70. "dementia questionnaire".ti,ab.

71. "7MS".ti,ab.

72. ("concord informant dementia scale" or CIDS).ti,ab.

73. (SAPH or "dementia screening and perceived harm*").ti,ab.

74. or $/ 1-73$

75. exp Dementia/

76. Delirium, Dementia, Amnestic, Cognitive Disorders/

77. dement*.ti,ab.

78. alzheimer*.ti,ab.

79. AD.ti,ab.

80. ("lewy bod*" or DLB or LBD).ti,ab.

81. "cognit* impair*".ti,ab.

82. (cognit* adj4 (disorder* or declin* or fail* or function*)).ti,ab.

83. (memory adj3 (complain* or declin* or function*)).ti,ab.

84. or $/ 75-83$

85. exp "sensitivity and specificity"I

86. "reproducibility of results"I

87. (predict* adj3 (dement* or AD or alzheimer*)).ti,ab.

88. (identif* adj3 (dement* or AD or alzheimer*)).ti,ab.

89. (discriminat* adj3 (dement* or AD or alzheimer*)).ti,ab.

9o. (distinguish* adj3 (dement* or AD or alzheimer*)).ti,ab.

91. (differenti* adj3 (dement* or AD or alzheimer*)).ti,ab.

92. diagnos*.ti.

93. di.fs.

94. sensitivit*.ab. 


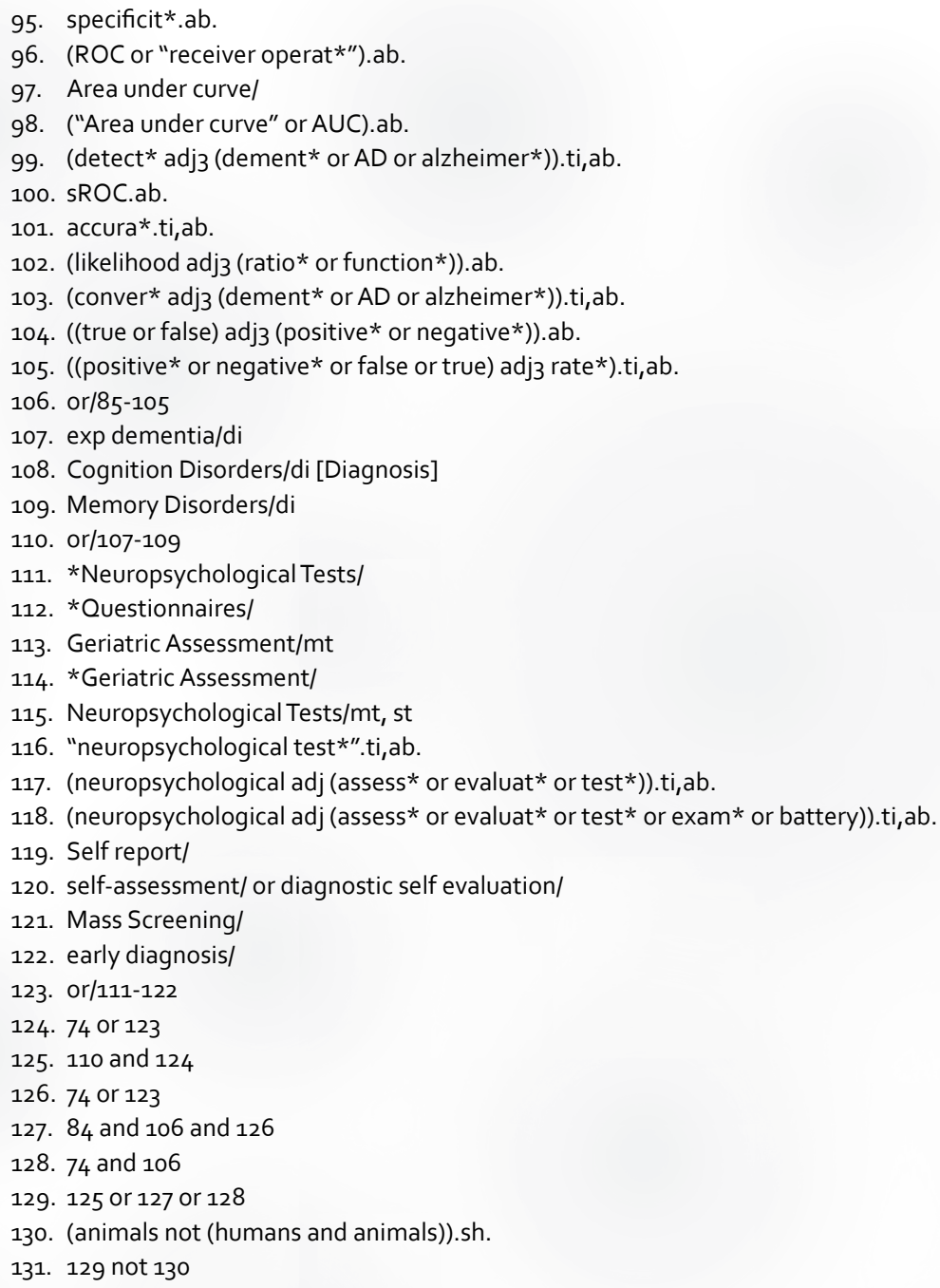

\section{The concepts for this are:}

A Specific neuropsychological tests

B General terms (both free text and MeSH) for tests/testing/screening

C Outcome: dementia diagnosis (unfocused MeSH with diagnostic sub-headings)

D Condition of interest: Dementia (general dementia terms both free text and MeSH - exploded and unfocused) E Methodological filter: not used to limit all search The concept combinations are:
1. (A OR B) AND C
2. (A OR B) AND D AND E
3. AANDE 


\section{Appendix 3 Data extraction forms}

Appendix 3.1 General information of the study

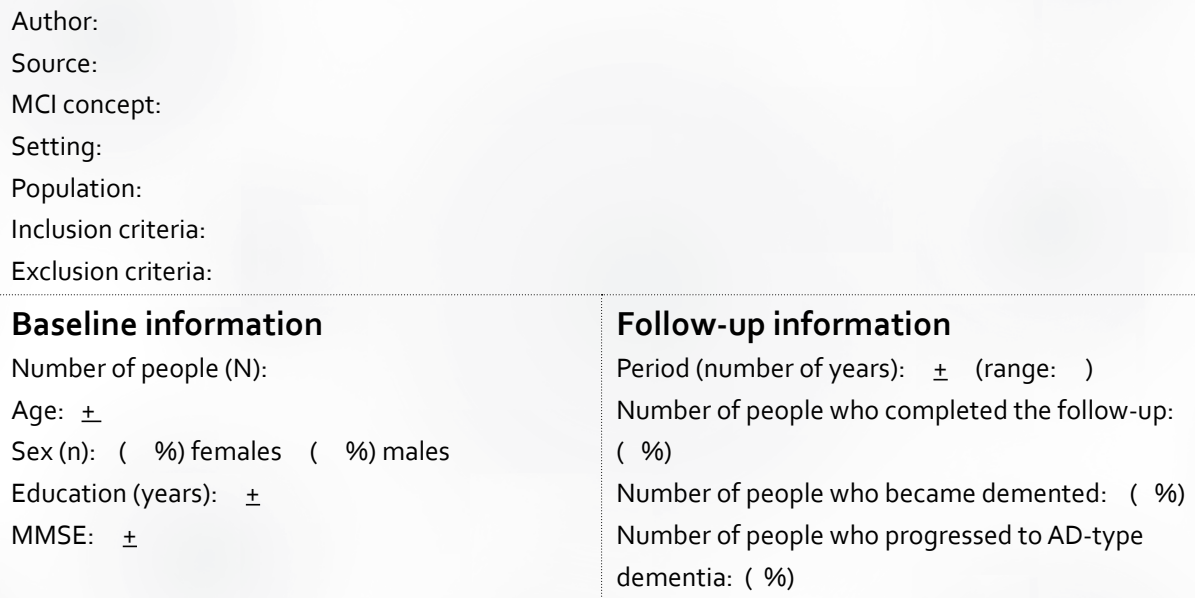

\section{Baseline information}

Number of people $(\mathrm{N})$ :

Age: \pm

Sex $(n)$ : ( \%) females ( \%) males

Education (years): $\quad \pm$

MMSE: \pm

\section{Follow-up information}

Period (number of years): \pm (range: ) Number of people who completed the follow-up: ( \%) Number of people who became demented: ( \%) Number of people who progressed to AD-type dementia: ( \%)

Table legend: $\mathrm{MCl}=$ mild cognitive impairment; MMSE=Mini-Mental State Examination; $\mathrm{AD}=\mathrm{Alzheimer}$ 's disease

Appendix 3.2 Demographic information according to outcome

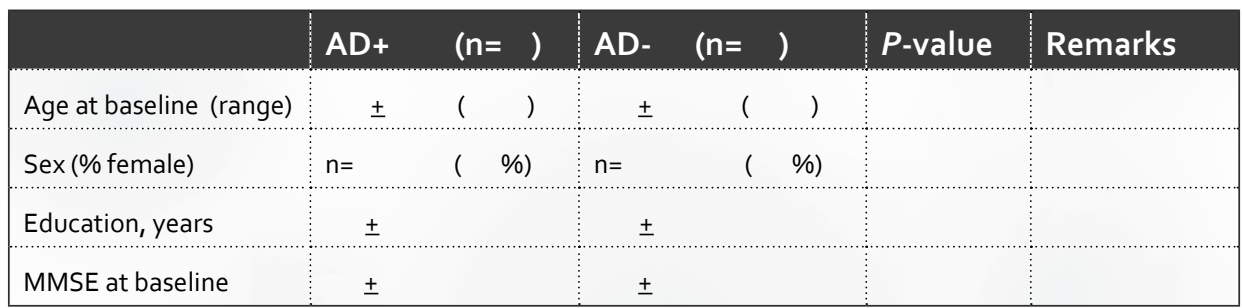

Table legend: $A D+=$ with Alzheimer's disease; AD- = without Alzheimer's disease; MMSE=Mini-Mental State Examination

Appendix 3.3 Genotyping data: APOE ع4 allele carriership

\begin{tabular}{|c|c|c|c|c|}
\hline & \multicolumn{2}{|c|}{$\varepsilon_{4+}$} & \multicolumn{2}{|c|}{$\varepsilon_{4^{-}}$} \\
\hline$A D+$ & & ( \%) & $\mathrm{n}=$ & ( \%) \\
\hline$A D-$ & & $(\%)$ & $\mathrm{n}=$ & ( \%) \\
\hline
\end{tabular}

Table legend: $\varepsilon_{4^{+}}=$carriers of at least 1 APOE $\varepsilon_{4}$ allele; $\left.\varepsilon_{4}\right\urcorner=$ noncarriers of the $A P O E \varepsilon_{4}$ allele; $A D+=$ with Alzheimer's disease; AD- = without Alzheimer's disease 
Appendix 3.4 Genotyping data: APOE genotype

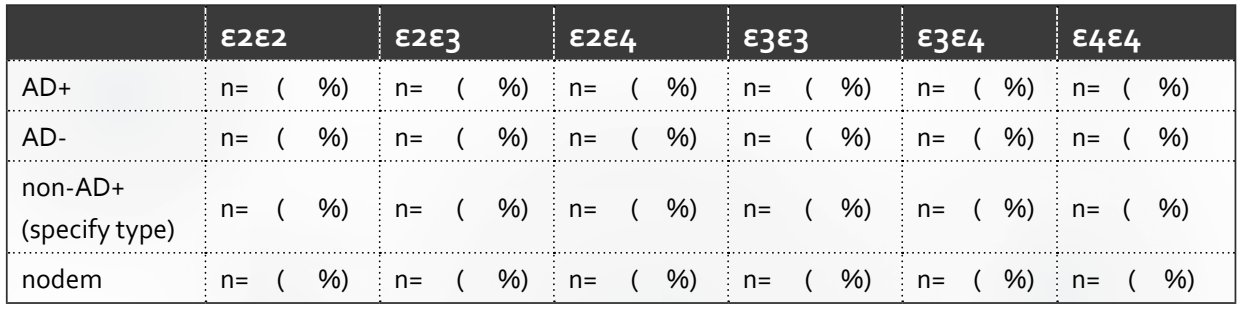

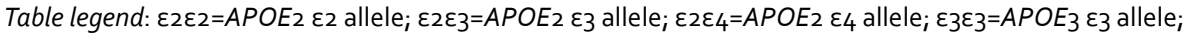
$\varepsilon_{3} \varepsilon_{4}=A P O E_{3} \varepsilon_{4}$ allele; $\varepsilon_{4} \varepsilon_{4}=A P O E_{4} \varepsilon_{4}$ allele; $A D+=$ with Alzheimer's disease; $A D$ - = without $A$ lzheimer's disease; non-AD+ = with dementia but not of the Alzheimer-type; nodem= not demented

Appendix 4 Assessment of methodological quality table QUADAS-2 tool

\begin{tabular}{|c|c|c|c|c|}
\hline Domain & Patient selection & Index test & $\begin{array}{l}\text { Reference } \\
\text { standard }\end{array}$ & Flow and timing \\
\hline Description & $\begin{array}{l}\text { Describe methods of } \\
\text { patient selection: De- } \\
\text { scribe included } \\
\text { patients (prior test- } \\
\text { ing, presentation, } \\
\text { intended use of index } \\
\text { test and setting): }\end{array}$ & $\begin{array}{l}\text { Describe the } \\
\text { index test and } \\
\text { how it was } \\
\text { conducted and } \\
\text { interpreted }\end{array}$ & $\begin{array}{l}\text { Describe the } \\
\text { reference stan- } \\
\text { dard and how it } \\
\text { was conducted } \\
\text { and interpreted }\end{array}$ & $\begin{array}{l}\text { Describe any patients } \\
\text { who did not receive the } \\
\text { index test(s) and/or ref- } \\
\text { erence standard or who } \\
\text { were excluded from the } \\
2 \times 2 \text { table (refer to flow } \\
\text { diagram): Describe the } \\
\text { time interval and any } \\
\text { interventions between } \\
\text { index test(s) and refer- } \\
\text { ence standard }\end{array}$ \\
\hline \multirow[t]{4}{*}{$\begin{array}{l}\text { Signalling ques- } \\
\text { tions } \\
\text { (yes/no/un- } \\
\text { clear) }\end{array}$} & $\begin{array}{l}\text { Was a consecutive } \\
\text { or random sample of } \\
\text { patients enrolled? }\end{array}$ & $\begin{array}{l}\text { Were the index } \\
\text { test results in- } \\
\text { terpreted with- } \\
\text { out knowledge } \\
\text { of the results of } \\
\text { the reference } \\
\text { standard? }\end{array}$ & $\begin{array}{l}\text { Is the reference } \\
\text { standard likely } \\
\text { to correctly } \\
\text { classify the tar- } \\
\text { get condition? }\end{array}$ & $\begin{array}{l}\text { Was there an appropri- } \\
\text { ate interval between } \\
\text { index test(s) and refer- } \\
\text { ence standard? }\end{array}$ \\
\hline & $\begin{array}{l}\text { Was a case-control } \\
\text { design avoided? }\end{array}$ & \multirow{3}{*}{$\begin{array}{l}\text { If a threshold } \\
\text { was used, was } \\
\text { it pre-speci- } \\
\text { fied? }\end{array}$} & \multirow{3}{*}{$\begin{array}{l}\text { Were the refer- } \\
\text { ence standard } \\
\text { results inter- } \\
\text { preted without } \\
\text { knowledge of } \\
\text { the results of } \\
\text { the index test? }\end{array}$} & $\begin{array}{l}\text { Did all patients receive a } \\
\text { reference standard? }\end{array}$ \\
\hline & \multirow[t]{2}{*}{$\begin{array}{l}\text { Did the study avoid } \\
\text { inappropriate exclu- } \\
\text { sions? }\end{array}$} & & & $\begin{array}{l}\text { Did all patients receive } \\
\text { the same reference } \\
\text { standard? }\end{array}$ \\
\hline & & & & $\begin{array}{l}\text { Were all patients in- } \\
\text { cluded in the analysis? }\end{array}$ \\
\hline
\end{tabular}


Appendix 4 Assessment of methodological quality table QUADAS- 2 tool Continued

\begin{tabular}{|c|c|c|c|c|}
\hline Domain & Patient selection & Index test & $\begin{array}{l}\text { Reference } \\
\text { standard }\end{array}$ & Flow and timing \\
\hline $\begin{array}{l}\text { Risk of bias: } \\
\text { High/low/ } \\
\text { unclear }\end{array}$ & $\begin{array}{l}\text { Could the selection of } \\
\text { patients have intro- } \\
\text { duced bias? }\end{array}$ & $\begin{array}{l}\text { Could the } \\
\text { conduct or } \\
\text { interpretation } \\
\text { of the index } \\
\text { test have intro- } \\
\text { duced bias? }\end{array}$ & $\begin{array}{l}\text { Could the refer- } \\
\text { ence standard, } \\
\text { its conduct, or } \\
\text { its interpreta- } \\
\text { tion have intro- } \\
\text { duced bias? }\end{array}$ & $\begin{array}{l}\text { Could the patient flow } \\
\text { have introduced bias? }\end{array}$ \\
\hline $\begin{array}{l}\text { Concerns } \\
\text { regarding appli- } \\
\text { cability: High/ } \\
\text { low/ unclear }\end{array}$ & $\begin{array}{l}\text { Are there concerns } \\
\text { that the included } \\
\text { patients do not match } \\
\text { the review question? }\end{array}$ & $\begin{array}{l}\text { Are there } \\
\text { concerns that } \\
\text { the index test, } \\
\text { its conduct, or } \\
\text { interpretation } \\
\text { differ from the } \\
\text { review ques- } \\
\text { tion? }\end{array}$ & $\begin{array}{l}\text { Are there con- } \\
\text { cerns that the } \\
\text { target condition } \\
\text { as defined by } \\
\text { the reference } \\
\text { standard does } \\
\text { not match the } \\
\text { review ques- } \\
\text { tion? }\end{array}$ & \\
\hline
\end{tabular}

Appendix 5 Anchoring statements for quality assessment of APOE $\varepsilon_{4}$ allele diagnostic studies

\begin{tabular}{|c|c|c|}
\hline Category & Review Question & Inclusion Criteria \\
\hline Patients & $\begin{array}{l}\text { Participants with mild cognitive } \\
\text { impairment, no dementia }\end{array}$ & $\begin{array}{l}\text { Participants fulfilling the criteria for the clinical } \\
\text { diagnosis of } \mathrm{MCl} \text { at baseline }\end{array}$ \\
\hline Index Test & APOE genotype & APOE genotype \\
\hline $\begin{array}{l}\text { Target Con- } \\
\text { dition }\end{array}$ & $\begin{array}{l}\text { Alzheimer's disease dementia } \\
\text { (conversion from MCl to Alzheimer's } \\
\text { disease dementia) } \\
\text { Any other forms of dementia (conver- } \\
\text { sion from MCl to any other forms of } \\
\text { dementia }\end{array}$ & $\begin{array}{l}\text { Alzheimer's disease dementia (conversion from } \\
\mathrm{MCl} \text { to Alzheimer's disease dementia) } \\
\text { Any other forms of dementia (conversion from } \\
\mathrm{MCl} \text { to any other forms of dementia) }\end{array}$ \\
\hline $\begin{array}{l}\text { Reference } \\
\text { Standard }\end{array}$ & $\begin{array}{l}\text { AD dementia } \\
\text { Pathological: Braak, CERAD, NIA-RIA } \\
\text { Clinical: NINCDS-ADRDA; DSM; ICD } \\
\text { Other dementia } \\
\text { NINDS-AIREN; Lund; McKeith; DSM; } \\
\text { ICD }\end{array}$ & $\begin{array}{l}\text { AD dementia } \\
\text { Pathological: Braak, CERAD, NIA-RIA } \\
\text { Clinical: NINCDS-ADRDA; DSM; ICD } \\
\text { AD dementia } \\
\text { NINDS-AIREN; Lund; McKeith; DSM; ICD }\end{array}$ \\
\hline Outcome & N/A & Data to construct $2 X_{2}$ table \\
\hline $\begin{array}{l}\text { Study } \\
\text { Design }\end{array}$ & N/A & $\begin{array}{l}\text { Longitudinal cohort studies and } \\
\text { Nested case-control studies if they incorporate a } \\
\text { delayed verification design (case-control nested } \\
\text { in cohort studies) }\end{array}$ \\
\hline
\end{tabular}

Table: Review question and inclusion criteria 


\section{Anchoring statements to assist with assessment for risk of bias} Patient selection

Was the sampling method appropriate?

Where sampling is used, the designs least likely to cause bias are consecutive sampling or random sampling. Sampling that is based on volunteers or selecting subjects from a clinic or research resource is prone to bias.

Weighting: High risk of bias ('no')

Was a case-control or similar design avoided?

Designs similar to case control that may introduce bias are those designs where the study team deliberately increase or decrease the proportion of subjects with the target condition, which may not be representative. For example a population study may be enriched with extra dementia subjects from a secondary care setting, which are typically more diseased. Some case control methods may already be excluded if they mix subjects from various settings.

Weighting: High risk of bias ('no')

Are exclusion criteria described and appropriate?

The study will be automatically graded as unclear if exclusions are not detailed (pending contact with study authors). Where exclusions are detailed, the study will be graded as "low risk" if exclusions are felt to be appropriate by the review authors. Certain exclusions common to many studies of dementia are: medical instability; terminal disease; alcohol/substance misuse; concomitant psychiatric diagnosis; other neurodegenerative condition. Exclusions are not felt to be appropriate if 'difficult to diagnose' patients are excluded.

Post hoc and inappropriate exclusions will be labeled "high risk" of bias. Weighting: High risk ('no')

\section{Index test}

Was APOE genotyping performed without knowledge of clinical dementia diagnosis?

Terms such as "blinded" or "independently and without knowledge of" are sufficient and full details of the blinding procedure are not required. 
Interpretation of the results of the index test may be influenced by knowledge of the results of reference standard. If the index test is always interpreted prior to the reference standard then the person interpreting the index test cannot be aware of the results of the reference standard and so this item could be rated as 'yes'.

For certain index tests the result is objective and knowledge of reference standard should not influence result, for example level of protein in cerebrospinal fluid, in this instance the quality assessment may be "low risk" even if blinding was not achieved.

Weighting: High risk ('no')

\section{Reference standard}

Is the assessment used for clinical diagnosis of dementia acceptable?

Commonly used international criteria to assist with clinical diagnosis of dementia include those detailed in DSM-IV and ICD-10. Criteria specific to dementia subtypes include but are not limited to NINCDSADRDA criteria for Alzheimer's dementia; McKeith criteria for Lewy Body dementia; Lund criteria for frontotemporal dementias; and the NINDS-AIREN criteria for vascular dementia. Where the criteria used for assessment is not familiar to the review authors or the Cochrane Dementia and Cognitive Improvement group ('unclear') this item should be classified as "high risk of bias".

Weighting: High risk ('no')

Was clinical assessment for dementia performed without knowledge of the APOE genotype results?

Terms such as "blinded" or "independently and without knowledge of" are sufficient and full details of the blinding procedure are not required. Interpretation of the results of the reference standard may be influenced by knowledge of the results of index test.

Weighting: High risk ('no')

\section{Patient flow}

Was there an appropriate interval between APOE genotyping and clinical dementia assessment?

As we test the accuracy of the $A P O E \varepsilon_{4}$ allele for $\mathrm{MCl}$ progression to 
dementia, there will always be a delay between the index test and the reference standard assessments. The time between reference standard and index test will influence the accuracy (Okello 2009; Visser 2006; Geslani 2005), and therefore we will note time as a separate variable (both within and between studies) and will test its influence on the diagnostic accuracy. We have set a minimum mean time to follow-up assessment of nine months. If more than $30 \%$ of subjects of subjects have assessment for $\mathrm{MCl}$ conversion before nine months this item will score 'no'.

Weighting: High risk ('no')

Did all subjects get the same assessment for dementia regardless of APOE genotyping result?

There may be scenarios where subjects who score "test positive" on index test have a more detailed assessment. Where dementia assessment differs between subjects this should be classified as high risk of bias.

Weighting: High risk (no)

Were all patients who underwent APOE genotyping included in the final analysis?

If the number of patients enrolled differs from the number of patients included in the $2 X_{2}$ table then there is the potential for bias. If patients lost to follow-up differ systematically from those who remain, then estimates of test performance may differ. If drop outs these should be accounted for; a maximum proportion of drop outs to remain low risk of bias has been specified as $20 \%$.

Weighting: High risk ('no')

Were missing or uninterpretable APOE genotyping results reported? Where missing or uninterpretable results are reported, and if there is substantial attrition (we have set an arbitrary value of $50 \%$ missing data), this should be scored as 'no'. If those results are not reported, this should be scored as 'unclear' and authors will be contacted.

Weighting: High risk ('no' and 'unclear') 


\section{Anchoring statements to assist with assessment for applicability} Patient selection

Were included patients representative of the general population of interest?

The included patients should match the intended population as described in the review question. The review authors should consider population in terms of symptoms; pre-testing; potential disease prevalence; setting

We recognise that identifying all $\mathrm{MCl}$ patients in a given population may be particularly hard to achieve; therefore the information about the judgements for this criterion is particularly likely to be suboptimal. We expect that all included studies will be sub-optimally reported to some degree. If there is a clear ground for suspecting an unrepresentative spectrum the item should be rated poor applicability.

\section{Index test}

Are there concerns that the index test differs from the review question? In this review we are looking at APOE genotype ascertained at baseline. The genotype will not change at follow-up. If the accuracy of the index test was based on genotype results, this item should be rated high applicability.

Were sufficient data on APOE genotyping given for the test to be repeated in an independent study?

Variation in technology, test execution, and test interpretation may affect estimate of accuracy. A common method of genotyping APOE is by extracting genomic DNA from EDTA anti-coagulated blood and amplifying this via polymerase chain reaction. DNA may also be extracted from buccal cell sample. Different genotyping platforms may be used. These platforms have generally comparable accuracy. In addition, the background, and training/expertise of the assessor should be reported and taken in consideration. If $A P O E$ genotyping was not performed consistently this item should be rated poor applicability. 


\section{Reference standard}

\section{Was clinical diagnosis of dementia made in a manner similar to current clinical practice?}

For many reviews, inclusion criteria and assessment for risk of bias will already have assessed the dementia diagnosis. For certain reviews an applicability statement relating to reference standard may not be applicable. There is the possibility that a form of dementia assessment, although valid, may diagnose a far larger proportion of subjects with disease than usual clinical practice. In this instance the item should be rated poor applicability.

Appendix 6 Standards for Reporting of Diagnostic Accuracy (STARD) checklist

\begin{tabular}{|c|c|c|}
\hline \multicolumn{3}{|l|}{ Section and Topic } \\
\hline $\begin{array}{l}\text { TITLE/ABSTRACT } \\
\text { KEYWORDS }\end{array}$ & 1 & $\begin{array}{l}\text { Identify the article as a study of diagnostic accuracy (recommend MeSH } \\
\text { heading 'sensitivity and specificity'). }\end{array}$ \\
\hline INTRODUCTION & 2 & $\begin{array}{l}\text { State the research questions or study aims, such as estimating diagnos- } \\
\text { tic accuracy or comparing accuracy between tests or across participant } \\
\text { groups. }\end{array}$ \\
\hline \multicolumn{3}{|l|}{ Methods } \\
\hline \multirow[t]{4}{*}{ Participants } & 3 & $\begin{array}{l}\text { The study population: The inclusion and exclusion criteria, setting and } \\
\text { locations where data were collected. }\end{array}$ \\
\hline & 4 & $\begin{array}{l}\text { Participant recruitment: Was recruitment based on presenting symp- } \\
\text { toms, results from previous tests, or the fact that the participants had } \\
\text { received the index tests or the reference standard? }\end{array}$ \\
\hline & 5 & $\begin{array}{l}\text { Participant sampling: Was the study population a consecutive series } \\
\text { of participants defined by the selection criteria in item } 3 \text { and } 4 \text { ? If not, } \\
\text { specify how participants were further selected. }\end{array}$ \\
\hline & 6 & $\begin{array}{l}\text { Data collection: Was data collection planned before the index test and } \\
\text { reference standard were performed (prospective study) or after (retro- } \\
\text { spective study)? }\end{array}$ \\
\hline \multirow[t]{3}{*}{ Test methods } & 7 & The reference standard and its rationale. \\
\hline & 8 & $\begin{array}{l}\text { Technical specifications of material and methods involved including how } \\
\text { and when measurements were taken, and/or cite references for index } \\
\text { tests and reference standard. }\end{array}$ \\
\hline & 9 & $\begin{array}{l}\text { Definition of and rationale for the units, cut-offs and/or categories of the } \\
\text { results of the index tests and the reference standard. }\end{array}$ \\
\hline
\end{tabular}


Appendix 6 Standards for Reporting of Diagnostic Accuracy (STARD) checklist Continued

\begin{tabular}{|c|c|c|}
\hline \multicolumn{3}{|l|}{ Methods Continued } \\
\hline & 10 & $\begin{array}{l}\text { The number, training and expertise of the persons executing and reading } \\
\text { the index tests and the reference standard. }\end{array}$ \\
\hline & 11 & $\begin{array}{l}\text { Whether or not the readers of the index tests and reference standard } \\
\text { were blind (masked) to the results of the other test and describe any } \\
\text { other clinical information available to the readers. }\end{array}$ \\
\hline \multirow[t]{2}{*}{ Statistical methods } & 12 & $\begin{array}{l}\text { Methods for calculating or comparing measures of diagnostic accuracy, } \\
\text { and the statistical methods used to quantify uncertainty (e.g. } 95 \% \text { confi- } \\
\text { dence intervals). }\end{array}$ \\
\hline & 13 & Methods for calculating test reproducibility, if done. \\
\hline \multicolumn{3}{|l|}{ Results } \\
\hline \multirow[t]{3}{*}{ Participants } & 14 & $\begin{array}{l}\text { When study was performed, including beginning and end dates of recruit- } \\
\text { ment. }\end{array}$ \\
\hline & 15 & $\begin{array}{l}\text { Clinical and demographic characteristics of the study population (at least } \\
\text { information on age, gender, spectrum of presenting symptoms). }\end{array}$ \\
\hline & 16 & $\begin{array}{l}\text { The number of participants satisfying the criteria for inclusion who did or } \\
\text { did not undergo the index tests and/or the reference standard; describe } \\
\text { why participants failed to undergo either test (a flow diagram is strongly } \\
\text { recommended). }\end{array}$ \\
\hline \multirow[t]{4}{*}{ Test results } & 17 & $\begin{array}{l}\text { Time-interval between the index tests and the reference standard, and } \\
\text { any treatment administered in between. }\end{array}$ \\
\hline & 18 & $\begin{array}{l}\text { Distribution of severity of disease (define criteria) in those with the target } \\
\text { condition; other diagnoses in participants without the target condition. }\end{array}$ \\
\hline & 19 & $\begin{array}{l}\text { A cross tabulation of the results of the index tests (including indetermi- } \\
\text { nate and missing results) by the results of the reference standard; for } \\
\text { continuous results, the distribution of the test results by the results of the } \\
\text { reference standard. }\end{array}$ \\
\hline & 20 & $\begin{array}{l}\text { Any adverse events from performing the index tests or the reference } \\
\text { standard. }\end{array}$ \\
\hline \multirow[t]{4}{*}{ Estimates } & 21 & $\begin{array}{l}\text { Estimates of diagnostic accuracy and measures of statistical uncertainty } \\
\text { (e.g. } 95 \% \text { confidence intervals). }\end{array}$ \\
\hline & 22 & $\begin{array}{l}\text { How indeterminate results, missing data and outliers of the index tests } \\
\text { were handled. }\end{array}$ \\
\hline & 23 & $\begin{array}{l}\text { Estimates of variability of diagnostic accuracy between subgroups of } \\
\text { participants, readers or centers, if done. }\end{array}$ \\
\hline & 24 & Estimates of test reproducibility, if done. \\
\hline DISCUSSION & 25 & Discuss the clinical applicability of the study findings. \\
\hline
\end{tabular}


APOE COCHRANE DTA PROTOCOL 
Neuropsychiatric symptoms are common in mild cognitive impairment. In our study, agitation, irritability and reduced depression were related to $A P O E-\varepsilon 4$ 
LS Elias-Sonnenschein, IHGB Ramakers, FRJ Verhey, C Graff, GB Frisoni, P Scheltens, FM Nobili, M Damian, H Soininen, L Spiru, RW Jones, M Olde Rikkert, G Wilcock, H Hampel, P Aalten, LM Shaw and JQ Trojanowski for the Alzheimer's Disease Neuroimaging Initiative, PJ Visser Submitted

\section{CHAPTER 4}

Neuropsychiatric symptoms related to the APOE $\varepsilon_{4}$ allele in subjects with mild cognitive impairment in the DESCRIPA and ADNI cohorts 


\section{ABSTRACT}

Background: Neuropsychiatric symptoms are common in mild cognitive impairment $(\mathrm{MCl})$ and Alzheimer's disease $(A D)$. Their relation with the apolipoprotein $E(A P O E)$ \&4 allele, a major genetic risk factor for $A D$, in $\mathrm{MCl}$ remains unclear.

Methods: Subjects with $\mathrm{MCl}$ were selected from the multicenter "Development of Screening Guidelines and Criteria for Predementia Alzheimer's Disease" (DESCRIPA) and the "Alzheimer's Disease Neuroimaging Initiative" (ADNI) studies. Neuropsychiatric symptoms were assessed using the Neuropsychiatric Inventory (NPI). We tested the relation between $A P O E$, the presence of neuropsychiatric symptoms (NPI score $>0$, pooled cohort) and the presence of clinically significant symptoms (NPI score >3, DESCRIPA cohort) by generalized linear models corrected for age, gender and study site.

Results: In the pooled cohort ( $N=696), A P O E-\varepsilon 4$ was correlated with the presence of agitation ( $\mathrm{OR}=1.51,95 \% \mathrm{Cl} 1.22-1.87, P<0.001)$. Subanalysis in subjects with amnestic $\mathrm{MCl}$ showed in addition correlation between $A P O E-\varepsilon 4$ and irritability (OR=1.24, 95\% Cl 1.09-1.42, $P=0.001)$. In DESCRIPA, APOE- $\varepsilon 4$ was related with clinically significant delusions $(\mathrm{OR}=2.74,95 \% \mathrm{Cl}$ 1.48-5.06, $P=0.001)$ and with reduced clinically significant depression (OR=0.64, 95\% Cl 0.48-0.85, $P=0.002$ ).

Conclusion: At the $\mathrm{MCl}$ stage, $A P O E-\varepsilon 4$ is associated with agitation, irritability and delusions and inversely with depression. These symptoms in part may be related to underlying $A D$ pathology.

Keywords: Neuropsychiatric symptoms, $A P O E$, mild cognitive impairment, Alzheimer's disease, agitation, delusion, depression, irritability 


\section{INTRODUCTION}

Neuropsychiatric symptoms are common in subjects with mild cognitive impairment $(\mathrm{MCl}){ }^{1,2}$ Depression, apathy, agitation and aggression are prevalent symptoms that have been reported in both subjects with $\mathrm{MCl}$ and Alzheimer's disease (AD).3-5 Previous studies in subjects with $A D$ indicated that neuropsychiatric symptoms may be associated with the apolipoprotein E $\varepsilon_{4}$ allele (APOE $\varepsilon 4$ allele), one of the major genetic risk factors for $A D .^{6-12}$ While it is conceivable that the same neuropsychiatric symptoms that are associated with the $A P O E \varepsilon 4$ allele in $A D$ are manifested in $\mathrm{MCl}$, the role of $A P O E$ in the neuropsychiatric symptomatology of subjects with $\mathrm{MCl}$ is unclear and has not been investigated to date. The aim of our study is therefore to investigate the full spectrum of neuropsychiatric and behavioral symptoms in relation to the $A P O E \& 4$ allele in subjects with $\mathrm{MCI}$.

\section{METHODS}

\section{Subjects}

Selected were subjects with $\mathrm{MCl}$ from the "Development of Screening Guidelines and Criteria for Predementia Alzheimer's Disease" (DESCRIPA) study, and from the "Alzheimer's Disease Neuroimaging Initiative" (ADNI). DESCRIPA is a European multicenter prospective cohort study concerned with developing screening guidelines and clinical criteria for the early detection of $A D$ in subjects with $\mathrm{MCl}$. It included at baseline subjects aged 55 years or older who were referred to a memory clinic because of cognitive impairment not due to dementia according to the Diagnostic and Statistical Manual of Mental Disorders, fourth edition (DSM-IV) ${ }^{13}$ criteria or to any psychiatric, somatic or neurological disorder that may have caused the cognitive impairment. ${ }^{14}$ Subjects with severe depression were excluded from DESCRIPA. For the present study, we defined $\mathrm{MCl}$ as an overall Clinical Dementia Rating (CDR) ${ }^{15}$ score of 0.5 . We selected subjects from the 13 DESCRIPA centers who were assessed for neuropsychiatric symptoms with the Neuropsychiatric Inventory (NPI) $(n=402)$ of whom 386 had $\mathrm{MCl}$. Of these, 304 (59\% females) had available APOE genotype data. Subjects with APOE data had lower Mini-Mental State Examination (MMSE) ${ }^{16}$ scores $(26.9 \pm 2.4$ in subjects genotyped for APOE vs. $27.6 \pm$ 
1.8 in those not assessed for the APOE genotype, $P=0.004)$, while age and education did not differ between the groups (70.5Y $\pm 8.1 \mathrm{vs} .70 .6 \mathrm{y} \pm$ $7.1, p=0.88$ for age and $10 y \pm 4.2$ vs. $10.2 y \pm 4.7, P=0.66$ for education).

$A D N I$ data used in the preparation of this article were obtained from the ADNI database (adni.loni.ucla.edu). The ADNI was launched in 2003 by the National Institute on Aging (NIA), the National Institute of Biomedical Imaging and Bioengineering (NIBIB), the Food and Drug Administration (FDA), private pharmaceutical companies and non-profit organizations, as a $\$ 60$ million, 5 -year public-private partnership. The primary goal of ADNI has been to test whether serial magnetic resonance imaging (MRI), positron emission tomography (PET), other biological markers, and clinical and neuropsychological assessment can be combined to measure the progression of mild cognitive impairment $(\mathrm{MCl})$ and early Alzheimer's disease (AD). Determination of sensitive and specific markers of very early $A D$ progression is intended to aid researchers and clinicians to develop new treatments and monitor their effectiveness, as well as lessen the time and cost of clinical trials.The Principal Investigator of this initiative is Michael W. Weiner, MD, VA Medical Center and University of California - San Francisco. ADNI is the result of efforts of many coinvestigators from a broad range of academic institutions and private corporations, and subjects have been recruited from over 50 sites across the U.S. and Canada. The initial goal of ADNI was to recruit 800 adults, ages 55 to 90 , to participate in the research, approximately 200 cognitively normal older individuals to be followed for 3 years, 400 people with $\mathrm{MCl}$ to be followed for 3 years and 200 people with early $A D$ to be followed for 2 years." For up-to-date information, see www. adni-info.org.

ADNI included at baseline subjects aged 55 to 90 years clinically diagnosed with probable AD according to the National Institute of Neurological and Communication Disorders-Alzheimer's Disease and Related Disorders Association (NINCDS- ADRDA) ${ }^{17}$ criteria, amnestic $\mathrm{MCl}(\mathrm{aMCl})$, or normal cognition. ${ }^{18}$ Among the exclusion criteria were the presence of neurological disease other than $A D$, brain lesions or head trauma, the use of psychoactive medication, major depression and psychotic features as detailed in the ADNI 
protocol (http://www.adni-info.org). Subjects with aMCI who had available NPI scores and APOE data $(n=392)$ were included.

At baseline, all subjects underwent routine physical and neurological examinations; and were assessed using the MMSE and other standardized neuropsychological tests, as described elsewhere. ${ }^{14,}$ ${ }^{18}$ The medical ethical commission of the participating centers has approved all procedures, and all participants gave their written informed consent.

\section{Assessment of neuropsychiatric symptoms}

We used the 12 -item NPI, ${ }^{19}$ which is informant-rated and evaluates the following symptoms: delusions, hallucination, agitation, depression, anxiety, euphoria, apathy, disinhibition, irritability, aberrant motor behavior, nighttime behavior, and appetite/eating abnormalities. The DESCRIPA study made use of the full NPI, which indicated the presence or absence of a symptom (scored as $1=$ present and $0=a b s e n t$ ), its frequency (range: 1-4, wherein 1=occasionally, $2=$ often, $3=$ frequently, and $4=$ very frequently) and severity (range: $1-3$, corresponding respectively to mild, moderate, and severe). In cases wherein a symptom was present, a composite score for this symptom was computed by multiplying the frequency by the severity. A composite score of $\geq 4$ is considered clinically significant, that is, the symptom is considered severe enough to disrupt a subject's functioning and merits treatment. ${ }^{20}$ In the ADNI study, the NPI-questionnaire (NPI-Q) ${ }^{21}$ was used, which only indicated whether or not a symptom was present, and the symptom severity. The NPI-Q was scored as symptom present or absent. The NPI-O has been cross-validated with the NPI and has been shown to have good test-retest reliability, ${ }^{21}$ which allowed us to pool the scores for both instruments.

\section{APOE genotyping}

$A P O E$ genotype was determined on genomic DNA extracted at baseline from $10 \mathrm{ml}$ EDTA anti-coagulated blood and amplified using the TaQMan polymerase chain reaction technique (Applied Biosystems, Foster City, CA) for the ADNI cohort, ${ }^{18}$ and the SNaPshot technique for the DESCRIPA cohort. ${ }^{22}$ 
Table 1 Subject characteristics and prevalence of neuropsychiatric symptoms

\begin{tabular}{|c|c|c|c|}
\hline Characteristic & $\begin{array}{l}\text { Pooled cohorts } \\
N=696\end{array}$ & $\begin{array}{l}\text { DESCRIPA } \\
n=304\end{array}$ & $\begin{array}{l}\text { ADNI } \\
n=392\end{array}$ \\
\hline Age, y & $72.9 \pm 8.0$ & $70.6 \pm 8.1$ & $74 \cdot 7 \pm 7 \cdot 4$ \\
\hline Gender, \% f & 46 & 59 & 35 \\
\hline Education, y & $13.2 \pm 4.7$ & $10.0 \pm 4.2$ & $15.7 \pm 3.1$ \\
\hline MMSE & $27.0 \pm 2.1$ & $26.9 \pm 2.4$ & $27.0 \pm 1.8$ \\
\hline $\begin{array}{l}A P O E \varepsilon 4^{+} / \varepsilon 4^{-} \\
\left(\% \varepsilon \varepsilon_{4}^{+}\right)\end{array}$ & $\begin{array}{l}349 / 347 \\
(50)\end{array}$ & $\begin{array}{l}139 / 165 \\
(46)\end{array}$ & $\begin{array}{l}210 / 182 \\
(54)\end{array}$ \\
\hline \multicolumn{4}{|c|}{ Prevalence of neuropsychiatric symptoms, $n(\%), n \varepsilon 4^{+} / \varepsilon_{4}^{-}$} \\
\hline Delusions & $21(3), 10 / 11$ & $16(5), 8 / 8$ & $5(1), 2 / 3$ \\
\hline Hallucinations & $11(2), 6 / 5$ & $10(3), 5 / 5$ & $1(0.3), 1 / 0$ \\
\hline Agitation & $122(18), 72 / 50$ & $50(16), 27 / 23$ & $72(18), 45 / 27$ \\
\hline Depression & $187(27), 94 / 93$ & $111(37), 48 / 63$ & $76(19), 46 / 30$ \\
\hline Anxiety & $172(25), 92 / 80$ & $101(33), 48 / 53$ & $71(18), 44 / 27$ \\
\hline Euphoria & $25(4), 11 / 14$ & $14(5), 5 / 9$ & $11(3), 6 / 5$ \\
\hline Apathy & $148(21), 78 / 70$ & $92(30), 47 / 45$ & $56(14), 31 / 25$ \\
\hline Disinhibition & $52(7), 29 / 23$ & $22(7), 8 / 14$ & $30(8), 21 / 9$ \\
\hline Irritability & $204(29), 108 / 96$ & $96(32), 46 / 50$ & $108(28), 62 / 46$ \\
\hline Aberrant motor behavior & $39(6), 23 / 16$ & $19(6), 13 / 6$ & $20(5), 10 / 10$ \\
\hline Night-time behavior & $139(20), 64 / 75$ & $94(31), 38 / 56$ & $45(12), 26 / 19$ \\
\hline Eating abnormalities & $90(13), 49 / 41$ & $45(15), 25 / 20$ & $45(12), 24 / 21$ \\
\hline
\end{tabular}

Abbreviations: $\mathrm{f}=\mathrm{female}, \mathrm{y}=\mathrm{years}, \mathrm{MMSE}=$ Mini-Mental State Examination, $\varepsilon 4^{+}=A P O E \varepsilon 4$ allele carrier, $\varepsilon_{4}=A P O E \varepsilon_{4}$ allele noncarrier

Note: All data are mean \pm standard deviation, unless otherwise specified.

\section{Statistical analyses}

The IBM SPSS version 19 for Mac Os X (SPSS Inc., USA, 2010) was used. Group comparisons on mean age, education and MMSE scores were performed using independent samples t-test. Generalized linear models (GLM) corrected for age, gender and study site were used to analyze the relation between $A P O E-\varepsilon 4$ carriership and the presence of neuropsychiatric symptoms (item score of o vs. item score $>0$ ). These analyses were conducted in the pooled DESCRIPA and ADNI cohorts, and in each cohort separately. When the correlation between $A P O E$ and neuropsychi- 
atric symptom was significant, we tested for possible interaction effects with age and gender.

In the DESCRIPA study, the relation between APOE-ع4 carriership and the presence of clinically significant neuropsychiatric symptoms (composite score $\geq 4$ ) was also analyzed. We also examined the effects of psychopharmacological medications (anti-depressives and anxiolytics/ sedatives) by subgroup analyses to investigate whether results significantly differed from those who did and did not use these medications.

Because the ADNI study only included subjects with aMCI and the DESCRIPA study included both subjects with aMCI and non-amnestic $\mathrm{MCl}(\mathrm{naMCl})$, we repeated the GLM analyses after exclusion of subjects with naMCl. The significance level for the main effects between APOE and neuropsychiatric symptoms was set at $P=0.004$, which was obtained by dividing the preset $P=0.05$ by the 12 neuropsychiatric items, following Bonferroni correction for multiple testing.

\section{RESULTS}

The pooled DESCRIPA and ADNI cohorts consisted of 696 subjects. Their baseline characteristics and symptom prevalence are summarized in Table 1. Of the 349 subjects who carried at least 1 APOE $\varepsilon_{4}$ allele (50\%), 73 ( $10 \%$ of the whole sample) were homozygotes. The most common neuropsychiatric symptoms were irritability (29\%), depression (27\%), and anxiety (25\%). In ADNI, agitation was also a common symptom (18\%). The least common symptoms in both the pooled cohorts and independent cohorts were euphoria, delusions and hallucinations (all $<5 \%$ ). In general, the prevalence of neuropsychiatric symptoms in DESCRIPA was higher compared to that in ADNI. In the pooled DESCRIPA and ADNI cohorts, APOE $\varepsilon_{4}$ allele carriers more often had symptoms of agitation compared to noncarriers ( $21 \%$ vs. $14 \%, O R=1.51$, $95 \% \mathrm{Cl}$ 1.22-1.87, $P<0.001$ ) (Table 2 ). Exploratory analysis suggested an interaction between agitation and age (uncorrected $P=0.04$ ), as well as between agitation and gender (uncorrected $P=0.02$ ). The APOE $\varepsilon_{4}$ allele was related to agitation among subjects who were older than 70 years ( $O R=1.80,95 \% \mathrm{Cl}$ 1.29-2.50, $P=0.001)$ but not in younger subjects. Agitation was more common among males than females (68\% vs. $32 \%$ ) but was significantly related to the APOE $\varepsilon_{4}$ allele only among females 
Table 2 Association between APOE \&4 allele and neuropsychiatric symptoms in $\mathrm{MCl}$

\begin{tabular}{|c|c|c|c|c|}
\hline \multirow[t]{2}{*}{ NPI Items } & \multicolumn{3}{|c|}{ Presence of symptoms ${ }^{a}$} & \multirow{2}{*}{$\begin{array}{l}\text { Clinically signifi- } \\
\text { cant symptoms }^{b} \\
\text { DESCRIPA } \\
\text { OR }(95 \% \mathrm{CI})\end{array}$} \\
\hline & $\begin{array}{l}\text { Pooled cohorts } \\
\text { OR }(95 \% \mathrm{Cl})\end{array}$ & $\begin{array}{l}\text { ADNI } \\
\text { OR }(95 \% \mathrm{CI})\end{array}$ & $\begin{array}{l}\text { DESCRIPA } \\
\text { OR }(95 \% \mathrm{CI})\end{array}$ & \\
\hline Delusions & $0.92(0.49-1.72)$ & $0.55(0.09-3.37)$ & $1.33(0.75-2.38)$ & $2.74 * *(1.48-5.06)$ \\
\hline Hallucinations & $1.38(0.65-2.93)$ & --- & $1.50(0.68-3.34)$ & $1.63(0.43-6.13)$ \\
\hline Agitation & $1.51 * *(1.22-1.87)$ & $1.59(0.94-2.71)$ & $1.37(0.84-2.24)$ & $0.75(0.40-1.38)$ \\
\hline Depression & $0.94(0.68-1.30)$ & $1.37(0.82-2.29)$ & $0.79(0.58-1.07)$ & $0.64 * *(0.48-0.85)$ \\
\hline Anxiety & $1.19(0.88-1.61)$ & $1.47(0.86-2.50)$ & $1.18(0.72-1.93)$ & $1.36(0.78-2.36)$ \\
\hline Euphoria & $0.77(0.34-1.75)$ & $1.06(0.32-3.54)$ & $0.67(0.15-3.01)$ & -- \\
\hline Apathy & $1.13(0.86-1.48)$ & $1.16(0.65-2.07)$ & $1.37(0.83-2.25)$ & $0.47(0.47-1.48)$ \\
\hline Disinhibition & $1.25(0.66-2.39)$ & $2.11(0.94-4.75)$ & $0.64(0.40-1.03)$ & $--^{c}$ \\
\hline Irritability & $1.13(0.91-1.39)$ & $1.25(0.79-1.97)$ & $1.06(0.71-1.58)$ & $1.25(0.74-2.11)$ \\
\hline $\begin{array}{l}\text { Aberrant motor } \\
\text { behavior }\end{array}$ & $1.47(0.70-3.09)$ & $0.89(0.36-2.20)$ & $2.85 *(1.10-7 \cdot 39)$ & $2.21(0.68-7.14)$ \\
\hline $\begin{array}{l}\text { Night-time } \\
\text { behavior }\end{array}$ & $0.79(0.52-1.21)$ & $1.16(0.61-2.18)$ & $0.77(0.37-1.63)$ & $0.61(0.24-1.59)$ \\
\hline $\begin{array}{l}\text { Eating abnor- } \\
\text { malities }\end{array}$ & $1.30(0.93-1.82)$ & $1.08(0.57-2.04)$ & $1.75^{*}(1.02-3.03)$ & $1.74(0.61-4.94)$ \\
\hline
\end{tabular}

Abbreviations: $\mathrm{NPI}=$ neuropsychiatric inventory, $\mathrm{OR}=$ odds ratio, $\mathrm{Cl}=$ confidence interval

a item score $\geq 1$.

b composite score $\geq 4$.

c not computed because of insufficient number of subjects.

* $P<0.05$, no longer significant after Bonferroni correction

** $P<0.004$, remained significant after Bonferroni correction

$(\mathrm{OR}=2.57,95 \% \mathrm{Cl}$ 1.44-4.57, $P=0.001)$. In order to correct for possible effects of cognitive impairment severity, we repeated analysis with correction for MMSE score post hoc. The results were essentially the same. The $A P O E$ \&4 allele was associated with agitation $(O R=1.54,95 \% \mathrm{Cl}$ 1.25-1.90, $P<0.001)$. There was no significant interaction between the APOE $\varepsilon_{4}$ allele and MMSE score (OR=1.14, 95\% Cl 0.93-1.40, $P=0.22)$.

In the DESCRIPA cohort, APOE $\varepsilon_{4}$ allele carriers more often had aberrant motor behavior $(\mathrm{OR}=2.85,95 \% \mathrm{Cl}$ 1.10-7.39, $P=0.03)$ and eating 
abnormalities ( $\mathrm{OR}=1.75,95 \% \mathrm{Cl}$ 1.02-3.03, $P=0.04$ ). Similar results were obtained when we adjusted for the use of anxiolytic/sedatives. None of the results remained significant after Bonferroni correction, indicating that $A P O E$ is not a robust predictor of aberrant motor behavior and eating abnormalities in this cohort. These symptoms were also not related with the use of antidepressives/antipsychotics. Analyses with clinically significant symptoms as outcome showed that APOE $\varepsilon 4$ allele carriers less often had clinically significant symptoms of depression ( $O R=0.64$, $95 \% \mathrm{Cl} 0.48-0.85, P=0.002$ ). These associations remained statistically significant after correcting for multiple testing. No significant interaction was found between depression, and age $(P=0.76)$ and gender $(P=0.25)$. Adjusting for the use of antidepressants yielded similar results: symptoms of depression were higher among $A P O E \varepsilon_{4}$ allele noncarriers. We observed that $A P O E \varepsilon_{4}$ allele carriers had more frequent symptoms of delusions compared to noncarriers, but the small number of subjects with delusions did not allow for meaningful analyses.

In ADNI, the APOE $\varepsilon_{4}$ allele was not significantly associated with any neuropsychiatric symptom.

We repeated the analyses in the pooled DESCRIPA and ADNI cohorts ( $n=545$ ) after exclusion of subjects with naMCI in DESCRIPA $(n=151)$. The association between agitation and APOE- $\varepsilon 4$ status remained essentially the same. In addition, $A P O E-\varepsilon 4$ was now associated with irritability ( $\mathrm{OR}=1.24,95 \% \mathrm{Cl}$ 1.09-1.42, $P=0.001)$. There was no significant interaction with age and gender $(P=0.63$ and $P=0.75$, respectively).

In subjects with $\mathrm{aMCl}(n=153,62 \%$ females, mean age $=71.5 \pm 8.0$, mean education $=9.9 \pm 4.0 y$, mean MMSE $=26.4 \pm 2.4$ ) from the DESCRIPA cohort, $A P O E \varepsilon 4$ allele carriers frequently had symptoms of delusions $(\mathrm{OR}=3.81,95 \% \mathrm{Cl} 1.88-7.69, P<0.001)$. Other symptoms were not associated with $A P O E$.

\section{DISCUSSION}

Our findings show that the previously reported associations between the $A P O E$ genotype and the neuropsychiatric symptoms of agitation, irritation, depression and delusions in $A D^{8,23-26}$ are already evident at the $\mathrm{MCl}$ stage. The prevalence of these symptoms in our study is in accordance 
with the literature. ${ }^{1,2}$ The symptoms were less frequent but had similar patterns in dementia and AD. ${ }^{2,27}$

Agitation and irritability are common neuropsychiatric symptoms in $\mathrm{MCl} 1,3,4$ and have been reported to be more prevalent in $A D$ than in $\mathrm{MCl}^{28,}{ }^{29}$ In our study, the APOE $\varepsilon 4$ allele was also related to agitation and irritability. This is in line with previous findings in AD showing the $A P O E \varepsilon_{4}$ allele to be a risk factor for agitation and aggression. $8,23,24$

Age and gender interacted with the $A P O E \varepsilon_{4}$ allele and agitation. While age has been shown to modify the effect of $A P O E$ on conversion from $\mathrm{MCl}$ to $A D$ and on $A D$ neuropathology, ${ }^{30}$ it has been reported to be unrelated to neuropsychiatric symptoms in $\mathrm{MCl} .{ }^{31} \mathrm{~A}$ follow-up study may help clarify whether agitation among elderly $A P O E-\varepsilon_{4}$ carriers signals early pathology or is independent of the neuropsychiatric symptom. The APOE $\varepsilon 4$ allele was significantly associated with agitation among females, although agitation was more prevalent among males. This suggests that agitation among males is independent of the APOE- $\varepsilon_{4}$ status.

Depression has been reported to be highly prevalent in $\mathrm{MCl}$ compared to cognitively normal subjects. ${ }^{4}$ It has been associated with increased risk of developing $\mathrm{MCl}$ and conversion to $\mathrm{AD}$ although others did not find this association. ${ }^{32,33}$ In the present study, we found that clinically significant symptoms of depression were less common among APOE $\varepsilon_{4}$ allele carriers. Our findings do not support the risk for depression in the presence of the APOE $\varepsilon 4$ allele among subjects with $\mathrm{MCl}$. This is consistent with studies in AD that showed a protective effect of the APOE $\varepsilon 4$ allele on depression.9,34

The relation between clinically significant delusions and $A P O E$ has also been reported in subjects with $A D .25,26$ In contrast, a recent genome-wide association study of AD with psychosis 35 and a review of currently known genetic basis of psychosis in $A D^{11}$ reported that neither $A P O E-\varepsilon 4$ status nor $A P O E-\varepsilon 4$ dose were associated with psychosis. Delusions and hallucinations are commonly seen in $A^{36,37}$ but are less common in $\mathrm{MCl}_{1}^{1,4,38}$ as confirmed by the low prevalence of these symptoms in our study. Post hoc analyses showed that delusions mainly occurred in subjects with $\mathrm{aMCl}$. Because subjects with $\mathrm{aMCl}$ are more likely to progress to $A D$ than subjects with naMCl, ${ }^{1}$ our findings suggest that delusions signal early underlying pathology, although the low prevalence of 
delusions does not allow firm conclusions.

There are several possible explanations for the relation between $A P O E$ and neuropsychiatric symptoms. The APOE $\varepsilon 4$ allele may cause neuropsychiatric symptoms through its effects on brain atrophy. The $A P O E$ \& 4 allele has been shown to correlate with increased rate of hippocampal atrophy among subjects with $\mathrm{MCl} .{ }^{39,40}$ Neuroimaging studies showed that in aMCl, delusions and disinhibition were correlated with gray matter (GM) atrophy in the medial temporal lobe and anterior cingulate gyrus. ${ }^{27}$ These confirm findings in mild AD, wherein agitation, delusions and also apathy have been reported to correlate with cortical atrophy. ${ }^{41}$ Depression was not associated with $\mathrm{GM}$ atrophy in aMCl. ${ }^{27}$ Among older people with no dementia but with late-life depression, depression was related to hippocampal neuronal loss but not to Alzheimer pathology. ${ }^{42}$

Alternatively, the $A P O E$ \&4 allele may cause neuropsychiatric symptoms through its effect on beta amyloid processing. It has been shown to increase beta-amyloid deposition in the frontal cortex of subjects who were not demented. 43 We previously showed that irritation and agitation were related to abeta concentrations in the cerebrospinal fluid of subjects with $\mathrm{MCl} .44$

Neuropsychiatric symptoms may also be due to the effect of $A P O E$ on synaptic acetylcholine concentrations and cholinergic function. ${ }^{45-47} A P O E-\varepsilon 4$ has been shown to interact with the cholinergic system by altering the activity of acetylcholinesterase (AChE) and choline acetyltransferase (ChAT), which are needed for the formation of acetylcholine. ${ }^{48,49}$ In AD, AChE and ChAT activities have been reported to be lower among $A P O E-\varepsilon 4$ carriers, indicating cholinergic neurodegeneration, 47,48 although increased cholinergic function among $A P O E$ carriers have also been reported in subjects with $\mathrm{MCl}$ and mild AD.49, 50 Reduced cholinergic function has been correlated with increased agitation and reduced depression, the latter being a result of disrupted neural mechanisms for expressing depression. ${ }^{45}$ This is consistent with studies that showed that a hypercholinergic state reduced agitation and induced depression due to reduced noradrenergic activity. ${ }^{50,51}$ This observation is consistent with our study in which the APOE $\varepsilon_{4}$ allele was related to increased agitation and reduced depression. 
The effect of the APOE genotype on neuropsychiatric symptoms may also result from the subjects' psychological reaction to incipient dementia.

In a post hoc analysis, disease severity as assessed by the MMSE did not change our results. Given the small range in the MMSE score of subjects included in the analyses, the MMSE may not be a sensitive tool for measuring disease severity that could affect the manifestation of neuropsychiatric symptoms.

We performed our study in two independent cohorts. The relation between agitation and APOE genotype was similar in both cohorts although it did not reach statistical significance in each cohort separately. In examining the effects of medication and exclusion of subjects with naMCI in DESCRIPA, we obtained essentially similar findings.

As far as we know, ours is the first study to investigate the association between $A P O E$ and the full spectrum of neuropsychiatric and behavioral symptoms in $\mathrm{MCl}$. Among the strengths of this study are the large sample size, two independent well-defined study populations, and the use of the same well-validated assessment tool in both cohorts. These enabled us to perform various statistical analyses while correcting for covariates and the effects of the multicenter nature of the pooled cohorts. We were able to examine the relationship between APOE and neuropsychiatric symptoms according to presence and clinical significance of symptoms. Because the subjects in our study were recruited from memory centers or research settings, our findings may have limited generalizability outside of these settings. Neuropsychiatric symptoms may be transient and may also reflect the subjects' reaction to cognitive changes. Longitudinal study will help clarify the role of $A P O E$ in neuropsychiatric symptoms among subjects with $\mathrm{MCl}$ and determine whether they have an increased risk of converting to $A D$ or other types of dementia.

In conclusion, our findings show that at the $\mathrm{MCl}$ stage, the symptoms of agitation and delusions reported in $A D$ and associated with the $A P O E \varepsilon_{4}$ allele were already evident. The association between APOE and agitation is modest. Clinically significant symptoms of delusions among $\mathrm{aMCI} A P O E-\varepsilon_{4}$ carriers warrant further investigation to find out if these subjects are at an increased risk of developing $A D$ or other dementia. 
Acknowledgments: ADNI data used in the preparation of this article were obtained from the Alzheimer's Disease Neuroimaging Initiative (ADNI) database (adni.loni.ucla.edu). As such, the investigators within the ADNI contributed to the design and implementation of ADNI and/ or provided data but did not participate in the analysis or writing of this report. A complete list of ADNI investigators can be found at: http://adni. loni.ucla.edu/wp-content/uploads/how_to_apply/ADNI_Acknowledgement_List.pdf

The DESCRIPA study was funded by the European Commission as part of the $5^{\text {th }}$ Framework Programme (OLT-6-CT-2002-02455). The ADNI data collection and sharing of data was funded by the National Institutes of Health (NIH) Grant Uo1 AG024904. ADNI is funded by the National Institute on Aging, the National Institute of Biomedical Imaging and Bioengineering (NIBIB), and through generous contributions from the following: Abbott, AstraZeneca AB, Bayer Schering Pharma AG, Bristol-Myers Squibb, Eisai Global Clinical Development, Elan Corporation, Genentech, GE Healthcare, GlaxoSmithKline, Innogenetics, Johnson and Johnson, Eli Lilly and Co., Medpace Inc., Merck \& Co. Inc, Novartis AG, Pfizer Inc., F. Hoffman-La Roche, Schering-Plough, Synarc Inc., as well as non-profit partners the Alzheimer's Association and Alzheimer's Drug Discovery Foundation, with participation from the U.S. Food and Drug Administration. Private sector contributions to ADNI are facilitated by the Foundation for the National Institutes of Health (www.fnih.org). The grantee organization is the Northern California Institute for Research and Education, and the study is coordinated by the Alzheimer's Disease Cooperative Study at the University of California, San Diego. ADNI data are disseminated by the Laboratory of Neuro Imaging at the University of California, Los Angeles. This research was also supported by NIH grants P30 AG010129, K01 AG030514, and the Dana Foundation. JQT also is funded by $\mathrm{AG}_{10124}$. LMS is supported by ADNI UO ${ }_{1} \mathrm{AG}_{024904 .}$ LMS is supported by ADNI UOI AG024904. The funders had no role in the study design, the data collection and analyses, the decision to publish, or the preparation of the manuscript. The authors thank Nico Rozendaal for his help with the design of the database and data management of the DESCRIPA study. 


\section{REFERENCES}

1. Apostolova LG, Cummings JL. Neuropsychiatric manifestations in mild cognitive impairment: a systematic review of the literature. Dement Geriatr Cogn Disord 2008; 25(2): 115-26.

2. Monastero R, Mangialasche F, Camarda C, Ercolani S, Camarda R. A systematic review of neuropsychiatric symptoms in mild cognitive impairment. J Alzheimers Dis 2009; 18(1): 11-30.

3. Feldman $H$, Scheltens $P$, Scarpini E, Hermann N, Mesenbrink $P$, Mancione $L$, et al. Behavioral symptoms in mild cognitive impairment. Neurology 2004; 62(7): 1199-201.

4. Lyketsos CG, Lopez O, Jones B, Fitzpatrick AL, Breitner J, DeKosky S. Prevalence of neuropsychiatric symptoms in dementia and mild cognitive impairment: results from the cardiovascular health study. JAMA 2002; 288(12): 1475-83.

5. Sierksma AS, van den Hove DL, Steinbusch HW, Prickaerts J. Major depression, cognitive dysfunction and Alzheimer's disease: is there a link? EurJ Pharmacol 2010; 626(1): 72-82.

6. Holmes C, Levy R, McLoughlin DM, Powell JF, Lovestone S. Apolipoprotein E: non-cognitive symptoms and cognitive decline in late onset Alzheimer's disease. J Neurol Neurosurg Psychiatry 1996; 61(6): 580-3.

7. Monastero R, Mariani, E., Camarda, C., Ingegni, T., Averna, M.R., Senin, U., Camarda, R., Mecocci, P. Association between apolipoprotein E $\varepsilon_{4}$ allele and apathy in probable Alzheimer's disease. Acta Psychiatrica Scandinavica 2006; 113: 59-63.

8. van der Flier WM, Staekenborg S, Pijnenburg YA, Gillissen F, Romkes R, Kok A, et al. Apolipoprotein $\mathrm{E}$ genotype influences presence and severity of delusions and aggressive behavior in Alzheimer disease. Dement Geriatr Cogn Disord 2007; 23(1): 42-6.

9. Ballard C, Massey H, Lamb H, Morris C. Apolipoprotein E: non-cognitive symptoms and cognitive decline in late onset Alzheimer's disease. J Neurol Neurosurg Psychiatry 1997; 63(2): 273-4.

10. Panza F, Frisardi V, Seripa D, D’Onofrio G, Santamato A, Masullo C, et al. Apolipoprotein E genotypes and neuropsychiatric symptoms and syndromes in late-onset Alzheimer's disease. Ageing Res Rev 2012; 11(1): 87-103.

11. DeMichele-Sweet MA, Sweet RA. Genetics of psychosis in Alzheimer's disease: a review. J Alzheimers Dis 2010; 19(3): 761-80.

12. Fritze F, Ehrt U, Sonnesyn $H$, Kurz M, Hortobagyi T, Nore SP, et al. Depression in mild dementia: associations with diagnosis, APOE genotype and clinical features. Int $J$ Geriatr Psychiatry 2011; 26(10): 1054-61.

13. APA. Diagnostic and statistical manual of mental dsorders (DSM-IV). Fourth edition ed. Washington, DC: American Psychiatric Association; 1994.

14. Visser PJ, Verhey FRJ, Boada M, Bullock R, De Deyn PP, Frisoni GB, et al. Development of Screening Guidelines and Clinical Criteria for Predementia Alzheimer's Disease: The DE- 
SCRIPA Study. Neuroepidemiology 2008; 30(4): 254-65.

15. Morris JC. The Clinical Dementia Rating (CDR): current version and scoring rules. Neurology 1993; 43(11): 2412-4.

16. Folstein MF, Folstein SE, McHugh PR. "Mini-mental state". A practical method for grading the cognitive state of patients for the clinician. J Psychiatr Res 1975; 12(3): 189-98.

17. McKhann G, Drachman D, Folstein M, Katzman R, Price D, Stadlan EM. Clinical diagnosis of Alzheimer's disease: report of the NINCDS-ADRDA Work Group under the auspices of Department of Health and Human Services Task Force on Alzheimer's Disease. Neurology 1984; 34(7): 939-44.

18. Shaw LM, Vanderstichele $H$, Knapik-Czajka M, Clark CM, Aisen PS, Petersen RC, et al. Cerebrospinal fluid biomarker signature in Alzheimer's disease neuroimaging initiative subjects. Ann Neurol 2009; 65(4): 403-13.

19. Cummings JL. The Neuropsychiatric Inventory: assessing psychopathology in dementia patients. Neurology 1997; 48(5 Suppl 6): S10-6.

20. Caputo M, Monastero R, Mariani E, Santucci A, Mangialasche F, Camarda R, et al. Neuropsychiatric symptoms in 921 elderly subjects with dementia: a comparison between vascular and neurodegenerative types. Acta Psychiatr Scand 2008; 117(6): 455-64.

21. Kaufer DI, Cummings JL, Ketchel P, Smith V, MacMillan A, Shelley T, et al. Validation of the $\mathrm{NPI}-\mathrm{Q}$, a brief clinical form of the Neuropsychiatric Inventory. J Neuropsychiatry Clin Neurosci 2000; $12(2)$ : 233-9.

22. Ingelsson M, Shin Y, Irizarry MC, Hyman BT, Lilius L, Forsell C, et al. Genotyping of apolipoprotein E: comparative evaluation of different protocols. Curr Protoc Hum Genet 2003; Chapter 9: Unitg 14 .

23. Craig D, Hart DJ, McCool K, Mcllroy SP, Passmore AP. Apolipoprotein E $\varepsilon 4$ allele influences aggressive behaviour in Alzheimer's disease. J Neurol Neurosurg Psychiatry 2004; 75(9): 132730.

24. Pritchard AL, Harris J, Pritchard CW, Coates J, Haque S, Holder R, et al. The effect of the apolipoprotein $\mathrm{E}$ gene polymorphisms and haplotypes on behavioural and psychological symptoms in probable Alzheimer's disease. J Neurol Neurosurg Psychiatry 2007; 78(2): 123-6.

25. Zdanys KF, Kleiman TG, MacAvoy MG, Black BT, Rightmer TE, Grey M, et al. Apolipoprotein E epsilon 4 allele increases risk for psychotic symptoms in Alzheimer's disease. Neuropsychopharmacology 2007; 32(1): 171-9.

26. Scarmeas N, Brandt J, Albert M, Devanand DP, Marder K, Bell K, et al. Association between the $A P O E$ genotype and psychopathologic symptoms in Alzheimer's disease. Neurology 2002; 58(8): 1182-8. 
27. Serra L, Perri R, Cercignani M, Spano B, Fadda L, Marra C, et al. Are the behavioral symptoms of Alzheimer's disease directly associated with neurodegeneration? J Alzheimers Dis 2010; 21(2): 627-39.

28. Palmer K, Berger AK, Monastero R, Winblad B, Backman L, Fratiglioni L. Predictors of progression from mild cognitive impairment to Alzheimer disease. Neurology 2007; 68(19): 1596-602.

29. Di lulio F, Palmer K, Blundo C, Casini AR, Gianni W, Caltagirone C, et al. Occurrence of neuropsychiatric symptoms and psychiatric disorders in mild Alzheimer's disease and mild cognitive impairment subtypes. Int Psychogeriatr 2010; 22(4): 629-40.

30. Ghebremedhin E, Schultz C, Thal DR, Rub U, Ohm TG, Braak E, et al. Gender and age modify the association between $A P O E$ and AD-related neuropathology. Neurology 2001; 56(12): 1696-701.

31. Chan DC, Kasper JD, Black BS, Rabins PV. Prevalence and correlates of behavioral and psychiatric symptoms in community-dwelling elders with dementia or mild cognitive impairment: the Memory and Medical Care Study. Int J Geriatr Psychiatry 2003; 18(2): 174-82.

32. Modrego PJ, Ferrandez J. Depression in patients with mild cognitive impairment increases the risk of developing dementia of Alzheimer type: a prospective cohort study. Arch Neurol 2004; 61(8): 1290-3.

33. Ramakers IH, Visser PJ, Aalten P, Kester A, Jolles J, Verhey FR. Affective symptoms as predictors of Alzheimer's disease in subjects with mild cognitive impairment: a 10-year follow-up study. Psychol Med 2010; 40(7): 1193-201.

34. Lyketsos CG, Baker L, Warren A, Steele C, Brandt J, Steinberg M, et al. Depression, delusions, and hallucinations in Alzheimer's disease: no relationship to apolipoprotein E genotype. $J$ Neuropsychiatry Clin Neurosci 1997; 9(1): 64-7.

35. Hollingworth P, Sweet R, Sims R, Harold D, Russo G, Abraham R, et al. Genome-wide association study of Alzheimer's disease with psychotic symptoms. Mol Psychiatry 2011.

36. Emanuel JE, Lopez OL, Houck PR, Becker JT, Weamer EA, Demichele-Sweet MA, et al. Trajectory of cognitive decline as a predictor of psychosis in early Alzheimer disease in the cardiovascular health study. Am J Geriatr Psychiatry 2011; 19(2): 160-8.

37. Hwang TJ, Masterman DL, Ortiz F, Fairbanks LA, Cummings JL. Mild cognitive impairment is associated with characteristic neuropsychiatric symptoms. Alzheimer Dis Assoc Disord 2004; 18(1): 17-21.

38. Teng E, Lu PH, Cummings JL. Neuropsychiatric symptoms are associated with progression from mild cognitive impairment to Alzheimer's disease. Dement Geriatr Cogn Disord 2007; 24(4): 253-9. 
39. Hamalainen A, Grau-Olivares M, Tervo S, Niskanen E, Pennanen C, Huuskonen J, et al. Apolipoprotein $\mathrm{E}$ epsilon 4 allele is associated with increased atrophy in progressive mild cognitive impairment: a voxel-based morphometric study. Neurodegener Dis 2008; 5(3-4): 186-9.

40. van de Pol LA, van der Flier WM, Korf ES, Fox NC, Barkhof F, Scheltens P. Baseline predictors of rates of hippocampal atrophy in mild cognitive impairment. Neurology 2007; 69(15): 14917.

41. Bruen PD, McGeown WJ, Shanks MF, Venneri A. Neuroanatomical correlates of neuropsychiatric symptoms in Alzheimer's disease. Brain 2008; 131(Pt 9): 2455-63.

42. Tsopelas C, Stewart R, Savva GM, Brayne C, Ince P, Thomas A, et al. Neuropathological correlates of late-life depression in older people. BrJ Psychiatry 2011; 198(2): 109-14.

43. Yamaguchi H, Sugihara S, Ogawa A, Oshima N, Ihara Y. Alzheimer beta amyloid deposition enhanced by apoE epsilon 4 gene precedes neurofibrillary pathology in the frontal association cortex of nondemented senior subjects. J Neuropathol Exp Neurol 2001; 6o(7): 731-9.

44. Ramakers IH, Verhey FR, Scheltens $P$, Hampel $H$, Soininen $H$, Aalten $P$, et al. Anxiety is related to Alzheimer cerebrospinal fluid markers in subjects with mild cognitive impairment. Psychol Med 2012: 1-10.

45. Cummings JL, Kaufer D. Neuropsychiatric aspects of Alzheimer's disease: the cholinergic hypothesis revisited. Neurology $1996 ; 47(4): 876-83$.

46. Del Prete M, Spaccavento S, Craca A, Fiore P, Angelelli P. Neuropsychiatric symptoms and the APOE genotype in Alzheimer's disease. Neurol Sci 2009; 30(5): 367-73.

47. Soininen H, Kosunen O, Helisalmi S, Mannermaa A, Paljarvi L, Talasniemi S, et al. A severe loss of choline acetyltransferase in the frontal cortex of Alzheimer patients carrying apolipoprotein epsilon 4 allele. Neurosci Lett 1995; 187(2): 79-82.

48. Poirier J, Delisle MC, Quirion R, Aubert I, Farlow M, Lahiri D, et al. Apolipoprotein $\varepsilon 4$ allele as a predictor of cholinergic deficits and treatment outcome in Alzheimer disease. Proc Natl Acad SciUS A 1995; 92(26): 12260-4.

49. Eggers C, Herholz K, Kalbe E, Heiss WD. Cortical acetylcholine esterase activity and ApoE4genotype in Alzheimer disease. Neurosci Lett 2006; 408(1): 46-50.

50. MineurYS, Picciotto MR. Nicotine receptors and depression: revisiting and revising the cholinergic hypothesis. Trends Pharmacol Sci 2010; 31(12): 580-6.

51. Figiel G, Sadowsky C. A systematic review of the effectiveness of rivastigmine for the treatment of behavioral disturbances in dementia and other neurological disorders. Curr Med Res Opin 2008; 24(1): 157-66. 
Abnormal concentrations of amyloid beta $(A \beta)$ and tau may indicate underlying AD pathology.

We reviewed the effects of the most compelling genetic risk factors for $A D$ on $A \beta$ and tau. 
LS Elias-Sonnenschein, L Bertram, PJ Visser

Biomarkers in Medicine. 2012; 6 (4):477-95

\section{CHAPTER 5}

Relationship between genetic risk factors and markers for Alzheimer's disease pathology

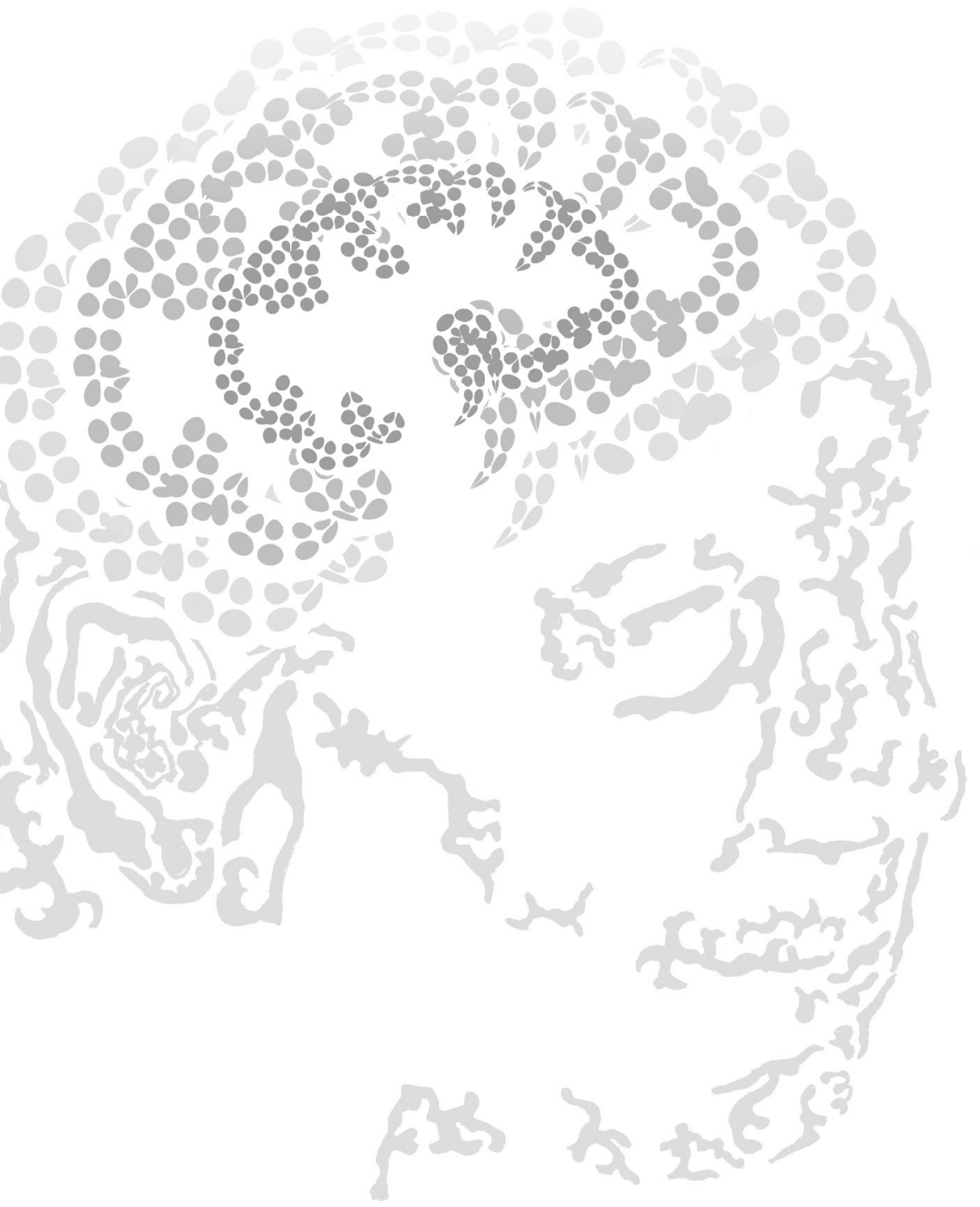




\begin{abstract}
Alzheimer's disease (AD) is a neurodegenerative disorder characterized by neuritic plaques (main constituent: amyloid beta, $A \beta$ ) and neurofibrillary tangles (hyperphosphorylated tau protein) in the brain. Abnormalities in $A \beta$ and tau can be measured upon neuropathological examination, in cerebrospinal fluid (CSF) or by positron emission tomography (PET). Etiologically, a growing body of evidence suggests that susceptibility to $A D$ is genetically controlled. However, the precise nature of the underlying risk genes and their relation to $A D$ biomarkers remains largely elusive. To this end, we performed a qualitative review of 17 studies (covering 47 polymorphisms in 26 genes) and investigated the potential relation between the most compelling $A D$ risk genes and markers for $A \beta$ and tau in CSF, PET imaging and neuropathological examination. Of all covered genes, only APOE and PICALM showed consistent effects on A $\beta$ but not on tau, while no obvious effects were observed for $C L U, C R 1$, $A C E$, SORL and MAPT.
\end{abstract}

Keywords: Alzheimer, AlzGene, genetics, amyloid, biomarker, CSF, genetics, GWAS, pathology, SNP, tau 


\section{INTRODUCTION}

Alzheimer's disease (AD) is a neurodegenerative disorder characterized by senile or neuritic plaques and neurofibrillary tangles (NFTs)., ${ }^{1,2}$ The main component of neuritic plaques is amyloid beta $(A \beta)$, whereas NFTs consist of hyperphosphorylated tau ( $\mathrm{p}$-tau) protein. ${ }^{2,3} \mathrm{Abnormalities}$ in $A \beta$ and tau can be measured on neuropathological examination, or in-vivo in cerebrospinal fluid (CSF) or by positron emission tomography (PET) imaging. ${ }^{4-7}$ Genetically, AD represents a so-called complex disease showing a great deal of genetic (and phenotypic) heterogeneity. To date, more than 250 autosomal dominant mutations have been identified in genes that affect $A \beta$ production or metabolism (APP, PSEN1, $P S E N 2$; see ${ }^{8}$ for a recent review). However, these mutations account for only a small fraction of the disease. Recently, a number of genetic risk factors for $A D$ has been identified but their relation to $A D$ pathology remains unclear. ${ }^{9}$ Here, we performed a qualitative review of studies including genome-wide association studies (GWAS) - investigating the potential role of genetic risk factors in the pathophysiology of AD by correlating them with in-vivo amyloid and tau biomarkers and neuropathological markers for AD.

\section{AD pathophysiology}

According to the amyloid cascade hypothesis, $A D$ is the result of an imbalance between the production and clearance of $A \beta$ in the brain. ${ }^{2,10}$ Aggregated $A \beta$ is supposed to be neurotoxic and to initiate a cascade of events, including abnormal tau phosphorylation and aggregation, oxidative stress, inflammation and dysregulation of lipid metabolism. ${ }^{6}$ The soluble oligomeric forms of $A \beta$, such as dimers of high molecular weight oligomers, are considered the main toxic species. ${ }^{11-13}$ They have been reported to interfere with synaptic functioning ${ }^{11}$ and to have a higher correlation with synaptic loss and cognitive impairment severity compared to non-soluble aggregated $A \beta .{ }^{13}$

Different isoforms of the $A \beta$ peptide are generated from the amyloid precursor protein (APP) by $\alpha, \beta$ and $\gamma$ secretases. In the nonamyloidogenic pathway, APP cleavage by $\alpha$-secretase occurs within the $A \beta$ region, thus precluding the formation of $A \beta .^{14}$ In the amyloidogenic metabolic pathway, APP is first cleaved in its extracellular domain by 
the $\beta$-site APP cleaving enzyme 1 (BACE1; a.k.a. $\beta$-secretase) to generate soluble APP (SAPP) containing the entire $A \beta$ sequence, ${ }^{15}$ which is subsequently cleaved in the transmembrane region by $\gamma$-secretase to produce $A \beta_{1-40}$ and $A \beta_{1-42} \cdot{ }^{1}$

In $A D$, especially $A \beta_{1-42}$ seems to be important as it is more prone to aggregate compared to other isoforms. ${ }^{1}$ The increase in aggregated $A \beta$ may be caused by either increased production, disturbance of the post-translational modification or reduced clearance of $A \beta . .^{1,2} A b n o r m a l$ CSF concentrations of $A \beta_{1-42}$ can indicate if there is abnormal trafficking of this peptide and are correlated to amyloid plaques, whereas total tau ( $t$-tau) and phosporylated tau ( $p$-tau) concentrations are related to neuronal degeneration. ${ }^{16} \mathrm{CSF} A \beta_{1-42}$ is decreased while t-tau and $p$-tau are increased among subjects with $A D .^{2}$ This $A D$ profile has been shown to be predictive of progression to $A D$ among subjects in the pre-dementia stage. ${ }^{17}$ Compared to $A \beta_{1-42,}$ the $A \beta_{1-42} / A \beta_{40}$ ratio has been reported as a better predictor of incipient $A D,{ }_{1}^{18}$ whereas $p$-tau $/ A \beta_{1-42}$ and t-tau/A $\beta_{1-42}$ ratios are better predictors of $A D$ than each marker individually have been reported to distinguishing those with $A D$ from healthy controls. ${ }^{19-21}$

\section{Genetics of AD}

$A D$ presents clinically as familial AD with Mendelian disease transmission or sporadic $A D$ with no obvious familial aggregation (non-Mendelian). ${ }^{9}$ Familial AD with Mendelian inheritance usually have an onset age of below 65 years (early onset familial AD, EOFAD) and account for less than $5 \%$ of all $A D$ cases. ${ }^{3,9}, 22$ The majority of $A D$ cases are of the non-Mendelian forms ('sporadic $A D$ ') and typically have an onset age after age 65 years (late-onset $A D, L O A D$ ). ${ }^{8}$ It is thought that familial $A D$ is caused by abnormalities in the production of $A \beta$, while sporadic $A D$ is mainly the result of inefficient $A \beta$ clearance from the brain. ${ }^{2}$

\section{Mendelian forms of $A D$}

Highly penetrant mutations in APP, presenilin 1 (PSEN1) and presenilin 2 (PSEN2) genes have been identified to cause autosomal dominant EOFAD. ${ }^{2,23}$ The APP gene encodes APP, whose physiological role remains largely elusive but which has been reported to promote neuritic outgrowth and synaptogenesis. ${ }^{24} \mathrm{AD}$-causing APP mutations are typi- 
cally located near the $A \beta$-sequence and affect proteolytic processing by BACE1 and/or $\gamma$-secretase. This typically leads to an increase in the $A \beta_{1-42} / A \beta_{1-40}$ ratio, with or without a concommitant increase in total A $\beta$-levels. ${ }^{25}$ Presenilins, i.e. PSEN1 and PSEN2, encode proteins that constitute the catalytic center of the $\gamma$-secretase complex. ${ }^{26}$ Mutations in PSEN1 and PSEN2 alter the proteolytic site for APP cleavage thereby also affecting the $A \beta_{1-42 / 1-40}$ ratio. ${ }^{25}$ Eventually, the changes induced by the currently known missense mutations in all three genes result in $A \beta$ accumulation and deposition in neuritic plaques. ${ }^{1,3,27-30}$ Non-AD type dementia has also been linked to PSEN1 as not all mutations in PSEN1 lead to increased $A \beta$ production. ${ }^{31} A P P, P S E N 1$ and $P S E N 2$ mutations account for less than $5 \%$ of all early onset familial $A D$, and for $30-50 \%$ of all AD cases. ${ }^{32}$

A recent study has identified mutations in the sortilin-related receptor (SORL1) gene among patients with autosomal dominant early onset AD. ${ }^{33}$ SORL1 encodes the protein SorLA, which is involved in modulating $A \beta$ peptide production, ${ }^{33}$ and is part of a group of proteintrafficking molecules in the endocytic and retromer pathways, which are sites for $A \beta$ peptide production. ${ }^{34}$ These novel data suggest that SORL1 may represent a genetic risk factor for both early and late-onset forms of $A D$, although these findings still await independent replication.

\section{Non-Mendelian forms of AD}

\section{Association studies using disease state as outcome}

Hypothesis-driven candidate gene association studies, e.g. focused on proteins suspected or known to be involved in the production or clearance of $A \beta$, have led to the discovery of the association between the apolipoprotein $\mathrm{E}(A P O E)$ gene and $\mathrm{AD}$ in 1993.35 APOE has three isoforms $(\varepsilon 2, \varepsilon 3$ and $\varepsilon 4)$ and six genotypes $\left(\varepsilon 2 \varepsilon 2, \varepsilon 2 \varepsilon 3, \varepsilon 2 e_{4}, \varepsilon 3 \varepsilon 3, \varepsilon 3 e 4\right.$ and $\mathrm{e}_{4 \mathrm{e}}$ ) resulting from a combination of two single nucleotide polymorphisms (SNPs). APOE, particularly its $\varepsilon_{4}$-allele, has been observed to have a high-avidity binding to $A \beta .{ }^{36,37} A P O E$ binds to $A \beta$ in cerebrospinal fluid (CSF), transports cholesterol and other lipids in the brain, and modulates neuronal repair. The $A P O E \varepsilon_{4}$ allele is less efficient in carrying out these functions. ${ }^{1,2}$ In addition, this allele has been reported to stimulate aggregation of $A \beta$ in vitro and deposition of amyloid plaques in 
vivo. ${ }^{38,39}$ Until recently, only the $\varepsilon_{4}$-allele of $A P O E$ had been established as a bona fide genetic risk factor for sporadic $A D .{ }^{36,40-42}$ At the predementia stage, the $A P O E \varepsilon_{4}$ allele has been correlated with a moderately increased risk of developing AD-type dementia. ${ }^{43}$

GWAS in the past years have identified a number of SNPs associated with clinical $A D$ or with $A D$ biomarkers. Compared to $A P O E$, these SNPs exert only small risk effects, which when taken in combination, may have a considerable role in the development of AD. Early case-control GWAS with sample sizes of typically less than 1,000 have identified other susceptible loci 44-50 (for a review, see Bertram $2010^{9}$ and the AlzGene database ${ }^{41}$ ). Except for $A P O E$, these findings could not be replicated in more recently conducted GWAS including much larger sample sizes. Instead, these latter studies have identified other genetic risk factors which can now be considered as established AD risk genes: clusterin $(C L U){ }_{1}^{23,51}$ phosphatidylinositol binding clathrin assembly protein (PICALM), ${ }^{51,52}$ siglec3 (CD 33$),{ }^{53,54}$ and ATP-binding cassette subfamily $A$ member $7(A B C A 7)$, membrane-spanning 4 domains, subfamily $A$, member $6 \mathrm{~A}\left(M S_{4} A 6 \mathrm{~A}\right)$, membrane-spanning 4-domains, subfamily $\mathrm{A}$, member $4 \mathrm{E}\left(M \mathrm{~S}_{4} \mathrm{~A}_{4} E\right), \mathrm{EPH}$ receptor $\mathrm{A}_{1}(E P H A 1)$, and $\mathrm{CD}_{2}$-associated protein $\left(C D_{2} A P\right) .53,55$

Association studies using biomarker levels as outcome

Biomarker association studies aim to identify susceptibility loci correlated with biomarker levels, either as binary ('normal' vs. 'abnormal') or quantitative (e.g. raw or normalized concentrations) traits in a given study population. As for the disease state studies outlined above, there exist a number of hypothesis-driven studies ${ }^{56-58}$ and, more recently, genome wide analyses in the form of GWAS. How to interpret the results from either approach remains a challenge, given the numerous susceptibility loci that have been identified but not replicated, the inconsistency in findings and the heterogeneity of the trait in the population(s) under study. 


\section{METHODS}

\section{Search strategy and inclusion criteria}

Three approaches were used to identify genes for inclusion in this review. First, we selected SNPs from genes listed in the 'Top Results' list of AlzGene, ${ }^{41}$ a regularly updated online database of published genetic association studies in AD. These included APOE, CLU, PICALM, CD 33, $A B C A_{7}, M S_{4} A 6 A, M S_{4} A_{4} E_{1}, D_{2} A P$, bridging integrator 1 ( $\left.B I N 1\right)$ and complement receptor (3b/4b) 1 ( $C R 1)$. On AlzGene, cross-study metaanalyses for disease risk (but not quantitative) association studies are provided for all polymorphisms with a minor allele frequency of more than $1 \%$ in healthy controls and for which genotype data in four or more independent case-control samples are available for the same polymorphism. ${ }^{41}$

Second, we chose a number of additional candidate genes for $A D$, which were selected since multiple independent studies indicated that these could represent promising genetic risk factors for AD. These genes are angiotensin-converting enzyme $(A C E)$, microtubule-associated protein tau $(M A P T)$, translocase of outer mitochondrial membrane 40 homolog (TOMM4O) and SORL1. ${ }^{34,56,59-68}$ ACE is an endopeptidase associated with hypertension and cardiovascular diseases. ${ }^{69}$ At the same time, it mediates the degradation of $A \beta_{1-42}$ to $A \beta_{1-40}$. Inhibition of $A C E$ results in increased $A \beta$ deposition. ${ }^{70}$ MAPT codes for the tau proteins, which stabilizes microtubules and maintains the integrity of neurons, axonal transport and polarity. ${ }^{71}$ Tau hyperphosphorylation and aggregation results in NFTs, the overabundance of which is one of the causes of neurodegeneration. TOMM4O controls the outer mitochondrial membrane pore subunit (Tom40) through which proteins enter the mitochondria, and as such is crucial for the survival of the mitochondria. ${ }^{72} \mathrm{Mi}-$ tochondrial dysfunction that leads to APP accumulation and A $\beta$ cellular influx has been hypothesized to be the key pathological event in AD. ${ }^{72-74}$ $S O R L 1$ is involved in $A \beta$ production, as previously explained.

Finally, we identified SNPs highlighted in published biomarker GWAS. ${ }^{75-77}$ In all instances, we arbitrarily limited the number of SNPs to be included for each gene to five.

The PubMed database was then searched for publications in English using the broad terms 'Alzheimer', 'SNPs', 'biomarker' and 
'genes'. The search yielded 240 hits, covering the period 2000-2012. Their titles and abstracts were screened. Sixty studies pertaining to diseases other than Alzheimer and/or to animal studies, and 2 studies not written in English were excluded. Of the remaining 178, we further excluded 40 studies that did not have data on biomarkers; 42 studies of SNPs that were not selected for our review; 23 studies that were reviews, commentaries or part of a seminar series; 16 studies that measured mRNA, gene or protein expression; 10 neuroimaging studies; 11 studies that did not have genetic data; 7 studies on cognition; 2 studies on plasma markers; 10 other irrelevant studies; and 3 duplicates. Studies that had data on AD-related SNPs and biomarker correlations according to abovementioned criteria were included. Additional references were identified from the reference list of the reviewed articles. For $C R_{1}$ and SORL1, more than five different SNPs were identified that had been tested in relation to $A D$ markers. For $C R 1$ only SNPs that were listed in AlzGene were included in the review.

For SORL1, only the SNPs that were statistically significantly correlated with clinical $A D$ in a recent meta-analysis were selected. ${ }^{34}$ From the AlzGene 'Top Results' loci, studies with biomarker outcome have been conducted on APOE, BIN1,CLU,CR1, and PICALM. ORs originating from case-control studies of the SNPs from the top AlzGene loci or from the candidate genes from the AlzGene meta-analysis are shown in Table 1. The final list of 26 genes and 47 SNPs included in our review is shown in Tables 2-4.

\section{Data extraction}

A data extraction file was completed for each study. Studies were classified into three categories: (1) AlzGene 'Top Result' genes with biomarkers as outcome, (2) candidate genes with biomarkers as outcome, and (3) GWAS with biomarkers as outcome. The outcomes for biomarkers were $A \beta$ and tau, specified as to whether they were measured in CSF, PET imaging or on neuropathological examination. If studies provided multiple outcome measures for a single marker, we only chose the outcome measure that was most indicative of AD pathology. The odds ratio or p-value, uncorrected for multiple testing if available, for the biomarker correlation was extracted. Information on minor and risk alleles 
Table 1 Odds ratios from AlzGene meta-analyses for SNPs included in this review

\begin{tabular}{|c|c|c|c|c|}
\hline Gene & SNP & Minor & Risk & OR $(95 \% \mathrm{Cl})$ \\
\hline \multicolumn{5}{|c|}{ AlzGene 'Top Results'a } \\
\hline APOE & & $\varepsilon 2$ & $\varepsilon_{4}$ & $3.68(3.30-4.11)$ \\
\hline$B I N_{1}$ & rs744373 & G & G & $1.17(1.13-1.20)$ \\
\hline CLU & rs11136ooo & A & G & $0.89(0.86-0.91)$ \\
\hline \multirow[t]{3}{*}{$C R 1$} & $\mathrm{rs} 3818361$ & $\mathrm{~T}$ & $\mathrm{~T}$ & $1.15(1.11-1.20)$ \\
\hline & rs1408077 & A & A & $1.13(1.06-1.20)$ \\
\hline & rs6656401 & A & A & $1.19(1.09-1.30)$ \\
\hline \multirow[t]{3}{*}{ PICALM } & rs3851179 & A & G & $0.88(0.86-0.91)$ \\
\hline & rs541458 & C & $\mathrm{T}$ & $0.88(0.85-0.91)$ \\
\hline & rs7110631 ${ }^{\mathrm{b}}$ & na & na & na \\
\hline \multicolumn{5}{|c|}{ Other SNPs in AD candidate genes } \\
\hline \multirow[t]{3}{*}{$A C E$} & rs18oo764 & C & $\mathrm{T}$ & $0.88(0.80-0.97)$ \\
\hline & rs4291 & $\mathrm{T}$ & A & $0.88(0.81-0.96)$ \\
\hline & rs4343 & G & A & $0.96(0.82-1.12)$ \\
\hline \multirow[t]{5}{*}{ SORLI } & rs2070045 (SNP19) & G & G & $1.12(1.04-1.20)$ \\
\hline & rs64112o (SNP10) & $\mathrm{T}$ & C & $0.93(0.87-1.00)$ \\
\hline & rs661057 (SNP4) & c & $\mathrm{T}$ & $0.92(0.85-0.99)$ \\
\hline & rs668387 (SNP8) & $\mathrm{T}$ & C & $0.93(0.88-0.99)$ \\
\hline & rs689o21 (SNP9) & A & G & $0.94(0.89-1.00)$ \\
\hline \multirow[t]{2}{*}{ MAPT } & rs2471738 & $\mathrm{T}$ & $\mathrm{T}$ & $1.14(0.98-1.33)$ \\
\hline & rs242557 & A & A & $1.10(0.98-1.23)$ \\
\hline$M A P T H_{1} / H_{2}$ & rs1052553 & $\mathrm{H}_{2}(\mathrm{G})$ & $\mathrm{H}_{2}(\mathrm{G})$ & $1.01(0.94-1.07)$ \\
\hline \multirow[t]{3}{*}{$\mathrm{TOMM}_{40}$} & rs15758o & G & A & $0.60(0.56-0.65)$ \\
\hline & rs157581 & C & C & $2.57(2.15-3.06)$ \\
\hline & rs207565o & G & G & $2.79(2.38-3.27)$ \\
\hline
\end{tabular}

Abbreviations: $\mathrm{SNP}=$ single nucleotide polymorphism; $\mathrm{OR}=\mathrm{Odds}$ ratio; $\mathrm{Cl}=$ confidence interval; na=not available

a For more details, consult the AlzGene database. ${ }^{41}$

${ }^{b}$ One study 87 used rs7110631 as proxy for this SNP (not included in meta-analysis). 
were obtained from the AlzGene for SNPs with available meta-analysis data. In general, an odds ratio of $<1$ indicates that the allele is protective, whereas an odds ratio of $>1$ is suggestive of a risk allele.

Results are presented per study population ( $A D$, mild cognitive impairment, ${ }^{12}$ controls and combined), as applicable. Other demographic data extracted were study setting (clinical, population or mixed), cohort and mean age of the study sample.

\section{RESULTS}

Seventeen studies were included in the review, of which 14 assessed biomarkers in CSF, 1 with amyloid PET, and 5 by neuropathological examination. Data on pathology originated from three prospective cohort studies while two came from convenience sampling. Four studies were performed in the general population, four in a clinical setting, and nine in a mixed setting. Three studies only included healthy controls, two studies with only $A D$, and five studies included subjects with $\mathrm{MCl}$. The remaining studies selected subjects from multiple diagnostic categories and presented data for the pooled sample $(n=7)$ or for separate diagnostic groups $(n=4)$.

One study classified subjects as CSF positive $\left(\mathrm{CSF}^{+}\right)$or CSF negative (CSF), regardless of the $A D, \mathrm{MCl}$ or control diagnosis. $\mathrm{CSF}^{+}$were subjects with a low CSF $A \beta_{1-42}(<192 \mathrm{pg} / \mathrm{ml})$ and high p-tau $(>23 \mathrm{pg} / \mathrm{ml})$, which indicated $A D$ pathology, whereas CSF- were those with high CSF $A \beta_{1-42}(>192 \mathrm{pg} / \mathrm{ml})$ and low $\mathrm{p}$-tau $(<23 \mathrm{pg} / \mathrm{ml})$, which was an unlikely $A D$ profile. ${ }^{78}$ Subjects who were neither $\mathrm{CSF}^{+}$nor CSF- were excluded from the study.

Another study used ${ }^{11} \mathrm{C}$-Pittsburgh Compound-B-Positron Emission Tomography (PiB-PET). ${ }^{79} \mathrm{PiB}$ binds to fibrillar $A \beta$ and thus measures $A \beta$ deposition in the brain.

One study measured senile plaques and NFTs from various areas of the brain. ${ }^{80}$ We included here only the results for the middle frontal lobe as this is a more vulnerable area in AD compared to other brain areas measured.

A GWAS classified subjects with a Braak score of 2 or lower as low Braak, and those with a score of 4 or higher as high Braak. ${ }^{77}$ Subjects with a score of 3 were excluded. 


\section{Biomarkers and top results AlzGene SNPs}

\section{APOE}

In CSF, the $A P O E \varepsilon_{4}$ allele was consistently linked with lower $A \beta_{1-42}$ and $A \beta_{1-42} / A \beta_{1-40}$ ratio. It did not correlate with total $A \beta$ concentration. $5^{6}$ One population study using (PiB-PET) reported higher $\mathrm{PiB}$ retention among cognitively normal $A P O E$ \&4 allele carriers..$^{79}$ In neuropathological studies, $A \beta$ deposition in senile plaques was related to carriership of the $A P O E \varepsilon 4$ allelle as well. ${ }^{80-82}$ Except in one study, ${ }^{83}$ the effect of $A P O E$ on $A \beta$ was present in both $A D, M C l$, control or mixed populations.

The $A P O E \varepsilon_{4}$ allele also correlated with the $A D$ profile of low $A \beta$ and high $p$-tau levels in $\mathrm{CSF}^{78}$ or with a combined neuropathological score of plaques and tangles in a mixed population of subjects with $A D$, $\mathrm{MCl}$ and controls. ${ }^{80}$

Results for tau in CSF were inconsistent. Two studies did not find a link with tau or p-tau in $A D, M C l$ and controls, 83,84 while two studies did in a combined $A D$ and control population. ${ }^{84,85}$ Moreover, in one study, the correlation was in the opposite direction, i.e. noncarriers of the $A P O E \varepsilon_{4}$ allele had higher tau concentrations. ${ }^{84}$ Another study reported that the effect of the APOE $\varepsilon 4$ allele on p-tau among subjects with AD was moderated by age. ${ }^{86}$ The relation between tau and neuropathology was similarly inconsistent. A study with a mixed population found tau in NFT to correlate with the APOE $\varepsilon_{4}$ allele, ${ }^{80}$ but these findings were not confirmed by another study with a mixed population ${ }^{82}$ and two population studies found no correlation. 77,81

\section{$B I N 1$}

$B I N_{1}$ belongs to the Bin1/amphiphysin/RVS167 (BAR) family of proteins that are involved in clathrin-mediated endocytosis and apoptosis. ${ }^{25}$ Only one study tested the relation between $B I N_{1}$ and biomarkers..$^{8}$ The study showed that rs744373 was not linked with the AD profile of abnormal $A \beta$ and p-tau.

\section{$C L U$}

$C L U$ is an extracellular chaperone molecule involved in lipid transport and in the aggregation as well as clearance of $A \beta$ through endocytosis. ${ }^{25}$ Like $A P O E, C L U$ binds soluble $A \beta$ and is present in amyloid plaques. 
Data were available for four independent studies testing eight biomarker associations in rs11136000 in CLU.78, 82, 84, 87 This SNP did not correlate with $A \beta$ and tau in $\mathrm{CSF}_{1}{ }^{8,8} 84$ nor with plaques and tangles on neuropathology. ${ }^{82,87}$

\section{$C R 1$}

$C R 1$ regulates the complement cascade and has a role in $A \beta$ clearance by binding $A \beta$ oligomers to its $C_{3} b$ complement factor. ${ }^{25} A \beta$ in plasma has also been reported to bind to $C_{3} b$, suggesting a role in clearing pathogens from the bloodstream. ${ }^{88}$ Data were available for 5 independent studies testing 12 biomarker associations in 3 SNPs. ${ }^{78,82,84,87,89} C R 1$ rs1408077 was marginally correlated with abnormal $A \beta$ and $p$-tau in CSF in a combined population of subjects with $A D$ and $M C l$, and controls $(P=0.04) . .^{7}$ This SNP did not correlate with any other marker in CSF nor on neuropathology in the other studies. There was no correlation between $\mathrm{rs}_{3818361}$ and abnormal $A \beta$ and $p$-tau in $\mathrm{CSF}$, as well as between rs6656401 and markers in neuropathology.

Table 2 Qualitative summary of biomarker studies assessing AlzGene 'top results' loci

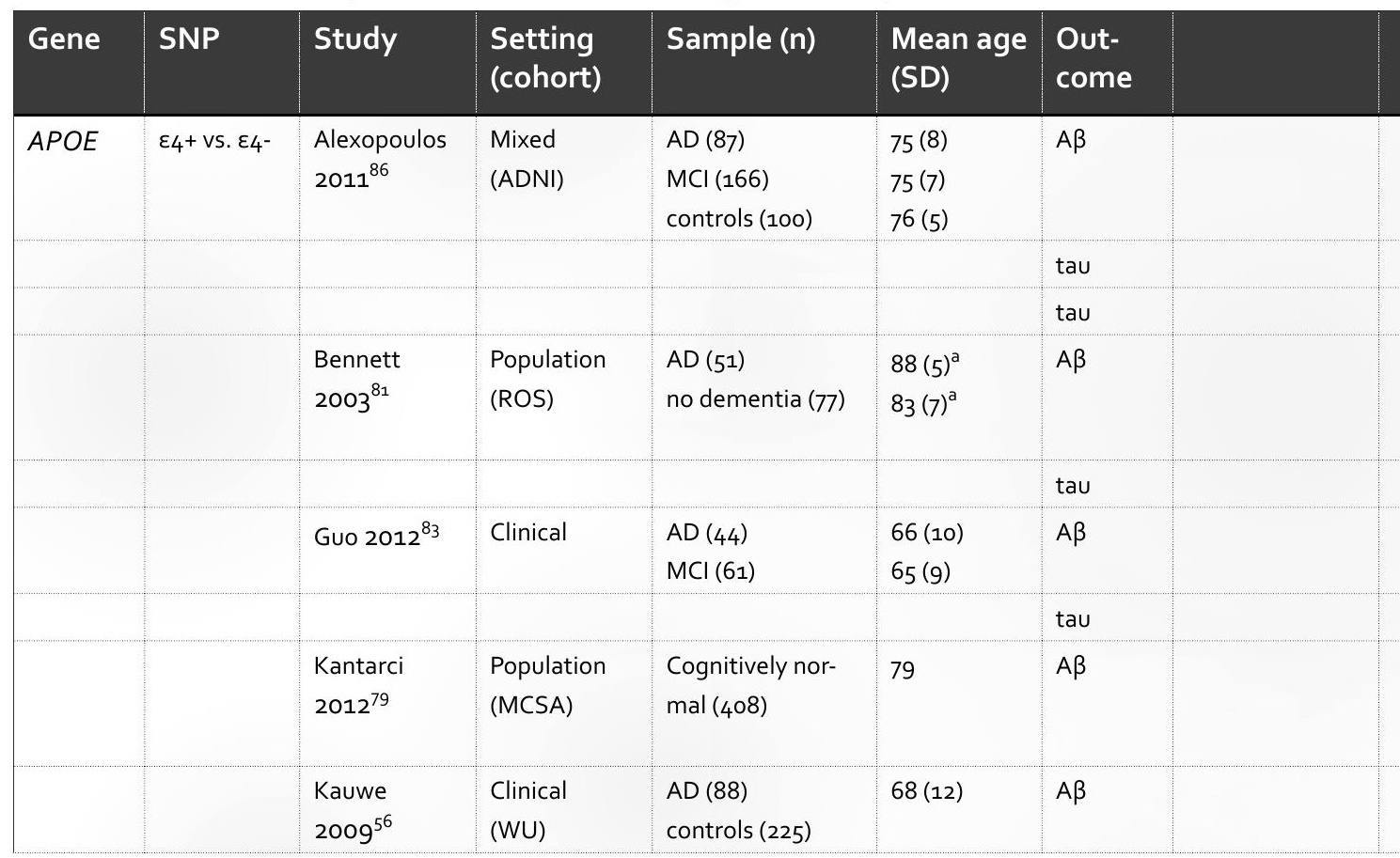




\section{PICALM}

PICALM is involved in clathrin-mediated endocytosis. It has been suggested to modify APP or its proteases by altering the trafficking of vesicle-associated membrane protein (VAMP), which in turn results in the increased production of $A \beta .9^{\circ}$ Moreover, PICALM has been reported to influence $A \beta$ neurotoxicity by regulating endocytosis. ${ }^{91}$

Data were available for four independent studies testing eight biomarker associations in three SNPs. $78,82,84,87$ PICALM SNPs correlated with CSF $A \beta_{1-42}^{84}$ or aggregated $A \beta$ on neuropathological examination ${ }^{82,}$ ${ }^{87}$ in all studies. It did not correlate with CSF tau or tangles on neuropathological examination. ${ }^{82,87}$ The combination of abnormal $A \beta_{1-42}$ and $\mathrm{p}$-tau in CSF was linked with r\$541458 but not with rs3851179. ${ }^{78} \mathrm{~A}$ neuropathological study found a correlation between AD pathology load of plaques and tangles with rs7110631, which was used in that study as a surrogate marker for rs3851179. ${ }^{87}$

\begin{tabular}{|c|c|c|c|c|c|}
\hline \multirow{2}{*}{$\begin{array}{l}\text { Marker } \\
\text { (modality) }\end{array}$} & \multicolumn{4}{|l|}{ Result } & \multirow[t]{2}{*}{ Comment } \\
\hline & AD & $\mathrm{MCl}$ & Controls & Combined & \\
\hline$A \beta_{1-42}(C S F)$ & $P<0.001$ & $P<0.001$ & $P<0.001$ & --- & \\
\hline p-tau (CSF) & ns & $P<0.01$ & $P<0.01$ & --- & \\
\hline t-tau (CSF) & ns & $P=0.02$ & $P=0.02$ & --- & \\
\hline$N P(P A)$ & --- & --- & --- & $\begin{array}{l}\text { odds }=2.69 \\
(1.01-7.13)\end{array}$ & $\begin{array}{l}\text { Adjusted for } \\
\text { age, gender } \\
\text { and education }\end{array}$ \\
\hline $\mathrm{NFT}(\mathrm{PA})$ & --- & --- & --- & odds $=2.41(0.92-6.33)$ & \\
\hline $\mathrm{A} \beta_{1-42}(\mathrm{CSF})$ & ns & $P<0.001$ & --- & --- & \\
\hline tau (CSF) & ns & ns & --- & --- & \\
\hline $\begin{array}{l}A \beta_{1-4^{2}} \text { (average } \\
\text { binding to } A \beta \\
\text { deposition) }\end{array}$ & --- & --- & $P<0.001$ & --- & \\
\hline $\begin{array}{l}\mathrm{A} \beta_{1-42} / \mathrm{A} \beta_{1-40} \\
(\mathrm{CSF})\end{array}$ & --- & --- & --- & $P<0.0001$ & \\
\hline
\end{tabular}


Table 2 Qualitative summary of biomarker studies assessing AlzGene 'top results' loci Continued

\begin{tabular}{|c|c|c|c|c|c|c|}
\hline Gene & SNP & Study & $\begin{array}{l}\text { Setting } \\
\text { (cohort) }\end{array}$ & Sample (n) & $\begin{array}{l}\text { Mean age } \\
\text { (SD) }\end{array}$ & $\begin{array}{l}\text { Out- } \\
\text { come }\end{array}$ \\
\hline & & & & & & $A \beta$ \\
\hline & & $\begin{array}{l}\text { Kauwe } \\
2010^{85}\end{array}$ & $\begin{array}{l}\text { Clinical } \\
(\mathrm{WU}) \\
\text { Mixed (ADNI) }\end{array}$ & $\begin{array}{l}A D(97) \\
\text { controls (248) } \\
A D(154) \\
\text { controls (103) }\end{array}$ & $\begin{array}{l}74(8) \\
66(11) \\
75(8) \\
77(5)\end{array}$ & $A \beta$ \\
\hline & & & & & & tau \\
\hline & & Kok $2011^{82}$ & $\begin{array}{l}\text { Mixed } \\
\text { (TASTY) }\end{array}$ & $\begin{array}{l}A D \text {, other demen- } \\
\text { tia, brain donors } \\
(484-530)\end{array}$ & $63^{b}$ & $A \beta$ \\
\hline & & & & & & tau \\
\hline & & $\begin{array}{l}\text { Schott } \\
2011^{78}\end{array}$ & Mixed (ADNI) & $\begin{array}{l}\mathrm{AD}(88) \\
\mathrm{MCl}(163) \\
\text { controls (75) }\end{array}$ & 75 (1) & $\begin{array}{l}A D \\
\text { profile }\end{array}$ \\
\hline & & Wider $2012^{80}$ & $\begin{array}{l}\text { Mixed } \\
\text { (MCJ brain } \\
\text { bank) }\end{array}$ & $\begin{array}{l}A D(517) \\
\text { other dementia } \\
(114) \text { mixed (131) }\end{array}$ & $81^{\mathrm{e}}$ & $A \beta$ \\
\hline & & & & & & tau \\
\hline & $\varepsilon_{4}$ vs. $\varepsilon_{3}$ & $\begin{array}{l}\text { Schjeide } \\
2011^{84}\end{array}$ & Mixed & $\begin{array}{l}\text { AD (200) } \\
\text { controls (169) } \\
\text { combined (395) }\end{array}$ & --- & $A \beta$ \\
\hline & & & & $\begin{array}{l}\text { AD (199) } \\
\text { controls (170) }\end{array}$ & & tau \\
\hline & & $\begin{array}{l}\text { Kramer } \\
2011^{77}\end{array}$ & Population & controls (299) & $85(7)$ & tau \\
\hline & & $\begin{array}{l}\text { Schott } \\
2011^{78}\end{array}$ & $\begin{array}{l}\text { Mixed } \\
(\mathrm{ADNI})\end{array}$ & $\begin{array}{l}\mathrm{AD}(88) \\
\mathrm{MCl}(163) \\
\text { controls (75) }\end{array}$ & $75(1)$ & $\begin{array}{l}A D \\
\text { profile }\end{array}$ \\
\hline$B / N_{1}$ & rs744373 & $\begin{array}{l}\text { Schott } \\
2011^{78}\end{array}$ & Mixed (ADNI) & $\begin{array}{l}\mathrm{AD}(88) \\
\mathrm{MCl}(163) \text { controls } \\
(75)\end{array}$ & $75(1)$ & $\begin{array}{l}A D \\
\text { profile }\end{array}$ \\
\hline CLU & rs111360oo & $\begin{array}{l}\text { Chibnik } \\
2011^{87}\end{array}$ & $\begin{array}{l}\text { Population } \\
\text { (ROS, MAP) }\end{array}$ & $\begin{array}{l}\text { No dementia } \\
\text { (553) }\end{array}$ & $88(6)^{a}$ & $A \beta$ \\
\hline
\end{tabular}




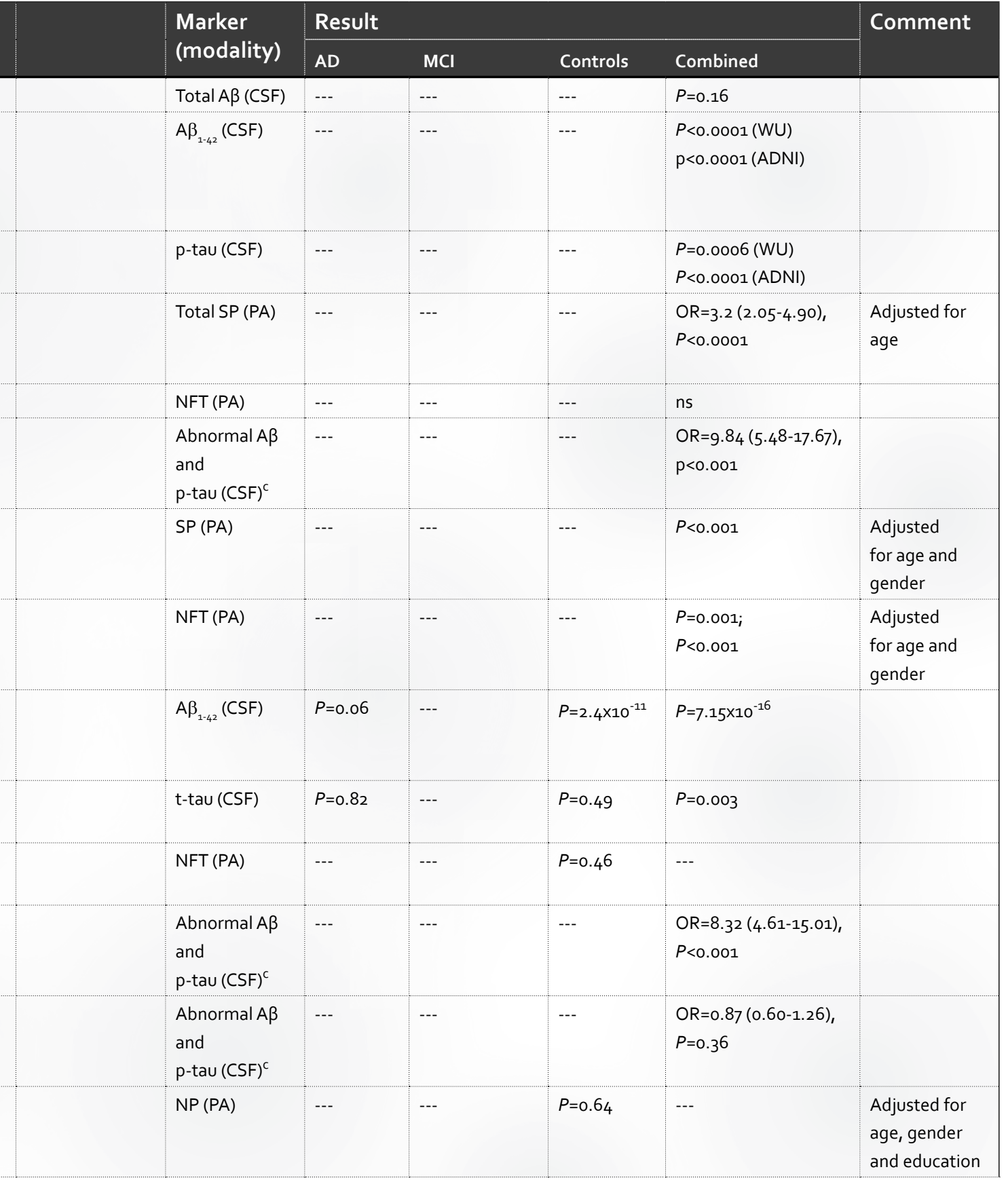


Table 2 Qualitative summary of biomarker studies assessing AlzGene 'top results' loci Continued

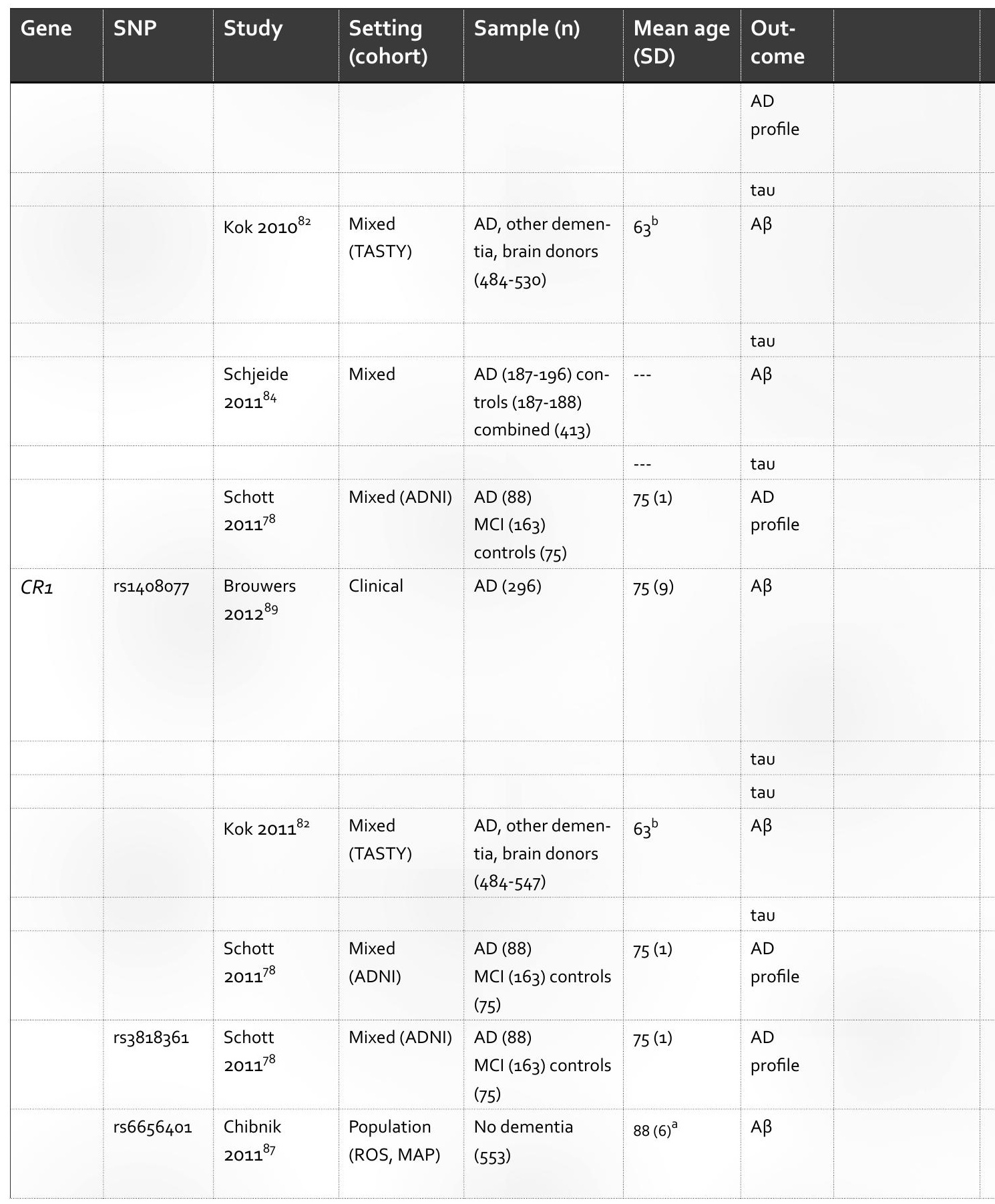




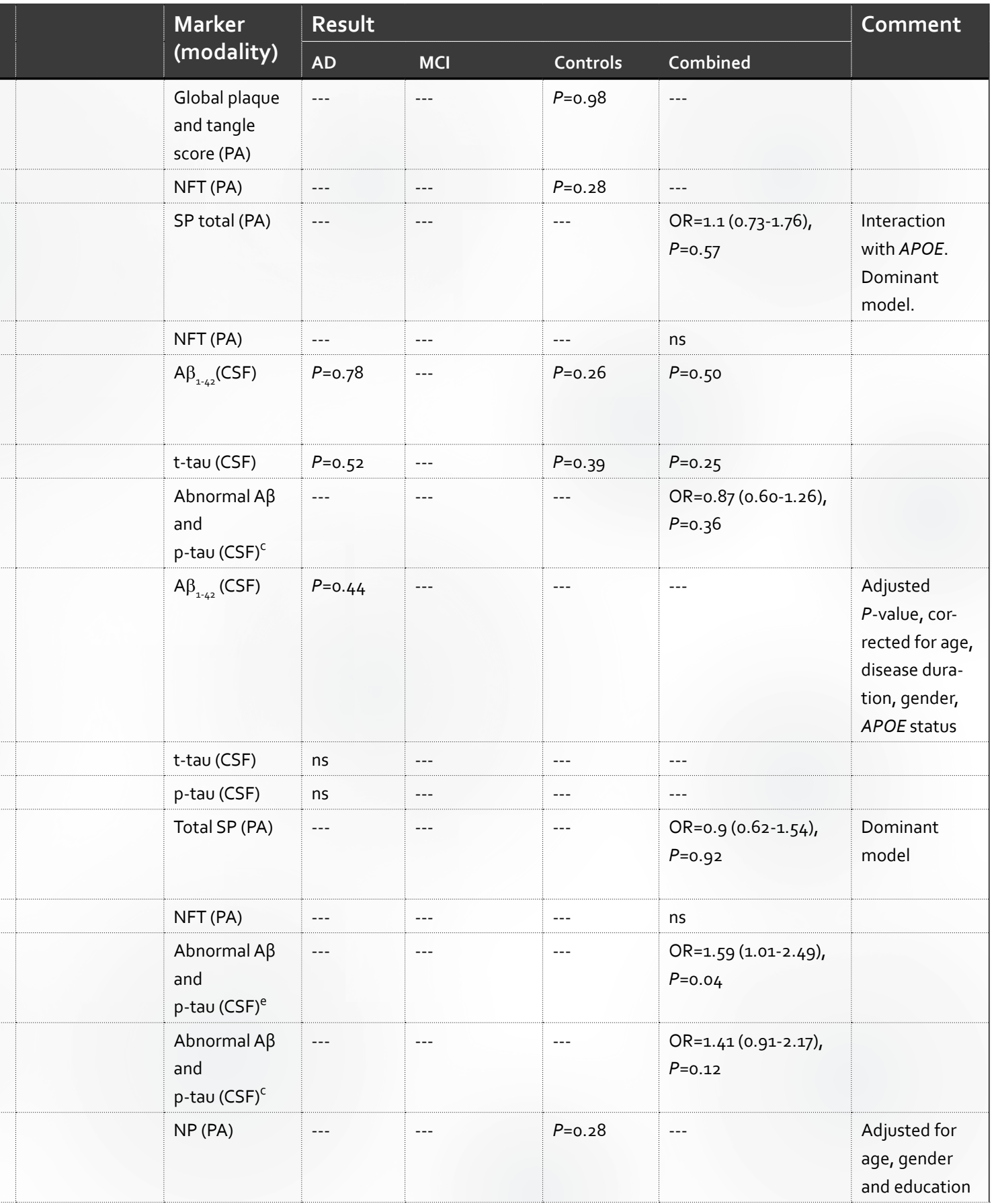


Table 2 Qualitative summary of biomarker studies assessing AlzGene 'top results' loci Continued

\begin{tabular}{|c|c|c|c|c|c|c|c|}
\hline Gene & SNP & Study & $\begin{array}{l}\text { Setting } \\
\text { (cohort) }\end{array}$ & Sample (n) & $\begin{array}{l}\text { Mean age } \\
\text { (SD) }\end{array}$ & $\begin{array}{l}\text { Out- } \\
\text { come }\end{array}$ & \\
\hline & & & & & & $\begin{array}{l}A D \\
\text { profile }\end{array}$ & \\
\hline & & & & & & tau & \\
\hline & & $\begin{array}{l}\text { Schjeide } \\
2011^{84}\end{array}$ & Mixed & $\begin{array}{l}\text { AD (200-202) con- } \\
\text { trols (187-188) } \\
\text { combined }(416)\end{array}$ & --- & $A \beta$ & \\
\hline & & & & & & tau & \\
\hline \multirow[t]{9}{*}{ PICALM } & rs3851179 & Kok $2010^{82}$ & $\begin{array}{l}\text { Mixed } \\
\text { (TASTY) }\end{array}$ & $\begin{array}{l}A D \text {, other demen- } \\
\text { tia, brain donors } \\
(484-546)\end{array}$ & $63^{b}$ & $A \beta$ & \\
\hline & & & & & & tau & \\
\hline & & $\begin{array}{l}\text { Schott } \\
2011^{78}\end{array}$ & Mixed (ADNI) & $\begin{array}{l}\mathrm{AD}(88) \\
\mathrm{MCl}(163) \text { controls } \\
(75)\end{array}$ & $75(1)$ & $\begin{array}{l}A D \\
\text { profile }\end{array}$ & \\
\hline & rs541458 & $\begin{array}{l}\text { Schjeide } \\
2011^{84}\end{array}$ & Mixed & $\begin{array}{l}\text { AD (195-196) con- } \\
\text { trols (191-19o) } \\
\text { combined (412- } \\
413)\end{array}$ & --- & $A \beta$ & \\
\hline & & & & & & tau & \\
\hline & & $\begin{array}{l}\text { Schott } \\
2011^{78}\end{array}$ & Mixed (ADNI) & $\begin{array}{l}\mathrm{AD}(88) \\
\mathrm{MCl}(163) \text { controls } \\
(75)\end{array}$ & $75(1)$ & $\begin{array}{l}A D \\
\text { profile }\end{array}$ & \\
\hline & rs7110631 & $\begin{array}{l}\text { Chibnik } \\
2011^{87}\end{array}$ & $\begin{array}{l}\text { Population } \\
\text { (ROS, MAP) }\end{array}$ & $\begin{array}{l}\text { No dementia } \\
\text { (553) }\end{array}$ & $88(6)^{a}$ & $A \beta$ & \\
\hline & & & & & & $A \beta$ & \\
\hline & & & & & & tau & \\
\hline
\end{tabular}

Abbreviations: $\mathrm{SNP}=$ single nucleotide polymorphism; $\mathrm{SD}=$ standard deviation; $\mathrm{AD}=\mathrm{Alzheimer}$ 's disease; $\mathrm{MCl}=$ mild cognitive impairment; $C S F=$ cerebrospinal fluid; $A \beta=$ amyloid beta; $t$-tau=total tau; p-tau=phosphorylated tau; $\mathrm{SP}=$ senile plaques; $\mathrm{NP}=$ neuritic plaques; $\mathrm{DP}=$ diffuse plaques; $\mathrm{NFT}=$ neurofibrillary tangles; $\mathrm{PA}=$ pathology; $\mathrm{p}=\mathrm{p}$-value; $\mathrm{OR}(\mathrm{)}=$ odds ratio ( $95 \%$ confidence interval); ns=not significant; PiB-PET=11C-Pittsburgh Compound-B-Positron Emission Tomography; TASTY=Tampere Autopsy Study; ADNI=Alzheimer's Disease Neuroimaging Initiative; ROS=Religious Order Study; MCSA=Mayo Clinic Study of Aging; MAP=Rush Memory Aging Project; WU=Washington University cohort; $\mathrm{MCJ}=$ Mayo Clinic Jacksonville brain bank for neurodegenerative disorders 


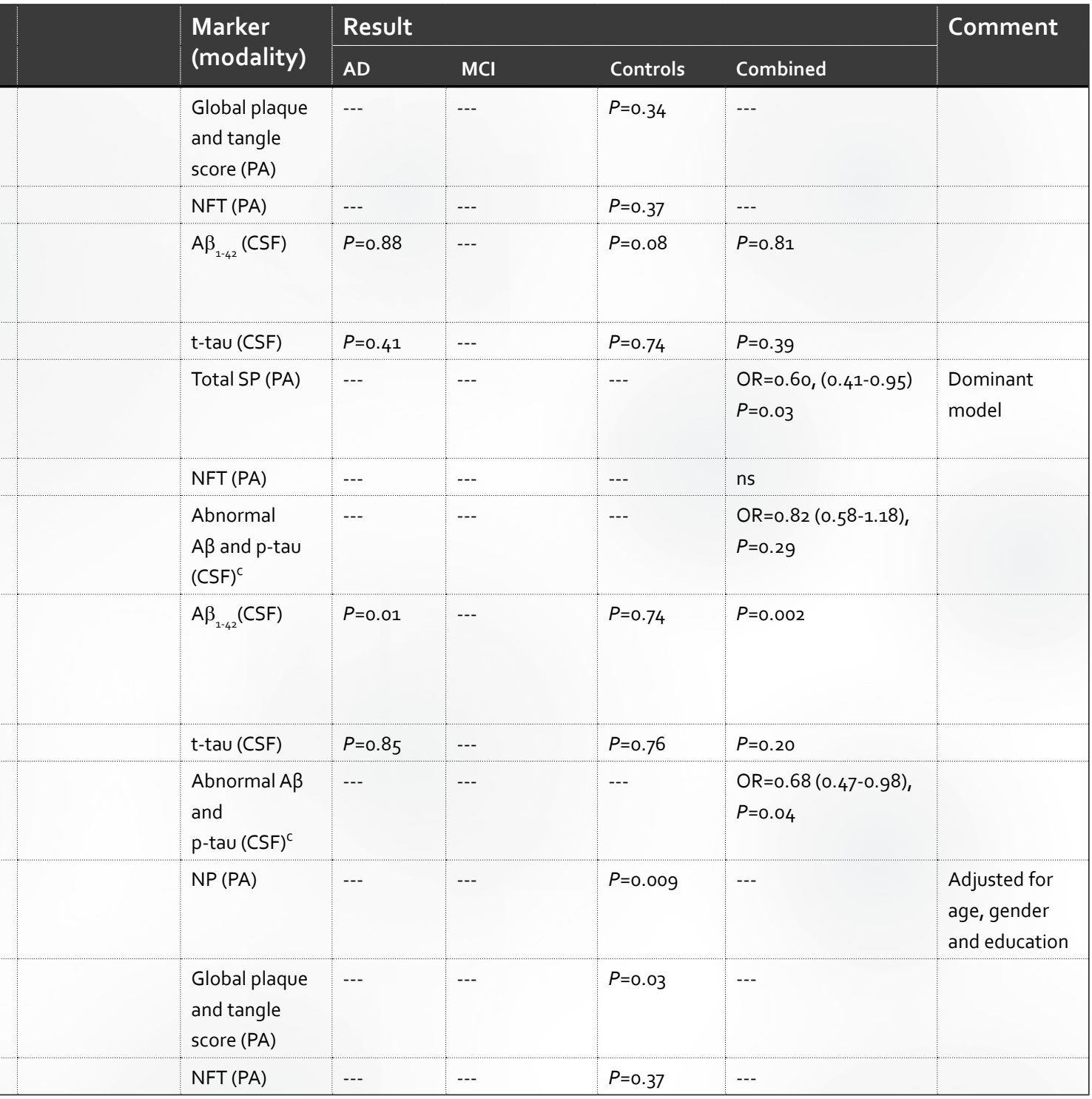

a Mean age at death.

${ }^{b}$ Based on $\mathrm{N}=603$.

c Subjects classified as CSF+ (that is, low $A \beta_{1-42}$ and high p-tau) or CSF- (that is, high $A \beta_{1-42}$ and low p-tau).

d Mixed population for this study consisted of subjects with Parkinson's disease $(n=50)$; non-Parkinson movement disorders $(n=20)$; and cognitively normal, mild cognitive impairment and psychiatric disorders ( $n=61)$.

e Median age at death. 


\section{Biomarkers and SNPs in other candidate genes}

$A C E$

Only one case-control study investigated the relation between $A C E$ and CSF A $\beta_{1-42 / 1-40}$ ratio. $5^{6}$ In a combined population, only rs1800764 showed a marginal effect on $A \beta_{1-42} / A \beta_{1-40}(P=0.01)$. Rs4291 and rs4242 were not linked with CSFA

\section{SORL1}

SORL1 was the best-studied candidate gene in relation to biomarkers with data from four independent studies, all performed with CSF samples. Of the top seven SORL1 SNPs previously reported to be linked with $A D,{ }^{34}$ data on the correlation with CSF markers were available for rs661057 (SNP4), rs668387 (SNP8), rs689021 (SNP9), rs641120 (SNP10) and rs2070045 (SNP19) but not for rs11218304 (SNP5) and rs12285364 (SNP19).

One study reported a link between $\mathrm{SNP}_{4}$ and tau concentrations in subjects with $A D(P=0.03)^{83}$ (Table 3$)$. In another study, SNP8 correlated with $A \beta_{1-42}$ in subjects with $A D(P=0.04) .{ }^{86}$ This study found SNP8, SNP9 and SNP10 to interact with $A P O E-\varepsilon 4$, which affected $A \beta_{1-42}$ concentrations. Given the small sample sizes and large number of comparisons performed in these studies, these results may represent false positive findings.

$\mathrm{SNP}_{4}$ was not linked with tau among subjects with $\mathrm{MCl}_{\text {. SNP4 }}$, SNP8, SNP9, SNP10 and SNP19 did not correlate with any other CSF markers in controls and among subjects with $A D$. One study reported increased SORL1 levels for subjects with $\mathrm{MCl}$ who were homozygous minor allele carriers of SNP8 (TT), SNP9 (AA) and SNP10 (CC) (all $P=0.04) .{ }^{83}$ In summary, except in one study, ${ }^{83}$ it appears that SORL1 markers do not correlate with CSF A $\beta$ and tau.

\section{MAPT}

Data were available for three independent studies testing seven biomarker associations in two SNPs. ${ }^{56,57,80}$ MAPT H1/H2 rs1052553 correlated with NFT ( $P=0.03)$ on neuropathologcial examination and was marginally linked with $A \beta$ in senile plaques in a mixed population study. ${ }^{80}$ The other MAPT variants (rs2471738, rs7210728, and rs242557) were not related to biomarkers in CSF nor to neuropathology in the other studies. 


\section{$\mathrm{TOMM}_{40}$}

Data were available for four CSF studies from two independent cohorts (including three studies based on ADNI data) testing eight biomarker associations in three SNPs. ${ }^{56,75,76,78}$ TOMM4O rs157580 and rs2075650 correlated with CSF $A \beta_{1-42}$ or the ratio of $A \beta$ and tau or $p$-tau in four biomarker GWAS analyses based on ADNI data. ${ }^{75,76,78}$ These GWAS studies did not find an association with CSF tau. Rs207560 further had significant effects on the combination of abnormal CSF $A \beta_{1-42}$ and $p$-tau in ADNI data, which the study reported as likely to be driven by $A \beta_{1-42}$ given that rs207560 correlated with $A \beta$ but no with tau. Rs157581 was not associated with the CSF A $\beta_{1-42} I_{1-40}$ ratio in a cohort from Washington University. ${ }^{56}$ These results generally reflect those reported for $A P O E$, which is expected given the physical proximity ( 2,000 base pairs) and degree of linkage disequilibrium between the APOE and TOMM4O loci.

\section{GWAS biomarkers}

Three GWAS have been performed that used CSF markers or neuropathological markers as outcome.

One study in the ADNI cohort with CSF markers as outcome found that CSF $A \beta_{1-42}$ in controls was related with $A R L B 5 B$ rs11015839, CYP19A1 rs2899472 and NCAM2 rs1022442.75 CSF t-tau was associated with $\mathrm{CDH}_{4} \mathrm{rs}_{4925189}$ in subjects with $A D$, and with polymorphisms at FLJ21511 (rs2768975 and rs6850199) in subjects with MCI. CSF p-tau correlated with different genetic variants in subjects with $A D$ (UNC ${ }_{5} C$ rs12643654), subjects with $\mathrm{MCl}$ (CHN2 rs121724 and MTUS1 rs7842088), and controls (UPP2 rs2074955).

Another GWAS using CSF data from the ADNI cohort combined controls and subjects with $A D$ and $\mathrm{MCl}$ and found that genetic variants in EPC2 correlated with CSF t-tau (rS10171238, rs1374441, rs2121433 and rs4499362) and the t-tau/A $\beta_{1-42}$ ratio (rs10171238 and rs4499362)..$^{76}$

Both GWAS with ADNI data used APOE status as covariate. It is noteworthy that although their sample size was comparable ( $N=390$ vs. $\mathrm{N}=377$ ) and the same genetic data were studied, the outcomes were highly divergent. 
Table 3 Qualitative summary of biomarker studies assessing SNPs in other AD candidate genes

\begin{tabular}{|c|c|c|c|c|c|c|}
\hline Gene & SNP & Study & $\begin{array}{l}\text { Setting } \\
\text { (cohort) }\end{array}$ & Subjects (n) & $\begin{array}{l}\text { Mean } \\
\text { age (SD) }\end{array}$ & $\begin{array}{l}\text { Out- } \\
\text { come }\end{array}$ \\
\hline \multirow[t]{3}{*}{$A C E$} & rs1800764 & Kauwe $2009^{56}$ & $\begin{array}{l}\text { Clinical } \\
\text { (WU) }\end{array}$ & $\begin{array}{l}A D(88) \text { controls } \\
(225)\end{array}$ & $68(12)$ & $A \beta$ \\
\hline & rs4291 & Kauwe $2009^{56}$ & $\begin{array}{l}\text { Clinical } \\
(\mathrm{WU})\end{array}$ & $\begin{array}{l}\text { AD (88) controls } \\
(225)\end{array}$ & $68(12)$ & $A \beta$ \\
\hline & rs4343 & Kauwe $2009^{56}$ & $\begin{array}{l}\text { Clinical } \\
(W U)\end{array}$ & $\begin{array}{l}\text { AD (88) } \\
\text { controls (225) }\end{array}$ & $68(12)$ & $A \beta$ \\
\hline \multirow[t]{12}{*}{ SORL1 } & $\begin{array}{l}\text { rs661057 } \\
\left(S_{N P 4}\right)\end{array}$ & $\begin{array}{l}\text { Alexopoulos } \\
2011^{86}\end{array}$ & $\begin{array}{l}\text { Mixed } \\
(\mathrm{ADNI})\end{array}$ & $\begin{array}{l}\mathrm{AD}(87) \\
\mathrm{MCl}(166) \\
\text { controls (100) }\end{array}$ & $\begin{array}{l}76(5) \\
75(7) \\
75(8)\end{array}$ & $A \beta$ \\
\hline & & & & & & tau \\
\hline & & & & & & tau \\
\hline & & Guo $2012^{83}$ & Clinical & $\begin{array}{l}\mathrm{AD}(44) \\
\mathrm{MCl}(61)\end{array}$ & $\begin{array}{l}66(10) \\
65(9)\end{array}$ & $A \beta$ \\
\hline & & & & & & tau \\
\hline & & Kauwe $2010^{85}$ & $\begin{array}{l}\text { Clinical, } \\
\text { mixed } \\
(\mathrm{WU}, \mathrm{ADNI})\end{array}$ & $\begin{array}{l}\mathrm{AD}(251) \\
\text { controls (351) }\end{array}$ & $\begin{array}{l}75(8) \\
69(9)\end{array}$ & $A \beta$ \\
\hline & $\begin{array}{l}\text { rs668387 } \\
\text { (SNP8) }\end{array}$ & $\begin{array}{l}\text { Alexopoulos } \\
2011^{86}\end{array}$ & $\begin{array}{l}\text { Mixed } \\
(\mathrm{ADNI})\end{array}$ & $\begin{array}{l}\mathrm{AD}(87) \\
\mathrm{MCl}(166) \\
\text { controls (100) }\end{array}$ & $\begin{array}{l}76(5) \\
75(7) \\
75(8)\end{array}$ & $A \beta$ \\
\hline & & & & & & tau \\
\hline & & & & & & tau \\
\hline & & Guo $2012^{83}$ & Clinical & $\begin{array}{l}\mathrm{AD}(44) \\
\mathrm{MCl}(61)\end{array}$ & $\begin{array}{l}66(10) \\
65(9)\end{array}$ & $A \beta$ \\
\hline & & & & & & tau \\
\hline & & Kauwe $2010^{85}$ & $\begin{array}{l}\text { Clinical, } \\
\text { mixed } \\
(\mathrm{WU}, \mathrm{ADNI})\end{array}$ & $\begin{array}{l}\text { AD (251) } \\
\text { controls (351) }\end{array}$ & $\begin{array}{l}75(8) \\
69(9)\end{array}$ & $A \beta$ \\
\hline
\end{tabular}


Table 3 Qualitative summary of biomarker studies assessing SNPs in other AD candidate genes Continued

\begin{tabular}{|c|c|c|c|c|c|c|}
\hline \multirow[t]{19}{*}{ Gene } & SNP & Study & $\begin{array}{l}\text { Setting } \\
\text { (cohort) }\end{array}$ & Subjects (n) & $\begin{array}{l}\text { Mean } \\
\text { age (SD) }\end{array}$ & $\begin{array}{l}\text { Out- } \\
\text { come }\end{array}$ \\
\hline & $\begin{array}{l}\text { rs689o21 } \\
\text { (SNP9) }\end{array}$ & $\begin{array}{l}\text { Alexopoulos } \\
2011^{86}\end{array}$ & $\begin{array}{l}\text { Mixed } \\
(\mathrm{ADNI})\end{array}$ & $\begin{array}{l}\mathrm{AD}(87) \\
\mathrm{MCl}(166) \\
\text { controls (100) }\end{array}$ & $\begin{array}{l}76(5) \\
75(7) \\
75(8)\end{array}$ & $A \beta$ \\
\hline & & & & & & tau \\
\hline & & & & & & tau \\
\hline & & Guo $2012^{83}$ & Clinical & $\begin{array}{l}\mathrm{AD}(44) \\
\mathrm{MCl}(61)\end{array}$ & $\begin{array}{l}66(10) \\
65(9)\end{array}$ & $A \beta$ \\
\hline & & & & & & tau \\
\hline & & Kauwe $2010^{85}$ & $\begin{array}{l}\text { Clinical, } \\
\text { mixed } \\
(\mathrm{WU}, \mathrm{ADNI})\end{array}$ & $\begin{array}{l}\text { AD (251) } \\
\text { controls (351) }\end{array}$ & $\begin{array}{l}75(8) \\
69(9)\end{array}$ & $A \beta$ \\
\hline & $\begin{array}{l}\text { rs641120 } \\
\left(S_{N P 10}\right)\end{array}$ & $\begin{array}{l}\text { Alexopoulos } \\
2011^{86}\end{array}$ & $\begin{array}{l}\text { Mixed } \\
(\mathrm{ADNI})\end{array}$ & $\begin{array}{l}\mathrm{AD}(87) \\
\mathrm{MCl}(166) \\
\text { controls (100) }\end{array}$ & $\begin{array}{l}76(5) \\
75(7) \\
75(8)\end{array}$ & $A \beta$ \\
\hline & & & & & & tau \\
\hline & & & & & & tau \\
\hline & & Guo $2012^{83}$ & Clinical & $\begin{array}{l}A D(44), \\
M C I(61)\end{array}$ & $\begin{array}{l}66(10) \\
65(9)\end{array}$ & $A \beta$ \\
\hline & & & & & & tau \\
\hline & $\begin{array}{l}\text { rs2070045 } \\
\text { (SNP19) }\end{array}$ & $\begin{array}{l}\text { Alexopoulos } \\
2011^{86}\end{array}$ & $\begin{array}{l}\text { Mixed } \\
(\mathrm{ADNI})\end{array}$ & $\begin{array}{l}\mathrm{AD}(87) \\
\mathrm{MCl}(166) \\
\text { controls (100) }\end{array}$ & $\begin{array}{l}76(5) \\
75(7) \\
75(8)\end{array}$ & $A \beta$ \\
\hline & & & & & & tau \\
\hline & & & & & & tau \\
\hline & & Guo $2012^{83}$ & Clinical & $\begin{array}{l}\mathrm{AD}(44) \\
\mathrm{MCl}(61)\end{array}$ & $\begin{array}{l}66(10) \\
65(9)\end{array}$ & $A \beta$ \\
\hline & & & & & & tau \\
\hline & & Kauwe $2010^{85}$ & $\begin{array}{l}\text { Clinical, } \\
\text { mixed } \\
(\mathrm{WU}, \mathrm{ADNI})\end{array}$ & $\begin{array}{l}\text { AD (251) } \\
\text { controls (351) }\end{array}$ & $\begin{array}{l}75(8) \\
69(9)\end{array}$ & $A \beta$ \\
\hline & & Kolsch $2008^{99}$ & $\begin{array}{l}\text { Clinical } \\
\text { (DCN) }\end{array}$ & $A D(153)$ & $71(8)$ & $A \beta$ \\
\hline MAPT & rs2471738 & Kauwe $2009^{56}$ & $\begin{array}{l}\text { Clinical } \\
\text { (WU) }\end{array}$ & $\begin{array}{l}A D(88) \text { controls } \\
(225)\end{array}$ & $68(12)$ & $A \beta$ \\
\hline
\end{tabular}




\begin{tabular}{|c|c|c|c|c|c|}
\hline \multirow{2}{*}{$\begin{array}{l}\text { Marker } \\
\text { (modality) }\end{array}$} & \multicolumn{4}{|c|}{$P$-value } & \multirow{2}{*}{ Comment } \\
\hline & AD & $\mathrm{MCl}$ & Control & Combined & \\
\hline$A \beta_{1-42}(C S F)$ & $n s^{c}$ & $n s^{c}$ & $n s^{c}$ & & $\begin{array}{l}\text { SNP interacted with } \\
A P O E-\varepsilon_{4}(P=0.04)\end{array}$ \\
\hline t-tau (CSF) & ns & ns & ns & --- & \\
\hline p-tau (CSF) & ns & ns & ns & --- & \\
\hline$A \beta_{1-42}(C S F)$ & ns & ns & -- & --- & \\
\hline $\operatorname{tau}(\mathrm{CSF})$ & ns & ns & -- & --- & \\
\hline$A \beta_{1-42}(C S F)$ & --- & -- & --- & $P=0.34^{a}$ & $\begin{array}{l}\text { Adjusted for age, } \\
A P O E-\varepsilon 4 \text { status and } \\
\text { CDR }\end{array}$ \\
\hline $\mathrm{A} \beta_{1-42}(\mathrm{CSF})$ & $n s^{b}$ & $\mathrm{~ns}^{\mathrm{b}}$ & $n s^{b}$ & --- & $\begin{array}{l}\text { SNP interacted with } \\
A P O E-\varepsilon 4(P<0.001) .\end{array}$ \\
\hline t-tau (CSF) & ns & ns & ns & -- & \\
\hline p-tau (CSF) & ns & ns & ns & --- & \\
\hline$A \beta_{1-42}(C S F)$ & ns & ns & -- & -- & \\
\hline $\operatorname{tau}(\mathrm{CSF})$ & ns & ns & -- & --- & \\
\hline$A \beta_{1-42}(C S F)$ & $n s^{b}$ & $\mathrm{~ns}^{\mathrm{b}}$ & $n s^{b}$ & --- & \\
\hline t-tau (CSF) & ns & ns & ns & --- & \\
\hline p-tau (CSF) & ns & ns & ns & --- & \\
\hline$A \beta_{1-4^{2}}(C S F)$ & ns & ns & -- & --- & \\
\hline tau (CSF) & ns & ns & -- & --- & \\
\hline$A \beta_{1-42}(C S F)$ & --- & --- & --- & $P=0.29^{a}$ & $\begin{array}{l}\text { Adjusted for age, } \\
A P O E-\varepsilon 4 \text { status and } \\
\text { CDR }\end{array}$ \\
\hline$A \beta_{1-42}(C S F)$ & $P=0.11$ & --- & --- & --- & $\begin{array}{l}\text { Adjusted for } A P O E- \\
\text { e4status and MMSE }\end{array}$ \\
\hline $\begin{array}{l}\text { Total A } \beta \\
\text { (CSF) }\end{array}$ & --- & --- & --- & $P=0.65^{a}$ & $\begin{array}{l}\text { Adjusted for } A P O E-\varepsilon 4 \\
\text { status and CDR }\end{array}$ \\
\hline
\end{tabular}


Table 3 Qualitative summary of biomarker studies assessing SNPs in other AD candidate genes Continued

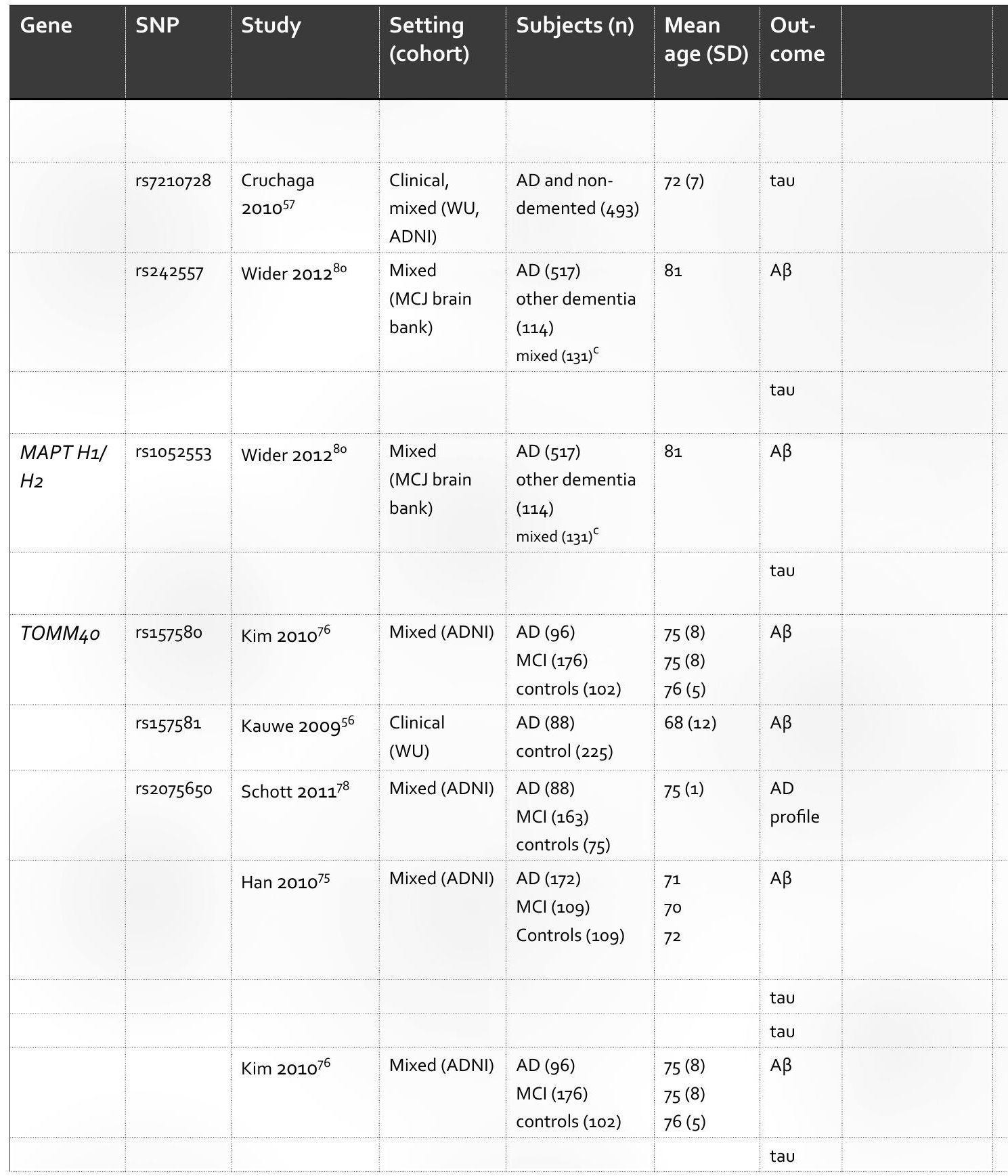


Table 3 Qualitative summary of biomarker studies assessing SNPs in other AD candidate genes Continued

\begin{tabular}{|l|l|l|l|l|l|l|l|}
\hline Gene & SNP & Study & $\begin{array}{l}\text { Setting } \\
\text { (cohort) }\end{array}$ & Subjects (n) & $\begin{array}{l}\text { Mean } \\
\text { age (SD) }\end{array}$ & $\begin{array}{l}\text { Out- } \\
\text { come }\end{array}$ & \\
\hline & & & & & $\begin{array}{l}\text { AD } \\
\text { profile }\end{array}$ \\
\hline
\end{tabular}

Abbreviations: SNP=single nucleotide polymorphism; SD=standard deviation; OR=odds ratio ( $95 \%$ confidence interval); $A D=A$ lzheimer's disease; $M C l=$ mild cognitive impairment; $A \beta=$ amyloid beta; t-tau=total tau; $\mathrm{p}$-tau=phosphorylated tau; $\mathrm{CSF}=$ cerebrospinal fluid; $\mathrm{PA}=$ neuropathology; $\mathrm{SP}=$ senile plaques; $N F T=$ neurofibrillary tangles; $C D R=$ clinical dementia rating; $n s=$ not significant; $W U=W a s h i n g t o n$ University; $A D N I=A l z h e i m e r ' s$ Disease neuroimaging Initiative; $D C N=G e r m a n$ Dementia Competence Network; GWAS=genome-wide association study

${ }^{a}$ Not adjusted for multiple testing.

${ }^{b}$ Not significant after applying Bonferroni or other correction for multiple testing.

c Mixed population for this study consisted of subjects with Parkinson's disease $(n=50)$; non-Parkinson movement disorders $(n=20)$; and cognitively normal, mild cognitive impairment and psychiatric disorders $(n=61)$.

${ }^{d}$ Subjects were classified as CSF+ (that is, low $A \beta_{1-42}$ and high p-tau) or CSF- (that is, high $A \beta_{1-42}$ and low p-tau).

Table 4 Qualitative summary of genome-wide association studies using biomarkers as outcome

\begin{tabular}{|c|c|c|c|c|c|}
\hline Study & Setting & Subjects (n) & $\begin{array}{l}\text { Mean age } \\
\text { (SD) }\end{array}$ & Modality & $\begin{array}{l}\text { Out- } \\
\text { come }\end{array}$ \\
\hline \multirow{10}{*}{$\begin{array}{l}\text { Han } \\
2010^{75 b}\end{array}$} & Mixed (ADNI) & $A D(172)$ & 71 & CSF & t-tau \\
\hline & & & & & p-tau \\
\hline & & $\mathrm{MCl}$ (109) & 70 & CSF & $p$-tau \\
\hline & & & & & t-tau \\
\hline & & & & & t-tau \\
\hline & & & & & p-tau \\
\hline & & Controls (109) & 72 & CSF & $A \beta_{1-42}$ \\
\hline & & & & & $A \beta_{1-42}$ \\
\hline & & & & & $A \beta_{1-42}$ \\
\hline & & & & & p-tau \\
\hline & & & & & \\
\hline
\end{tabular}




\begin{tabular}{|c|c|c|c|c|c|c|}
\hline & \multirow{2}{*}{$\begin{array}{l}\text { Marker } \\
\text { (modality) }\end{array}$} & \multicolumn{4}{|c|}{ P-value } & \multirow[t]{2}{*}{ Comment } \\
\hline & & AD & $\mathrm{MCl}$ & Control & Combined & \\
\hline & $p-\operatorname{tau} / A \beta_{1-42}(C S F)$ & --- & & & $P=1 \times 10^{-06}$ & $\begin{array}{l}\text { Effect likely driven by } \\
A \beta_{1-42}\end{array}$ \\
\hline
\end{tabular}

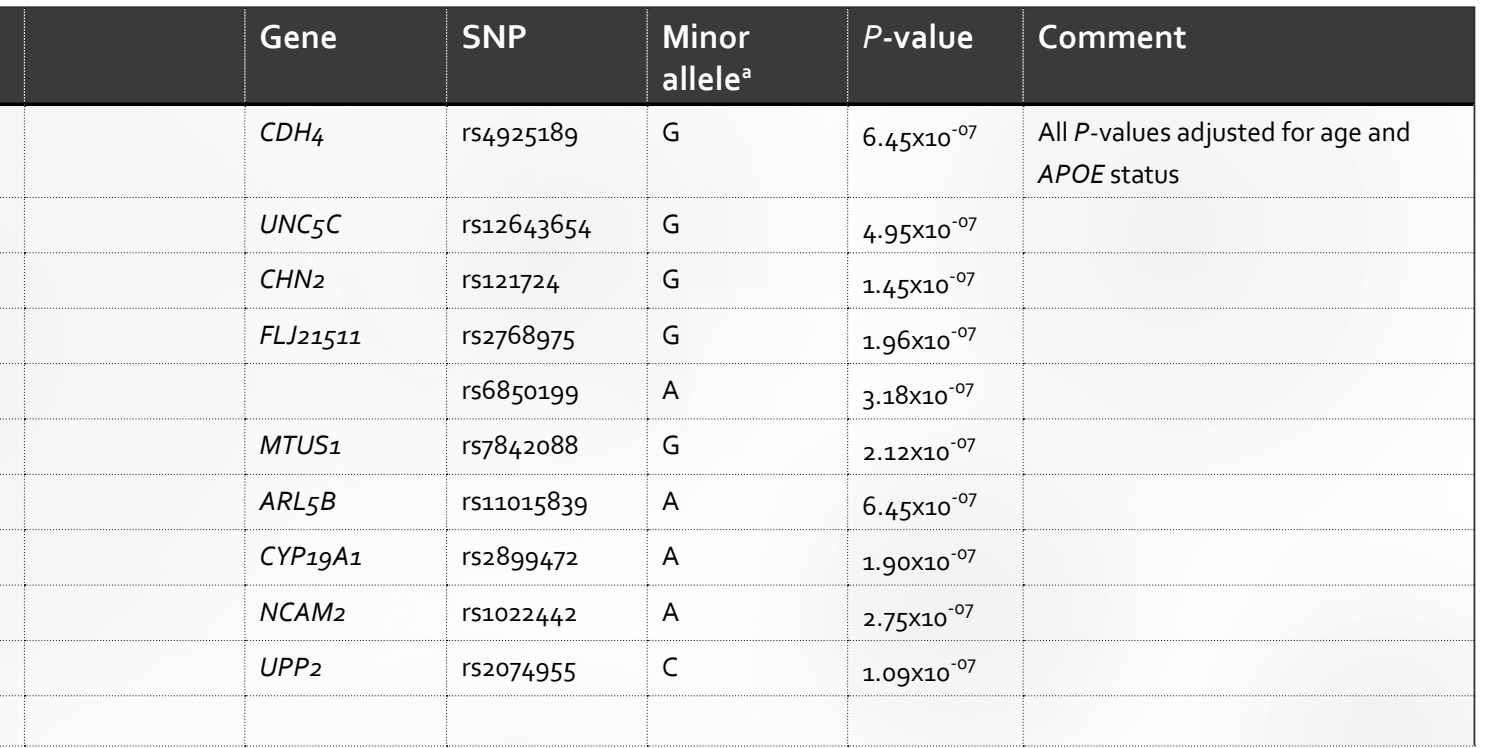


Table 4 Qualitative summary of genome-wide association studies using biomarkers as outcome Continued

\begin{tabular}{|c|c|c|c|c|c|}
\hline Study & Setting & Subjects (n) & $\begin{array}{l}\text { Mean age } \\
\text { (SD) }\end{array}$ & Modality & $\begin{array}{l}\text { Out- } \\
\text { come }\end{array}$ \\
\hline \multirow[t]{6}{*}{ Kim $2010^{76 c}$} & $\begin{array}{l}\text { Mixed } \\
(\mathrm{ADNI})\end{array}$ & $\begin{array}{l}\mathrm{AD}(96) \\
\mathrm{MCl}(176) \\
\text { controls (102) }\end{array}$ & $\begin{array}{l}75(8) \\
75(8) \\
76(5)\end{array}$ & CSF & $\mathrm{t}-\operatorname{tau} / \mathrm{A} \beta_{1-42}$ \\
\hline & & & & & t-tau \\
\hline & & & & & $\mathrm{t}-\mathrm{tau} / \mathrm{A} \beta_{1-42}$ \\
\hline & & & & & t-tau \\
\hline & & & & & t-tau \\
\hline & & & & & t-tau \\
\hline & & & & & \\
\hline $\begin{array}{l}\text { Kramer } \\
2011^{77 d}\end{array}$ & Population & controls (299) & $85(7)$ & PA & tau in NFT \\
\hline & & & & & \\
\hline & & & & & \\
\hline & & & & & \\
\hline & & & & & \\
\hline & & & & & \\
\hline & & & & & \\
\hline & & & & & \\
\hline & & & & & \\
\hline
\end{tabular}

Abbreviations: $\mathrm{SD}=$ standard deviation; $\mathrm{SNP}=$ single nucleotide polymorphism; $\mathrm{AD}=\mathrm{Alzheimer}$ 's disease; $\mathrm{MCl}=$ mild cognitive impairment; $\mathrm{ADNI}=$ Alzheimer's Disease Neuroimaging Initiative; $C S F=$ cerebrospinal fluid; $A \beta=$ amyloid beta; $t$-tau=total tau; $p$-tau=phosphorylated tau; $P A=$ pathology; $N F T=$ neurofibrillary tangles

a Obtained from the National Center for Biotechnology information (NCBI), when not specified in the study.

b The study also reported an association between SNPs in TOMM4O and CSF biomarkers (see Table 3) and an association between $A P O E-\varepsilon 4$ allele dose and CSF $A \beta_{1-4_{2}}$. The APOE- $\varepsilon_{4}$ allele dose was not associated with CSF t-tau and p-tau.

c The study also reported an association between SNPs in TOMM4O and CSF biomarkers (see Table 3) and an association between $A P O E$ rs429358 and CSF $A \beta_{1-42^{\prime}}$ p-tau and ratio of $A \beta /$ tau and $A \beta_{1-42} / t$-tau.

$\mathrm{d}$ The study also reported no association between $A P O E$ alleles and tangles (see Table 2). 


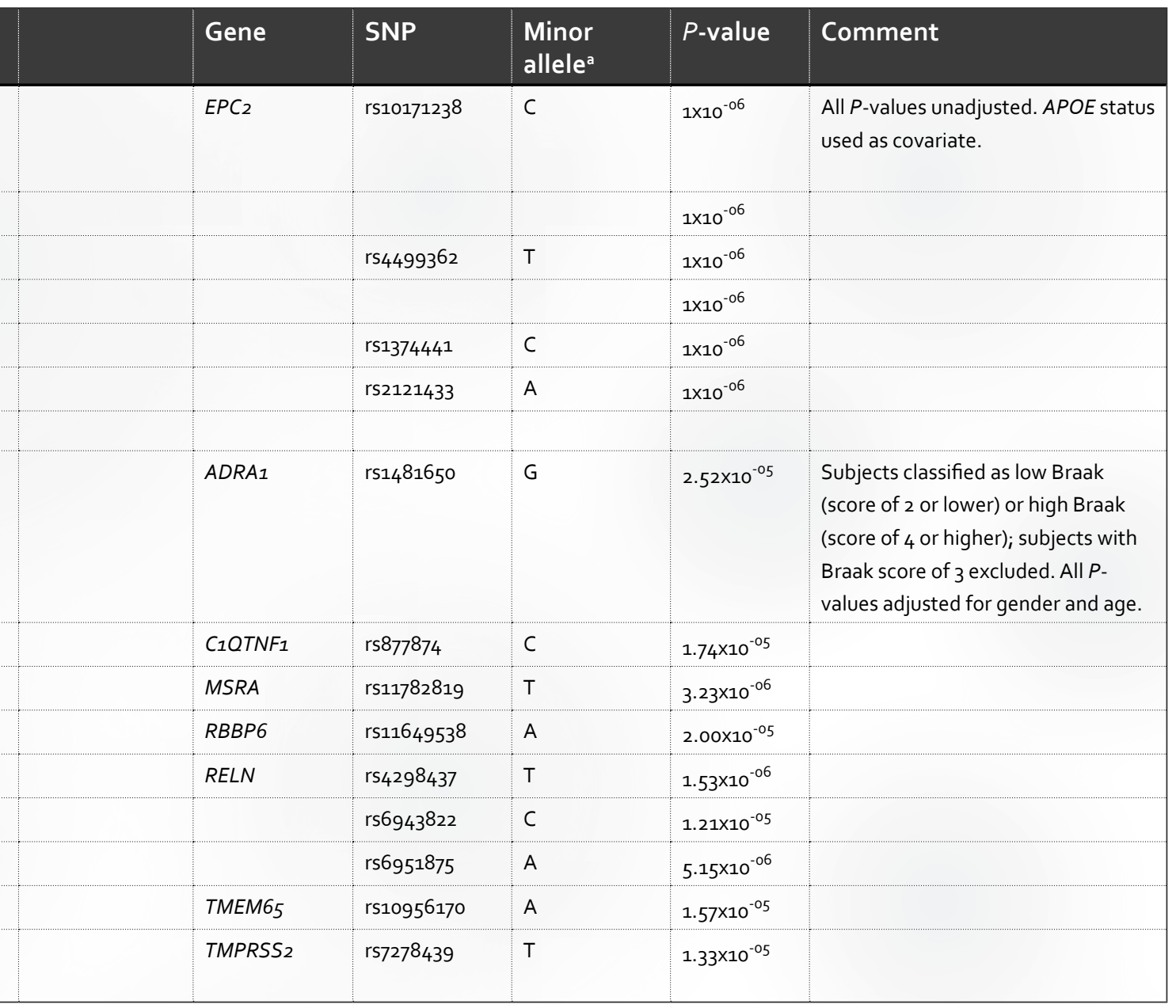


Kramer and colleagues performed a GWAS with Braak stages of NFTs as outcome in subjects from the general population. ${ }^{77}$ They reported correlations with polymorphisms in 7 different genes (Table 4). They also investigated the effects of $A P O E$ on neuropathology by testing whether the $A P O E \varepsilon_{4}$ allele frequency of subjects with a high Braak score differed significantly from those with a low Braak score. There was no significant difference between the two groups $(p=0.56)$, which they explained as likely due to the advance age of their subjects.

\section{DISCUSSION}

We investigated the effect of 47 SNPs from 26 genes on AD markers in CSF, amyloid PET or neuropathology. Our main conclusion is that - similar to the well-established and very highly significant effect on disease risk - effects were strongest for APOE and less evident/consistent for the other genes.

$A P O E$ was the most frequently tested gene in relation to $A D$ markers. Despite the limited number of studies we included in this review, we found a consistent correlation between the APOE $\varepsilon_{4}$ allele and abnormal amyloid, but its effect on tau remains questionable. This latter result is in agreement with observations from in vitro and animal studies typically not showing any correlations between tau and the $A P O E-\varepsilon 4$ allele and the findings that $A P O E$ is associated with aggregated $A \beta$.

TOMM40 was strongly suggested to be associated with CSF $A \beta_{1-42}$ but not with tau. This pattern is similar to that observed for the APOE \& 4 allele. TOMM4O, located in chromosome 19, is in linkage disequilibrium with $A P O E$. That is, DNA sequence variants (such as SNPs) in one locus are strongly correlated with SNPs at the other locus. Some authors have discussed the possibility that genetic variants in TOMM 40 exert their effects independent of $A P O E_{1}{ }^{63,92-94}$ while other studies have not confirmed this. ${ }^{95,96}$

$C R 1$ marginally correlated with CSF A $\beta$. There was no further indication of a link between the SNPs we selected for inclusion in the study and other AD biomarkers. Brouwers and colleagues ${ }^{89}$ have analyzed a range of other SNPs that were not included in the present study. Their findings suggested that SNPs in 'linkage disequilibrium 
block 4' were associated with CSF A $\beta_{1-42}$. However, rs1408077, which is a SNP from this block included in our review, was not associated with CSF $A \beta_{1-42}$ in their study or in any of the selected studies. Two other SNPs (rs12034383 and rs11803956) showed marginal correlation with $A \beta$, while no link with biomarkers was found with any of the other tested SNPs rs11118131, rs11118166, rs11118167, rs12034598, rs1746659, rs3738468, rs4844610, rs646817 and rs6691117.

$C L U$ was not associated with $A \beta$. Its lack of correlation with tau is consistent with the report of another study. ${ }^{77}$ For PICALM, there was a moderately strong suggestion of correlation with abnormal A $\beta$ in CSF or with neuropathology from independent studies. It was not associated with tau. BIN 1 did not correlate with the $A D$ profile of abnormal $A \beta$ and $p$-tau, but there was only one study available, which was insufficient to base a meaningful conclusion.

With respect to the candidate genes assessed here, previous studies have reported that $A C E$ rs1800764, rs4343 and rs4291 maybe associated with risk for $A D .{ }^{59,60,98}$ However, the overall effect of these $A C E$ polymorphisms on $A D$ biomarkers remains inconclusive and is certainly much less compelling in terms of statistical significance than the associations observed with the GWAS-derived loci discussed above.

The effect of SORL1 variants on AD biomarkers equally remains inconclusive. Moreover, $A \beta$ concentrations have been reported to be affected by the interaction between SORL1 and APOE. ${ }^{86}$ SORL1 is an apolipoprotein E receptor. ${ }^{88}$ However, another study which corrected for $A P O E$ status and which had substantial statistical power still did not detect any correlation between SORL1 polymorphisms and CSF A $\beta_{1-42} \cdot{ }^{85}$ Other SNPs that have been studied but did not yield significant results in relation to biomarkers were rs1010159, rs11600875, rs1699102, rs2282649, rs3824968, SORL1-18ex26.56,83, 85, 86, 99 Thus, in addition to being at best a modest genetic risk factor for $A D$, the presence of substantial allelic heterogeneity makes it much more difficult to conclusively assess the potential link between SORL1 and AD compared to other genes. ${ }^{34}$

Studies of SORL haplotypes showing correlations with AD biomarkers ${ }^{8,99,100}$ may yield more insight as to how these polymorphisms affect pathophysiology. 
Similarly, there is no strong evidence yet for the effect of MAPT polymorphisms on AD biomarkers, although the limited number of studies on this gene makes it difficult to reach more definitive conclusions.

The few currently available biomarker GWAS identified a range of genes but except for APOE and TOMM4O, these have not been identified by previous GWAS that used a case-control design with clinical $A D$ as outcome. This may be due to a number of factors including small effect size of the variant under study, small sample size, imprecision in the methods of reliably determining biomarker 'levels'. Thus, a number of the proposed findings may be false positive. Alternatively, the currently inconclusive findings may indicate that different sets of genes and/or polymorphisms modulate biomarker vs. susceptibility outcomes. Further, it is noteworthy that in the two GWAS performed with ADNI data no noteworthy overlap in association signals was reported. Given that both datasets were identical or at least largely overlapping in terms of included subjects as well as measured phenotypes and genotypes this discrepancy appears striking. Replication studies in larger samples are direly needed to reassess these findings.

Given the complexity of the considered traits and body of literature in the field, our study is, naturally, not without limitations. First, the small number of studies included limits our ability to distinguish true from possibly erroneous signals. However, our final collection of studies was determined following a systematic review of the literature, so this factor is beyond our control. Second, owing to the small number of available studies, we only conducted a qualitative analysis of the published data on genetic risk factors and markers for $A \beta$ and tau. Once more data become available, future analyses should also include a quantitative synthesis of all available data, similar to what is done the field of genetic association studies in AD. ${ }^{41}$ Third, we only focused on what we consider the "best-established" risk genes for AD to date. It needs to be emphasized that a wide range of additional genes has been investigated in relation to AD biomarkers but a careful review of these studies was outside the scope of this review. Finally, we only concentrated on markers for amyloid and tau, but it may also be worthwhile to focus on cognition and brain atrophy as useful endpoints in future assessments of this kind. ${ }^{72,101}$ 


\section{Conclusions and future perspectives}

Of the genes included in our study, APOE was by far most strongly and most consistently correlated with biomarkers and neuropathological markers of $A D$, in particular those that correlate with $A \beta$ pathology. It needs to be resolved whether the similar effects observed with polymorphisms in TOMM4O - which are highly correlated with those in $A P O E$ - represent genuinely independent effects. If that were the case, it would strengthen the notion that mitochondrial dysfunction may represent one of the key pathological events in $A D .^{72}$ Of all other potential gene-biomarker effects assessed here, it appears that only the potential relation between PICALM and A $\beta$ deserves further exploration. PICALM has been posited to promote $A \beta$ synthesis through endocytosis regulation, which leads to changes in $A \beta$ concentrations. ${ }^{23,88}$

The finding that $B I N 1, C L U, C R 1, A C E, S O R L$ and MAPT did not correlate with $A \beta$ or tau biomarkers may suggest that these genes exert their effects on $A D$ through pathways other than those directly related to tau and $A \beta$. The lack of correlation, however, may also result from the small number of studies available for this review and the small sample sizes in most studies.

In general, the current lack of consistent patterns for genes other than APOE and TOMM4O to correlate with biomarkers in GWAS strongly argues for performing future studies on a much larger scale. Just like GWAS assessing the genetic architecture underlying disease susceptibility, this will require forming national and international collaborations that will allow sharing, pooling and harmonizing raw data. Future collaborative efforts should also attempt to harmonize the techniques employed to determine biomarker phenotypes in order to reduce the chance of bias due to technical imprecision. However, it needs to be emphasized that 'bigger' does not always equal 'better', as the correlation between most of today's biomarkers with the underlying pathophysiology is less than perfect. Thus, future studies also need to focus on identifying novel markers that more closely and specifically reflect the underlying disease process. Ideally, these biomarkers should be easy to measure with high precision, while at the same time being only minimally invasive and most cost effective than current variables. This idealized future may seem long ahead and will necessitate a broad range of 
new developments in the fields of high-throughput proteomics, specimen ascertainment, and bioinformatics. However, recent advances in DNA sequencing methodology - which now allows researchers to decipher whole genomes at base-pair resolution at constantly increasing precision and cost-efficiency - have shown that revolutionary progress is sometimes closer than it may appear. Applying these technologies on large collections of carefully ascertained study cohorts will lay the foundation to develop better and more reliable disease biomarkers. In the meantime, efforts are ongoing to consolidate published materials on AD-related biomarkers and making these publicly available in an 'AlzBiomarkers' database, which will follow the same general idea as the AlzGene database. All these developments will hopefully lead to a vast improvement of our means for early detection and monitoring of the biochemical consequences elicited by $A D$ and other devastating neurodegenerative diseases.

\section{Executive summary}

\section{Alzheimer's disease (AD) is a neurodegenerative disease}

- Neuritic plaques, mainly composed of aggregated $A \beta$, and neurofibrillary tangles, consisting of hyperphosphorylated tau, are characteristic lesions in AD.

- $\quad A D$ markers can be measured in-vivo or upon neuropathological examination.

\section{AD pathophysiology}

- $\quad A D$ results from the imbalance in the production and clearance of $A \beta$ in the brain.

- $A \beta_{1-40}$ and $A \beta_{1-42}$ are produced by $\beta$ and $\gamma$-secretase cleavage of the $\beta$-amyloid precursor protein. $A \beta_{1-42}$ is prone to aggregate.

\section{Genetics of AD}

- Less than $5 \%$ of all AD cases are caused by autosomal dominant mutations following Mendelian disease transmission.

- Non-Mendelian forms of AD caused by the interplay of genetic (and non-genetic) susceptibility factors of small effect sizes represent the vast majority of cases. 


\section{Biomarkers and top results AlzGene SNPs}

- $\quad A P O E$ and PICALM correlated with abnormal $A \beta$ but not with tau in CSF and in neuritic plaques.

- $\quad C R 1$ was marginally correlated with $A \beta$ and tau.

- $B I N 1$ and $C L U$ did not correlate with $A \beta$ or with tau.

Biomarkers and other SNPs in AD candidate genes

- $A C E$, SORL1 and MAPT had no conclusive effect on $A \beta$ and tau.

- TOMM4O correlated with CSF A $\beta$, but TOMM4O is in strong linkage disequilibrium with $A P O E$.

Genome-wide association studies (GWAS) with biomarker outcomes

- Except for APOE/TOMM40, findings from GWAS assessing disease risk currently show no or little overlap with findings from biomarker GWAS.

- Other GWAS signals currently show weak, inconsistent or no correlation with AD markers.

\section{Conclusion}

- $\quad A P O E$ is currently the only gene that correlates strongly with biomarkers and neuropathological markers of $A D$, while the correlation with PICALM is less definitive.

- Larger scale studies using current and future biomarkers are needed to elucidate the role of susceptibility genes on the pathophysiology of AD.

Acknowledgements: The study was in part funded by Zon-Mw (PJV) as part of the BIOMARKAPD project in the frame of the European Joint Programming Initiative on Neurodegenerative Disorders (JPND).

\section{REFERENCES}

1. Bu G. Apolipoprotein E and its receptors in Alzheimer's disease: pathways, pathogenesis and therapy. Nat Rev Neurosci 2009; 10(5): 333-44.

2. Blennow K, de Leon MJ, Zetterberg H. Alzheimer's disease. Lancet 2006; 368(9533): 387403.

3. Bertram L, Tanzi RE. Genome-wide association studies in Alzheimer's disease. Hum Mol Genet 2009; 18(R2): R137-45. 
4. Villain N, Chetelat G, Grassiot B, Bourgeat P, Jones G, Ellis KA, et al. Regional dynamics of amyloid-beta deposition in healthy elderly, mild cognitive impairment and Alzheimer's disease: a voxelwise PiB-PET longitudinal study. Brain 2012.

5. Hampel H. Amyloid-beta and Cognition in Aging and Alzheimer's Disease: Molecular and Neurophysiological Mechanisms. J Alzheimers Dis 2012.

6. Jack CR, Jr. Alzheimer disease: new concepts on its neurobiology and the clinical role imaging will play. Radiology 2012; 263(2): 344-61.

7. Zetzsche T, Rujescu D, Hardy J, Hampel H. Advances and perspectives from genetic research: development of biological markers in Alzheimer's disease. Expert Rev Mol Diagn 2010; 10(5): 667-90.

8. Lill CM, Bertram L. Towards unveiling the genetics of neurodegenerative diseases. Semin Neurol 2011; 31(5): 531-41.

9. Bertram L, Lill CM, Tanzi RE. The genetics of Alzheimer disease: back to the future. Neuron 2010; 68(2): 270-81.

10. Karran E, Mercken M, De Strooper B. The amyloid cascade hypothesis for Alzheimer's disease: an appraisal for the development of therapeutics. Nat Rev Drug Discov 2011; 10(9): 698-712.

11. Nimmrich V, Ebert U. Is Alzheimer's disease a result of presynaptic failure? Synaptic dysfunctions induced by oligomeric beta-amyloid. Rev Neurosci 2009; 20(1): 1-12.

12. Kayed R, Head E, Thompson JL, McIntire TM, Milton SC, Cotman CW, et al. Common structure of soluble amyloid oligomers implies common mechanism of pathogenesis. Science 2003; 300(5618): 486-9.

13. Cerf E, Gustot A, Goormaghtigh E, Ruysschaert JM, Raussens V. High ability of apolipoprotein $\mathrm{E}_{4}$ to stabilize amyloid-beta peptide oligomers, the pathological entities responsible for Alzheimer's disease. FASEB J 2011; 25(5): 1585-95.

14. Haass C, Lemere CA, Capell A, Citron M, Seubert P, Schenk D, et al. The Swedish mutation causes early-onset Alzheimer's disease by beta-secretase cleavage within the secretory pathway. Nat Med 1995; 1(12): 1291-6.

15. Lannfelt L, Basun H, Wahlund LO, Rowe BA, Wagner SL. Decreased alpha-secretasecleaved amyloid precursor protein as a diagnostic marker for Alzheimer's disease. Nat Med 1995; 1(8): 829-32.

16. Dean RA, Shaw LM. Use of cerebrospinal fluid biomarkers for diagnosis of incipient Alzheimer disease in patients with mild cognitive impairment. Clin Chem 2010; 56(1): 7-9.

17. Visser PJ, Verhey F, Knol DL, Scheltens P, Wahlund LO, Freund-Levi Y, et al. Prevalence and prognostic value of CSF markers of Alzheimer's disease pathology in patients with subjective cognitive impairment or mild cognitive impairment in the DESCRIPA study: a 
prospective cohort study. Lancet Neurol 2009; 8(7): 619-27.

18. Hansson $\mathrm{O}$, Zetterberg $\mathrm{H}$, Buchhave $P$, Andreasson $U$, Londos $E$, Minthon L, et al. Prediction of Alzheimer's disease using the CSF Abeta42/Abeta40 ratio in patients with mild cognitive impairment. Dement Geriatr Cogn Disord 2007; 23(5): 316-20.

19. Shaw LM, Vanderstichele H, Knapik-Czajka M, Clark CM, Aisen PS, Petersen RC, et al. Cerebrospinal fluid biomarker signature in Alzheimer's disease neuroimaging initiative subjects. Ann Neurol 2009; 65(4): 403-13.

20. Maddalena A, Papassotiropoulos A, Muller-Tillmanns B, Jung HH, Hegi T, Nitsch RM, et al. Biochemical diagnosis of Alzheimer disease by measuring the cerebrospinal fluid ratio of phosphorylated tau protein to beta-amyloid peptide42. Arch Neurol 2003; 60(9): 1202-6.

21. van Rossum IA, Vos $S$, Handels R, Visser PJ. Biomarkers as predictors for conversion from mild cognitive impairment to Alzheimer-type dementia: implications for trial design. $J$ Alzheimers Dis 2010; 20(3): 881-91.

22. Huang Y. Apolipoprotein E and Alzheimer disease. Neurology 2006; 66(2 Suppl 1): S79-85.

23. Harold D, Abraham R, Hollingworth P, Sims R, Gerrish A, Hamshere ML, et al. Genomewide association study identifies variants at CLU and PICALM associated with Alzheimer's disease. Nat Genet 2009; 41(10): 1088-93.

24. Thinakaran G, Koo EH. Amyloid precursor protein trafficking, processing, and function. J Biol Chem 2008; 283(44): 29615-9.

25. Schellenberg GD, Montine TJ. The genetics and neuropathology of Alzheimer's disease. Acta Neuropathol 2012.

26. Esselens C, Sannerud R, Gallardo R, Baert V, Kaden D, Serneels L, et al. Peptides based on the presenilin-APP binding domain inhibit APP processing and Abeta production through interfering with the APP transmembrane domain. FASEB J 2012.

27. Duering $M$, Grimm MO, Grimm HS, Schroder J, Hartmann T. Mean age of onset in familial Alzheimer's disease is determined by amyloid beta 42. Neurobiol Aging 2005; 26(6): 785-8.

28. Muller UC, Pietrzik CU, DellerT. The physiological functions of the beta-amyloid precursor protein APP. Exp Brain Res 2012; 217(3-4): 325-9.

29. Papassotiropoulos A, Fountoulakis M, Dunckley T, Stephan DA, Reiman EM. Genetics, transcriptomics, and proteomics of Alzheimer's disease. J Clin Psychiatry 2006; 67(4): 65270.

30. Thonberg H, Fallstrom M, Bjorkstrom J, Schoumans J, Nennesmo I, Graff C. Mutation screening of patients with Alzheimer disease identifies APP locus duplication in a Swedish patient. BMC Res Notes 2011; 4: 476.

31. Tanzi RE, Bertram L. Twenty years of the Alzheimer's disease amyloid hypothesis: a genetic perspective. Cell 2005; 120(4): 545-55. 
32. Cruts M, Van Broeckhoven C. Molecular genetics of Alzheimer's disease. Ann Med 1998; 30(6): 560-5. (http://www.molgen.ua.ac.be/ADMutations/).

33. Pottier C, Hannequin D, Coutant $S$, Rovelet-Lecrux A, Wallon D, Rousseau $S$, et al. High frequency of potentially pathogenic SORL1 mutations in autosomal dominant early-onset Alzheimer disease. Mol Psychiatry 2012.

34. Reitz C, Cheng R, Rogaeva E, Lee JH, Tokuhiro S, Zou F, et al. Meta-analysis of the association between variants in SORL1 and Alzheimer disease. Arch Neurol 2011; 68(1): 99106.

35. Strittmatter WJ, Weisgraber KH, Huang DY, Dong LM, Salvesen GS, Pericak-Vance M, et al. Binding of human apolipoprotein $E$ to synthetic amyloid beta peptide: isoform-specific effects and implications for late-onset Alzheimer disease. Proc Natl Acad SciU S A 1993; 90(17): 8098-102.

36. Strittmatter WJ, Saunders AM, Schmechel D, Pericak-Vance M, Enghild J, Salvesen GS, et al. Apolipoprotein $\mathrm{E}$ : high-avidity binding to beta-amyloid and increased frequency of type 4 allele in late-onset familial Alzheimer disease. Proc Natl Acad SciUS A 1993; 90(5): 197781.

37. Avramopoulos D. Genetics of Alzheimer's disease: recent advances. Genome Med 2009; 1(3): 34 .

38. Leoni V. The effect of apolipoprotein E (ApoE) genotype on biomarkers of amyloidogenesis, tau pathology and neurodegeneration in Alzheimer's disease. Clin Chem Lab Med 2011; 49(3): 375-83.

39. Holtzman DM, Herz J, Bu G. Apolipoprotein e and apolipoprotein e receptors: normal biology and roles in Alzheimer disease. Cold Spring Harb Perspect Med 2012; 2(3): a006312.

40. Farrer LA, Cupples LA, Haines JL, Hyman B, Kukull WA, Mayeux R, et al. Effects of age, sex, and ethnicity on the association between apolipoprotein $E$ genotype and Alzheimer disease. A meta-analysis. APOE and Alzheimer Disease Meta Analysis Consortium. JAMA 1997; 278(16): 1349-56.

41. Bertram L, McQueen MB, Mullin K, Blacker D, Tanzi RE. Systematic meta-analyses of Alzheimer disease genetic association studies: the AlzGene database. Nat Genet 2007; 39(1): 17-23. (http://www.alzgene.org).

42. Abraham R, Moskvina V, Sims R, Hollingworth P, Morgan A, Georgieva L, et al. A genomewide association study for late-onset Alzheimer's disease using DNA pooling. BMC Med Genomics 2008; 1: 44 .

43. Elias-Sonnenschein LS, Viechtbauer W, Ramakers IH, Verhey FR, Visser PJ. Predictive value of $A P O E$-epsilon 4 allele for progression from $\mathrm{MCl}$ to $\mathrm{AD}$-type dementia: a meta-analysis. J Neurol Neurosurg Psychiatry 2011; 82(10): 1149-56. 
44. Grupe A, Abraham R, LiY, Rowland C, Hollingworth P, Morgan A, et al. Evidence for novel susceptibility genes for late-onset Alzheimer's disease from a genome-wide association study of putative functional variants. Hum Mol Genet 2007; 16(8): 865-73.

45. Coon KD, Myers AJ, Craig DW, Webster JA, Pearson JV, Lince DH, et al. A high-density whole-genome association study reveals that $A P O E$ is the major susceptibility gene for sporadic late-onset Alzheimer's disease. J Clin Psychiatry 2007; 68(4): 613-8.

46. Reiman EM, Webster JA, Myers AJ, Hardy J, Dunckley T, Zismann VL, et al. GAB2 alleles modify Alzheimer's risk in APOE epsilon4 carriers. Neuron 2007; 54(5): 713-20.

47. Beecham GW, Martin ER, LiYJ, Slifer MA, Gilbert JR, Haines JL, et al. Genome-wide association study implicates a chromosome 12 risk locus for late-onset Alzheimer disease. Am J Hum Genet 2009; 84(1): 35-43.

48. Potkin SG, Guffanti G, Lakatos A, Turner JA, Kruggel F, Fallon JH, et al. Hippocampal atrophy as a quantitative trait in a genome-wide association study identifying novel susceptibility genes for Alzheimer's disease. PLoS One 2009; 4(8): e6501.

49. Li H, Wetten S, Li L, St Jean PL, Upmanyu R, Surh L, et al. Candidate single-nucleotide polymorphisms from a genomewide association study of Alzheimer disease. Arch Neurol 2008; 65(1): 45-53.

50. Carrasquillo MM, Zou F, Pankratz VS, Wilcox SL, Ma L, Walker LP, et al. Genetic variation in $\mathrm{PCDH} \mathrm{H}_{11} \mathrm{X}$ is associated with susceptibility to late-onset Alzheimer's disease. Nat Genet 2009; 41(2): 192-8.

51. Seshadri S, Fitzpatrick AL, Ikram MA, DeStefano AL, Gudnason V, Boada M, et al. Genomewide analysis of genetic loci associated with Alzheimer disease. JAMA 2010; 303(18): 1832-40.

52. Lambert JC, Heath S, Even G, Campion D, Sleegers K, Hiltunen M, et al. Genome-wide association study identifies variants at CLU and CR1 associated with Alzheimer's disease. Nat Genet 2009; 41(10): 1094-9.

53. Hollingworth $P$, Harold D, Sims R, Gerrish A, Lambert JC, Carrasquillo MM, et al. Common variants at $A B C A 7, M S_{4} A 6 A / M S_{4} A_{4} E_{1} E P H A 1, C D_{33}$ and $C D_{2} A P$ are associated with Alzheimer's disease. Nat Genet 2011; 43(5): 429-35.

54. Bertram L, Lange C, Mullin K, Parkinson M, Hsiao M, Hogan MF, et al. Genome-wide association analysis reveals putative Alzheimer's disease susceptibility loci in addition to APOE. Am J Hum Genet 2008; 83(5): 623-32.

55. Naj AC, Jun G, Beecham GW, Wang LS, Vardarajan BN, Buros J, et al. Common variants at $\mathrm{MS}_{4} \mathrm{~A}_{4} / \mathrm{MS}_{4} \mathrm{~A} 6 \mathrm{E}, \mathrm{CD}_{2} \mathrm{AP}, \mathrm{CD}_{33}$ and $\mathrm{EPHA} 1$ are associated with late-onset Alzheimer's disease. Nat Genet 2011; 43(5): 436-41.

56. Kauwe JS, Wang J, Mayo K, Morris JC, Fagan AM, Holtzman DM, et al. Alzheimer's disease risk variants show association with cerebrospinal fluid amyloid beta. Neurogenetics 2009; 10(1): 13-7. 
57. Cruchaga C, Kauwe JS, Mayo K, Spiegel N, Bertelsen S, Nowotny P, et al. SNPs associated with cerebrospinal fluid phospho-tau levels influence rate of decline in Alzheimer's disease. PLoS Genet 2010; 6(9).

58. Natunen T, Helisalmi S, Vepsalainen S, Sarajarvi T, Antikainen L, Makinen P, et al. Genetic analysis of genes involved in amyloid-beta degradation and clearance in Alzheimer's disease. J Alzheimers Dis 2012; 28(3): 553-9.

59. Kehoe PG, Katzov H, Andreasen N, Gatz M, Wilcock GK, Cairns NJ, et al. Common variants of ACE contribute to variable age-at-onset of Alzheimer's disease. Hum Genet 2004; 114(5): 478-83.

6o. Ning M, Yang Y, Zhang Z, Chen Z, Zhao T, Zhang D, et al. Amyloid-beta-Related Genes SORL1 and ACE are Genetically Associated With Risk for Late-onset Alzheimer Disease in the Chinese Population. Alzheimer Dis Assoc Disord 2010.

61. Kimura R, Yamamoto M, Morihara T, Akatsu H, Kudo T, Kamino K, et al. SORL1 is genetically associated with Alzheimer disease in a Japanese population. Neurosci Lett 2009; 461(2): 177-80.

62. Takei N, Miyashita A, Tsukie T, Arai H, Asada T, Imagawa M, et al. Genetic association study on in and around the APOE in late-onset Alzheimer disease in Japanese. Genomics 2009; 93(5): 441-8.

63. Roses AD, Lutz MW, Amrine-Madsen H, Saunders AM, Crenshaw DG, Sundseth SS, et al. A TOMM 40 variable-length polymorphism predicts the age of late-onset Alzheimer's disease. Pharmacogenomics J 2010; 10(5): 375-84.

64. Cervantes S, Samaranch L, Vidal-Taboada JM, Lamet I, Bullido MJ, Frank-Garcia A, et al. Genetic variation in APOE cluster region and Alzheimer's disease risk. Neurobiol Aging 2011; 32(11): 2107 e7-17.

65. Di Maria E, Cammarata S, Parodi MI, Borghi R, Benussi L, Galli M, et al. The H1 haplotype of the tau gene (MAPT) is associated with mild cognitive impairment. J Alzheimers Dis 2010; 19(3): 909-14.

66. Schjeide BM, McQueen MB, Mullin K, DiVito J, Hogan MF, Parkinson M, et al. Assessment of Alzheimer's disease case-control associations using family-based methods. Neurogenetics 2009; 10(1): 19-25.

67. Gerrish A, Russo G, Richards A, Moskvina V, Ivanov D, Harold D, et al. The role of variation at AbetaPP, PSEN1, PSEN2, and MAPT in late onset Alzheimer's disease. J Alzheimers Dis 2012; 28(2): 377-87.

68. Zhang N, Yu JT, Yang Y, Yang J, Zhang W, Tan L. Association analysis of GSK ${ }_{3} B$ and MAPT polymorphisms with Alzheimer's disease in Han Chinese. Brain Res 2011; 1391: 147-53. 
69. Akatsu H, Ogawa N, Kanesaka T, Hori A, Yamamoto T, Matsukawa N, et al. Higher activity of peripheral blood angiotensin-converting enzyme is associated with later-onset of Alzheimer's disease. J Neurol Sci 2011; 300(1-2): 67-73.

70. Zou K, Yamaguchi H, Akatsu H, Sakamoto T, Ko M, Mizoguchi K, et al. Angiotensinconverting enzyme converts amyloid beta-protein 1-42 (Abeta(1-42)) to Abeta(1-40), and its inhibition enhances brain Abeta deposition. J Neurosci 2007; 27(32): 8628-35.

71. Heutink P. Untangling tau-related dementia. Hum Mol Genet 2000; 9(6): 979-86.

72. Ferencz B, Karlsson S, Kalpouzos G. Promising Genetic Biomarkers of Preclinical Alzheimer's Disease: The Influence of APOE and TOMM40 on Brain Integrity. Int J Alzheimers Dis 2012; 2012: 421452.

73. Devi L, Prabhu BM, Galati DF, Avadhani NG, Anandatheerthavarada HK. Accumulation of amyloid precursor protein in the mitochondrial import channels of human Alzheimer's disease brain is associated with mitochondrial dysfunction. J Neurosci 2006; 26(35): 905768.

74. Mancuso M, Calsolaro V, Orsucci D, Carlesi C, Choub A, Piazza S, et al. Mitochondria, cognitive impairment, and Alzheimer's disease. Int J Alzheimers Dis 2009; 2009.

75. Han MR, Schellenberg GD, Wang LS. Genome-wide association reveals genetic effects on human Abeta42 and tau protein levels in cerebrospinal fluids: a case control study. BMC Neurol 2010; 10: 90.

76. Kim S, Swaminathan S, Shen L, Risacher SL, Nho K, Foroud T, et al. Genome-wide association study of CSF biomarkers Abeta1-42, t-tau, and p-tau181p in the ADNI cohort. Neurology 2011; 76(1): 69-79.

77. Kramer PL, Xu H, Woltjer RL, Westaway SK, Clark D, Erten-Lyons D, et al. Alzheimer disease pathology in cognitively healthy elderly: a genome-wide study. Neurobiol Aging 2011; 32(12): 2113-22.

78. Schott JM. Using CSF biomarkers to replicate genetic associations in Alzheimer's disease. Neurobiol Aging 2011.

79. Kantarci K, Lowe V, Przybelski SA, Weigand SD, Senjem ML, Ivnik RJ, et al. APOE modifies the association between Abeta load and cognition in cognitively normal older adults. Neurology 2012; 78(4): 232-40.

8o. Wider C, Ross OA, Nishioka K, Heckman MG, Vilarino-Guell C, Jasinska-Myga B, et al. An evaluation of the impact of MAPT, SNCA and APOE on the burden of Alzheimer's and Lewy body pathology. J Neurol Neurosurg Psychiatry 2012; 83(4): 424-9.

81. Bennett DA, Wilson RS, Schneider JA, Evans DA, Aggarwal NT, Arnold SE, et al. Apolipoprotein E epsilon4 allele, AD pathology, and the clinical expression of Alzheimer's disease. Neurology 2003; 6o(2): 246-52. 
82. Kok EH, Luoto T, Haikonen S, Goebeler S, Haapasalo H, Karhunen PJ. CLU, CR1 and PICALM genes associate with Alzheimer's-related senile plaques. Alzheimers Res Ther 2011; 3(2): 12.

83. Guo LH, Westerteicher C, Wang XH, Kratzer M, Tsolakidou A, Jiang M, et al. SORL1 genetic variants and cerebrospinal fluid biomarkers of Alzheimer's disease. Eur Arch Psychiatry Clin Neurosci 2012.

84. Schjeide BM, Schnack C, Lambert JC, Lill CM, Kirchheiner J, Tumani H, et al. The role of clusterin, complement receptor 1 , and phosphatidylinositol binding clathrin assembly protein in Alzheimer disease risk and cerebrospinal fluid biomarker levels. Arch Gen Psychiatry 2011; 68(2): 207-13.

85. Kauwe JS, Cruchaga C, Bertelsen S, Mayo K, Latu W, Nowotny P, et al. Validating predicted biological effects of Alzheimer's disease associated SNPs using CSF biomarker levels. J Alzheimers Dis 2010; 21(3): 833-42.

86. Alexopoulos P, Guo LH, Kratzer M, Westerteicher C, Kurz A, Perneczky R. Impact of SORL1 single nucleotide polymorphisms on Alzheimer's disease cerebrospinal fluid markers. Dement Geriatr Cogn Disord 2011; 32(3): 164-70.

87. Chibnik LB, Shulman JM, Leurgans SE, Schneider JA, Wilson RS, Tran D, et al. CR1 is associated with amyloid plaque burden and age-related cognitive decline. Ann Neurol 2011; 69(3): 560-9.

88. Olgiati P, Politis AM, Papadimitriou GN, De Ronchi D, Serretti A. Genetics of late-onset Alzheimer's disease: update from the alzgene database and analysis of shared pathways. Int J Alzheimers Dis 2011; 2011: 832379.

89. Brouwers N, Cauwenberghe CV, Engelborghs S, Lambert JC, Bettens K, Bastard NL, et al. Alzheimer risk associated with a copy number variation in the complement receptor 1 increasing $\mathrm{C}_{3} \mathrm{~b} / \mathrm{C}_{4} \mathrm{~b}$ binding sites. Mol Psychiatry 2012; 17(2): 223-33.

9o. Miller SE, Sahlender DA, Graham SC, Honing S, Robinson MS, Peden AA, et al. The molecular basis for the endocytosis of small R-SNAREs by the clathrin adaptor CALM. Cell 2011; 147(5): 1118-31.

91. Maritzen T, Koo SJ, Haucke V. Turning CALM into excitement: AP180 and CALM in endocytosis and disease. Biol Cell 2012.

92. Carrasquillo MM, Morgan K. Commentary on 'Functional analysis of APOE locus genetic variation implicates regional enhancers in the regulation of both $\mathrm{TOMM}_{40} \mathrm{O}$ and $A P O E^{\prime}$. J Hum Genet 2012; 57(1): 3-4.

93. Roses AD. An inherited variable poly-T repeat genotype in $\mathrm{TOMM}_{40} \mathrm{in}$ Alzheimer disease. Arch Neurol 2010; 67(5): 536-41.

94. Bekris LM, Lutz $F, Y u C E$. Functional analysis of $A P O E$ locus genetic variation implicates regional enhancers in the regulation of both TOMM4O and APOE. J Hum Genet 2012; 57(1): 18-25. 
95. Maruszak A, Peplonska B, Safranow K, Chodakowska-Zebrowska M, Barcikowska M, Zekanowski C. TOMM40 rs10524523 polymorphism's role in late-onset Alzheimer's disease and in longevity. J Alzheimers Dis 2012; 28(2): 309-22.

96. Cruchaga C, Nowotny P, Kauwe JS, Ridge PG, Mayo K, Bertelsen S, et al. Association and expression analyses with single-nucleotide polymorphisms in $\mathrm{TOMM}_{40} \mathrm{O}$ in Alzheimer disease. Arch Neurol 2011; 68(8): 1013-9.

97. Calero M, Rostagno A, Matsubara E, Zlokovic B, Frangione B, Ghiso J. Apolipoprotein J (clusterin) and Alzheimer's disease. Microsc ResTech 2000; 50(4): 305-15.

98. Belbin O, Brown K, Shi H, Medway C, Abraham R, Passmore P, et al. A multi-center study of $\mathrm{ACE}$ and the risk of late-onset Alzheimer's disease. J Alzheimers Dis 2011; 24(3): 587-97.

99. Kolsch $\mathrm{H}$, Jessen $F$, Wiltfang J, Lewczuk P, Dichgans M, Kornhuber J, et al. Influence of SORL1 gene variants: association with CSF amyloid-beta products in probable Alzheimer's disease. Neurosci Lett 2008; 440(1): 68-71.

100. Caglayan S, Bauerfeind A, Schmidt V, Carlo AS, Prabakaran T, Hubner N, et al. Identification of Alzheimer disease risk genotype that predicts efficiency of SORL1 expression in the brain. Arch Neurol 2012; 69(3): 373-9.

101. Verhaaren BF, Vernooij MW, Koudstaal PJ, Uitterlinden AG, Duijn CM, Hofman A, et al. Alzheimer's Disease Genes and Cognition in the Nondemented General Population. Biol Psychiatry 2012. 
Changes in $A \beta$ and tau levels, hippocampal volume and memory occur at different stages of $A D$.

We tested how these may be related to genetic risk factors for $A D$. 
LS Elias-Sonnenschein, C Graff, RW Jones, PG Kehoe, AK Wallin, FM Nobili, M Olde Rikkert, P Scheltens, L Spiru, G Wilcock, K Blennow, R Wolz, FRJ Verhey, PJ Visser

Under review

\section{CHAPTER 6}

\section{Biomarker and cognitive correlates of $A D$ risk genes in nondemented individuals with cognitive impairment}

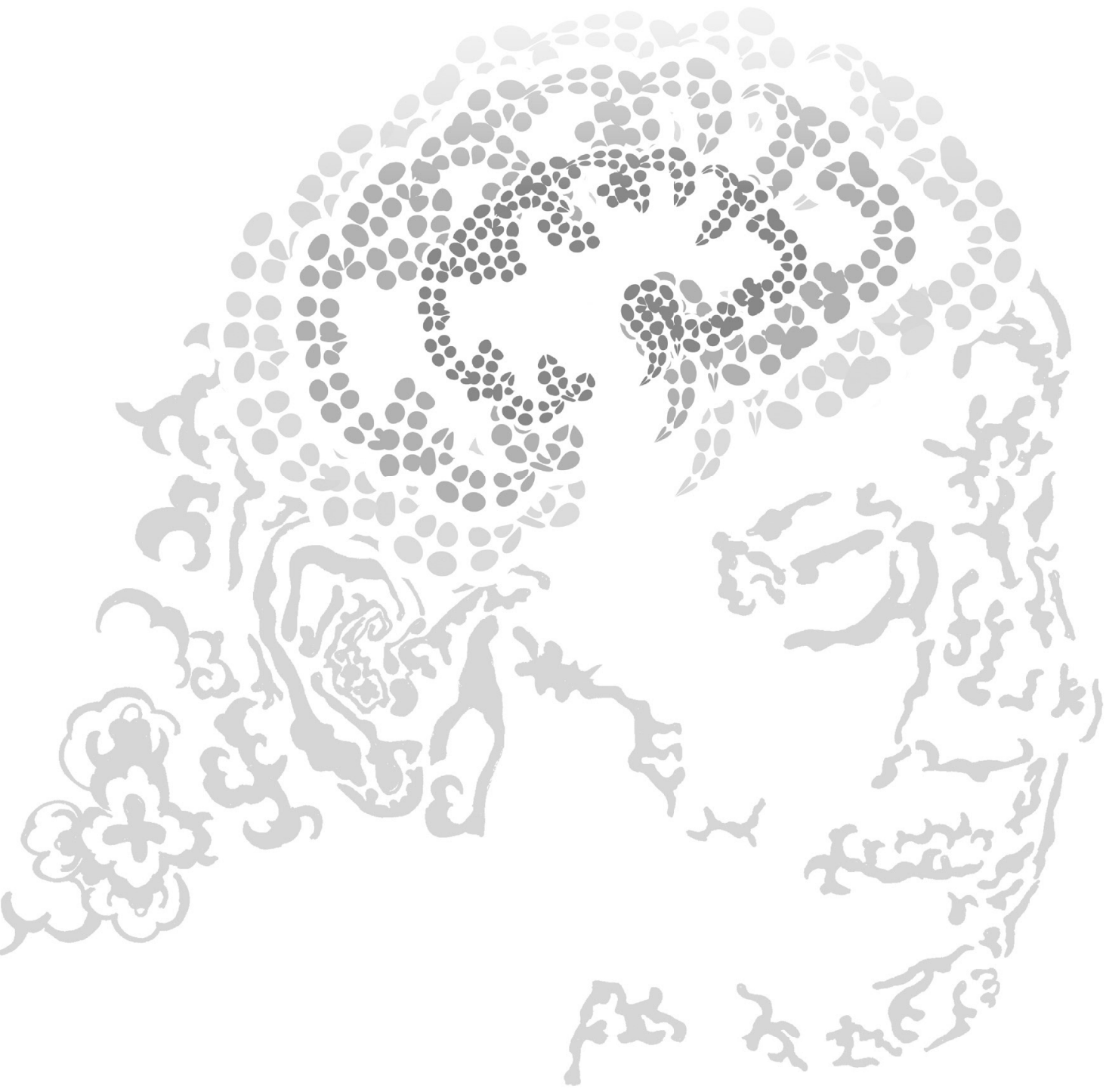




\section{ABSTRACT \\ Background}

Genome-wide association studies (GWAS) in recent years have identified single nucleotide polymorphisms (SNPs) associated with Alzheimer's disease (AD). To understand how these loci relate to key markers of $A D$ pathology, we tested their correlation with key markers of $A D$ pathology in cerebrospinal fluid (CSF) $A \beta_{1-42}$ and t-tau, hippocampal volume and delayed memory in nondemented individuals with cognitive impairment in a memory clinic setting. Furthermore, we tested the risk associated with these loci for progression to $A D$.

\section{Methods}

We tested the top 10 AlzGene risk variants in $A P O E, A B C A 7, B I N 1$, $C D_{2} A P, C D_{33}, C L U, C R 1, M S_{4} A_{4} E, M S_{4} A 6 A$ and PICALM. DNA was genotyped on Sequenom i-Plex platform. CSF $(n=66) A \beta_{1-42}$ and t-tau concentrations were measured using commercially available sandwich ELISAs; hippocampal volume $(n=58)$ using automated learning embeddings for atlas propagation (LEAP); and delayed memory $(n=265)$ using a word list-learning task. We used mixed and logistic regression models, and applied false discovery rate (FDR) correction for multiple testing.

\section{Results}

$A P O E \varepsilon_{4}$ allele carriers had a 2.5 -fold increased risk of progressing to $A D$, and showed decreased $A \beta_{1-42}$ levels $(P=0.001)$ and $A \beta_{1-42} / t$ tau ratio $(P=0.007)$. The other SNPs showed weak effects. None of the SNPs correlated with t-tau. PICALM homozygous risk allele carriers had decreased $A \beta_{1-42}$ concentrations $(P=0.02)$ and low $A \beta_{1-42} / t$-tau ratio $(P=0.05)$. Hippocampal volume was reduced among $C L U$ risk allele carriers $(P=0.02)$, but was larger among $C R 1$ risk allele carriers $(P=0.01)$. $C D_{2} A P$ risk allele carriers had poorer delayed memory $(P=0.02)$ while risk allele carriers of $A B C A 7$ performed better on memory tasks $(P=0.02)$. Except for $A P O E$, none of these results remained statistically significant after FDR correction. 


\section{Conclusion}

Only $A P O E$ predicted progression to $A D$, showed a consistent relation to $A D$ markers, and correlated significantly with CSF A $\beta_{1-42}$. The weak association of the other top GWAS SNPs with clinical outcome suggests that these may be of limited prognostic value for nondemented individuals with cognitive impairment.

Keywords: genetics, SNPs, cognitive impairment, Alzheimer, CSF, amyloid beta, tau, hippocampal atrophy, memory 


\section{INTRODUCTION}

Alzheimer's disease (AD) of the non-Mendelian form has been shown to also have a strong genetic component. 1,2 Apart from the apolipoprotein $\mathrm{E}(A P O E) \varepsilon_{4}$ allele, which is to date the strongest known genetic risk factor for $A D$, single nucleotide polymorphisms (SNPs) associated with $A D$ have been identified in the past years through genome-wide association studies (GWAS) and other high-throughout approaches to genetics. $A B C A 7, B I N_{1}, C D_{2} A P, C D_{33}, C L U, C R 1$, $M S_{4} A_{4} E, M S_{4} A 4 / M S_{4} A 6 A$ and PICALM have now also been considered as established risk genes for $A D .{ }^{3-8}$ Their effects on markers of $A D$ pathology are not clearly understood and warrant further research.

The aim of the current study was to investigate the relation between $A D$ risk genes and key measures of $A D$ pathology in cerebrospinal fluid (CSF), magnetic resonance imaging (MRI) and cognition. We tested CSF A $\beta_{1-42,}$ CSF total tau (t-tau) and hippocampal volume as biomarkers for $A D$, and delayed memory as a clinical marker.

$\operatorname{CSF} A \beta_{1-42}$ and tau reflect key pathological processes in the brain. In $A D, C S F A \beta_{1-42}$ concentrations are decreased and correlate with the presence of neuritic plaques, which are one of the pathological hallmarks of AD. Hyperphosphorylated tau ( $p$-tau) levels are increased in CSF and correlate with neurofibrillary tangles (NFTs). 9, 10 Abnormal p-tau and total tau (t-tau) concentrations are also related to neuronal degeneration. ${ }^{11-13}$ Abnormally decreased concentrations of $A \beta_{1-42}$ and increased levels of tau are regarded as supporting features for the diagnosis of AD in the revised National Institute of Neurological and Communicative Disorders and Stroke-Alzheimer's Disease and Related Disorders Association (NINCDS-ADRDA) criteria. ${ }^{14,15}$

CSF $A \beta_{1-42}$ and tau levels have been reported to differ significantly between $A P O E \varepsilon 4$ allele carriers and noncarriers who progressed to $A D .{ }^{13}$ In $A D$, PICALM has been shown to affect $A \beta_{1-42}$ but not tau ${ }_{1}^{16}$ while $C R 1$ has been reported to have no effect on both $A \beta_{1-42}$ and tau. ${ }^{17}$ In another study of a mixed sample of $A D, M C l$ and controls, $C R 1$ and PICALM, but not BIN1, have been related to the CSF AD profile of abnormal $A \beta$ and tau levels. ${ }^{18}$ 
Another biomarker of AD pathology is hippocampal volume. The hippocampus is one of the earliest brain regions affected by AD. ${ }^{19}$, ${ }^{20}$ Hippocampal atrophy is already present in patients with cognitive impairment but with no dementia, and predicts progression to $A D$ among subjects with mild cognitive impairment $(\mathrm{MCl})^{21}$ and in a memory clinic setting. ${ }^{22,23}$ The APOE $\varepsilon 4$ allele and PICALM have been found to significantly correlate with reduced hippocampal volume in a combined sample of cognitively normal controls, $\mathrm{MCI}$ nonconverters, $\mathrm{MCl}$ converters and patients with AD from a general population. ${ }^{24}$ In the same study, $B I N_{1}$ has been reported to marginally correlate with decreased hippocampal volume, while no significant effect was observed for $C R 1 .{ }^{24}$

Clinically, progressive memory loss is a key feature of AD and is already evident among patients in the predementia stage. A relation between decline in delayed memory and the APOE $\varepsilon_{4}$ allele has been reported among cognitively impaired elderly in a population study. ${ }^{25}$.The $A P O E \varepsilon_{4}$ allele has been shown to significantly correlate with poorer immediate and delayed memory in normal aging, ${ }^{26}$ but affected only delayed memory and not other memory scores in familial AD. ${ }^{27}$ APOE, CR1, PICALM, BIN and CLU have been reported to exert no significant effects on episodic memory among cognitively normal controls. ${ }^{28}$ However, a combination of the APOE $\varepsilon 4$ allele with the homozygote major alleles of $C R 1, P I C A L M, B I N$ and $C L U$ have been observed to correlate with significantly low episodic memory. ${ }^{28}$

The biomarkers and cognitive measure we selected for the present study become abnormal in different stages of AD. According to the amyloid cascade hypothesis, CSF A $\beta_{1-42}$ become abnormal first, while abnormal tau, hippocampal atrophy and memory decline occur later. $^{29,30}$

We investigated the relation of established $A D$ risk genes in the AlzGene top results loci with CSF A $\beta_{1-42}$ and t-tau, hippocampal volume and delayed memory and risk for progression to $A D$ in nondemented patients with cognitive impairment from a memory clinic setting. These patients have a high risk for progressing to AD although not all will have AD pathology. ${ }^{31}$ 


\section{METHODS}

\section{Study population}

\section{Cohort}

Participants were recruited from the 'Development of Screening Guidelines and Criteria for Predementia Alzheimer's Disease' (DESCRIPA) study, which is a multicenter prospective cohort study by the European $A D$ Consortium tasked to develop screening guidelines and clinical criteria for the diagnosis of predementia AD..$^{32}$ DESCRIPA included patients aged 55 years or older who were referred to memory clinics because of cognitive complaints but did not fulfill the clinical criteria for dementia according to the Diagnostic and Statistical Manual of Mental Disorders, fourth edition (DSM-IV) and the National Institute of Neurological and Communicative Disorders and Stroke-Alzheimer's Disease and Related Disorders Association (NINCDS-ADRDA).33,34 Participants who had memory complaints that could not be objectified through cognitive tests were diagnosed with subjective cognitive impairment (SCI). ${ }^{35}$ Those who obtained a total clinical dementia rating (CDR) of 0.5 were diagnosed with mild cognitive impairment $(\mathrm{MCl})$. Exclusion criteria were any psychiatric, somatic or neurological disorder, or a history of alcohol abuse that may have caused the cognitive impairment. ${ }^{32}$ Participants underwent clinical, neurological, neuropsychiatric, neuropsychological and functional assessments. A subset of participants underwent neuroimaging, provided CSF or venous blood for analyses. Contraindications for CSF collection were coagulation disorder, use of anticoagulants, spinal deformations or presence of neurological disorders that could lead to increased intracranial pressure. The local medical ethics committee of the participating centers approved the procedures. All participants gave their written informed consent.

Follow-up assessment was performed annually up to five years. Progression to AD-type dementia at follow-up was diagnosed according to the DSM-IV 33 and NINCDS-ADRDA criteria. ${ }^{34}$

\section{Selection of participants}

For the present study, we included all nondemented participants with cognitive impairment for whom venous blood for DNA extraction and CSF, MRI scan or scores on a memory domain test were available. 
Of the 881 DESCRIPA participants from 20 centers, genotype data were available for 287 from 9 centers. Participants who were genotyped were slightly younger than those who were not genotyped (mean 69.3 vs. 70.8 years, $P=0.01$ ). The two groups did not differ in terms of education and Mini-Mental State Examination (MMSE) $)^{36}$ score $(P>0.05)$.

Of the 287 participants, we included for the current study 265 $(\mathrm{MCl}=244, \mathrm{SCl}=21)$ from 9 centers who had available scores on a delayed recall memory test, $66(\mathrm{MCl}=57, \mathrm{SCl}=9)$ from 6 centers who provided CSF samples and $58(\mathrm{MCl}=53, \mathrm{SCl}=5)$ from 5 centers who had MRI scans. Participants with CSF data were younger than those without CSF data (68.4 vs. 70.8 years, $P<0.001$ ). The two groups were similar in terms of education and MMSE score ( $P>0.05)$. Participants with MRI scans had less years of education and lower MMSE scores compared to those without MRI scans ( 9.2 vs. 10.8 years, $P=0.03$ for education and 27.1 vs. 27.6, $P=0.003$ for MMSE score). Their age was comparable $(P>0.05)$. Participants who were and were not assessed for memory performance differed in age (69.9 vs. 73.5 years, $P<0.001$ ), but had comparable education and mean MMSE score $(P>0.05)$.

\section{Gene selection}

We selected for analyses $A P O E$, rs744373 in bridging integrator 1 ( $\left.B / N_{1}\right)$, rs111360oo in clusterin (CLU), rs3764650 in ATP-binding cassette, subfamily $\mathrm{A}$, member $7(A B C A 7)$, rs3818361 in complement component receptor 1 (CR1), rs3851179 in phosphatidylinositol binding clathrin assembly protein (PICALM), rs610932 and rs670139 in the membrane-spanning 4-domains, subfamily $A$ gene cluster $\left(M S_{4} A 6 A\right.$ and $M S_{4} A_{4} E_{1}$ respectively), rs3865444 in $C D_{33}$ molecule (CD33), and rs9349407 in $C D_{2}$-associated protein (CD $2 A P)$ (for a description of the functions of the genes, see ${ }^{37-39}$ ). These loci were listed as top 10 in AlzGene. The up-to-date online AlzGene database provides meta-analyses of published genetic association studies for $A D$ for all polymorphisms with a minor allele frequency of $>_{1} \%$ in healthy controls and for which genotype data for the same polymorphism is available in at least four case-control studies. ${ }^{40}$ The 'top results' lists polymorphisms with a nominally significant summary odds ratio $(\mathrm{OR})$, which are subsequently ranked according to the interim criteria of the Human Genome Epidemiology Network (HuGENet)..$^{\circ}$ The criteria 
developed by HuGENet, also known as Venice criteria, takes into consideration the amount of evidence (operationalized as sample size, statistical power or false discovery rate); extent and consistency of replication (as assessed among others by measures of heterogeneity); and protection from potential sources of bias (such as population stratification and genotyping error) in assessing the epidemiologic credibility of the genetic association..$^{41}$ In the present study, we used the term 'risk allele' as the risk allele reported in AlzGene meta-analysis of genetic association studies.

\section{Genetic analysis}

Genomic DNA was extracted from EDTA anticoagulated blood and amplified by polymerase chain reaction (PCR). A total of $2.5 \mathrm{ng}$ of genomic DNA with the SNP site of interest was amplified in a $5 \mu$ total volume of reaction mixture containing forward and reverse primers. Residual dNTPs were dephosphorylated with shrimp alkaline phosphatase (SAP). Extension primers were added following SAP treatment. Multiplex assays for amplification and extension primers were designed using the Sequenom MassARRAY Assay Design 3.1 software. DNA samples, with a number of duplicates as controls, were randomly placed on 384-well plates. SNPs were genotyped on Sequenom i-Plex platform (Sequenom Inc., Hamburg, Germany). APOE genotype was determined through the combination of two SNPs, rs7412 and rs429358.42 The bioanalysts who performed the genotyping were blinded to clinical information.

Chi-square test of genotypic frequencies showed that the SNPs selected for the present study were in Hardy-Weinberg equilibrium $(P>0.05)$. All samples included had a call rate of $\geq 90 \%$.

Genotypic frequencies of the minor allele variant was $<20 \%$ for $90 \%$ of the SNPs tested. This indicated that assessing the effects of the SNPs on AD markers through an overall analysis or using a recessive model would yield unreliable results due to the small number of homozygous carriers of the minor allele which reduced statistical power for these models. In this case, it is not unusual to assume a dominant model. ${ }^{43} \mathrm{We}$ therefore assessed carrier risk against the major genotype in a dominant model, wherein carriers of homozygous major alleles were compared with carriers of the pooled homozygous minor and heterozygous alleles. For $A P O E$, participants were dichotomized as $\varepsilon 4$ allele carriers vs. noncarriers. 


\section{Cognitive assessment}

We used delayed memory as a clinical marker. Memory performance was assessed according to the neuropsychological protocol at each center. Consequently, the tests used varied. Of the 265 participants with genotype and cognitive data, 200 were tested using the Rey Auditory Verbal Learning Test, ${ }^{44} 42$ took the Buschke Selective Reminding Test 45 and 23 underwent the Hopkins Verbal Learning Tests..$^{46}$ To pool the data, raw scores were transformed into z-scores adjusted for age, gender and education using normative data that were locally collected or were published. ${ }^{32} \mathrm{~A}$ z-score of -1.5 corresponds to a score of 1.5 standard deviation (SD) below the expected score after correction for age, gender and education. Z-scores were used in the analyses.

\section{CSF collection and analysis}

CSF was obtained through lumbar puncture of the $\mathrm{L}_{3} / \mathrm{L}_{4}$ or $\mathrm{L}_{4} / \mathrm{L}_{5}$ intervertebral space. The samples were centrifuged and stored in sterile polypropylene tubes at -80 degree Celsius until analyses. $A \beta_{1-42}$ and t-tau concentrations were measured using commercially available INNOTEST enzyme-linked immunosorbent assays (ELISAs) (Innotest $\beta$-amyloid ${ }_{(1-42),}$ Innotest hTau Ag, Innogenetics, Ghent, Belgium). All CSF measurements were performed at the Clinical Neurochemistry Laboratory, Sahlgrenska University Hospital in Mölndal, Sweden by bioanalysts who were unaware of the clinical data.

Concentrations below $500 \mathrm{pg} / \mathrm{ml}$ for CSF A $\beta_{1-42}$ and above $375 \mathrm{pg} /$ $\mathrm{ml}$ for CSF t-tau were considered abnormal. ${ }^{47}$ For SNPs showing significant correlation with CSF markers, we further examined whether a CSF profile for $A D$ was present. This was done by computing the ratio of CSF $A \beta_{1-42}$ to t-tau and defining scores lower than 1.14 as indicative of an CSF AD profile. 48,49

\section{Neuroimaging acquisition and analysis}

All MRI scans were acquired at 1.0 or 1.5T and included a T1-weighted three-dimensional gradient echo sequence and a fast fluid attenuated inversion recovery (FLAIR) sequence..$^{50}$ Hippocampal volume was measured using automated learning embeddings for atlas propagation (LEAP). Details of this method have been described elsewhere. ${ }^{51}$ For the 
present study, we used the sum of the left and right hippocampal volume corrected for intracranial pressure using the Montreal Neurological Institute space..$^{2} \mathrm{Hippocampal}$ volume of less than $5300 \mathrm{~cm}^{349}$ was considered abnormal. All measurements using LEAP were performed at the Department of Computing, Imperial College in London by experienced technicians who were blinded to clinical information.

\section{Statistical analysis}

The IBM SPSS Statistics version 19 (IBM Corp., NY, USA) for Mac OS X and Stata 11.2 (Stata Corp., TX, USA) was used for the statistical analyses. Group differences in terms of mean age, education and MMSE score were assessed using independent samples t-test. The Hardy-Weinberg equilibrium was computed using Chi-square test. Progression to AD was assessed through logistic regression, with correction for age and gender. In examining the effects of SNPs on the markers of AD pathology, we used mixed models to adjust for confounders.

Prior to statistical analyses, we assessed normality of data distribution using Shapiro-Wilk. Data for $A \beta_{1-42}$ and t-tau levels were skewed $(P<0.001)$ and were thus transformed into their natural logarithms to normalize distribution. Log transformed CSF data were used in the statistical analyses. Age and gender were included as covariates for all analyses, and adjustment for education was done for the cognitive measure. Correction for center was made for analyses involving centers with more than one participant.

The unadjusted statistical significance level was $P<0.05$. We corrected for multiple testing using the procedure of Benjamini and Liu for controlling the false discovery rate (FDR). ${ }^{53,54} \mathrm{FDR}$ is the expected proportion of false positives among all significant results, ${ }^{55}$ which we defined in the present study as no more than $5 \%$. In this method, the observed $P$-values were ranked from smallest to largest and successively compared with FDR adjusted $P$-values ( $P$-adj). The $P$-adj were computed using the formula: $\min (0.05,0.05 \times$ total number of SNPs tested/(total number of SNPs tested +1 -rank of the observed $P$-value) $\left.{ }^{2}\right) .{ }^{53}$ Observed $P$-values that were equal or smaller than $P$-adj were considered significant. 


\section{RESULTS}

\section{Characteristics of the study population}

Table 1 shows the demographic characteristics of the study population per subgroup. Of the 66 participants with available CSF, 41 (62\%) had abnormally reduced $A \beta_{1-42}$ concentrations, $30(45 \%)$ had abnormally elevated t-tau levels and 22 (33\%) had abnormally low CSF A $\beta_{1-42} / t$-tau ratio. Ten of the 58 participants (17\%) with MRI scans had abnormally reduced hippocampal volume. Of the 265 participants who underwent cognitive assessment, 110 (41\%) performed below the expected score for the delayed memory test (z-score of -1.5 or lower).

The genotype and minor allele frequencies of participants with available memory test score, which constituted the biggest subgroup, are presented in Table 2. Participants with data on CSF biomarkers and hippocampal volume had similar genotypic distributions (Supplementary Table 1).

Of the 151 participants seen for follow-up assessment (average follow-up 2.6 years, $S D=1.1), 19 \%(n=29)$ progressed to $A D$ within 5 years, with $12 \%$ of the conversion occurring within the first 2 years (average conversion 2.5 years, $S D=1.1$ ).

Table 1 Baseline characteristics of the study population

\begin{tabular}{|c|c|c|c|c|c|c|}
\hline Characteristic & $\begin{array}{l}\text { CSF } \\
\text { subgroup }\end{array}$ & $\mathbf{n}$ & $\begin{array}{l}\text { Hippocampal } \\
\text { volume subgroup }\end{array}$ & n & $\begin{array}{l}\text { Memory } \\
\text { subgroup }\end{array}$ & $\mathbf{n}$ \\
\hline Age (years) & $68.0(8.2)$ & 66 & $69.3(8.6)$ & 58 & $69.2(8.0)$ & 265 \\
\hline Sex (female) & & 33 & & 35 & & 159 \\
\hline Education (years) & $11.3(4 \cdot 3)$ & 66 & $9.5(4.0)$ & 58 & $10.7(4.5)$ & 265 \\
\hline MMSE score & $27.7(2.4)$ & 66 & $27.9(2.1)$ & 58 & $27.5(2.3)$ & 265 \\
\hline Memory z-score & $-0.63(1.27)$ & 60 & $-1.25(1.08)$ & 56 & $-1.14(1.40)$ & 265 \\
\hline $\mathrm{A} \beta_{1-42}$ level, $\mathrm{pg} / \mathrm{ml}$ & $464(213)$ & 66 & 482 (219) & 15 & $462(222)$ & 60 \\
\hline $\begin{array}{l}\text { Total tau level, } \\
\mathrm{pg} / \mathrm{ml}\end{array}$ & $383(276)$ & 66 & $423(342)$ & 15 & $380(256)$ & 60 \\
\hline $\begin{array}{l}\text { Hippocampal } \\
\text { volume, } \mathrm{cm}^{3}\end{array}$ & $5996(787)$ & 15 & $6132(714)$ & 58 & $6183(673)$ & 56 \\
\hline
\end{tabular}

All data are mean (standard deviation) unless otherwise specified. CSF, cerebrospinal fluid; $n$, number of cases; MMSE, Mini-Mental State Examination; $A \beta$, amyloid beta. 
Table 2 Genotype and minor allele frequencies of subgroup with memory test scores

\begin{tabular}{|c|c|c|c|c|c|}
\hline Gene & SNP & Cases, $n$ & Genotype & $\begin{array}{l}\text { Genotypic frequen- } \\
\text { cies, } \%\end{array}$ & $\begin{array}{l}\text { MAF, } \\
\%\end{array}$ \\
\hline$C R_{1}$ & rs 6656401 & 265 & GG/GA/AA & $55 \cdot 1 / 39.2 / 5.7$ & 25 \\
\hline$B I N_{1}$ & rs744373 & 259 & $\mathrm{TT} / \mathrm{TC} / \mathrm{CC}$ & $49.8 / 41.7 / 8.5$ & 29 \\
\hline$C D_{2} A P$ & rs9349407 & 262 & GG/GC/CC & $53.0 / 40.5 / 6.5$ & 27 \\
\hline$C L U$ & rs111360oo & 264 & $\mathrm{CC} / \mathrm{CT} / \mathrm{TT}$ & $36.7 / 43 \cdot 9 / 19 \cdot 3$ & 41 \\
\hline$M S_{4} A_{4} E$ & rs670139 & 261 & $\mathrm{CC} / \mathrm{CA} / \mathrm{AA}$ & $36.4 / 54.0 / 9.6$ & 37 \\
\hline$M S_{4} A 6 A$ & rs610932 & 260 & CC/CA/AA & $29.2 / 48.0 / 22.7$ & 47 \\
\hline PICALM & r3851179 & 262 & GG/GA/AA & $45.0 / 45.8 / 9.2$ & 32 \\
\hline$A B C A 7$ & rs 3764650 & 251 & $\mathrm{TT} / \mathrm{TG} / \mathrm{GG}$ & $80.1 / 18.3 / 1.6$ & 11 \\
\hline$C D_{33}$ & rs3865444 & 259 & GG/GT/TT & $50.6 / 39.4 / 10.0$ & 30 \\
\hline$A P O E$ & & 258 & $0 \varepsilon_{4} / 1 \varepsilon_{4} / 2 \varepsilon 4^{a}$ & $63.6 / 31.0 / 5.4$ & $--^{b}$ \\
\hline
\end{tabular}

SNP, single nucleotide polymorphism; $n$, number of cases; MAF, minor allele frequency; $C R 1$, complement component receptor $1 ; B I N 1$, bridging integrator $1 ; C D 2 A P, C D 2$-associated

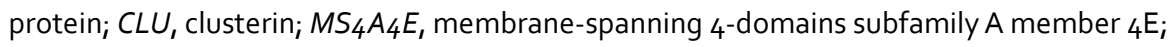
$M S_{4} A 6 A$, membrane-spanning 4-domains subfamily A member 6A; PICALM, phosphatidylinositol binding clathrin assembly protein; $A B C A 7$, ATP-binding cassette, subfamily $\mathrm{A}$, member 7 ; $C D_{33}, C D_{33}$ molecule; $A P O E$, apolipoprotein $\mathrm{E}$.

a Presented as $\varepsilon_{4}$ allele carriership, wherein o $\varepsilon_{4}=$ noncarriers, $1 \varepsilon_{4}=$ carrier of one $\varepsilon_{4}$ allele, $2 \varepsilon_{4}=$ carriers of two $\varepsilon_{4}$ alleles.

${ }^{b}$ Minor allele frequency not computed because $A P O E$ is tri-allelic.

\section{Relation of SNPs to CSF biomarkers} $\operatorname{CSFAB}_{1-42}$

Only the $A P O E \varepsilon_{4}$ allele was significantly correlated to reduced concentration of $A \beta_{1-42}$ after adjusting for multiple testing ( $P=0.001$; Table 3). PICALM was correlated with decreased $A \beta_{1-42}$ concentrations among homozygous risk allele carriers $(P=0.02)$, but this effect did not pass FDR correction.

Risk allele carriers of $C D_{2} A P$ showed a trend of reduced $A \beta_{1-42}$ $(P=0.06)$. A clear opposite effect was observed for $B I N 1$, wherein carriers of the risk allele had increased $A \beta_{1-42}$ concentrations ( $P=0.69$; Figure 1a). 


\section{CSF tau}

None of the SNPs studied were significantly related with CSF t-tau (Figure $1 \mathrm{~b}$, Table 3). The strongest effects were seen for CLU and APOE. Increased t-tau levels were observed among CLU homozygous risk allele carriers ( $P=0.15$; Table 3$)$ and APOE $\varepsilon 4$ allele carriers $(P=0.17)$.

\section{CSF AD profile}

SNPs in APOE and PICALM showed correlation with individual CSF measures. We therefore tested whether there was also a correlation between these SNPs and CSF A $\beta_{1-42} / t$-tau ratio. We used continuous CSF values in the computations. The APOE $\varepsilon_{4}$ allele significantly correlated with the ratio $(P=0.007)$, while a marginal correlation was observed for the risk allele of PICALM $(P=0.05)$. We did not adjust for multiple testing because this was a sub-analysis involving two SNPs.

\section{Relation of SNPs to hippocampal volume}

The SNPs tested did not show a consistent pattern of correlation to hippocampal volume (Figure 1C, Table 3). Only CLU correlated with decreased hippocampal volume among homozygote risk allele carriers $(P=0.02)$, although this effect did not remain significant after FDR correction. The $\varepsilon_{4}$ allele of $A P O E$ showed marginal correlation with reduced hippocampal volume $(P=0.08)$. $C R 1$ risk allele carriers had larger hippocampal volume $(P=0.01)$ instead of the expected reduced volume. This effect was no longer significant after correction for multiple testing.

\section{Relation of SNPs to delayed memory}

The majority of the SNPs we tested were not related to delayed memory performance (Figure $1 \mathrm{~d}$, Table 3 ). A lower memory performance was seen for $C D_{2} A P$ risk allele carriers $(P=0.02)$, while risk allele carriers of $A B C A 7$ performed better on memory tasks $(P=0.02)$. These effects did not withstand multiple test correction. $A P O E \varepsilon_{4}$ allele carriers showed poorer memory compared to noncarriers, although this result was not significant $(P=0.08)$. 
Table 3 Effects of SNPs on markers of AD pathology

\begin{tabular}{|c|c|c|c|c|c|}
\hline Chr, Gene & SNP & Genotype & $\begin{array}{l}\mathrm{A} \beta_{1-42^{\prime}} \mathrm{pg} / \mathrm{ml} \\
\text { Mean (SD) }\end{array}$ & $\begin{array}{l}P \text {-value } \\
\text { DM }\end{array}$ & $\begin{array}{l}\text { T-tau, } \\
\mathrm{pg} / \mathrm{ml} \\
\text { Mean (SD) }\end{array}$ \\
\hline \multirow[t]{3}{*}{$1, C R 1$} & rs6656401 & GG & $482(215)$ & 0.21 & $384(292)$ \\
\hline & & $A G$ & $455(217)$ & & 394 (270) \\
\hline & & $A \underline{A}$ & $293(124)$ & & 385 (209) \\
\hline \multirow[t]{3}{*}{$2, B / N_{1}$} & rs744373 & $\mathrm{TT}$ & $428(213)$ & 0.69 & $375(244)$ \\
\hline & & $\mathrm{CT}$ & $473(197)$ & & $452(317)$ \\
\hline & & $\subset \underline{C}$ & $544(243)$ & & $271(264)$ \\
\hline \multirow[t]{3}{*}{$6, C D_{2} A P$} & rs9349407 & GG & $526(254)$ & 0.06 & $376(312)$ \\
\hline & & GC & $405(165)$ & & $406(252)$ \\
\hline & & $C \underline{C}$ & $475(102)$ & & $340(95)$ \\
\hline \multirow[t]{3}{*}{ 8, CLU } & rs111360oo & $\subset \underline{C}$ & $460(225)$ & 0.53 & $447(312)$ \\
\hline & & $\mathrm{CT}$ & $433(202)$ & & $385(271)$ \\
\hline & & TT & $555(208)$ & & $252(184)$ \\
\hline \multirow[t]{3}{*}{$11, M S_{4} A_{4} E$} & rs670139 & CC & $486(226)$ & 0.63 & $300(242)$ \\
\hline & & $C A$ & $457(213)$ & & $419(300)$ \\
\hline & & AA & $444(205)$ & & $402(158)$ \\
\hline \multirow[t]{3}{*}{$11, M S_{4} A 6 A$} & rs610932 & $C \underline{C}$ & $433(201)$ & 0.40 & $361(287)$ \\
\hline & & $C A$ & $448(205)$ & & $442(292)$ \\
\hline & & AA & $542(250)$ & & $276(200)$ \\
\hline \multirow[t]{3}{*}{11, PICALM } & rs3851179 & $\mathrm{G} \underline{\mathrm{G}}$ & $384(170)$ & 0.02 & $311(218)$ \\
\hline & & GA & $527(222)$ & & $551(303)$ \\
\hline & & AA & $582(318)$ & & $384(289)$ \\
\hline \multirow[t]{3}{*}{$19, A B C A 7$} & rs 3764650 & TT & $464(227)$ & 0.86 & $383(257)$ \\
\hline & & TG & $467(123)$ & & 398 (409) \\
\hline & & $G \underline{G}$ & $464^{a}$ & & $296^{a}$ \\
\hline \multirow[t]{3}{*}{ 19, $C D_{33}$} & rs3865444 & $\mathrm{GG}$ & $447(203)$ & 0.57 & $397(318)$ \\
\hline & & GT & $504(254)$ & & 371 (239) \\
\hline & & TT & $433(118)$ & & 479 (207) \\
\hline \multirow[t]{3}{*}{$19, A P O E$} & & $o \varepsilon 4^{b}$ & $547(234)$ & $0.001^{c_{*}}$ & $317(258)$ \\
\hline & & $1 \varepsilon 4^{b}$ & 372 (134) & & $434(272)$ \\
\hline & & $2 \underline{\varepsilon \varepsilon^{b}}$ & $321(130)$ & & $604(298)$ \\
\hline
\end{tabular}

$A D$, Alzheimer's disease; $C h r=$ chromosome; SNPs, single nucleotide polymorphisms; $A \beta$, amyloid beta; SD, standard deviation; T-tau, total tau; DM, dominant model.

AlzGene risk allele underlined and in bold, presented for reference purposes. Genotypes for the current study presented in the following order: major/major, major/minor, minor/minor. Analyses were corrected for age, gender, education and study center, as appropriate. Adjustment for education was done only for memory. No correction for study site was done for hippocampal volume because in one of the study sites there was only one participant. 


\begin{tabular}{|c|c|c|c|c|}
\hline $\begin{array}{l}P \text {-value } \\
\text { DM }\end{array}$ & $\begin{array}{l}\text { Hippocampal volume, } \mathrm{cm}^{3} \\
\text { Mean (SD) }\end{array}$ & $\begin{array}{l}\text { P-value } \\
\text { DM }\end{array}$ & $\begin{array}{l}\text { Memory score } \\
\text { Mean (SD) }\end{array}$ & $\begin{array}{l}P \text {-value } \\
\text { DM }\end{array}$ \\
\hline \multirow[t]{3}{*}{0.78} & $5909(788)$ & 0.01 & $-1.13(1.38)$ & 0.74 \\
\hline & $6452(480)$ & & $-1.21(1.46)$ & \\
\hline & $6113(670)$ & & $-0.83(1.28)$ & \\
\hline \multirow[t]{3}{*}{0.69} & $6212(669)$ & 0.45 & $-1.17(1.33)$ & 0.77 \\
\hline & $5969(792)$ & & $-1.15(1.45)$ & \\
\hline & $6434(528)$ & & $-1.02(1.66)$ & \\
\hline \multirow[t]{3}{*}{0.55} & $6240(715)$ & 0.43 & $-0.92(1.32)$ & 0.02 \\
\hline & 6068 (733) & & $-1.27(1.42)$ & \\
\hline & $6001(710)$ & & $-2.27(1.47)$ & \\
\hline \multirow[t]{3}{*}{0.15} & $5866(812)$ & 0.02 & $-1.30(1.57)$ & 0.27 \\
\hline & $6375(531)$ & & $-1.24(1.26)$ & \\
\hline & $6058(768)$ & & $-0.64(1.26)$ & \\
\hline \multirow[t]{3}{*}{0.76} & $6042(696)$ & 0.43 & $-1.09(1.53)$ & 0.95 \\
\hline & $6256(670)$ & & $-1.15(1.36)$ & \\
\hline & $5863(922)$ & & $-1.30(1.11)$ & \\
\hline \multirow[t]{3}{*}{0.25} & $6306(646)$ & 0.32 & $-1.25(1.32)$ & 0.42 \\
\hline & $6093(74)$ & & $-1.17(1.38)$ & \\
\hline & 6068 (679) & & $-0.98(1.57)$ & \\
\hline \multirow[t]{3}{*}{0.29} & $6133(542)$ & 0.99 & $-1.08(1.31)$ & 0.23 \\
\hline & $6024(824)$ & & $-1.20(1.48)$ & \\
\hline & $6646(878)$ & & $-1.24(1.55)$ & \\
\hline \multirow[t]{3}{*}{0.64} & $6175(687)$ & 0.47 & $-1.24(1.37)$ & 0.02 \\
\hline & $6010(853)$ & & $-0.87(1.55)$ & \\
\hline & $6177^{\mathrm{a}}$ & & $0.43(1.54)$ & \\
\hline \multirow[t]{3}{*}{0.99} & 6194 (721) & 0.32 & $-1.09(1.38)$ & 0.85 \\
\hline & $6162(538)$ & & $-1.18(1.45)$ & \\
\hline & $5407(1043)$ & & $-1.27(1.48)$ & \\
\hline \multirow[t]{3}{*}{$0.17^{c}$} & $6200(697)$ & $0.08^{c}$ & $-1.10(1.33)$ & $0.08^{c}$ \\
\hline & $5923(631)$ & & $-1.24(1.45)$ & \\
\hline & $5312(910)$ & & $-1.88(1.69)$ & \\
\hline
\end{tabular}

* Significant after False Discovery Rate correction.

a Only $1 A B C A 7$ rs $3764650 \mathrm{GG}$ carrier had available CSF and hippocampal volume measurement;

${ }^{b}$ Presented as $A P O E \varepsilon_{4}$ allele carriership, wherein o $\varepsilon_{4}=$ noncarriers, $1 \varepsilon_{4}=$ carrier of one $\varepsilon_{4}$ allele, $2 \varepsilon_{4}=$ carriers of two $\varepsilon_{4}$ alleles;

${ }^{c}$ Result for $A P O E \varepsilon_{4}$ allele carriers vs. noncarriers. 


\section{Figure 1a}

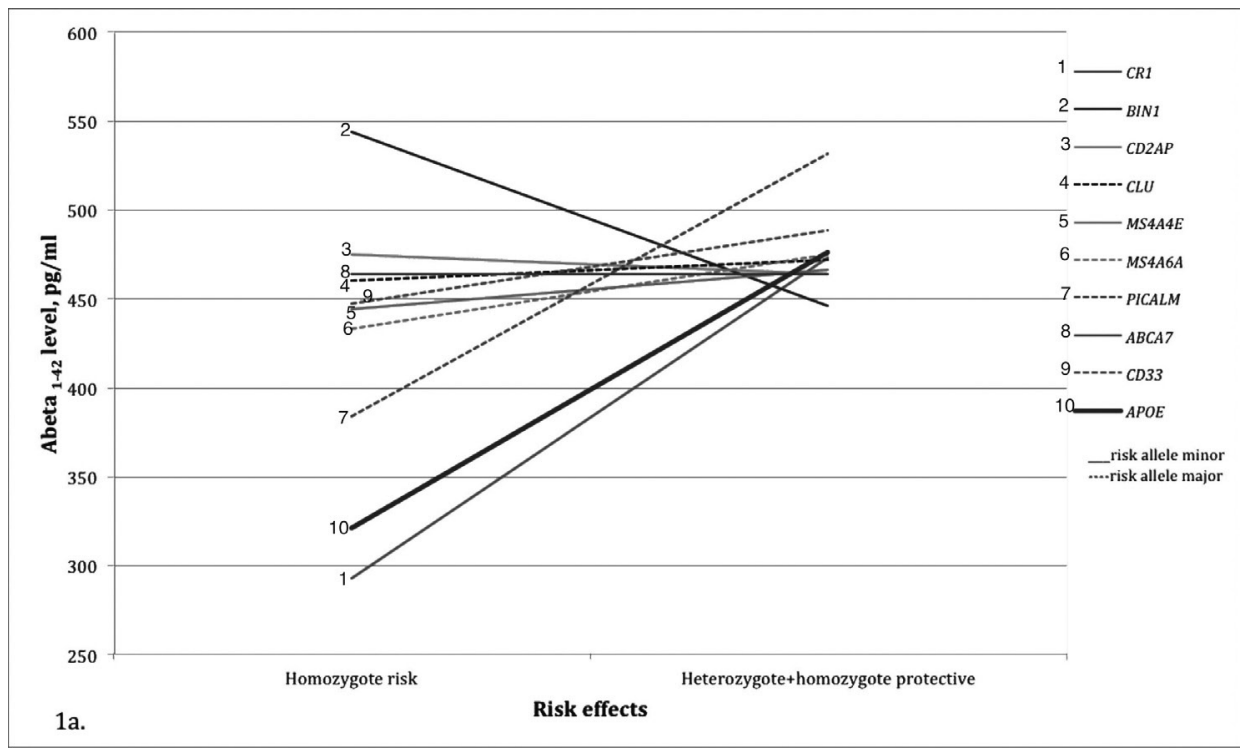

Relation between AD risk genes and markers in CSF Aß1-42. All data are means.

\section{Figure $1 b$}

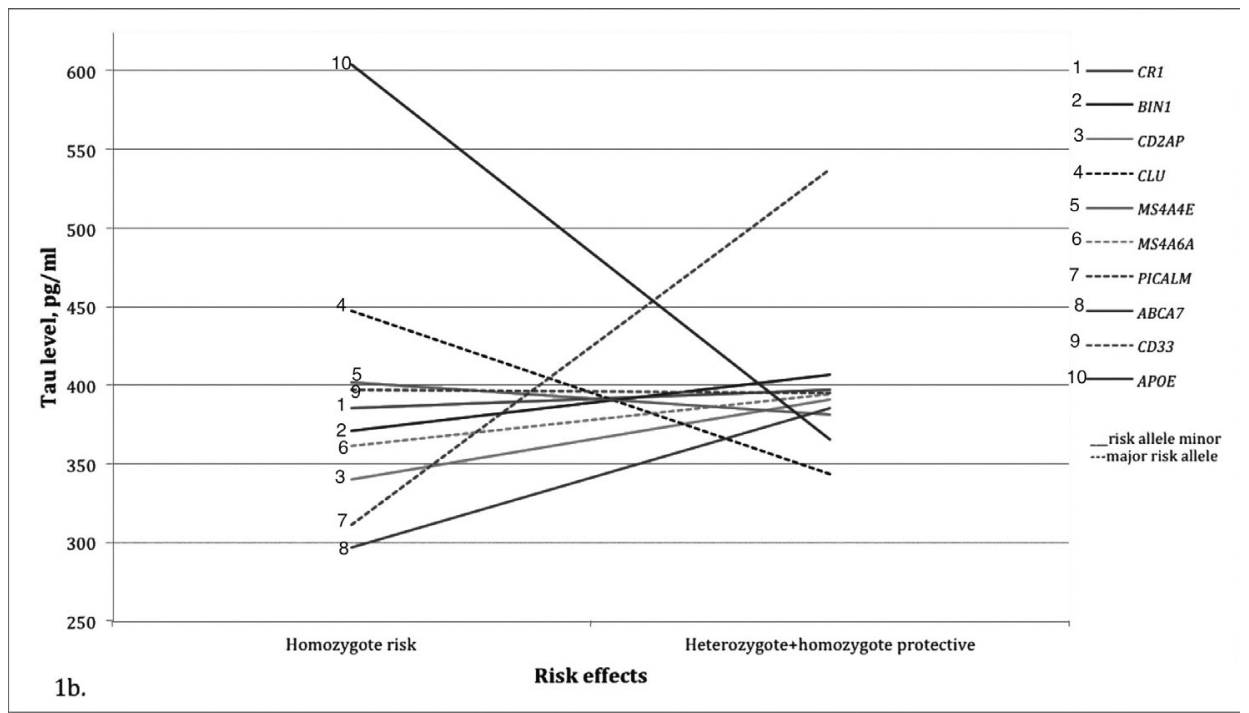

Relation between $A D$ risk genes and markers in t-tau. All data are means. 
Figure 1c

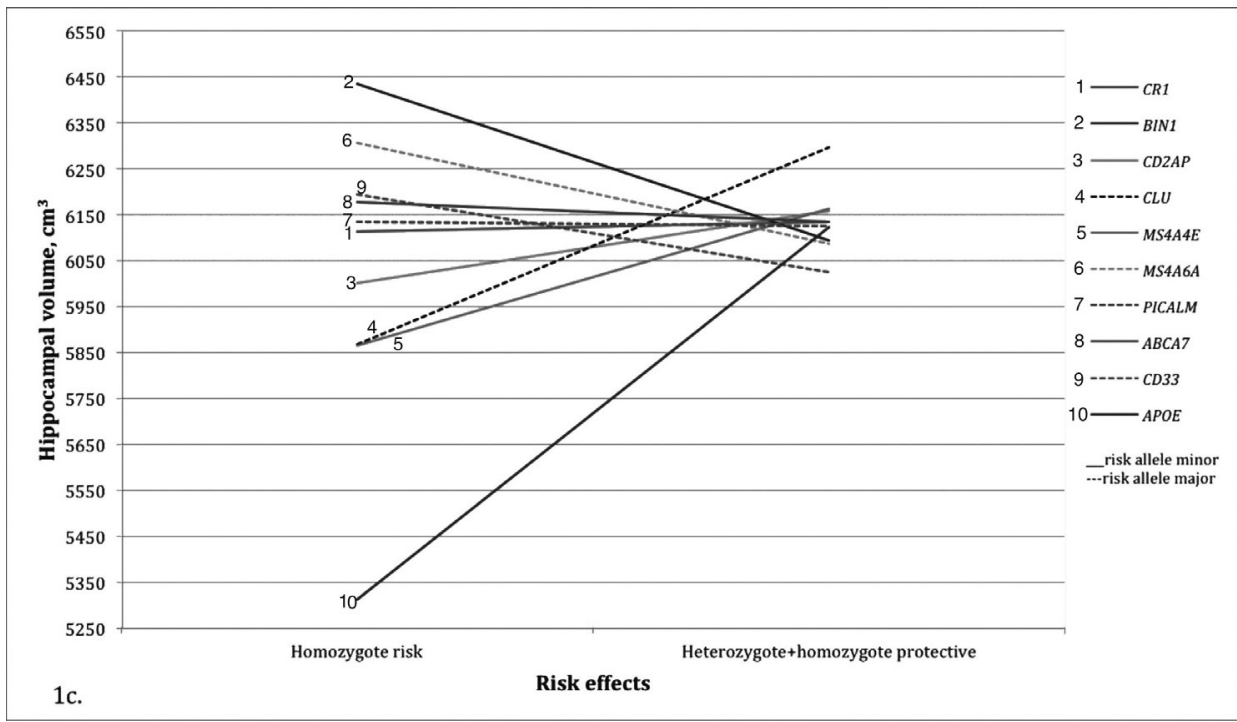

Relation between $A D$ risk genes and markers in hippocampal volume. All data are means.

Figure 1d

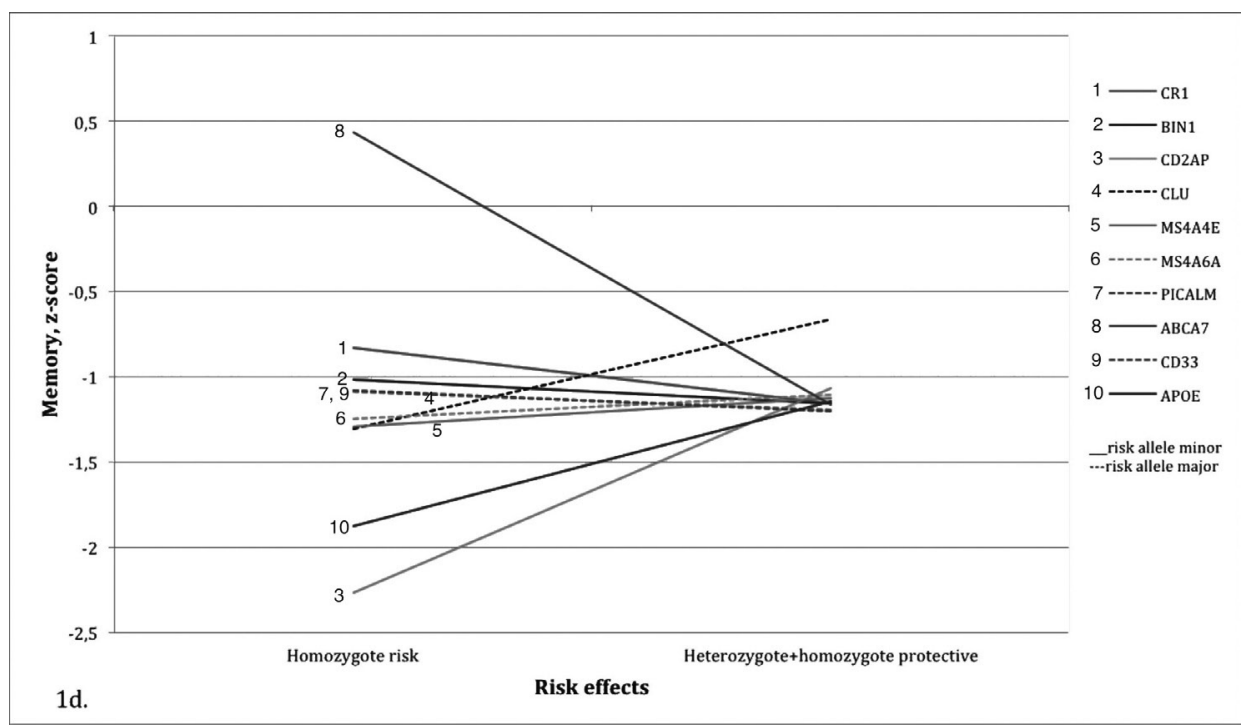

Relation between AD risk genes and markers in delayed memory. All data are means. 


\section{Effects of SNPs on progression to AD}

The risk effects related to the SNPs studied for progression to AD are presented in Table 4. As a reference, we also showed the odds ratio for $A D$ from the AlzGene.

Only the $\varepsilon_{4}$ allele of $A P O E$ was a significant predictor of $A D$ (OR 2.5, 95\% Cl 1.06-6.02, uncorrected $P=0.04$ ). CD2AP, MS4A4E, CLU, $M S_{4} A 6 A$ and PICALM showed an association with AD line with AlzGene findings, although this was not statistically significant. The outcomes for $C R 1, B I N 1, A B C A 7$ and $C D_{33}$ were in the opposite direction of what would be expected based on AlzGene meta-analyses.

Table 4 Predictive value of SNPs for progression to AD within 5 years $(n=29)$

\begin{tabular}{|l|l|l|l|l|}
\hline Chr, Gene & SNP/allele & OR $(95 \% \mathrm{Cl})$ & $P$-value & AlzGene OR $(95 \% \mathrm{CI})$ \\
\hline $1, C R 1$ & rs6656401 & $0.62(0.25-1.50)$ & 0.29 & $1.19(1.09-1.30)$ \\
\hline $2, B I N_{1}$ & rs744373 & $0.55(0.23-1.34)$ & 0.19 & $1.17(1.13-1.20)$ \\
\hline $6, C D 2 A P$ & rs9349407 & $1.70(0.70-4.02)$ & 0.24 & $1.12(1.08-1.16)$ \\
\hline $8, C L U$ & rs11136000 & $0.55(0.23-1.33)$ & 0.19 & $0.89(0.86-0.91)$ \\
\hline $11, M S_{4} A 4 E$ & rs670139 & $1.34(0.52-3.45)$ & 0.54 & $1.08(1.05-1.11)$ \\
\hline $11, M S_{4} A 6 A$ & rs610932 & $0.52(0.20-1.34)$ & 0.17 & $0.90(0.88-0.93)$ \\
\hline $11, P I C A L M$ & rs3851179 & $0.89(0.37-2.12)$ & 0.79 & $0.88(0.86-0.91)$ \\
\hline $19, A B C A 7$ & rs3764650 & $0.28(0.06-1.34)$ & 0.11 & $1.23(1.18-1.28)$ \\
\hline $19, C D 33$ & rs3865444 & $1.41(0.58-3.42)$ & 0.45 & $0.89(0.84-0.95)$ \\
\hline $19, A P O E$ & $\varepsilon 4$ & $2.53(1.06-6.02)$ & 0.04 & $3.68(3.30-4.11)$ \\
\hline
\end{tabular}

Dominant model used in the analyses. Odds ratio from AlzGene presented for reference purposes. SNPs, single nucleotide polymorphisms; AD, Alzheimer's disease; Chr, chromosome; $\mathrm{OR}$, odds ratio; $\mathrm{Cl}$, confidence interval.

\section{Post hoc analyses}

Our study sample was composed of patients with $\mathrm{MCl}$ and $\mathrm{SCl}$. When we excluded subjects with $\mathrm{SCl}$, the results remained essentially the same.

\section{DISCUSSION}

We tested the effects of the top 10 AlzGene loci on progression to $A D$ in nondemented patients with cognitive impairment, and performed a 
correlational study of these loci with $A \beta_{1-42}$ and tau in CSF, hippocampal volume and delayed memory.

\section{Relation to CSF biomarkers

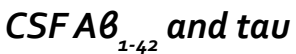

In the analyses with CSF biomarkers, the SNPs we tested generally showed some weak effects on CSF $A \beta_{1-42}$ but not on t-tau. We found that $A \beta_{1-42}$ concentrations were significantly reduced among APOE $\varepsilon 4$ allele carriers in our cohort. This is in accordance with previous findings in $\mathrm{MCl}$ in a clinical setting, ${ }^{56-58}$ and in a mixed clinical and population setting. ${ }^{59}$ In the largest study so far, the CSF level of $A \beta_{1-42}$ decreased with approximately $100 \mathrm{pg} / \mathrm{ml}$ for each APOE $\varepsilon 4$ allele, ${ }^{60}$ which is similar to that in the present study.

$A P O E$ did not correlate with t-tau in our patient population. Changes in tau have been reported to occur in the later phase of $A D$ pathogenesis. ${ }^{13}$ Previous studies have shown that $A P O E$ is involved in amyloid rather than tau pathology. ${ }^{56,61}$ In the present study, the APOE $\varepsilon_{4}$ allele was also related with the CSF $A \beta_{1-42} / t$-tau ratio which could be attributed to significantly reduced $A \beta_{1-42}$ levels and nonsignificant increase in t-tau concentrations.

PICALM was related to reduced CSF A $\beta_{1-42}$ levels in our cohort (unadjusted $P=0.02$ ), although this effect did not remain significant after multiple test correction. PICALM has been reported to increase $A \beta$ production and affect $A \beta$ neurotoxicity through endocytic regulation. ${ }^{62,}$ ${ }^{6}$ Neuropathological examination of a sample population composed mainly of individuals with no dementia has found a correlation between PICALM and amyloid but not tau pathology. A population study of individuals with no dementia that used a surrogate marker (rs7110631 for rs3851179) likewise obtained significant correlation with $A \beta$ but not tau upon brain autopsy. Another loci in PICALM (rs541458) has been linked with CSF $A \beta_{1-42}$ in AD but not in cognitively healthy controls, whereas no correlation was found with CSF t-tau. ${ }^{16}$ These results suggest that PICALM affects amyloid and this effect could be detected in the absence of dementia.

In PICALM, we found that the low CSF A $\beta_{1-42} / t$-tau ratio was driven by decreased $A \beta_{1-42}$ concentration among homozygous risk allele carriers, despite the fact that these subjects also had decreased t-tau 
levels. The correlation was marginal $(P=0.05)$. In a previous study, it was not rs3851179 but another loci in PICALM (rs541458) that was related to a CSF AD profile. ${ }^{64}$

$C D_{2} A P$ marginally correlated with reduced CSF $A \beta_{1-42}$ (unadjusted $P=0.06) . C D_{2} A P$ has a role in synapse formation in the immune system.$^{8}$ It has been reported to interact with an $A \beta$ toxicity modifier gene $\left(S Y N J_{1}\right)^{65}$ and has been suggested to contribute to $A D$ pathogenesis through synaptic dysfunction and cell membrane processes. ${ }^{66}$

None of the SNPs we tested correlated with t-tau. Abnormalities in tau concentrations have been linked to a later event in the pathogenesis of $A D^{13,22,67}$ rather than in predementia stages, which could explain why we found no effect of the SNPs on tau.

\section{Relation to hippocampal volume}

None of the SNPs tested significantly correlated with reduced hippocampal volume after multiple test correction. We observed a nonsignificant decrease in hippocampal volume in relation to $C L U, A P O E$ and $C R 1$.

$C L U$ is an apolipoprotein involved in lipid transport ${ }^{38}$. It binds soluble $A \beta$ and is present in amyloid plaques ${ }^{68} \mathrm{It}$ is interesting to note that CLU affected hippocampal volume more than CSF $A \beta_{1-42}$ in our cohort. As mentioned, decrease in hippocampal volume is a later event in the $A D$ pathogenesis.

The APOE $\varepsilon 4$ allele marginally correlated with reduced hippocampal volume in our cohort. This is in line with previous studies reporting hippocampal volume loss related to $A P O E$ in $\mathrm{MCl}$ and among cognitively healthy control subjects but not in $A D .69,70$

$C R 1$ has a suggested role in neuroinflammation and in $A \beta$ clearance since it binds $A \beta$ oligomers to its $C_{3} b$ complement factor. ${ }^{38,71}$ In the present study, $C R 1$ homozygous nonrisk allele carriers had reduced hippocampal volume. This finding is not supported by literature and may have been the result of our small sample size. $C R 1$ has not been shown in previous studies to affect the hippocampus. ${ }^{24,72}$ In a study of young healthy individuals, homozygous risk allele carriers of $C R 1$ rs6656401 have been shown to have reduced gray matter in the entorhinal cortex..$^{22}$ A similar finding for another loci in $\mathrm{CR}_{1}$ ( $\mathrm{rs1408077)}$ has been reported in another study in a mixed clinical and population setting. ${ }^{24}$ In the same study, rs1408077 was not related to hippocampal atrophy. 


\section{Relation to delayed memory}

$C D_{2} A P$ showed correlation to delayed memory at an unadjusted $P$-value. $C D_{2} A P$ has not been shown in a previous study to significantly affect memory, although this study pertained to nondemented individuals in a general population. ${ }^{73}$ It is conceivable that subtle effects of $C D_{2} A P$ on memory are more detectable in a population of nondemented individuals with cognitive impairment in a clinical setting, such as our cohort. Further research is needed to verify the influence of $C D_{2} A P$ on memory.

We observed a weak correlation between $A P O E$ and delayed memory $(P=0.08)$. APOE does not appear to directly affect cognition. Rather, it influenced CSF $A \beta_{1-42}$ concentrations in our cohort. In MCl, $A P O E$ has been correlated with poor episodic memory in the presence of low CSF $A \beta_{1-42^{2}}{ }^{74} \mathrm{~A}$ high cerebral $A \beta$ load rather than $A P O E$ has been reported to strongly affect episodic memory among cognitively healthy elderly. ${ }^{75}$ However, NFTs rather than amyloid deposition have been hypothesized to be related to cognitive decline. ${ }^{76}$ This has been shown in clinicopathological studies wherein $A P O E$ has been correlated with $A \beta$ deposition and NFTs. 77,78 In turn, NFTs have been associated with cognitive decline and the clinical diagnosis of AD. ${ }^{79}$ Our cohort consisted of nondemented patients, and because tangle formation is a later pathogenic event in $A D$, this partly explains why we found no significant correlation with delayed memory.

The observation that risk allele carriers of $A B C A 7$ rs3764650 appeared to have better delayed recall compared to noncarriers was unexpected but may be due to the small number of risk allele carriers in our cohort. A recent study has found no correlation between $A B C A 7$, memory and other cognitive domains among nondemented individuals in a population setting. ${ }^{73}$

\section{Effects on clinical $A D$ as outcome}

Only APOE was a significant predictor of AD in our cohort. Carriers of the $\varepsilon_{4}$ allele had a 2.5 -fold risk of progressing to $A D$ compared to noncarriers. This approximates the findings of a previous study of the predictive accuracy of the $\varepsilon_{4}$ allele allele for progression from $\mathrm{MCl}$ to $\mathrm{AD}$-type dementia. ${ }^{80} \mathrm{~A}$ few loci we tested conferred weak effects on the risk of developing $A D$, in line with AlzGene cross-sectional findings. Other genes, 
however, showed an opposite effect. These genes, including $A B C A 7$, also showed an opposite effect with delayed recall.We tested four markers that become abnormal in different stages of AD. Only APOE showed a consistent pattern for all markers. $C D_{2} A P$ showed both an effect on CSF $A \beta_{1-42}$ and memory, but for the other SNPs, patterns were less consistent. The observation that SNPs correlated with some markers but not with others may indicate that the SNPs are associated with different pathophysiological mechanisms, but larger studies are needed to confirm this.

Our study was performed in a memory clinic population of nondemented patients. Some of these may have early stage AD while others may have cognitive impairments due to other causes. It is likely that the association between SNPs and AD markers will be dependent on the sample and stage of $A D$, as markers will vary with disease stage. This may also explain some of the discrepant findings with studies performed in other settings. The observation that SNPs had a very weak association with clinical outcome suggests that they are of limited use for giving patients with $\mathrm{SCl}$ or $\mathrm{MCl}$ a prognosis.

\section{Strengths and limitations}

One of the strengths, and a novel aspect, of the present study is the combination of $\mathrm{MCl}$ and $\mathrm{SCl}$ patients in a memory clinic setting. This patient population is at risk of progressing to $A D$, yet has not been studied before in relation to $A D$ risk genes and key markers of $A D$ pathology. Another strength is that we examined four markers that reflect different stages of AD. Our small sample size and the subsequent use of a dominant genetic model in the analyses is a limitation. Our findings must be interpreted in the exploratory context of the present study.

\section{Conclusion}

Only $A P O E$ predicted progression to $A D$, showed a consistent effect on $A D$ markers, and correlated significantly with $C S F A \beta_{1-42^{2}}$. APOE showed stronger effects on all outcomes compared to recently discovered AD genetic risk factors. This is in line with stronger association with clinical $A D$ according to AlzGene. Given the weak effects of the newly discovered genetic risk factors on $A D$, larger studies are needed to better understand the relation between these genes and AD pathophysiology. 


\section{REFERENCES}

1. Lambert JC, Amouyel P. Genetics of Alzheimer's disease: new evidences for an old hypothesis? Curr Opin Genet Dev 2011; 21(3): 295-301.

2. Bertram L, Tanzi RE. Thirty years of Alzheimer's disease genetics: the implications of systematic metaanalyses. Nat Rev Neurosci 2008; 9(10): 768-78.

3. Harold D, Abraham R, Hollingworth $P$, Sims R, Gerrish A, Hamshere ML, et al. Genome-wide association study identifies variants at CLU and PICALM associated with Alzheimer's disease. Nat Genet 2009; 41(10): 1088-93.

4. Seshadri S, Fitzpatrick AL, Ikram MA, DeStefano AL, Gudnason V, Boada M, et al. Genome-wide analysis of genetic loci associated with Alzheimer disease. JAMA 2010; 303(18): 1832-40.

5. Lambert JC, Heath S, Even G, Campion D, Sleegers K, Hiltunen M, et al. Genome-wide association study identifies variants at CLU and CR1 associated with Alzheimer's disease. Nat Genet 2009; 41(10): 1094-9.

6. Hollingworth P, Harold D, Sims R, Gerrish A, Lambert JC, Carrasquillo MM, et al. Common variants at $A B C A 7, M_{4} A 6 A / M S_{4} A_{4} E_{1}, E P H A 1, C D_{33}$ and $C_{2} A P$ are associated with Alzheimer's disease. Nat Genet 2011; 43(5): 429-35.

7. Bertram L, Lange C, Mullin K, Parkinson M, Hsiao M, Hogan MF, et al. Genome-wide association analysis reveals putative Alzheimer's disease susceptibility loci in addition to APOE. Am J Hum Genet 2008; 83(5): $623-32$.

8. Naj AC, Jun G, Beecham GW, Wang LS, Vardarajan BN, Buros J, et al. Common variants at MS4A4/ $\mathrm{MS}_{4} \mathrm{~A} 6 \mathrm{E}, \mathrm{CD}_{2} \mathrm{AP}, \mathrm{CD}_{33}$ and EPHA1 are associated with late-onset Alzheimer's disease. Nat Genet 2011; 43(5): 436-41.

9. Blennow K, de Leon MJ, Zetterberg H. Alzheimer's disease. Lancet 2006; 368(9533): 387-403.

10. Braithwaite SP, Stock JB, Lombroso PJ, Nairn AC. Protein phosphatases and Alzheimer's disease. Prog Mol Biol Transl Sci 2012; 106: 343-79.

11. Spires-Jones TL, Stoothoff WH, de Calignon A, Jones PB, Hyman BT. Tau pathophysiology in neurodegeneration: a tangled issue. Trends Neurosci 2009; 32(3): 150-9.

12. Cruchaga C, Kauwe JS, Mayo K, Spiegel N, Bertelsen S, Nowotny P, et al. SNPs associated with cerebrospinal fluid phospho-tau levels influence rate of decline in Alzheimer's disease. PLoS Genet 2010; 6(9).

13. Buchhave $P$, Minthon L, Zetterberg H, Wallin AK, Blennow K, Hansson O. Cerebrospinal fluid levels of beta-amyloid 1-42, but not of tau, are fully changed already 5 to 10 years before the onset of Alzheimer dementia. Arch Gen Psychiatry 2012; 69(1): 98-106.

14. Dubois B, Feldman HH, Jacova C, Dekosky ST, Barberger-Gateau P, Cummings J, et al. Research criteria for the diagnosis of Alzheimer's disease: revising the NINCDS-ADRDA criteria. Lancet Neurol 2007; 6(8): 734-46.

15. Dubois B, Feldman HH, Jacova C, Cummings JL, Dekosky ST, Barberger-Gateau P, et al. Revising the definition of Alzheimer's disease: a new lexicon. Lancet Neurol 2010; 9(11): 1118-27. 
16. Schjeide BM, Schnack C, Lambert JC, Lill CM, Kirchheiner J, Tumani H, et al. The role of clusterin, complement receptor 1 , and phosphatidylinositol binding clathrin assembly protein in Alzheimer disease risk and cerebrospinal fluid biomarker levels. Arch Gen Psychiatry 2011; 68(2): 207-13.

17. Brouwers N, Cauwenberghe CV, Engelborghs S, Lambert JC, Bettens K, Bastard NL, et al. Alzheimer risk associated with a copy number variation in the complement receptor 1 increasing $\mathrm{C}_{3} \mathrm{~b} / \mathrm{C}_{4} \mathrm{~b}$ binding sites. Mol Psychiatry 2012; 17(2): 223-33.

18. Schott JM. Using CSF biomarkers to replicate genetic associations in Alzheimer's disease. Neurobiol Aging 2012; 33(7): 1486 eg-15.

19. Padurariu M, Ciobica A, Mavroudis I, Fotiou D, Baloyannis S. Hippocampal neuronal loss in the $C_{1}$ and $C A_{3}$ areas of Alzheimer's disease patients. Psychiatr Danub 2012; 24(2): 152-8.

20. Chupin M, Gerardin E, Cuingnet R, Boutet C, Lemieux L, Lehericy S, et al. Fully automatic hippocampus segmentation and classification in Alzheimer's disease and mild cognitive impairment applied on data from ADNI. Hippocampus 2009; 19(6): 579-87.

21. Morra JH, Tu Z, Apostolova LG, Green AE, Avedissian C, Madsen SK, et al. Automated mapping of hippocampal atrophy in 1-year repeat MRI data from 490 subjects with Alzheimer's disease, mild cognitive impairment, and elderly controls. Neuroimage 2009; 45(1 Suppl): S3-15.

22. van Rossum IA, Visser PJ, Knol DL, van der Flier WM, Teunissen CE, Barkhof F, et al. Injury markers but not amyloid markers are associated with rapid progression from mild cognitive impairment to dementia in Alzheimer's disease. J Alzheimers Dis 2012; 29(2): 319-27.

23. Visser PJ, Verhey FR, Hofman PA, Scheltens P, Jolles J. Medial temporal lobe atrophy predicts Alzheimer's disease in patients with minor cognitive impairment. J Neurol Neurosurg Psychiatry 2002; 72(4): 491-7.

24. Biffi A, Anderson CD, Desikan RS, Sabuncu M, Cortellini L, Schmansky N, et al. Genetic variation and neuroimaging measures in Alzheimer disease. Arch Neurol 2010; 67(6): 677-85.

25. Dik MG, Jonker C, Bouter LM, Geerlings MI, van Kamp GJ, Deeg DJ. APOE-epsilon 4 is associated with memory decline in cognitively impaired elderly. Neurology 2000; 54(7): 1492-7.

26. Reynolds CA, Prince JA, Feuk L, Brookes AJ, Gatz M, Pedersen NL. Longitudinal memory performance during normal aging: twin association models of APOE and other Alzheimer candidate genes. Behav Genet 2006; 36(2): 185-94.

27. Lee JH, Flaquer A, Stern Y, Tycko B, Mayeux R. Genetic influences on memory performance in familial Alzheimer disease. Neurology 2004; 62(3): 414-21.

28. Barral S, Bird T, Goate A, Farlow MR, Diaz-Arrastia R, Bennett DA, et al. Genotype patterns at PICALM, CR1, BIN1, CLU, and APOE genes are associated with episodic memory. Neurology 2012; 78(19): 1464-71. 
29. Jack CR, Jr. Alzheimer disease: new concepts on its neurobiology and the clinical role imaging will play. Radiology 2012; 263(2): 344-61.

30. van Rossum IA, Vos SJ, Burns L, Knol DL, Scheltens $P$, Soininen $H$, et al. Injury markers predict time to dementia in subjects with $\mathrm{MCl}$ and amyloid pathology. Neurology 2012.

31. Visser PJ, Kester A, Jolles J, Verhey F. Ten-year risk of dementia in subjects with mild cognitive impairment. Neurology 2006; 67(7): 1201-7.

32. Visser PJ, Verhey FRJ, Boada M, Bullock R, De Deyn PP, Frisoni GB, et al. Development of Screening Guidelines and Clinical Criteria for Predementia Alzheimer's Disease: The DESCRIPA Study. Neuroepidemiology 2008; 30(4): 254-65.

33. APA. Diagnostic and statistical manual of mental dsorders (DSM-IV). Fourth edition ed. Washington, DC: American Psychiatric Association; 1994.

34. McKhann G, Drachman D, Folstein M, Katzman R, Price D, Stadlan EM. Clinical diagnosis of Alzheimer's disease: report of the NINCDS-ADRDA Work Group under the auspices of Department of Health and Human Services Task Force on Alzheimer's Disease. Neurology 1984i 34(7): 939-44.

35. Visser PJ, Verhey F, Knol DL, Scheltens P, Wahlund LO, Freund-LeviY, et al. Prevalence and prognostic value of CSF markers of Alzheimer's disease pathology in patients with subjective cognitive impairment or mild cognitive impairment in the DESCRIPA study: a prospective cohort study. Lancet Neurol 2009; 8(7): 619-27.

36. Folstein MF, Folstein SE, McHugh PR. "Mini-mental state". A practical method for grading the cognitive state of patients for the clinician. J Psychiatr Res 1975; 12(3): 189-98.

37. Elias-Sonnenschein LS, Bertram L, Visser PJ. Relationship between genetic risk factors and markers for Alzheimer's disease pathology. Biomark Med 2012; 6(4): 477-95.

38. Schellenberg GD, Montine TJ. The genetics and neuropathology of Alzheimer's disease. Acta Neuropathol 2012.

39. Olgiati P, Politis AM, Papadimitriou GN, De Ronchi D, Serretti A. Genetics of late-onset Alzheimer's disease: update from the alzgene database and analysis of shared pathways. Int J Alzheimers Dis 2011; 2011: 832379.

40. Bertram L, McQueen MB, Mullin K, Blacker D, Tanzi RE. Systematic meta-analyses of Alzheimer disease genetic association studies: the AlzGene database. Nat Genet 2007; 39(1): 17-23.

41. Ioannidis JP, Boffetta P, Little J, O'Brien TR, Uitterlinden AG, Vineis P, et al. Assessment of cumulative evidence on genetic associations: interim guidelines. Int J Epidemiol 2008; 37(1): 120-32.

42. Ghebranious N, Ivacic L, Mallum J, Dokken C. Detection of ApoE E2, E3 and E4 alleles using MALDI-TOF mass spectrometry and the homogeneous mass-extend technology. Nucleic Acids Res 2005; 33(17): e149. 
43. Salanti G, Southam L, Altshuler D, Ardlie K, Barroso I, Boehnke M, et al. Underlying genetic models of inheritance in established type 2 diabetes associations. Am J Epidemiol 2009; 170(5): 537-45.

44. Van der Elst W, van Boxtel MP, van Breukelen GJ, Jolles J. Rey's verbal learning test: normative data for 1855 healthy participants aged $24-81$ years and the influence of age, sex, education, and mode of presentation. J Int Neuropsychol Soc 2005; 11(3): 290-302.

45. Buschke H. Selective reminding analysis of memory and learning. Journal of Verbal Learning and Verbal Behavior 1973; 12: 543-50.

46. Brandt J. The Hopkins Verbal Learning Test: Development of a New Memory Test with Six Equivalent Forms. The Clinical Neuropsychologist 1991; 5(2): 125-42.

47. Mulder C, Verwey NA, van der Flier WM, Bouwman FH, Kok A, van Elk EJ, et al. Amyloidbeta(1-42), total tau, and phosphorylated tau as cerebrospinal fluid biomarkers for the diagnosis of Alzheimer disease. Clin Chem 2010; 56(2): 248-53.

48. van Rossum IA, Vos S, Handels R, Visser PJ. Biomarkers as predictors for conversion from mild cognitive impairment to Alzheimer-type dementia: implications for trial design. J Alzheimers Dis 2010; 20(3): 881-91.

49. Vos $S$, van Rossum I, Burns L, Knol D, Scheltens P, Soininen $H$, et al. Test sequence of CSF and MRI biomarkers for prediction of $A D$ in subjects with $\mathrm{MCl}$. Neurobiol Aging 2012; 33(10): 2272-81.

50. van de Pol LA, Verhey F, Frisoni GB, Tsolaki M, Papapostolou P, Nobili F, et al. White matter hyperintensities and medial temporal lobe atrophy in clinical subtypes of mild cognitive impairment: the DESCRIPA study. J Neurol Neurosurg Psychiatry 2009; 80(10): 1069-74.

51. Wolz R, Aljabar P, Hajnal JV, Hammers A, Rueckert D. LEAP: learning embeddings for atlas propagation. Neuroimage 2010; 49(2): 1316-25.

52. Evans AC, Collins DL, Mills SR, Brown ED, Kelly RL, Peters TM. 3D statistical neuroanatomical models from 305 MRI volumes. Proc IEEE Nucl Sci Symp Med Imaging Conf 1993: 1813-7.

53. BenjaminiY, Drai D, Elmer G, Kafkafi N, Golani I. Controlling the false discovery rate in behavior genetics research. Behav Brain Res 2001; 125(1-2): 279-84.

54. BenjaminiY, Yekutieli D. Quantitative trait Loci analysis using the false discovery rate. Genetics 2005; 171(2): 783-90.

55. Pawitan Y, Michiels S, Koscielny S, Gusnanto A, Ploner A. False discovery rate, sensitivity and sample size for microarray studies. Bioinformatics 2005; 21(13): 3017-24.

56. Guo LH, Westerteicher C, Wang XH, Kratzer M, Tsolakidou A, Jiang M, et al. SORL1 genetic variants and cerebrospinal fluid biomarkers of Alzheimer's disease. Eur Arch Psychiatry Clin Neurosci 2012. 
57. Kester MI, Verwey NA, van Elk EJ, Blankenstein MA, Scheltens P, van der Flier WM. Progression from $\mathrm{MCl}$ to $\mathrm{AD}$ : predictive value of CSF Abeta 42 is modified by APOE genotype. Neurobiol Aging 2011; 32(8): 1372-8.

58. Seppala TT, Koivisto AM, Hartikainen P, Helisalmi S, Soininen $H$, Herukka SK. Longitudinal changes of CSF biomarkers in Alzheimer's disease. J Alzheimers Dis 2011; 25(4): 583-94.

59. Alexopoulos P, Guo LH, Kratzer M, Westerteicher C, Kurz A, Perneczky R. Impact of SORL1 single nucleotide polymorphisms on Alzheimer's disease cerebrospinal fluid markers. Dement Geriatr Cogn Disord 2011; 32(3): 164-70.

6o. Prince JA, Zetterberg H, Andreasen N, Marcusson J, Blennow K. APOE epsilon4 allele is associated with reduced cerebrospinal fluid levels of Abeta42. Neurology 2004; 62(11): 2116-8.

61. Kok EH, Luoto T, Haikonen S, Goebeler S, Haapasalo H, Karhunen PJ. CLU, CR1 and PICALM genes associate with Alzheimer's-related senile plaques. Alzheimers Res Ther 2011; 3(2): 12.

62. Miller SE, Sahlender DA, Graham SC, Honing S, Robinson MS, Peden AA, et al. The molecular basis for the endocytosis of small R-SNAREs by the clathrin adaptor CALM. Cell 2011; 147(5): 1118-31.

63. Maritzen T, Koo SJ, Haucke V. Turning CALM into excitement: AP180 and CALM in endocytosis and disease. Biol Cell 2012.

64. Anderson VM, Schott JM, Bartlett JW, Leung KK, Miller DH, Fox NC. Gray matter atrophy rate as a marker of disease progression in AD. Neurobiol Aging 2010.

65. Rosenthal SL, Wang X, Demirci FY, Barmada MM, Ganguli M, Lopez OL, et al. Beta-Amyloid Toxicity Modifier Genes and the Risk of Alzheimer's Disease. Am J Neurodegener Dis 2012; 1(2): 191-8.

66. Morgan K. The three new pathways leading to Alzheimer's disease. Neuropathol Appl Neurobiol 2011; 37(4): 353-7.

67. Andersson C, Blennow K, Almkvist O, Andreasen N, Engfeldt P, Johansson SE, et al. Increasing CSF phospho-tau levels during cognitive decline and progression to dementia. Neurobiol Aging 2008; 29(10): 1466-73.

68. Kida E, Choi-Miura NH, Wisniewski KE. Deposition of apolipoproteins E and J in senile plaques is topographically determined in both Alzheimer's disease and Down's syndrome brain. Brain Res 1995; 685(1-2): 211-6.

69. Chiang GC, Insel PS, Tosun D, Schuff N, Truran-Sacrey D, Raptentsetsang ST, et al. Impact of apolipoprotein $\mathrm{E}_{4}$-cerebrospinal fluid beta-amyloid interaction on hippocampal volume loss over 1 year in mild cognitive impairment. Alzheimers Dement 2011; 7(5): 514-20.

70. Tosun D, Schuff N, Truran-Sacrey D, Shaw LM, Trojanowski JQ, Aisen P, et al. Relations between brain tissue loss, CSF biomarkers, and the ApoE genetic profile: a longitudinal MRI study. Neurobiol Aging 2010; 31(8): 1340-54. 
71. Sleegers K, Lambert JC, Bertram L, Cruts M, Amouyel P, Van Broeckhoven C. The pursuit of susceptibility genes for Alzheimer's disease: progress and prospects. Trends Genet 2010; 26(2): 84-93.

72. Bralten J, Franke B, Arias-Vasquez A, Heister A, Brunner HG, Fernandez G, et al. CR1 genotype is associated with entorhinal cortex volume in young healthy adults. Neurobiol Aging 2011; 32(11): 2106 e7-11.

73. Verhaaren BF, Vernooij MW, Koudstaal PJ, Uitterlinden AG, Duijn CM, Hofman A, et al. Alzheimer's Disease Genes and Cognition in the Nondemented General Population. Biol Psychiatry 2012.

74. Thorvaldsson V, Nordlund A, Reinvang I, Blennow K, Zetterberg H, Wallin A, et al. Memory in individuals with mild cognitive impairment in relation to APOE and CSF Abeta42. Int Psychogeriatr 2010; 22(4): 598-606.

75. Lim YY, Ellis KA, Pietrzak RH, Ames D, Darby D, Harrington K, et al. Stronger effect of amyloid load than APOE genotype on cognitive decline in healthy older adults. Neurology 2012; 79(16): 1645-52.

76. Jack CR, Jr., Knopman DS, Jagust WJ, Shaw LM, Aisen PS, Weiner MW, et al. Hypothetical model of dynamic biomarkers of the Alzheimer's pathological cascade. Lancet Neurol 2010; 9(1): 119-28.

77. Bennett DA, Wilson RS, Schneider JA, Evans DA, Aggarwal NT, Arnold SE, et al. Apolipoprotein E epsilon 4 allele, AD pathology, and the clinical expression of Alzheimer's disease. Neurology 2003; 60(2): 246-52.

78. Bennett DA, Schneider JA, Wilson RS, Bienias JL, Berry-Kravis E, Arnold SE. Amyloid mediates the association of apolipoprotein $E \varepsilon_{4}$ allele to cognitive function in older people. $J$ Neurol Neurosurg Psychiatry 2005; 76(9): 1194-9.

79. Bennett DA, Schneider JA, Wilson RS, Bienias JL, Arnold SE. Neurofibrillary tangles mediate the association of amyloid load with clinical Alzheimer disease and level of cognitive function. Arch Neurol 2004; 61(3): 378-84.

8o. Elias-Sonnenschein LS, Viechtbauer W, Ramakers IH, Verhey FR, Visser PJ. Predictive value of APOE-epsilon 4 allele for progression from $\mathrm{MCl}$ to AD-type dementia: a meta-analysis. $J$ Neurol Neurosurg Psychiatry 2011; 82(10): 1149-56. 

Genetic variations-so-called SNPS-- in APOE, MS4A 4A and CLU were related to abnormally low $A \beta_{1-42}$ levels in Finnish patients with $A D$. 
LS Elias-Sonnenschein, S Helisalmi, T Natunen, A Hall, T Paajanen, S-K Herukka, M Laitinen, AM Remes, AM Koivisto, KM Mattila, T Lehtimäki, FRJ Verhey,

PJ Visser, $\mathrm{H}$ Soininen, $\mathrm{M}$ Hiltunen

PLOS ONE, 2013 (In Press)

\section{CHAPTER 7}

Genetic loci associated with Alzheimer's disease and cerebrospinal fluid biomarkers in a Finnish case-control study

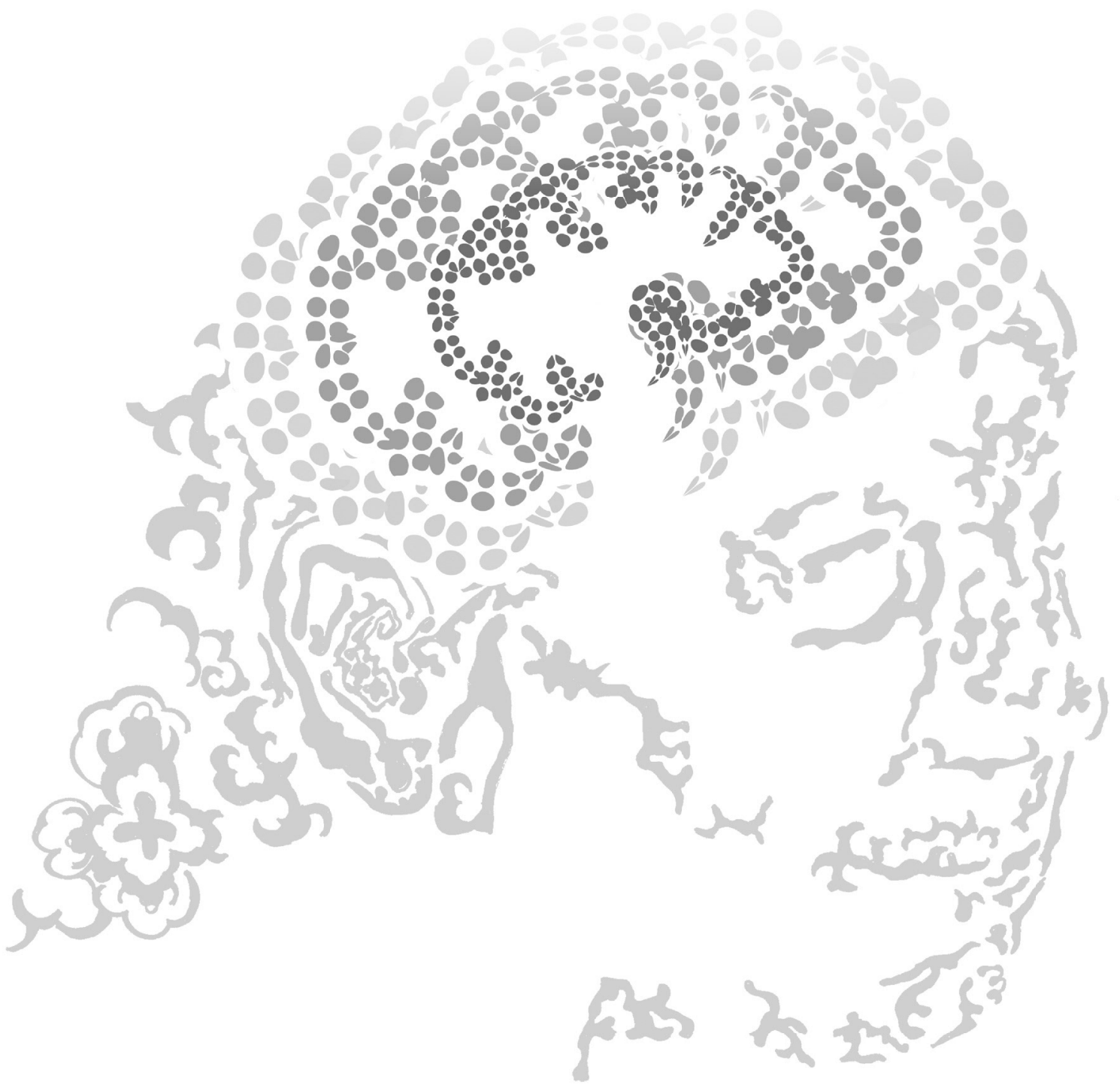




\section{ABSTRACT}

Background: To understand the relation between genetic risk factors for Alzheimer's disease (AD) and their influence on biomarkers for $A D$, we examined the association between $A D$ in the Finnish cohort and single nucleotide polymorphisms (SNPs) from top AlzGene loci, genome-wide association studies (GWAS), and candidate gene studies; and tested the correlation between these SNPs and AD markers $A \beta_{1-42}$ total tau (t-tau), and phosphorylated tau (p-tau) in cerebrospinal fluid (CSF).

Methods: We tested 24 SNPs for genetic association with clinical AD in our cohort comprised of 890 AD patients and 701-age matched healthy controls using logistic regression. For the correlational study with biomarkers, we tested 36 SNPs in a subset of 222 AD patients with available CSF using mixed models. Statistical analyses were adjusted for age, gender and $A P O E$ status. False discovery rate for multiple testing was applied. All participants were from academic hospital and research institutions in Finland.

Results: $A P O E-\varepsilon 4, C L U$ rs111360oo and MS4A 4 A rs2304933 correlated with significantly decreased $A \beta_{1-42}$ (corrected $P<0.05$ ). At an uncorrected $P<0.05, P P P_{3} R 1$ rs1868402 and MAPT rs2435211 were related with increased t-tau; while SORL1 rs73595277 and MAPT rs16940758, with increased p-tau. Only TOMM4O rs2075650 showed association with clinical $A D$ after adjusting for $A P O E-\varepsilon_{4}(P=0.007)$, but not after multiple test correction $(P>0.05)$.

Conclusions: We provide evidence that $A P O E-\varepsilon_{4}, C L U$ and $M S_{4} A_{4} A$, which have been identified in GWAS to be associated with $A D$, also significantly reduced CSF A $\beta_{1-42}$ in AD. None of the other AlzGene and GWAS loci showed significant effects on CSF tau. The effects of other SNPs on CSF biomarkers and clinical AD diagnosis did not reach statistical significance. Our findings suggest that $C L U$ and $M S_{4} A_{4} A$ influence both $A D$ risk and CSF $A \beta_{1-42}$

Keywords: Alzheimer, genetics, single nucleotide polymorphisms, amyloid, tau, biomarkers, cerebrospinal fluid, case-control 


\section{INTRODUCTION}

Alzheimer's disease (AD) is a neurodegenerative disease with a complex etiology. Neuritic plaques mainly composed of aggregated amyloid beta $(A \beta)$ and neurofibrillary tangles (NFTs) resulting from hyperphosporylated tau protein ( $p$-tau) are pathological hallmarks of $A D .{ }^{1} A \beta_{1-42}$ tends to aggregate more compared to other $A \beta$ isoforms. ${ }^{2}$ Total tau (t-tau) concentrations in cerebrospinal fluid (CSF) have been suggested to indicate the extent of neuronal damage, while p-tau levels reflected the phosphorylated state of tau. ${ }^{3} \mathrm{P}$-tau and t-tau levels signal axonal degeneration. ${ }^{4}, 5$ In $A D$, the concentration of CSF $A \beta_{1-42}$ is decreased, which is supposed to reflect sequestration of $A \beta_{1-42}$ in amyloid plaques in the brain, ${ }^{6}$ while $t$-tau and $p$-tau levels are increased. ${ }^{1}$

Genetically, AD is differentiated into Mendelian and non-Mendelian forms. AD with a Mendelian disease transmission typically has an early onset age (below 65 years) and caused by rare, highly penetrant mutations in the amyloid precursor protein (APP), presenilin 1 (PSEN1), or presenilin 2 (PSEN2) genes. The prevalence of AD due to APP, PSEN1, and PSEN 2 mutations is less than $5 \% .{ }^{7}$ The majority of $A D$ cases are of the non-Mendelian forms, which have been reported to have a strong genetic component. ${ }^{8}$ The apolipoprotein $\mathrm{E}(A P O E) \varepsilon_{4}$ allele is the strongest known genetic risk factor for AD.

Other high-risk genetic variants have been identified in genome-wide association studies (GWAS) (for review, see9). In addition, previous studies showed that a number of candidate genes correlated with $A \beta$ or tau. However, the relation between these AD risk genes and $A D$ biomarkers remains ambiguous. With the exception of $A P O E$ and translocase of outer mitochondrial membrane 40 homolog (TOMM4O), single nucleotide polymorphisms (SNPs) identified in case-control GWAS with clinical AD as outcome have not been replicated in GWAS with biomarkers as outcome..$^{10}$

In this study, we first investigated whether previously reported genetic risk factors for $A D$ were associated with $A D$ risk in a Finnish case-control cohort. Second, we tested in the AD group the effects of these variants on the AD markers $A \beta_{1-42}$ and tau in CSF. We selected SNPs from AlzGene and GWAS, and from candidate genes that previously showed a relation with CSF A $\beta_{1-42}$ and tau. 


\section{METHODS}

\section{Study population}

The Finnish-AD is a multicenter cohort comprised of $890 \mathrm{AD}$ patients and 701 age-matched healthy controls from Kuopio, Oulu and Tampere in Finland. All patients were diagnosed with probable AD according to the National Institute of Neurological and Communicative Disorders and Stroke and the Alzheimer's Disease and Related Disorders Association (NINCDS-ADRDA) criteria. ${ }^{11}$ AD patients with an early onset did not show conclusive evidence of autosomal dominant transmission or mutations in APP, PSEN1 or PSEN2. Control subjects had no symptoms of cognitive impairment based on clinical interview and neuropsychological examination. Of the 890 AD patients, 222 from Kuopio provided CSF for our study.

The Ethics Committee of the North-Savo Hospital District, Kuopio, Finland, approved the study. The physician and/or the study nurse gave written information of the study and explained the study protocol to the patient and caretaker if available. All participants provided written informed consent. A next of kin, caretakers or guardians consented on behalf of participants whose capacity to consent was compromised. In these cases, also the patient's own opinion was asked and considered, and the patient was recruited in the study only when he or she also agreed with this. The ethics committee approved this informed consent procedure.

\section{Gene selection}

We selected genes based on their reported association with AD or effect on CSF A $\beta$ and tau. We included the 10 'top results' loci from AlzGene, which is an online database providing meta-analyses of published genetic association studies (for AlzGene top results criteria, see ${ }^{12}$ ), and selected the most promising SNPs from GWAS or other candidate gene studies. APOE, CR1, BIN1, CD2AP, CLU, MS4A4E, MS4A6A, PICALM, $A B C A 7$ and $C D 33$ were from $A l z G e n e$ (for gene names, see Supplementary table). Analyses with $A P O E$ alone were performed for reference purposes only because $A P O E$ is an established susceptibility gene for sporadic $A D \cdot{ }^{12-14}$ Functions of the AlzGene variants in relation to $A D$ have been previously described. ${ }^{10,15,16} M S_{4} A_{4} A, E X O C_{3} L 2$ and $M T H F D_{1} L$ have 
been shown in GWAS to be associated with $A D^{17-19}$ but have not been included in the AlzGene top list to date.

CYP19A and TOMM40 have been shown in GWAS with biomarkers as outcome to be related to $A \beta$, whereas $E P C 2$ and $R E L N$ were associated with tau. ${ }^{20-22} C Y P_{19} A$ has also been reported to increase $A D$ risk. ${ }^{23}$

The candidate genes we selected that have been studied in relation to CSF biomarkers were $A C E$, IDE, MAPT, SORL1, CYP46A1, $B D N F_{1} T F_{1} P P_{3} R_{1}$ and another TOMM4O polymorphism. The effects of $A C E, M A P T, S O R L 1$ and TOMM4O on $A \beta$ and tau have been reported in a review (see ${ }^{10}$ ). $P P_{3} P_{1}$ has been correlated with increased p-tau. ${ }^{4} B D N F$ was linked with decreased total $A \beta$ while $T F$ was related to decreased $A \beta_{1-421} A \beta_{1-40}$ ratio. ${ }^{24} C Y P_{46} 61$ has been associated with $A D^{25}$ and correlated with $A \beta_{1-42 .}{ }^{26} I D E$ has been reported to decrease $A \beta_{1-42}$ in AD. ${ }^{27}$ Moreover, it has been associated with $A D$ risk $^{28}$ and neuropathological A $\beta$ deposition. ${ }^{29}$

Thirty-six SNPs in 25 genes were included in the analyses with CSF biomarkers (Supplementary table). For the genetic association analyses, we tested 24 genetic variants, excluding those in $A B C A 7, B I N_{1}$, $B D N F, C D_{2} A P, C D_{33}, C Y P_{4} 6, C L U, C R 1, E P H A 1, E X O C_{3} L_{2}, M S_{4} A_{4} E$ and $M S_{4} A 6 A$ because these genes were previously studied in the Finnish population and found to be associated with $A D$ either in the Finnish cohort alone or in multicenter GWAS. ${ }^{17,}$ 25, 30-32

\section{Genotyping}

DNA was extracted from peripheral blood with EDTA and amplified using polymerase chain reaction technique. DNA samples were randomly placed on 384-well plates and genotyped using Sequenom iPlex platform (Sequenom, Hamburg, Germany) at University of Eastern Finland (UEF) in Kuopio. Patients and controls were dichotomized as APOE-ع4 carriers or noncarriers.

Quality control procedures included using duplicates and negative controls, filtering on individual sample and SNP call rate, and testing whether the SNPs were in Hardy-Weinberg equilibrium (HWE). Samples with an average call rate of $90 \%$ were included. SNPs for the association analysis were in Hardy-Weinberg equilibrium $(P>0.001)$. 


\section{CSF analysis}

CSF was obtained through lumbar puncture performed at UEF and the Kuopio University Hospital. $A \beta_{1-42^{2}} \mathrm{t}$-tau, and $\mathrm{p}$-tau levels were measured using commercially available INNOTEST enzyme-linked immunosorbent assays (ELISAs) (Innotest $\beta$-amyloid ${ }_{\left.(1-4)^{\prime}\right)}$ Innotest hTau Ag, and Innotest Phospho-tau ${ }_{(181 P)^{\prime}}$ Innogenetics, Ghent, Belgium). All measurements were performed in one laboratory at UEF.

The relation between SNPs and biomarkers was assessed only for the AD group because the number of controls with available CSF $(n=30)$ was too small to allow for meaningful analyses.

\section{Statistical analysis}

SPSS version 19 (Chicago, IL, USA) was used for the statistical analyses. We performed power calculations for the genetic association analyses. ${ }^{33}$ Simulation analysis yielded more than $80 \%$ power to achieve $\sim 1.3-1.5$ risk effect at $P=0.05$, indicating that our case-control sample size was sufficient to find moderate genetic association with $A D$. The same risk effect for the false discovery rate (FDR) corrected $P=0.005$ yielded more than $50 \%$ power. For quantitative trait association, ${ }^{34}$ we computed $~ 80 \%$ power for an effect size of $60-70 \mathrm{pg} / \mathrm{ml}$ for the dominant model at $P=0.05$ and 50\% power at FDR corrected $P=0.005$. Similarly for t-tau, the effect size was $120-150 \mathrm{pg} / \mathrm{ml}$ and for $\mathrm{p}$-tau $15-20 \mathrm{pg} / \mathrm{ml}$ for a power of $80 \%$ at $P=0.05$ and $50 \%$ when FDR corrected $(P=0.005)$.

Genetic association with AD was examined using Pearson chisquare test for multiple group comparisons and binary logistic regression for pairwise comparisons in univariate and multivariate analysis adjusted for age, sex, and $A P O E-\varepsilon 4$ status. The relation between SNPs and biomarkers was assessed through mixed models for multiple group comparisons and pairwise comparisons, with correction for confounders. Normality was tested and assumed for biomarkers.

For the binary association, we first performed an overall test that provided information on genotype differences between cases and controls, and multiple comparison tests. For the quantitative association, we compared differences in mean biomarker values between genotypes in the overall test. Based on genotype frequencies, we opted to use a dominant model. Minor genotype frequencies for both genetic associa- 
tion and CSF biomarker analyses were $0-15 \%$ for $40-50 \%$ of the SNPs studied. This reduces statistical power of a recessive model in most SNPs. All analyses were first corrected for age and sex, and then repeated with corrections for age, sex, and $A P O E-\varepsilon 4$ status.

We used FDR correction for multiple testing, following the method of Benjamini and Hochberg. ${ }^{35}$ Corrections were based on the number of SNPs tested and were performed separately for binary and quantitative associations. Observed $P$-values were ranked from smallest to largest. Adjusted $P$-values were successively computed in a step-up manner, starting from the second largest $P$-value, as follows: observed $P$-value (total number of SNPs tested/rank). Statistical significance was set at FDR adjusted $P<0.05$.

\section{RESULTS}

\section{Characteristics of the cohort}

Table 1 shows the demographic characteristics of the participants. AD patients with available CSF did not differ from patients without CSF in terms of onset age $(P=0.07)$ and Mini-Mental State Examination ${ }^{36}$ score $(P=0.77)$.

\section{Genetic association with AD}

$A P O E$ conferred a significant AD risk of 6.30 times higher among $\varepsilon_{4}$ allele carriers compared to noncarriers $(P<0.0001$, Table 2$)$. Age and gender did not affect the results (OR=6.25,95\% Cl 5.22-8.15, $P<0.0001)$.

TOMM4O rs157580, rs2075650 and rs8106922 indicated association with $A D$ risk in the univariate analyses (FDR $P<0.05$ ). A protective effect was observed for $G$ allele carriers of rs157580 and rs8106922, and a risk effect for $G$ allele carriers of $r s 2075650$. Only rs2075650 remained significant in the multivariate analysis (unadjusted $P<0.007$ ) but did not pass FDR correction $(P>0.05)$.

Results for MAPT rs16940758 suggested no association with AD (FDR adjusted $P>0.05$ ), although $A D$ and control groups differed in multiple comparison test. $P P P_{3} R_{1}$ rs 1868402 and $A C E$ rs4293 showed association with $A D$ in multivariate analysis (unadjusted $P=0.03$ for rs 1868402 and $P=0.01$ for rs4293) but did not remain significant after FDR adjustment. Overall and univariate analyses with $\mathrm{rs} 1868402$ and rs4293 were not significant. 
Table 1 Characteristics of study participants

\begin{tabular}{|c|c|c|c|}
\hline Characteristics & $\begin{array}{l}\text { AD } \\
(\mathrm{N}=\mathbf{8 g 0})\end{array}$ & $\begin{array}{l}\text { Control } \\
(\mathrm{N}=701)\end{array}$ & $\begin{array}{l}\text { AD with CSF } \\
\text { subgroup } \\
(n=222)\end{array}$ \\
\hline Age, mean (SD), $y$ & $69.8(8.2)^{\mathrm{a}}$ & $69.1(6.2)^{b}$ & $69(8)^{a}$ \\
\hline Female sex (\%) & $596(67)$ & $420(60)$ & $149(67)$ \\
\hline MMSE score, mean (SD) & $19(5)$ & - & $19(6)$ \\
\hline$A P O E \varepsilon_{2} / \varepsilon_{3} / \varepsilon_{4}$ allelic distribution, $\%$ & $2 / 53 / 45$ & $4 / 80 / 16$ & - \\
\hline $\mathrm{A} \beta_{1-42}$ level (SD), $\mathrm{pg} / \mathrm{ml}$ & & $735(195)^{c}$ & $443(158)^{d}$ \\
\hline Phosphorylated tau level (SD), pg/ml & & $63(26)^{e}$ & $84(36)^{f}$ \\
\hline Total tau level (SD), pg/ml & & $311(143)^{9}$ & $546(269)^{h}$ \\
\hline
\end{tabular}

Abbreviations: $A D=A$ Alzheimer's disease; $C S F=$ cerebrospinal fluid; $N$, $n=$ sample size;

$\mathrm{SD}=$ standard deviation; $\mathrm{y}=$ years; MMSE=Mini-Mental State Examination.

a Onset age.

${ }^{\mathrm{b}}$ Age at examination.

c Available for 32 control subjects.

d Available for 222 AD patients.

e Available for 30 control subjects.

f Available for $151 \mathrm{AD}$ patients.

${ }^{9}$ Available for 30 control subjects.

${ }^{\text {h }}$ Available for 159 AD patients.

Effects of SNPs on CSF A $\beta_{1-42}$ $A P O E \varepsilon 4$ allele carriers had significantly reduced CSF A $\beta_{1-42}$ (FDR adjusted $P<0.05$, Table 3). Apart from APOE, only CLU significantly affected $A \beta_{1-42}$ among the AlzGene top loci. Carriers of rs1113600o major allele ( $C$, risk allele in AlzGene meta-analysis) showed significantly decreased $A \beta_{1-42}$ (FDR adjusted $P<0.05$ ).

Of the SNPs identified in GWAS but not in the top AlzGene loci, only MS4A $4 A$ correlated with $A \beta_{1-42 .}$ Minor allele carriers (C, risk allele in GWAS) of rs2304933 showed significantly decreased $A \beta_{1-42}$ levels (FDR adjusted $P<0.05)$ compared to major allele $(A)$ carriers. The correlation was strengthened when corrected for $A P O E-\varepsilon 4$ status. 
Decreased $A \beta_{1-42}$ levels among $E X O C_{3} L 2$ rs597668 minor allele carriers (C, risk allele in GWAS) were observed but the correlation did not pass FDR filter $(P>0.05)$.

Risk allele carriers of TOMM 40 SNPs identified through GWAS with biomarkers as outcome and through other candidate gene studies had decreased $A \beta_{1-42}$ concentrations, but this was not independent of $A P O E-\varepsilon 4$ status (FDR adjusted $P>0.05$ ).

The rest of the SNPs did not exhibit conclusive effects on $A \beta_{1-42}$ concentrations.

\section{Effects of SNPs on CSF tau}

None of the SNPs from the top AlzGene loci significantly correlated with CSF t-tau and p-tau. The strongest effect was for PICALM rs642949 and ttau $(P=0.06$, adjusted for age, sex, and $A P O E-\varepsilon 4$ status), with increased $\mathrm{t}$ tau levels among minor allele (C) carriers (Table 4 ). APOE $\varepsilon_{4}$ allele carriers also showed a nonsignificant increase in t-tau concentrations $(P=0.08)$.

None of the polymorphisms in other GWAS with clinical AD as outcome were linked with t-tau and p-tau.

From GWAS SNPs with biomarker as outcome, none of the results attained statistical significance. EPC2 rs1374441 and t-tau showed the strongest effect. T-tau levels increased among minor allele ( $C$, risk allele in GWAS) carriers ( $P=0.06$, corrected for age, sex, and $A P O E-\varepsilon 4$ status).

Of the SNPs selected from other candidate genes, marginal correlations at FDR unadjusted $P<0.05$ were obtained for polymorphisms in $P P P_{3} R 1, S O R L 1$ and MAPT. T-tau levels increased among carriers of $P P P_{3} R 1$ rs 1868402 major allele (T, FDR adjusted $P>0.05$ ). The effect was strengthened when corrected for $A P O E-\varepsilon 4$ status.

SORL1 rS73595277 minor allele carriers $(G)$ had increased p-tau (FDR adjusted $P>0.05$ ). Effects of SORL1 slightly decreased with $A P O E-\varepsilon 4$ correction.

In MAPT, minor allele carriers of $\mathrm{rs} 2435211$ ( $\mathrm{T}$ ) had increased ttau levels and minor allele carriers of rs16940758 had increased p-tau levels (FDR adjusted $P>0.05$ for both SNPs). Correcting for $A P O E-\varepsilon 4$ status enhanced the effects. These results, however, did not remain significant after FDR correction (adjusted $P>0.05$ for both SNPs). 
Table 2 Single nucleotide polymorphisms associated with Alzheimer's disease risk

\begin{tabular}{|c|c|c|c|c|c|}
\hline Chr, Gene & SNP & Genotypes & $\begin{array}{l}\text { Cases }(\mathrm{n}) \\
\text { genotypic } \\
\text { frequencies, } \%\end{array}$ & MAF, $\%$ & $\begin{array}{l}\text { Controls (n) } \\
\text { genotypic } \\
\text { frequencies, } \%\end{array}$ \\
\hline 2, $E P C 2$ & rs1374441 & $\mathrm{TT} / \mathrm{TC} / \mathrm{CC}$ & (868) $58 / 36 / 6$ & 24 & (681) $59 / 35 / 6$ \\
\hline 2, $E P C_{2}$ & rs4499362 & $\mathrm{CC} / \mathrm{CT} / \mathrm{TT}$ & (875) $57 / 37 / 6$ & 25 & (689) 58/35/7 \\
\hline $2, P P P_{3} R_{1}$ & rs1868402 & $\mathrm{TT} / \mathrm{TC} / \mathrm{CC}$ & (853) 53/39/8 & 27 & (668) $56 / 38 / 6$ \\
\hline $3, T F$ & rs1049296 & $\mathrm{CC} / \mathrm{CT} / \mathrm{TT}$ & (866) $81 / 18 / 1$ & 10 & (680) $81 / 18 / 1$ \\
\hline 6, MTHFD 1 L & rs11754661 & GG/GA/AA & (878) 92/8/o & 4 & (690) $92 / 8 / 0$ \\
\hline 7, RELN & rs 4298437 & $\mathrm{CC} / \mathrm{CT} / \mathrm{TT}$ & (879) $52 / 38 / 10$ & 29 & (690) 53/37/10 \\
\hline $10, I D E$ & rs1887922 & $\mathrm{TT} / \mathrm{TC} / \mathrm{CC}$ & (871) $72 / 26 / 2$ & 15 & (683) $75 / 23 / 2$ \\
\hline $11, M S_{4} A_{4} A$ & rs2304933 & CC/CA/AA & (882) $35 / 48 / 17$ & 41 & (690) $34 / 49 / 17$ \\
\hline $11, M S_{4} A_{4} A$ & rs 4938933 & $\mathrm{TT} / \mathrm{TC} / \mathrm{CC}$ & (872) $59 / 36 / 5$ & 23 & (683) 57/36/7 \\
\hline 11, PICALM & rs3851179 & GG/GA/AA & (878) 45/43/12 & 34 & (691) 43/42/15 \\
\hline 11, PICALM & $r s 642949$ & $\mathrm{TT} / \mathrm{TC} / \mathrm{CC}$ & (868) $58 / 36 / 6$ & 24 & (681) $58 / 37 / 5$ \\
\hline 11, SORL1 & rs2070045 & $\mathrm{TT} / \mathrm{TG} / \mathrm{GG}$ & (883) 57/37/6 & 25 & (695) 54/39/7 \\
\hline 11, SORL1 & rs3824968 & TT/TA/AA & (673) 44/39/17 & 36 & (568) $42 / 43 / 15$ \\
\hline 11, SORL1 & rs73595277 & $\mathrm{CC/CG/GG}$ & (873) $79 / 20 / 1$ & 11 & (688) $78 / 20 / 2$ \\
\hline 15, CYP19A & rs2899472 & CC/CA/AA & (883) 6o/35/5 & 22 & (69o) 6o/35/5 \\
\hline $17, A C E$ & rs4293 & $\mathrm{AA} / \mathrm{AG} / \mathrm{GG}$ & (866) 30/50/20 & 45 & (682) $26 / 53 / 21$ \\
\hline 17, MAPT & rs 1467967 & $\mathrm{AA} / \mathrm{AG} / \mathrm{GG}$ & (869) 43/45/12 & 34 & (685) 42/45/13 \\
\hline 17, MAPT & rs16940758 & $\mathrm{CC} / \mathrm{CT} / \mathrm{TT}$ & (886) 65/31/4 & 20 & (700) 63/30/7 \\
\hline $17, M A P T$ & rs2435211 & $\mathrm{CC} / \mathrm{CT} / \mathrm{TT}$ & (880) 37/48/15 & 39 & (691) 37/47/16 \\
\hline $17, M A P T$ & rs7521 & $\mathrm{AA} / \mathrm{AG} / \mathrm{GG}$ & (869) $25 / 50 / 25$ & 50 & (683) $26 / 50 / 24$ \\
\hline 19, TOMM4O & rs157580 & $\mathrm{AA} / \mathrm{AG} / \mathrm{GG}$ & (872) 69/29/2 & 17 & (685) 54/39/7 \\
\hline 19, TOMM 40 & rs 2075650 & $\mathrm{AA} / \mathrm{AG} / \mathrm{GG}$ & (881) 44/44/12 & 34 & (689) $74 / 23 / 3$ \\
\hline 19, TOMM 40 & rs8106922 & $\mathrm{AA} / \mathrm{AG} / \mathrm{GG}$ & (886) $43 / 44 / 13$ & 35 & (695) 26/43/31 \\
\hline 19, APOE & & $\varepsilon 2 / \varepsilon_{3} / \varepsilon_{4}$ & (890) 29/51/20 & $--^{c}$ & (701) $72 / 24 / 4$ \\
\hline
\end{tabular}

Abbreviations: Chr=chromosome; $\mathrm{SNP}=$ single nucleotide polymorphism; $\mathrm{n}=$ number of cases; $\mathrm{MAF}=$ minor allele frequency; $\mathrm{OR}=$ odds ratio; $\mathrm{Cl}=$ confidence interval; o $\varepsilon_{4}=A P O E \varepsilon_{4}$ allele noncarriers; $1 \varepsilon_{4}=$ carriers of 1 APOE $\varepsilon_{4}$ allele; $2 \varepsilon_{4}=$ carriers of $2 A P O E \varepsilon_{4}$ alleles.

Multiple comparison analysis (overall) was calculated by Pearson chi-square test. Univariate and multivariate analyses were calculated using binary logistic regression assuming a dominant model. Multivariate analyses were adjusted for age, sex and $A P O E-\varepsilon 4$ status. Analyses testing $A P O E$ adjusted for age and gender. Results for $A P O E$ are shown for comparative purposes only. 


\begin{tabular}{|c|c|c|c|c|c|c|}
\hline MAF, \% & $\begin{array}{l}\text { AD risk } \\
\text { Overall } \\
\text { P-value }\end{array}$ & $\begin{array}{l}\text { Genetic } \\
\text { model }\end{array}$ & $\begin{array}{l}\text { Univariate } \\
\text { analysis } \\
\text { OR }(95 \% \mathrm{CI})\end{array}$ & $P$-value & $\begin{array}{l}\text { Multivariate } \\
\text { analysis } \\
\text { OR }(95 \% \mathrm{Cl})\end{array}$ & $P$-value \\
\hline 24 & 0.87 & TT vs. TC+CC & $1.04(0.85-1.28)$ & 0.69 & $1.03(0.82-1.29)$ & 0.83 \\
\hline 24 & 0.52 & CC vs. CT+TT & $1.05(0.86-1.29)$ & 0.61 & $1.05(0.84-1.30)$ & 0.69 \\
\hline 25 & 0.30 & TT vs. TC+CC & $1.13(0.92-1.38)$ & 0.25 & $1.29(1.01-1.62)$ & $0.03^{b}$ \\
\hline 10 & 0.48 & CC vs. CT+TT & $0.99(0.77-1.28)$ & 0.93 & $0.96(0.72-1.27)$ & 0.76 \\
\hline 4 & 0.44 & GG vs. $G A+A A$ & $1.10(0.76-1.59)$ & 0.61 & $1.06(0.71-1.59)$ & 0.77 \\
\hline 29 & 0.98 & CC vs. CT+TT & $1.02(0.83-1.24)$ & 0.86 & $0.90(0.72-1.13)$ & 0.35 \\
\hline 14 & 0.27 & TT vs. $\mathrm{TC}+\mathrm{CC}$ & $1.19(0.95-1.50)$ & 0.13 & $1.27(0.99-1.64)$ & 0.07 \\
\hline 41 & 0.89 & $A A$ vs. $A C+C C$ & $0.95(0.77-1.18)$ & 0.66 & $1.06(0.84-1.34)$ & 0.61 \\
\hline 25 & 0.12 & TT vs. TC+CC & $0.93(0.76-1.14)$ & 0.48 & $1.02(0.81-1.27)$ & 0.89 \\
\hline 36 & 0.32 & GG vs. GA+AA & $0.93(0.76-1.14)$ & 0.50 & $0.97(0.77-1.21)$ & 0.77 \\
\hline 23 & 0.59 & TT vs. TC+CC & $1.02(0.83-1.25)$ & 0.84 & $1.00(0.80-1.26)$ & 0.97 \\
\hline 27 & 0.41 & TT vs. $T G+G G$ & $0.88(0.72-1.07)$ & 0.20 & $0.87(0.69-1.08)$ & 0.21 \\
\hline 36 & 0.42 & TT vs. TA+AA & $0.93(0.74-1.12)$ & 0.51 & $0.95(0.74-1.22)$ & 0.70 \\
\hline 12 & 0.48 & CC vs. CG+GG & $0.96(0.75-1.22)$ & 0.74 & $0.84(0.64-1.11)$ & 0.22 \\
\hline 22 & 0.98 & $C C$ vs. $C A+A A$ & $1.01(0.82-1.23)$ & 0.96 & $1.02(0.82-1.28)$ & 0.85 \\
\hline 47 & 0.20 & $A A$ vs. $A G+A A$ & $0.82(0.66-1.03)$ & 0.08 & $0.72(0.56-0.93)$ & $0.01^{a}$ \\
\hline 35 & 0.86 & $A A$ vs. $A G+G G$ & $0.98(0.78-1.17)$ & 0.67 & $0.96(0.77-1.20)$ & 0.72 \\
\hline 22 & $0.03^{b}$ & CC vs. CT+TT & $0.90(0.73-1.11)$ & 0.33 & $0.84(0.67-1.06)$ & 0.13 \\
\hline 38 & 0.77 & CC vs. CT+TT & $1.03(0.84-1.26)$ & 0.80 & $0.98(0.78-1.23)$ & 0.84 \\
\hline 49 & 0.83 & $A A$ vs. $A G+G G$ & $1.05(0.84-1.32)$ & 0.68 & $1.02(0.79-1.31)$ & 0.89 \\
\hline 27 & $<0.0001^{\mathrm{a}}$ & $A A$ vs. $A G+G G$ & $0.53(0.43-0.65)$ & $<0.0001^{a}$ & $0.76(0.60-0.96)$ & $0.02^{b}$ \\
\hline 15 & $<0.0001^{a}$ & $A A$ vs. $A G+G G$ & $3.63(2.92-4.50)$ & $<0.0001^{a}$ & $1.46(1.11-1.92)$ & $0.007^{b}$ \\
\hline 53 & $<0.0001^{a}$ & $A A$ vs. $A G+G G$ & $0.46(0.37-0.57)$ & $<0.0001^{a}$ & $1.05(0.81-1.37)$ & 0.60 \\
\hline$--^{c}$ & $<0.0001^{a}$ & ock vs. $1 \varepsilon_{4}+2 \varepsilon_{4}$ & $6.30(5.06-7.85)$ & $<0.0001^{a}$ & $6.25(5.22-8.15)$ & $<0.0001^{a}$ \\
\hline
\end{tabular}

a Significant at false discovery rate adjusted $P<0.05$.

${ }^{\mathrm{b}}$ Not significant after false discovery rate correction.

${ }^{c}$ Minor allele frequency not computed because $A P O E$ is tri-allelic. 
Table 3 Effects of SNPs on cerebrospinal fluid $A \beta_{1-42}$ in Alzheimer's disease

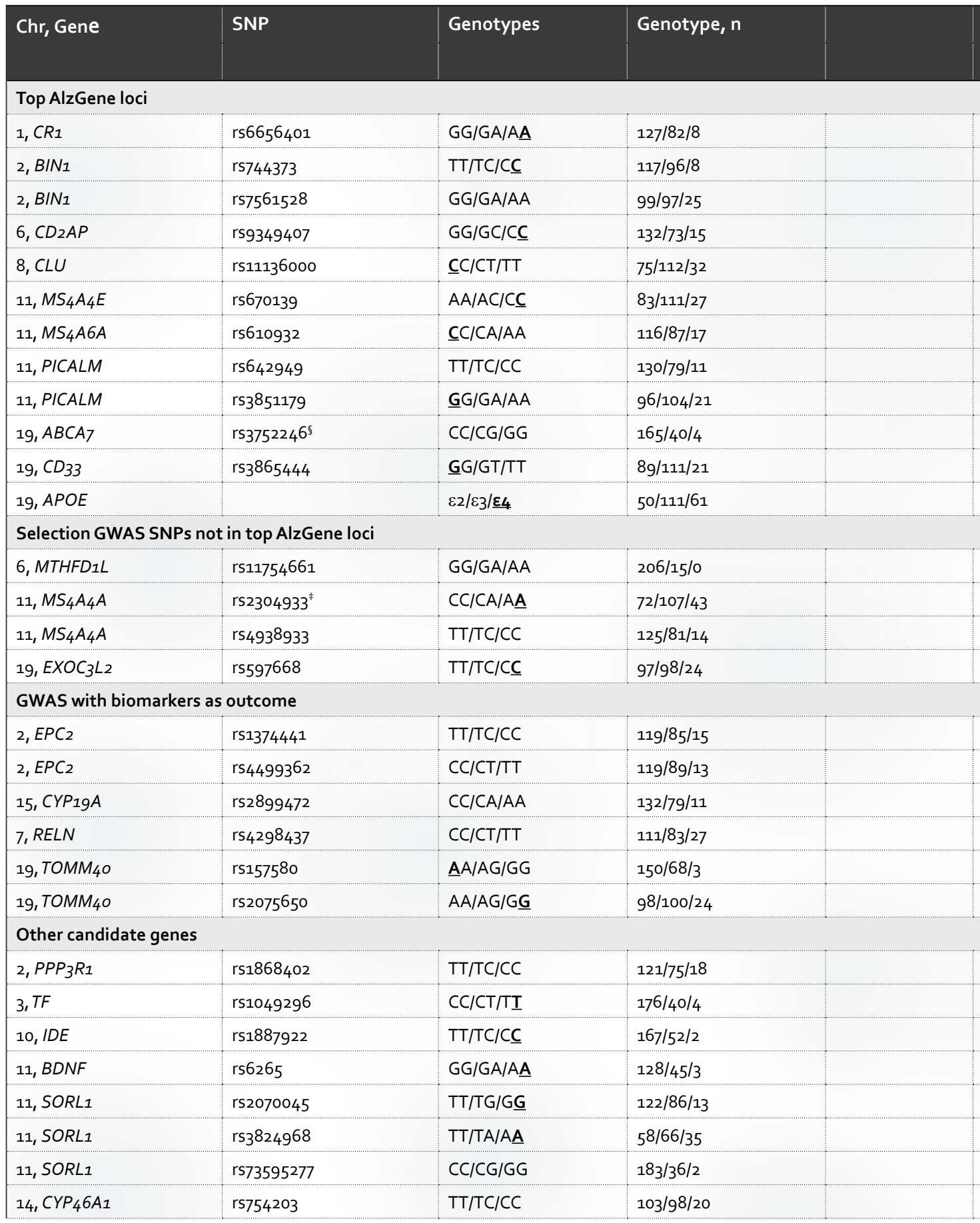




\section{Mean (SD) A $\beta_{1-42}$ level, pg/ml, per genotype $P$-value}

Overall

DM

\begin{tabular}{|c|c|c|}
\hline $446(168) / 443(142) / 370(150)$ & $0.48(0.21)$ & $0.82(0.96)$ \\
\hline $446(148) / 440(161) / 451(266)$ & $0.97(0.92)$ & $0.94(1.00)$ \\
\hline $447(152) / 441(163) / 443(173)$ & $0.92(0.71)$ & $0.85(0.77)$ \\
\hline $440(158) / 450(152) / 444(202)$ & $0.97(0.88)$ & $0.84(0.84)$ \\
\hline $400(116) / 459(166) / 497(194)$ & $0.005(0.01)$ & $0.003^{a}(0.005)$ \\
\hline $465(164) / 436(155) / 408(152)$ & $0.18(0.18)$ & $0.13(0.11)$ \\
\hline $447(153) / 443(163) / 410(176)$ & $0.67(0.74)$ & $0.73(0.51)$ \\
\hline $459(165) / 432(148) / 346(116)$ & $0.07(0.06)$ & $0.12(0.11)$ \\
\hline $441(172) / 453(149) / 412(140)$ & $0.52(0.34)$ & $0.95(0.61)$ \\
\hline $445(160) / 446(159) / 433(281)$ & $0.99(0.83)$ & $0.90(0.91)$ \\
\hline $437(169) / 448(155) / 441(135)$ & $0.87(0.78)$ & $0.65(0.48)$ \\
\hline $532(214) / 441(136) / 374(95)$ & $<0.001$ & $<0.001^{a}$ \\
\hline $440(156) / 490(189) /--{ }^{c}$ & $0.20(0.07)$ & $0.20(0.07)$ \\
\hline $494(192) / 428(133) / 395(130)$ & $0.002(0.001)$ & $0.001^{\mathrm{a}}(<0.0001)$ \\
\hline $453(160) / 435(152) / 411(188)$ & $0.60(0.54)$ & $0.41(0.29)$ \\
\hline $472(192) / 422(123) / 423(129)$ & $0.08(0.56)$ & $0.02(0.28)$ \\
\hline $440(172) / 456(147) / 411(109)$ & $0.52(0.38)$ & $0.67(0.58)$ \\
\hline $443(172) / 445(140) / 441(155)$ & $0.98(1.00)$ & $0.96(0.98)$ \\
\hline $454(163) / 433(152) / 378(122)$ & $0.36(0.22)$ & $0.27(0.19)$ \\
\hline $439(137) / 432(156) / 498(230)$ & $0.17(0.21)$ & $0.86(0.79)$ \\
\hline $426(146) / 476(175) / 593(202)$ & $0.04(0.27)$ & $0.02^{\mathrm{b}}(0.12)$ \\
\hline $485(195) / 418(112) / 377(104)$ & $0.002(0.24)$ & $0.001^{a}(0.19)$ \\
\hline $447(173) / 448(145) / 418(131)$ & $0.70(0.56)$ & $0.81(0.53)$ \\
\hline $449(165) / 412(120) / 539(146)$ & $0.22(0.37)$ & $0.42(0.42)$ \\
\hline $442(138) / 437(196) / 747(457)$ & $0.03(0.04)$ & $0.82(0.94)$ \\
\hline $430(156) / 453(173) / 432(142)$ & $0.79(0.62)$ & $0.49(0.35)$ \\
\hline 440(149)/453(166)/403(195) & $0.58(0.53)$ & 0.89 (o.89) \\
\hline $438(130) / 442(158) / 457(206)$ & $0.92(0.87)$ & $0.85(0.68)$ \\
\hline $449(168) / 421(102) / 397(76)$ & $0.65(0.87)$ & $0.35(0.60)$ \\
\hline $447(155) / 467(160) / 456(176)$ & $0.85(0.66)$ & $0.72(0.54)$ \\
\hline
\end{tabular}


Table 3 Effects of SNPs on cerebrospinal fluid A $\beta_{1-42}$ in Alzheimer's disease Continued

\begin{tabular}{|c|c|c|c|}
\hline Chr, Gene & SNP & Genotypes & Genotype, n \\
\hline $17, A C E$ & $r s 4293$ & $\underline{A} A / A G / G G$ & $60 / 107 / 54$ \\
\hline $17, M A P T$ & rs16940758 & $\mathrm{CC} / \mathrm{CT} / \mathrm{TT}$ & $146 / 68 / 8$ \\
\hline 17, MAPT & rs2435211 & $\mathrm{CC} / \mathrm{CT} / \mathrm{TT}$ & $71 / 118 / 32$ \\
\hline $17, M A P T$ & rs1467967 & $\underline{\mathrm{A} A / A G / G G}$ & $97 / 98 / 25$ \\
\hline $17, M A P T$ & rs7521 & $\mathrm{AA} / \mathrm{AG} / \mathrm{G} \underline{\mathrm{G}}$ & $62 / 112 / 46$ \\
\hline 19, TOMM4O & rs8106922 & $\mathrm{AA} / \mathrm{AG} / \mathrm{GG}$ & $113 / 91 / 18$ \\
\hline
\end{tabular}

Abbreviations: $\mathrm{Chr}=$ chromosome; SNP=single nucleotide polymorphism; n=number of cases; $\mathrm{SD}=$ standard deviation; $\mathrm{DM}=$ dominant model; GWAS=genome-wide association study Risk allele according to AlzGene meta-analyses or study source in bold and underscored. Information on risk allele was not available for all studies. $P$-values based on mixed model analyses adjusted for age and gender; values in parenthesis ( ) adjusted for age, gender and

Table 4 Effects of SNPs on cerebrospinal fluid tau in Alzheimer's disease

\begin{tabular}{|c|c|c|c|c|}
\hline Chr, Gene & SNP & Genotypes & $\begin{array}{l}\text { Geno- } \\
\text { type, } n\end{array}$ & $\begin{array}{l}\text { Mean (SD) t-tau level, } \\
\mathrm{pg} / \mathrm{ml} \text {, per genotype }\end{array}$ \\
\hline \multicolumn{5}{|c|}{ Top AlzGene loci } \\
\hline $1, C R_{1}$ & rs6656401 & GG/GA/A $\underline{A}$ & $93 / 57 / 7$ & $512(246) / 579(275) / 682(456)$ \\
\hline $2, B I N_{1}$ & rs744373 & $\mathrm{TT} / \mathrm{TC} / \mathrm{C} \underline{\mathrm{C}}$ & $80 / 74 / 5$ & $576(287) / 514(251) / 547(224)$ \\
\hline $2, B I N_{1}$ & rs7561528 & GG/GA/AA & $68 / 72 / 19$ & $583(281) / 511(247) / 544(305)$ \\
\hline $6, C D_{2} A P$ & rs9349407 & $\mathrm{GG} / \mathrm{GC} / \mathrm{C} \underline{\mathrm{C}}$ & $94 / 54 / 10$ & $551(281) / 537(245) / 566(305)$ \\
\hline 8, CLU & rs111360oo & $\underline{\mathrm{C}} \mathrm{C} / \mathrm{CT} / \mathrm{TT}$ & $59 / 79 / 19$ & $523(230) / 543(274) / 564(299)$ \\
\hline $11, M_{4} A_{4} E$ & rs670139 & $\mathrm{AA} / \mathrm{AC} / \mathrm{C} \underline{\mathrm{C}}$ & $60 / 81 / 18$ & $556(286) / 519(233) / 634(351)$ \\
\hline $11, M S_{4} A 6 A$ & rs610932 & CC/CA/AA & $77 / 71 / 9$ & $572(281) / 525(250) / 537(337)$ \\
\hline 11, PICALM & rs3851179 & $\underline{G} G / G A / A A$ & $75 / 69 / 15$ & $583(301) / 518(243) / 488(194)$ \\
\hline 11, PICALM & rs642949 & $\mathrm{TT} / \mathrm{TC} / \mathrm{CC}$ & $94 / 56 / 8$ & $499(221) / 612(313) / 525(223)$ \\
\hline 19, $A B C A 7$ & rs3752246 & $\mathrm{CC} / \mathrm{CG} / \mathrm{GG}$ & $119 / 25 / 4$ & $532(267) / 570(275) / 568(185)$ \\
\hline 19, $C D_{33}$ & rs3865444 & $\underline{\mathrm{GG}} / \mathrm{GT} / \mathrm{TT}$ & $63 / 81 / 14$ & $587(305) / 503(202) / 622(394)$ \\
\hline 19, APOE & & $\varepsilon 2 / \varepsilon 3 / \underline{\varepsilon} 4$ & $37 / 79 / 43$ & $468(289) / 537(249) / 630(269)$ \\
\hline \multicolumn{5}{|c|}{ Selection GWAS SNPs not in AlzGene top } \\
\hline 6, MTHFD1L & rs11754661 & GG/GA/AA & $149 / 10 / 0$ & $550(268) / 492(301) /-$-.a $^{2}$ \\
\hline
\end{tabular}


Mean (SD) A $\beta_{1-42}$ level, pg/ml, per genotype $P$-value

\begin{tabular}{|l|l|l|}
\cline { 2 - 3 } & Overall & DM \\
\hline $451(184) / 451(154) / 421(136)$ & $0.26(0.67)$ & $0.56(0.91)$ \\
\hline $439(169) / 449(141) / 467(99)$ & $0.90(0.84)$ & $0.68(0.57)$ \\
\hline $420(136) / 456(167) / 450(171)$ & $0.29(0.27)$ & $0.12(0.17)$ \\
\hline $446(168) / 451(161) / 409(100)$ & $0.58(0.57)$ & $0.81(0.99)$ \\
\hline $419(105) / 456(179) / 449(165)$ & $0.37(0.33)$ & $0.17(0.14)$ \\
\hline $417(126) / 461(169) / 520(236)$ & $0.02(0.75)$ & $0.02^{b}(0.55)$ \\
\hline
\end{tabular}

$A P O E-\varepsilon 4$ status. Analyses testing APOE adjusted for age and gender. Results for APOE are shown for comparative purposes only.

a Significant at false discovery rate corrected $P<0.05$.

${ }^{b}$ No longer significant after false discovery rate correction.

c No cerebrospinal fluid measured because none of the participants carried the rs11754661 AA genotype.

\begin{tabular}{|c|c|c|c|c|c|}
\hline \multicolumn{2}{|l|}{$P$-value } & \multirow{2}{*}{$\begin{array}{l}\text { Geno- } \\
\text { type, n }\end{array}$} & \multirow{2}{*}{$\begin{array}{l}\text { Mean (SD) p-tau } \\
\text { level, pg/ml, per } \\
\text { genotype }\end{array}$} & \multicolumn{2}{|l|}{$P$-value } \\
\hline Overall & DM & & & Overall & DM \\
\hline $0.48(0.44)$ & $0.28(0.30)$ & $90 / 53 / 7$ & $81(33) / 88(35) / 103(66)$ & $0.53(0.48)$ & $0.40(0.41)$ \\
\hline $0.29(0.26)$ & $0.11(0.10)$ & $76 / 69 / 6$ & $86(36) / 81(35) / 100(44)$ & $0.41(0.41)$ & $0.47(0.45)$ \\
\hline $0.26(0.26)$ & $0.10(0.10)$ & $65 / 66 / 20$ & $86(34) / 82(37) / 86(38)$ & $0.87(0.87)$ & $0.63(0.62)$ \\
\hline $0.95(0.89)$ & $0.95(0.84)$ & $90 / 50 / 10$ & $86(39) / 82(31) / 87(41)$ & $0.87(0.83)$ & $0.74(0.69)$ \\
\hline $0.77(0.65)$ & $0.47(0.36)$ & $59 / 72 / 18$ & $83(36) / 83(35) / 88(40)$ & $0.88(0.85)$ & $0.80(0.72)$ \\
\hline $0.20(0.25)$ & $0.68(0.78)$ & $55 / 77 / 19$ & $83(37) / 83(35) / 93(37)$ & $0.49(0.50)$ & $0.70(0.66)$ \\
\hline $0.57(0.67)$ & $0.30(0.42)$ & $74 / 66 / 9$ & $84(35) / 83(33) / 96(62)$ & $0.73(0.76)$ & $0.83(0.75)$ \\
\hline $0.49(0.40)$ & $0.25(0.20)$ & $72 / 65 / 14$ & $86(39) / 84(36) / 76(20)$ & $0.80(0.76)$ & $0.76(0.72)$ \\
\hline $0.11(0.10)$ & $0.07(0.06)$ & $89 / 54 / 7$ & $79(32) / 93(39) / 75(37)$ & $0.13(0.14)$ & $0.15(0.15)$ \\
\hline $0.98(0.98)$ & 0.83 (0.89) & $111 / 26 / 4$ & $81(36) / 93(37) / 82(30)$ & $0.43(0.45)$ & $0.25(0.56)$ \\
\hline $0.11(0.12)$ & $0.12(0.10)$ & $61 / 75 / 14$ & $87(45) / 82(26) / 87(43)$ & $0.62(0.60)$ & $0.37(0.34)$ \\
\hline 0.11 & 0.08 & $36 / 75 / 40$ & $78(42) / 84(35) / 91(31)$ & 0.54 & 0.36 \\
\hline $0.48(0.39)$ & $0.48(0.39)$ & $141 / 10 / 0$ & $85(36) / 72(38) /--^{a}$ & $0.26(0.22)$ & $0.26(0.22)$ \\
\hline
\end{tabular}


Table 4 Effects of SNPs on cerebrospinal fluid tau in Alzheimer's disease Continued

\begin{tabular}{|c|c|c|c|c|}
\hline Chr, Gene & SNP & Genotypes & $\begin{array}{l}\text { Geno- } \\
\text { type, n }\end{array}$ & $\begin{array}{l}\text { Mean (SD) t-tau level, } \\
\mathrm{pg} / \mathrm{ml} \text {, per genotype }\end{array}$ \\
\hline $11, M S_{4} A_{4} A$ & rs2304933 & $\mathrm{CC} / \mathrm{CA} / \mathrm{A} \underline{\mathrm{A}}$ & $54 / 76 / 29$ & $526(293) / 534(233) / 611(309)$ \\
\hline $11, M S_{4} A_{4} A$ & rs4938933 & $\mathrm{TT} / \mathrm{TC} / \mathrm{CC}$ & $86 / 64 / 8$ & $561(270) / 509(238) / 567(347)$ \\
\hline $19, E X O C_{3} L 2$ & rs597668 & $\mathrm{TT} / \mathrm{TC} / \mathrm{C} \underline{\mathrm{C}}$ & $73 / 70 / 14$ & $538(270) / 562(271) / 446(136)$ \\
\hline \multicolumn{5}{|c|}{ GWAS with biomarkers as outcome } \\
\hline $2, E P C_{2}$ & rs1374441 & $\mathrm{TT} / \mathrm{TC} / \mathrm{C} \underline{\mathrm{C}}$ & $87 / 60 / 10$ & $511(239) / 567(269) / 631(387)$ \\
\hline $2, E P C_{2}$ & rs4499362 & $\mathrm{CC} / \mathrm{CT} / \mathrm{TT}$ & $88 / 62 / 9$ & $539(293) / 559(242) / 528(221)$ \\
\hline 15, CYP19A & rs2899472 & $C C / C A / A A$ & $98 / 51 / 10$ & $534(274) / 567(235) / 557(387)$ \\
\hline $7, R E L N$ & rs4298437 & $\mathrm{CC} / \mathrm{CT} / \mathrm{TT}$ & $73 / 63 / 23$ & $519(255) / 588(264) / 516(318)$ \\
\hline 19, TOMM40 & rs157580 & $\underline{\mathrm{A}} \mathrm{A} / \mathrm{AG} / \mathrm{GG}$ & $113 / 43 / 2$ & $567(281) / 492(226) / 329(250)$ \\
\hline 19, TOMM 40 & rs 2075650 & $\mathrm{AA} / \mathrm{AG} / \mathrm{GG}$ & $74 / 71 / 14$ & $505(274) / 573(251) / 623(315)$ \\
\hline \multicolumn{5}{|c|}{ Other candidate genes } \\
\hline $2, P P P_{3} R_{1}$ & rs1868402 & $\mathrm{TT} / \mathrm{TC} / \mathrm{CC}$ & 95/50/9 & $515(173) / 624(316) / 497(264)$ \\
\hline $3, T F$ & rs1049296 & $\mathrm{CC} / \mathrm{CT} / \mathrm{TI}$ & $128 / 27 / 3$ & $547(285) / 543(189) / 563(310)$ \\
\hline $10, I D E$ & rs 1887922 & $\mathrm{TT} / \mathrm{TC} / \mathrm{C} \underline{\mathrm{C}}$ & $117 / 40 / 2$ & $547(275) / 551(259) / 368(145)$ \\
\hline $11, B D N F$ & $\mathrm{rs} 6265$ & GG/GA/AE & $98 / 30 / 2$ & $543(266) / 492(182) / 777(350)$ \\
\hline 11, SORL1 & rs2070045 & $\mathrm{TT} / \mathrm{TG} / \mathrm{GG}$ & $86 / 63 / 9$ & $583(288) / 503(236) / 532(270)$ \\
\hline 11, SORL1 & rs3824968 & TT/TA/A $\underline{A}$ & $38 / 41 / 28$ & $530(284) / 522(245) / 557(223)$ \\
\hline $11, S O R L 1$ & rs73595277 & $\mathrm{CC} / \mathrm{CG} / \mathrm{GG}$ & $132 / 25 / 2$ & $529(241) / 624(388) / 698(16)$ \\
\hline${ }_{14}, C_{4} P_{4} A_{1}$ & rs754203 & $\mathrm{TT} / \mathrm{TC} / \mathrm{CC}$ & $73 / 74 / 11$ & $564(281) / 526(257) / 479(116)$ \\
\hline $17, A C E$ & rs4293 & $\underline{\mathrm{A} A / A G / G G}$ & $43 / 82 / 34$ & $601(262) / 506(263) / 574(284)$ \\
\hline 17, MAPT & rs16940758 & $\mathrm{CC} / \mathrm{CT} / \mathrm{TT}$ & $108 / 46 / 5$ & $526(264) / 579(282) / 657(258)$ \\
\hline 17, MAPT & rs2435211 & $\mathrm{CC} / \mathrm{CT} / \mathrm{TT}$ & $50 / 86 / 23$ & $483(184) / 562(34) / 621(370)$ \\
\hline 17, MAPT & rs1467967 & $\mathrm{AA} / \mathrm{AG} / \mathrm{G} \underline{\mathrm{G}}$ & $64 / 74 / 20$ & $577(303) / 515(251) / 552(215)$ \\
\hline $17, M A P T$ & rs7521 & $\mathrm{AA} / \mathrm{AG} / \mathrm{G} \underline{\mathrm{G}}$ & $42 / 84 / 32$ & $543(240) / 534(266) / 554(281)$ \\
\hline 19, TOMM4O & rs8106922 & $\underline{A} A / A G / G G$ & $78 / 66 / 15$ & $570(257) / 526(257) / 512(375)$ \\
\hline
\end{tabular}

Abbreviations: $\mathrm{Chr}=$ chromosome; $\mathrm{SNP}=$ single nucleotide polymorphism; $\mathrm{n}=$ number of cases; $\mathrm{SD}=$ standard deviation; $\mathrm{t}$-tau=total tau; $\mathrm{p}$-tau=phosphorylated tau; $\mathrm{DM}=$ dominant model; GWAS=genome-wide association studies.

Risk allele according to AlzGene meta-analyses or study source in bold and underscored. Information on risk allele was not available for all studies. All CSF values are means (standard deviation). $P$-values based on mixed model analyses adjusted for age and gender; values in parenthe- 


\begin{tabular}{|c|c|c|c|c|c|}
\hline \multicolumn{2}{|l|}{$P$-value } & \multirow{2}{*}{$\begin{array}{l}\text { Geno- } \\
\text { type, n }\end{array}$} & \multirow{2}{*}{$\begin{array}{l}\text { Mean (SD) p-tau } \\
\text { level, pg/ml, per } \\
\text { genotype }\end{array}$} & \multicolumn{2}{|l|}{$P$-value } \\
\hline Overall & DM & & & Overall & DM \\
\hline $0.46(0.39)$ & $0.60(0.56)$ & $50 / 71 / 30$ & $81(40) / 85(35) / 88(33)$ & $0.18(0.79)$ & $0.56(0.55)$ \\
\hline $0.41(0.51)$ & $0.18(0.24)$ & $82 / 60 / 8$ & $86(37) / 82(33) / 80(40)$ & $0.59(0.61)$ & $0.36(0.39)$ \\
\hline $0.30(0.18)$ & $0.73(0.32)$ & $70 / 64 / 15$ & $85(41) / 84(33) / 78(20)$ & $0.72(0.58)$ & $0.54(0.37)$ \\
\hline $0.14(0.13)$ & $0.06(0.06)$ & $85 / 55 / 9$ & $80(30) / 86(38) / 102(63)$ & $0.17(0.16)$ & $0.13(0.13)$ \\
\hline $0.68(0.61)$ & $0.41(0.35)$ & $86 / 58 / 7$ & $84(37) / 86(36) / 73(26)$ & $0.53(0.48)$ & $0.61(0.57)$ \\
\hline $0.76(0.77)$ & $0.77(0.79)$ & $90 / 51 / 10$ & $84(38) / 86(31) / 80(44)$ & $0.69(0.68)$ & $0.84(0.84)$ \\
\hline $0.17(0.23)$ & $0.13(0.15)$ & $68 / 62 / 21$ & $83(35) / 90(37) / 73(35)$ & $0.13(0.16)$ & $0.53(0.60)$ \\
\hline $0.27(0.42)$ & $0.15(0.21)$ & $107 / 41 / 2$ & $85(36) / 83(38) / 15(53)$ & $0.56(0.66)$ & $0.86(0.96)$ \\
\hline $0.52(0.96)$ & $0.26(0.81)$ & $72 / 66 / 13$ & $81(36) / 87(36) / 87(32)$ & $0.80(0.92)$ & $0.59(0.91)$ \\
\hline $0.07(0.04)$ & $0.05(0.03)^{b}$ & $91 / 46 / 9$ & $82(33) / 93(41) / 78(40)$ & $0.24(0.20)$ & $0.20(0.17)$ \\
\hline $0.83(0.84)$ & $0.55(0.56)$ & $120 / 27 / 3$ & $82(35) / 94(41) / 80(43)$ & $0.53(0.51)$ & $0.35(0.32)$ \\
\hline $0.63(0.68)$ & $0.97(0.92)$ & $112 / 37 / 2$ & $84(35) / 87(39) / 65(34)$ & $0.69(0.71)$ & $0.80(0.76)$ \\
\hline $0.50(0.50)$ & $0.45(0.41)$ & $92 / 29 / 2$ & $84(37) / 79(31) / 121(57)$ & $0.45(0.45)$ & $0.75(0.74)$ \\
\hline $0.41(0.43)$ & $0.18(0.20)$ & $83 / 58 / 9$ & $86(36) / 81(36) / 89(36)$ & $0.84(0.85)$ & $0.79(0.80)$ \\
\hline $0.55(0.57)$ & $0.50(0.55)$ & $36 / 41 / 24$ & $87(43) / 83(36) / 89(29)$ & $0.72(0.72)$ & $0.96(0.99)$ \\
\hline $0.18(0.23)$ & $0.07(0.09)$ & $127 / 22 / 2$ & $82(32) / 98(53) / 91(40)$ & $0.11(0.12)$ & $0.04^{b}(0.05)$ \\
\hline $0.64(0.73)$ & $0.37(0.46)$ & $69 / 71 / 10$ & $81(34) / 88(39) / 73(17)$ & $0.36(0.32)$ & $0.31(0.26)$ \\
\hline $0.08(0.09)$ & $0.31(020)$ & $41 / 78 / 32$ & $86(29) / 83(41) / 84(33)$ & $0.84(0.89)$ & $0.96(0.94)$ \\
\hline $0.11(0.10)$ & $0.06(0.05)$ & $105 / 41 / 5$ & $80(36) / 93(37) / 90(24)$ & $0.08(0.08)$ & $\begin{array}{l}0.03^{b} \\
(0.02)^{b}\end{array}$ \\
\hline $0.08(0.05)$ & $0.03^{b}(0.02)^{b}$ & $47 / 81 / 23$ & $80(32) / 84(34) / 95(49)$ & $0.27(0.22)$ & $0.22(0.20)$ \\
\hline $0.59(0.50)$ & $0.37(0.28)$ & $61 / 70 / 19$ & $89(40) / 80(35) / 84(26)$ & $0.62(0.59)$ & $0.36(0.32)$ \\
\hline $0.91(0.92)$ & $0.78(0.71)$ & $41 / 76 / 33$ & $85(30) / 78(32) / 95(46)$ & $0.07(0.07)$ & $0.98(0.92)$ \\
\hline $0.75(0.82)$ & $0.49(0.93)$ & $36 / 75 / 40$ & $87(35) / 82(33) / 82(53)$ & $0.88(0.94)$ & $0.63(0.90)$ \\
\hline
\end{tabular}

sis ( ) adjusted for age, gender and APOE- 4 status. Analyses testing APOE adjusted for age and gender. Results for $A P O E$ are shown for comparative purposes only.

${ }^{a}$ No cerebrospinal fluid measured because none of the participants carried the rs $11754661 \mathrm{AA}$ genotype.

${ }^{\mathrm{b}}$ No longer significant after false discovery rate correction. 


\section{DISCUSSION}

We performed a case-control genetic association analysis of $25 \mathrm{AD}$ risk variants and tested the effects of 36 risk variants on CSF A $\beta_{1-42,}$ t-tau, and p-tau in the AD group.

Only APOE and TOMM4O showed genetic association with AD. However, TOMM4O is in linkage disequilibrium with $A P O E$ and did not exhibit an effect independent of $A P O E$, in accordance with recent evidence. ${ }^{37}$

Of the AlzGene top loci, CLU correlated significantly with decreased $A \beta_{1-42 .}$ Previous studies have not found the same effect, which may be attributed to their smaller sample size. ${ }^{88,39}$ Consistent with GWAS findings, the minor allele of CLU exerted a protective effect on $A D$ risk, ${ }^{30}$ and on CSF $A \beta_{1-42}$ in the Finnish cohort. CLU did not significantly affect tau CLU binds soluble $A \beta$ and plays a role in $A \beta$ clearance and aggregation, ${ }^{15}$ which could partly explain why it primarily affected $A \beta_{1-42}$.

PICALM affects $A \beta$ concentration in the brain through endocytic processes. Marker rs3851179 in PICALM has been reported to correlate with CSF $A \beta_{1-42}$ in another study, the major allele $(G)$ being the risk allele. ${ }^{39}$ In our cohort, we found no indication of a correlation between rs3851179 and CSF markers. Instead, rs642949 minor allele carriers (C) had decreased $A \beta_{1-42}$ and increased t-tau levels, although these were not statistically significant. The C allele of $\mathrm{rs} 642949$ has been reported to exert a risk effect in a case-control study..$^{\circ}$

$A P O E$ and the other top AlzGene loci did not correlate with t-tau and $p$-tau in our cohort.

Of the GWAS SNPs not in AlzGene top loci, MS4A4A showed significant correlation with $A \beta_{1-42}$ but not with tau. $M S_{4} A 4 A$ belongs to the MS4A cluster. ${ }^{19}$ Not much is known yet about MS4A4A rs2304933 but its effect on $A \beta_{1-42}$ is consistent with our genetic association analysis results suggesting a risk effect of the minor (C) allele. The mechanisms by which $M S_{4} A_{4} A$ affect CSF A $\beta_{1-42}$ levels need further investigation. As far as we know, studies of the relation between MS4A4A rs2304933 and CSF markers have not been published before.

The decrease in $A \beta_{1-42}$ levels among $C$ allele carriers of $E X O$ $C_{3}$ L2 rs597668 is interesting. Although not statistically significant (FDR adjusted $P>0.05)$, it conferred with a previous study identifying the $C$ al- 
lele as a risk allele in the Finnish population. ${ }^{31}$ The $C$ allele has also been reported in another study to promote AD progression. ${ }^{41}$

Among GWAS SNPs with biomarker as outcome, TOMM4O SNPs correlated with CSF A $\beta_{1-42}$ but not with tau, which was consistent with previous findings. ${ }^{20,}{ }^{21}$ None of the TOMM4O SNPs remained significant after APOE correction. This makes it likely that the TOMM4O effects

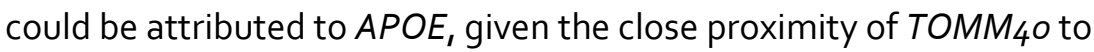
APOE.

$E P C 2$, which correlated with t-tau in biomarker GWAS, ${ }^{21}$ showed no effect on CSF t-tau and also $A \beta_{1-42}$ in our cohort. The aforementioned GWAS had a much smaller AD group than in our cohort. This and the variability in population could account for the different findings.

The SNPs from candidate genes were not related to CSF $A \beta_{1-42}$. For tau, marginal correlations were obtained for $P P P_{3} R_{1}, S O R L_{1}$ and MAPT at an FDR unadjusted $P<0.05$. Although none passed the FDR filter, the small effects observed were suggestive of a trend for variants in these three genes. $P P P_{3} R_{1}$ is a protein phosphatase and is the calcium binding regulatory subunit of calcineurin. ${ }^{42}$ Calcineurin is involved in modulating tau phosphorylation. ${ }^{43} \mathrm{~A}$ previous study found $P P P_{3} R_{1}$ to correlate with p-tau. ${ }^{4}$ In our cohort, we found an effect on t-tau but the effect on p-tau was weaker. This difference in results could partly be attributed to variability in population.

SORL1 binds to ApoE and plays a role in $A \beta_{1-42}$ production. ${ }^{44}$ Numerous SNPs in SORL1 have been studied in relation to $A D^{45}$ and CSF biomarkers ${ }^{44}$ but results so far have been inconclusive. ${ }^{10}$ One study found that rs3824968 in SORL1 significantly reduced $A \beta_{1-42}$ in $A D^{46}$ whereas another study reported no correlation. ${ }^{47}$ SORL1 appears to exert small effects likely to be detected only in mega-analysis of pooled samples ${ }^{48}$ or in haplotypes. 49 In general, single polymorphism in SORL1 did not correlate with CSF A $\beta_{1-42}$ and tau. ${ }^{10}$ Our result relating SORL with p-tau may be due to chance.

MAPT codes for tau proteins. Aggregated hyperphosphorylated tau proteins are a component of NFTs. Consistent with the findings of another study, we found MAPT to correlate with CSF t-tau..$^{\circ}$

We noted a number of changes in the strength of correlation between SNPs and biomarkers when we corrected for APOE. As mentioned above, TOMM4O was no longer associated with AD and CSF A $\beta_{1-42}$ 
after $A P O E$ correction. This confirms previous finding that TOMM 40 is in strong linkage disequilibrium with $A P O E$. The effect of $E X O C_{3} L 2$ on CSF $A \beta_{1-42}$ became nonsignificant after correcting for $A P O E$. This suggests that the effect was not independent of $A P O E$. Due to our small sample size, our result could also be a false positive. For the other SNPs, we found no or minor changes on either $A D$ risk or correlation with CSF markers after $A P O E$ correction. This means that the effects of these SNPs were independent of $A P O E$, or that our sample size was too small to detect interaction effects.

We tested the relation between SNPs and CSF biomarkers in $A D$ patients who were already demented. We found few SNP-related differences in CSF $A \beta$ because $A \beta$ may already be strongly decreased in demented patients. The effect of genetic risk factors on amyloid metabolism may be more evident in predementia stages. Although AD has been related to changes in tau, we only found weak correlations between the studied SNPs and tau. Of interest is the weak correlation of MAPT and $P P P_{3} R 1$ with tau, which confirms the role of these SNPs in tau metabolism. We note here that MAPT and $P P P_{3} R 1$ also showed weak associations with clinical AD in our case-control genetic association analyses, which suggest that the studied loci in these genes contribute to dementia risk. In the analyses with biomarkers, none of the AlzGene or other GWAS SNPs were related to tau, suggesting that these SNPs have no clear effect on tau metabolism.

Our study had the unique design that we tested SNPs both for genetic association in a clinical case-control design and for correlation with CSF biomarkers. This is one of the strengths of our exploratory study. Another strength was the large selection of high-risk SNPs identified by GWAS or reported in other candidate gene studies covering different possible pathophysiological pathways. The small sample size remained a limitation. We had sufficient power for finding moderate associations, but a larger sample is needed for detecting the very small effect sizes of the other SNPs studied.

In conclusion, we provide evidence that $A P O E, C L U$ and $M S_{4} A 4 A$, which have been identified in GWAS to be associated with $A D$, also significantly affected CSF $A \beta_{1-42 .}$ To our knowledge, ours is the first study to report on the correlation between $M S_{4} A_{4} A$ and $C S F A \beta_{1-42}$. 
None of the AD risk genes studied showed significant effects on CSF tau. The nonsignificant trends in $P P P_{3} R_{1}$ and $M A P T$ in relation to tau may be due to our small sample size rather than genuine lack of risk effects. Collaboration on a larger scale is necessary to ascertain the effects of the aforementioned SNPs and identify reliable genetic risk variants for AD markers in CSF.

Acknowledgements: The study was in part funded by the Health Research Council of Academy of Finland, EVO-funding from Kuopio University Hospital, 5772708, and strategic funding from University of Eastern Finland for UEFBRAIN (Soininen); Tampere University Hospital Medical Fund, gNo35 (Lehtimäki); and Zon-Mw (Visser) as part of the BIOMARKAPD project in the frame of the European Joint Programming Initiative on Neurodegenerative Disorders (JPND). Alzheimer Nederland and the Internationale Stichting Alzheimer Onderzoek provided financial assistance for the internship of Elias-Sonnenschein at the Institute of Clinical Medicine-Neurology, University of Eastern Finland.

\section{REFERENCES}

1. Blennow K, de Leon MJ, Zetterberg H. Alzheimer's disease. Lancet 2006; 368(9533): 387-403.

2. Bu G. Apolipoprotein $E$ and its receptors in Alzheimer's disease: pathways, pathogenesis and therapy. Nat Rev Neurosci 2009; 10(5): 333-44.

3. Bekris LM, Millard S, Lutz F, Li G, Galasko DR, Farlow MR, et al. Tau phosphorylation pathway genes and cerebrospinal fluid tau levels in Alzheimer's disease. Am J Med Genet $B$ Neuropsychiatr Genet 2012; 159B(7): 874-83.

4. Cruchaga C, Kauwe JS, Mayo K, Spiegel N, Bertelsen S, Nowotny P, et al. SNPs associated with cerebrospinal fluid phospho-tau levels influence rate of decline in Alzheimer's disease. PLoS Genet 2010; 6(9).

5. Spires-Jones TL, Stoothoff WH, de Calignon A, Jones PB, Hyman BT. Tau pathophysiology in neurodegeneration: a tangled issue. Trends Neurosci 2009; 32(3): 150-9.

6. Fagan AM, Mintun MA, Mach RH, Lee SY, Dence CS, Shah AR, et al. Inverse relation between in vivo amyloid imaging load and cerebrospinal fluid Abeta42 in humans. Ann Neurol 2006; 59(3): 512-9. 
7. Cruts M, Van Broeckhoven C. Molecular genetics of Alzheimer's disease. Ann Med 1998; 30(6): 560-5.

8. Lambert JC, Amouyel P. Genetics of Alzheimer's disease: new evidences for an old hypothesis? Curr Opin Genet Dev 2011; 21(3): 295-301.

9. Bertram L, Lill CM, Tanzi RE. The genetics of Alzheimer disease: back to the future. Neuron 2010; 68(2): 270-81.

10. Elias-Sonnenschein LS, Bertram L, Visser PJ. Relationship between genetic risk factors and markers for Alzheimer's disease pathology. Biomark Med 2012; 6(4): 477-95.

11. McKhann G, Drachman D, Folstein M, Katzman R, Price D, Stadlan EM. Clinical diagnosis of Alzheimer's disease: report of the NINCDS-ADRDA Work Group under the auspices of Department of Health and Human Services Task Force on Alzheimer's Disease. Neurology 1984; 34(7): 939-44.

12. Bertram L, McQueen MB, Mullin K, Blacker D, Tanzi RE. Systematic meta-analyses of Alzheimer disease genetic association studies: the AlzGene database. Nat Genet 2007; 39(1): 17-23.

13. Strittmatter WJ, Saunders AM, Schmechel D, Pericak-Vance M, Enghild J, Salvesen GS, et al. Apolipoprotein E: high-avidity binding to beta-amyloid and increased frequency of type 4 allele in late-onset familial Alzheimer disease. Proc Natl Acad SciU S A 1993; 90(5): 1977-81.

14. Farrer LA, Cupples LA, Haines JL, Hyman B, Kukull WA, Mayeux R, et al. Effects of age, sex, and ethnicity on the association between apolipoprotein $\mathrm{E}$ genotype and Alzheimer disease. A meta-analysis. APOE and Alzheimer Disease Meta Analysis Consortium. JAMA 1997; 278(16): 1349-56.

15. Schellenberg GD, Montine TJ. The genetics and neuropathology of Alzheimer's disease. Acta Neuropathol 2012.

16. Olgiati P, Politis AM, Papadimitriou GN, De Ronchi D, Serretti A. Genetics of late-onset Alzheimer's disease: update from the alzgene database and analysis of shared pathways. Int J Alzheimers Dis 2011; 2011: 832379.

17. Hollingworth $P$, Harold D, Sims R, Gerrish A, Lambert JC, Carrasquillo MM, et al. Common variants at $A B C A 7, M S_{4} A 6 A / M S_{4} A_{4} E_{1} E P H A_{1}, C D_{33}$ and $C D_{2} A P$ are associated with Alzheimer's disease. Nat Genet 2011; 43(5): 429-35.

18. Seshadri S, Fitzpatrick AL, Ikram MA, DeStefano AL, Gudnason V, Boada M, et al. Genomewide analysis of genetic loci associated with Alzheimer disease. JAMA 2010; 303(18): 1832-40.

19. Naj AC, Jun G, Beecham GW, Wang LS, Vardarajan BN, Buros J, et al. Common variants at $\mathrm{MS}_{4} \mathrm{~A}_{4} / \mathrm{MS}_{4} \mathrm{~A} 6 \mathrm{E}, \mathrm{CD}_{2} \mathrm{AP}, \mathrm{CD}_{33}$ and $\mathrm{EPHA} 1$ are associated with late-onset Alzheimer's disease. Nat Genet 2011; 43(5): 436-41.

20. Han MR, Schellenberg GD, Wang LS. Genome-wide association reveals genetic effects on human Abeta 42 and tau protein levels in cerebrospinal fluids: a case control study. BMC Neurol 2010; 10: 90. 
21. Kim S, Swaminathan S, Shen L, Risacher SL, Nho K, Foroud T, et al. Genome-wide association study of CSF biomarkers Abeta1-42, t-tau, and p-tau181p in the ADNI cohort. Neurology 2011; 76(1): 69-79.

22. Kramer $\mathrm{PL}, \mathrm{Xu} \mathrm{H}$, Woltjer RL, Westaway SK, Clark D, Erten-Lyons $\mathrm{D}$, et al. Alzheimer disease pathology in cognitively healthy elderly: a genome-wide study. Neurobiol Aging 2011; 32(12): 2113-22.

23. livonen S, Corder E, Lehtovirta M, Helisalmi S, Mannermaa A, Vepsalainen S, et al. Polymorphisms in the CYP19 gene confer increased risk for Alzheimer disease. Neurology 2004; 62(7): 1170-6.

24. Kauwe JS, Wang J, Mayo K, Morris JC, Fagan AM, Holtzman DM, et al. Alzheimer's disease risk variants show association with cerebrospinal fluid amyloid beta. Neurogenetics 2009; 10(1): 13-7.

25. Helisalmi S, Vepsalainen S, Koivisto AM, Mannermaa A, livonen S, Hiltunen M, et al. Association of CYP 46 intron 2 polymorphism in Finnish Alzheimer's disease samples and a global scale summary. J Neurol Neurosurg Psychiatry 2006; 77(3): 421-2.

26. Johansson A, Katzov H, Zetterberg H, Feuk L, Johansson B, Bogdanovic N, et al. Variants of CYP46A1 may interact with age and APOE to influence CSF Abeta 42 levels in Alzheimer's disease. Hum Genet 2004; 114(6): 581-7.

27. Vepsalainen S, Helisalmi S, Mannermaa A, Pirttila T, Soininen H, Hiltunen M. Combined risk effects of IDE and NEP gene variants on Alzheimer disease. J Neurol Neurosurg Psychiatry 2009; 80(11): 1268-70.

28. Vepsalainen S, Parkinson M, Helisalmi S, Mannermaa A, Soininen H, Tanzi RE, et al. Insulindegrading enzyme is genetically associated with Alzheimer's disease in the Finnish population. J Med Genet 2007; 44(9): 606-8.

29. Blomqvist ME, Chalmers K, Andreasen N, Bogdanovic N, Wilcock GK, Cairns NJ, et al. Sequence variants of IDE are associated with the extent of beta-amyloid deposition in the Alzheimer's disease brain. Neurobiol Aging 2005; 26(6): 795-802.

30. Lambert JC, Heath S, Even G, Campion D, Sleegers K, Hiltunen M, et al. Genome-wide association study identifies variants at CLU and CR1 associated with Alzheimer's disease. Nat Genet 2009; 41(10): 1094-9.

31. Lambert JC, Zelenika D, Hiltunen M, Chouraki V, Combarros O, Bullido MJ, et al. Evidence of the association of $\mathrm{BIN} 1$ and PICALM with the AD risk in contrasting European populations. Neurobiol Aging 2011; 32(4): 756 e11-5.

32. Vepsalainen S, Castren E, Helisalmi S, livonen S, Mannermaa A, Lehtovirta M, et al. Genetic analysis of BDNF and TrkB gene polymorphisms in Alzheimer's disease. J Neurol 2005; 252(4): $423-8$. 
33. Purcell S, Cherny SS, Sham PC. Genetic Power Calculator: design of linkage and association genetic mapping studies of complex traits. Bioinformatics 2003; 19(1): 149-50.

34. Benjamini Y, Hochberg Y. Controlling the false discovery rate: a practical and powerful approach to multiple testing. Journal of the Royal Statistical Society, Series B 1995; 57: 289-300.

35. Folstein MF, Folstein SE, McHugh PR. "Mini-mental state". A practical method for grading the cognitive state of patients for the clinician. J Psychiatr Res 1975; 12(3): 189-98.

36. Jun G, Vardarajan BN, Buros J, Yu CE, Hawk MV, Dombroski BA, et al. Comprehensive Search for Alzheimer Disease Susceptibility Loci in the APOE Region. Arch Neurol 2012: 1-10.

37. Schott JM. Using CSF biomarkers to replicate genetic associations in Alzheimer's disease. Neurobiol Aging 2011.

38. Schjeide BM, Schnack C, Lambert JC, Lill CM, Kirchheiner J, Tumani H, et al. The role of clusterin, complement receptor 1 , and phosphatidylinositol binding clathrin assembly protein in Alzheimer disease risk and cerebrospinal fluid biomarker levels. Arch Gen Psychiatry 2011; 68(2): 207-13.

39. Rosenthal SL, Wang X, Demirci FY, Barmada MM, Ganguli M, Lopez OL, et al. Beta-Amyloid Toxicity Modifier Genes and the Risk of Alzheimer's Disease. Am J Neurodegener Dis 2012; 1(2): 191-8.

40. Schmidt C, Wolff M, von Ahsen N, Zerr I. Alzheimer's disease: genetic polymorphisms and rate of decline. Dement Geriatr Cogn Disord 2012; 33(2-3): 84-9.

41. Karch CM, Jeng AT, Goate AM. Calcium phosphatase calcineurin influences tau metabolism. Neurobiol Aging 2012.

42. Reese LC, Taglialatela G. A role for calcineurin in Alzheimer's disease. Curr Neuropharmacol 2011; 9(4): 685-92.

43. Kauwe JS, Cruchaga C, Bertelsen S, Mayo K, Latu W, Nowotny P, et al. Validating predicted biological effects of Alzheimer's disease associated SNPs using CSF biomarker levels. J Alzheimers Dis 2010; 21(3): 833-42.

44. Reitz C, Cheng R, Rogaeva E, Lee JH, Tokuhiro S, Zou F, et al. Meta-analysis of the association between variants in SORL1 and Alzheimer disease. Arch Neurol 2011; 68(1): 99-106.

45. Alexopoulos P, Guo LH, Kratzer M, Westerteicher C, Kurz A, Perneczky R. Impact of SORL1 single nucleotide polymorphisms on Alzheimer's disease cerebrospinal fluid markers. Dement Geriatr Cogn Disord 2011; 32(3): 164-70.

46. Kolsch H, Jessen F, Wiltfang J, Lewczuk P, Dichgans M, Kornhuber J, et al. Influence of SORL1 gene variants: association with CSF amyloid-beta products in probable Alzheimer's disease. Neurosci Lett 2008; 440(1): 68-71.

47. Olgiati P, Politis A, Albani D, Rodilossi S, Polito L, Ateri E, et al. Association of SORL1 alleles with late-onset Alzheimer's disease. findings from the GIGAS_LOAD study and mega-analysis. Curr Alzheimer Res 2012; 9(4): 491-9. 
48. Cuenco KT, Lunetta KL, Baldwin CT, McKee AC, Guo J, Cupples LA, et al. Association of distinct variants in SORL1 with cerebrovascular and neurodegenerative changes related to Alzheimer disease. Arch Neurol 2008; 65(12): 1640-8.

49. Kauwe JS, Cruchaga C, Mayo K, Fenoglio C, Bertelsen S, Nowotny P, et al. Variation in MAPT is associated with cerebrospinal fluid tau levels in the presence of amyloid-beta deposition. Proc Natl Acad SciU S A 2008; 105(23): 8050-4.

Supplementary table Genetic variants included in the study. All were tested for biomarker analyses. SNPs tested in previous studies for genetic association with AD were not included in the present study, as indicated.

\begin{tabular}{|c|c|c|}
\hline Gene & SNP & Genetic association \\
\hline \multicolumn{3}{|c|}{ Top AlzGene loci } \\
\hline $1, C R 1$ & rs6656401 & Previously tested. Significant in GWAS ${ }^{a[1]}$ \\
\hline $2, B / N_{1}$ & rs744373 & Previously tested. Significant in replication study ${ }^{\mathrm{a}[2]}$ \\
\hline $2, B / N_{1}$ & rs7561528 & Gene previously tested in GWAS ${ }^{a[3]}$ \\
\hline $6, C D_{2} A P$ & rs9349407 & Previously tested. Significant in GWAS ${ }^{a[3]}$ \\
\hline $8, C L U$ & rs111360oo & Previously tested. Significant in GWAS ${ }^{a[1]}$ \\
\hline $11, M S_{4} A_{4} E$ & rs670139 & Previously tested. Significant in GWAS ${ }^{a[3]}$ \\
\hline $11, M S_{4} A 6 A$ & rs610932 & Previously tested. Significant in GWAS ${ }^{a[3]}$ \\
\hline 11, PICALM & rs3851179 & Included in current study \\
\hline 11, PICALM & rs642949 & Included in current study \\
\hline 19, $A B C A 7$ & rs3752246 & Previously tested. Significant in GWAS ${ }^{a[3]}$ \\
\hline $19, C D_{33}$ & rs3865444 & Previously tested. Significant in GWAS ${ }^{\mathrm{a}[3]}$ \\
\hline $19, A P O E^{b}$ & $\varepsilon 2 / \varepsilon 3 / \varepsilon 4$ & Included in current study \\
\hline \multicolumn{3}{|l|}{ GWAS } \\
\hline 6, MTHFD1L & rs11754661 & Included in current study \\
\hline $11, M S_{4} A_{4} A$ & rs2304933 & Included in current study \\
\hline $11, M_{4} A_{4} A$ & rs4938933 & Included in current study \\
\hline $19, E X O C_{3} L 2$ & rs597668 & Previously tested. Significant in replication study ${ }^{a[2]}$ \\
\hline 2. $E P C_{2}$ & rs1374441 & Included in current study \\
\hline 2. $E P C_{2}$ & rs4499362 & Included in current study \\
\hline $15, C Y P_{19 A}$ & rs2899472 & Included in current study ${ }^{\mathrm{c}[4]}$ \\
\hline
\end{tabular}


Supplementary table Continued. Genetic variants included in the study. All were tested for biomarker analyses. SNPs tested in previous studies for genetic association with AD were not included in the present study, as indicated.

\begin{tabular}{|c|c|c|}
\hline Gene & SNP & Genetic association \\
\hline 7, RELN & rs429837 & Included in current study \\
\hline 19, TOMM40 & rs15758o & Included in current study \\
\hline 19, TOMM4O & rs2075650 & Included in current study \\
\hline \multicolumn{3}{|c|}{ Other candidate genes } \\
\hline $2, P P P_{3} R_{1}$ & rs1868402 & Included in current study \\
\hline $3, T F$ & rs1049296 & Included in current study \\
\hline $10, I D E$ & rs1887922 & Included in current study ${ }^{\mathrm{c}[5]}$ \\
\hline $11, B D N F$ & $\mathrm{rs} 6265$ & $\begin{array}{l}\text { Previously tested. Not significant in genetic association analy- } \\
\operatorname{sis}^{a[6]}\end{array}$ \\
\hline 11, SORL1 & rs2070045 & Included in current study \\
\hline $11, S O R L 1$ & rs3824968 & Included in current study \\
\hline $11, S O R L_{1}$ & rs73595277 & Included in current study \\
\hline $14, C_{4} 6 a$ & rs754203 & Previously tested. Significant in candidate gene analysis ${ }^{[[7]}$ \\
\hline $17, A C E$ & rs4293 & Included in current study ${ }^{c[8]}$ \\
\hline 17, MAPT & rs16940758 & Included in current study \\
\hline 17, MAPT & rs2435211 & Included in current study \\
\hline 17, MAPT haplotype & rs1467967 & Included in current study \\
\hline 17, MAPT haplotype & rs7521 & Included in current study \\
\hline 19, TOMM40 & rs8106922 & Included in current study \\
\hline
\end{tabular}

Abbreviations: Chr, chromosome; SNP, single nucleotide polymorphism; CSF, cerebrospinal fluid; GWAS, genome-wide association study

Gene names: $C R 1$, complement component receptor $1_{;} B I N 1_{1}$, bridging integrator $1 ; C D_{2} A P_{1} C D_{2}$ associated protein; $C L U$, clusterin; $M S_{4} A_{4} E$, membrane-spanning 4-domains, subfamily $A$, member 4E; MS4A6A, membrane-spanning 4-domains, subfamily $\mathrm{A}$, member 6A; PICALM, phosphatidylinositol binding clathrin assembly protein; $A B C A 7$, ATP-binding cassette, subfamily $A$, member 7; $C D_{33}$, $C D_{33}$ molecule; $M T H F D_{1} L$, methylenetetrahydrofolate dehydrogenase 1-like; $R E L N$, reelin; MS4A4A, membrane-spanning 4-domains, subfamily $A_{1}$ member $4 \mathrm{~A}_{4} E X O C_{3} L_{2}$, exocyst complex component 3-like 2; $E P C_{2}$, enhancer of polycomb homolog 2; CYP19A, cytochrome $\mathrm{P}_{450}$, family 19 , subfamily a, polypeptide $1 ; T O M M_{40}$, translocase of outer mitochondrial membrane 40 homolog; $P P P_{3} R 1$, protein phosphatase 3 , regulatory subunit $\mathrm{B}$, alpha; $T F$, transferin ; $I D E$, insulindegrading enzyme; $B D N F$, brain-derived neurotrophic factor; SORL1, sortilin-related receptor; 
CYP 46a cytochrome $\mathrm{P}_{450}$, family 46, subfamily A, polypeptide; $A C E$, angiotensin I converting enzyme 1; MAPT, microtubule-associated protein tau; TOMM40, translocase of outer mitochondrial membrane 40 homolog; $A P O E$, apolipoprotein $\mathrm{E}$

a Gene previously genotyped in GWAS or SNP genotyped in genetic association studies that included the Finnish cohort and excluded from the genetic association analysis in the present study but included in the biomarker analysis.

${ }^{b} A P O E$ tested for reference purposes.

' Gene previously genotyped in the Finnish cohort but with different SNP(s). Present SNP included in the genetic association and biomarker analysis.

Number in table text [ ] denotes references.

\section{References}

1. Lambert JC, Heath S, Even G, Campion D, Sleegers K, et al. (2009) Genome-wide association study identifies variants at CLU and CR1 associated with Alzheimer's disease. Nat Genet 41: 1094-1099.

2. Lambert JC, Zelenika D, Hiltunen M, Chouraki V, Combarros O, et al. (2011) Evidence of the association of $\mathrm{BIN} 1$ and PICALM with the AD risk in contrasting European populations. Neurobiol Aging 32: 756 e711-755.

3. Hollingworth $P$, Harold D, Sims R, Gerrish A, Lambert JC, et al. (2011) Common variants at $A B C A 7, M S_{4} A 6 A / M S_{4} A_{4} E_{1} E P H A_{1}, C D_{33}$ and $C D_{2} A P$ are associated with Alzheimer's disease. Nat Genet 43: 429-435.

4. livonen S, Corder E, Lehtovirta M, Helisalmi S, Mannermaa A, et al. (2004) Polymorphisms in the CYP19 gene confer increased risk for Alzheimer disease. Neurology 62: 1170-1176.

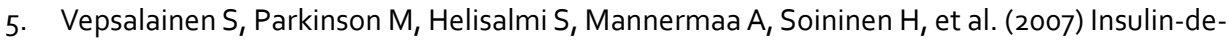
grading enzyme is genetically associated with Alzheimer's disease in the Finnish population. J Med Genet 44: 606-608.

6. Vepsalainen S, Castren E, Helisalmi S, livonen S, Mannermaa A, et al. (2005) Genetic analysis of BDNF and TrkB gene polymorphisms in Alzheimer's disease. J Neurol 252: 423-428.

7. Helisalmi S, Vepsalainen S, Koivisto AM, Mannermaa A, livonen S, et al. (2006) Association of CYP 46 intron 2 polymorphism in Finnish Alzheimer's disease samples and a global scale summary. J Neurol Neurosurg Psychiatry 77: 421-422.

8. Sarajarvi T, Helisalmi S, Antikainen L, Makinen P, Koivisto AM, et al. (2010) An association study of 21 potential Alzheimer's disease risk genes in a Finnish population. J Alzheimers Dis 21: 763-767. 
We previously found that MS $4 A_{4} A$ correlated with abnormally low $A B_{1-42}$ levels in patients with $A D$. We aimed to replicate the findings in an independent cohort composed of various diagnostic groups. 
LS Elias-Sonnenschein, FRJ Verhey, PJ Visser for the EDAR study Submitted

\section{CHAPTER 8}

Effects of $M S_{4} A$ variants on cerebrospinal fluid $A \beta 1-42$ in the EDAR cohort

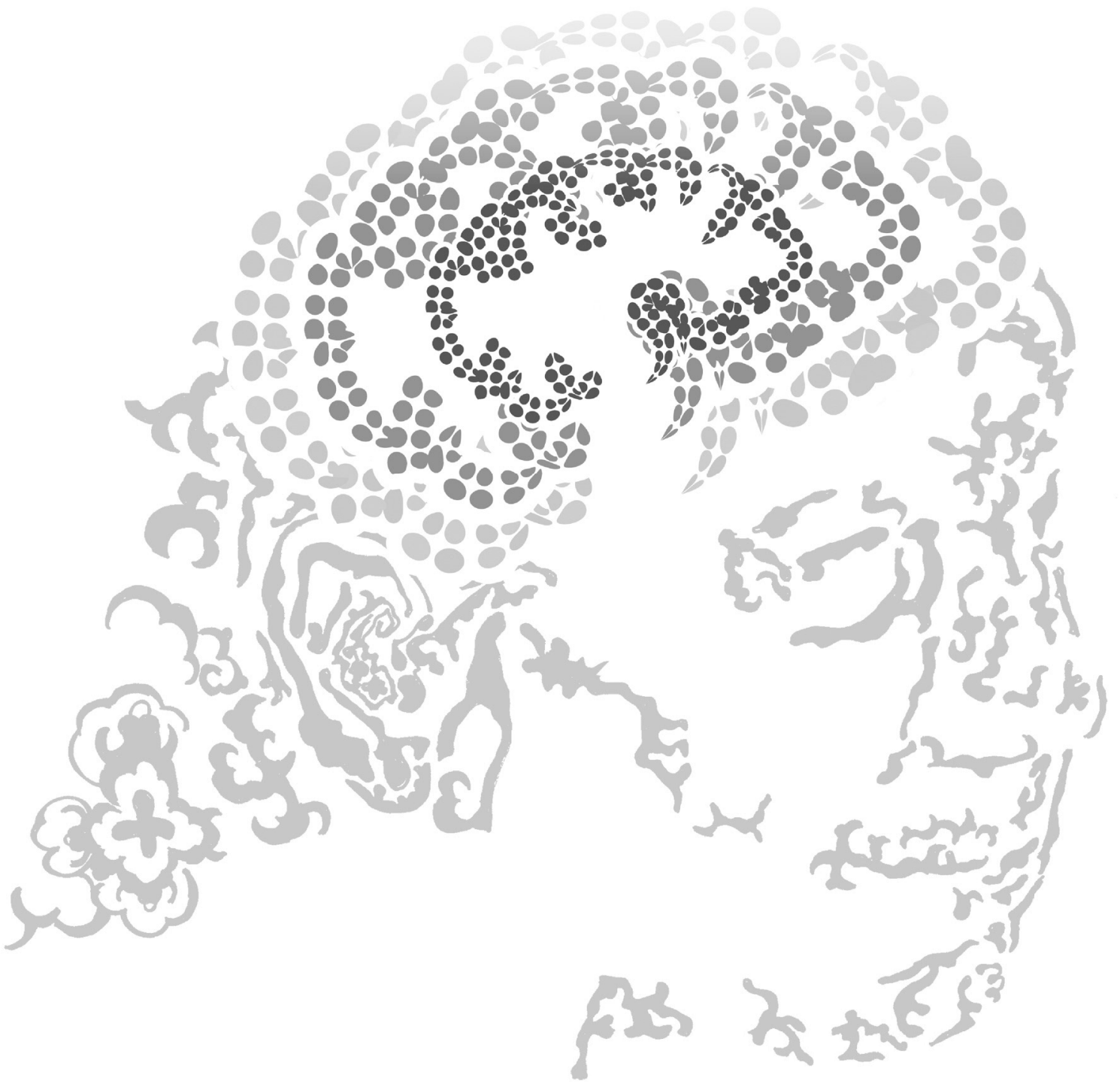




\section{ABSTRACT \\ Background}

Single nucleotide polymorphisms (SNPs) in the membrane-spanning 4-domains, subfamily A (MS4A) gene cluster have been identified in genome-wide association studies (GWAS) to be associated with Alzheimer's disease (AD). We recently reported that MS4A4A rs2304933, but not MS4A4E rs670139 and MS4A6A rs2304933, significantly reduced cerebrospinal fluid (CSF) amyloid beta 1-42 isoform $\left(A \beta_{1-42}\right)$ in a Finnish $A D$ population. We aim to replicate these findings in an independent cohort composed of various diagnostic groups.

\section{Methods}

We included 243 participants ( 78 AD, 93 mild cognitive impairment, 48 other type of dementia, 24 cognitively healthy control subjects) from the European multicenter EDAR study. Genomic DNA was extracted from EDTA anticoagulated blood using polymerase chain reaction technique. SNPs were genotyped on Sequenom I-plex platform. CSF was obtained through lumbar puncture and analysed using multiplex XMAP Luminex platform. Statistical analyses were performed using mixed models, corrected for age, sex, APOE- $\iota_{4}$ status and study site. Adjustment for multiple testing was set at a false discovery rate adjusted $P<0.05$.

\section{Results}

The mean CSF A $\beta_{1-42}$ levels of homozygote risk allele carriers are lower compared to other genotypes for MS4A4E rs670139, MS4A6A rs610932 and MS4A4A rs2304933. AD cases generally had lower CSF A $\beta_{1-42}$ concentrations compared to the other diagnostic groups and control subjects. Variant rs610932 significantly correlated with CSF A $\beta_{1-42}$ (unadjusted $P=0.001$, FDR adjusted $P<0.05)$ in a dominant model. A trend between CSF A $\beta_{1-42^{\prime}}$ and rs670139 (unadjusted $P=0.12$ ) and rs2304933 (unadjusted $P=0.08$ ) was observed in a recessive model. There was no interaction with age, sex, $A P O E-\varepsilon 4$ status and diagnosis for all analyses (all $P>0.05$ ). 


\section{Conclusion}

Our findings suggest that polymorphisms in the MS4A gene may influence CSF A $\beta_{1-42}$. This supports results from GWAS studies that this gene is a genetic risk factor for $A D$. Replication on a larger scale will further determine the influence of SNPs in the MS4A gene cluster on AD.

Keywords: MS4A, genetics, biomarker, amyloid, cerebrospinal fluid, Alzheimer, replication study 


\section{INTRODUCTION}

Genetic loci in MS4A4A, MS4 $444 E$ and $M S_{4} A 6 A$ from the membranespanning 4-domains, subfamily A (MS4A) gene cluster have been identified in genome-wide association studies (GWAS) to be associated with clinical Alzheimer's disease (AD) ${ }^{1-3}$ The role of MS4A on AD pathogenesis merits further investigation. The MS4A cluster, which is located in chromosome 11q12, includes at least 16 known genes of which some have been shown to be involved in immunity while the rest have no known specific functions. MS 4 A family members share common genomic features. ${ }^{2}$ They have been suggested to form part of oligomeric cell surface proteins and are important in cellular signal transduction. ${ }^{4}$ $M S_{4} A_{4} A, M S_{4} A_{4} E$ and $M S_{4} A 6 A$ have been reported to play a role in immunity, being structurally related to the immunoglobulin $E$ receptor and to $\mathrm{CD}_{20},{ }^{5}$ which is a $\mathrm{B}$-lymphocyte cell surface molecule. ${ }^{6}$ Inflammatory responses in $A D$ have been related to amyloid beta $(A \beta)$ oligomers and deposition..$^{7-10}$ In the present study, we focused on testing the correlation between $A \beta$ in cerebrospinal fluid (CSF) and variants in MS4A that have been associated with $A D$.

We recently reported that a single nucleotide polymorphism (SNP) in MS4A4A (rs2304933), but not in MS4A4E (rs670139) and $M S 4 A 6 A$ (rs2304933), was significantly related to reduced cerebrospinal fluid (CSF) amyloid beta (A $\beta$ ) in a Finnish AD population. ${ }^{11}$ Our purpose is to replicate this study in an independent cohort composed of various diagnostic groups.

\section{METHODS}

\section{Study population}

\section{Cohort}

Participants for the current study were recruited from the 'beta amyloid oligomers in the early diagnosis of $\underline{A} D$ and as marker for treatment response' (EDAR) study, a European multicenter prospective cohort study (for general information, see www.edarstudy.eu) with 15 partners across Europe. The goal of EDAR is to develop new diagnostic markers for $A D$ that can be used for the early diagnosis and for the monitoring of treatment response in drug trials. The project focuses on $A \beta$ oligomers in CSF, serum and plasma, and the effect of genes involved in $A \beta$ 
processing on these oligomers. EDAR recruited participants with $\mathrm{MCl}$, $A D$-type dementia, non-AD dementia and cognitively healthy controls from memory centers. $\mathrm{MCl}$ was broadly defined to include referral to a memory clinic because of cognitive impairments not due to dementia according to Diagnostic and Statistical Manual of Mental Disorders $4^{\text {th }}$ edition (DSM-IV) ${ }^{11}$ criteria at baseline, neurological or endocrine disorders, or severe depression. $\mathrm{MCl}$ patients aged above 60 years were included. For dementia, the inclusion criteria were age 40 years and above, Mini-Mental State Examination (MMSE) ${ }^{12}$ score above 18, a diagnosis of probable or possible AD according to the National Institute of Neurological and Communicative Disorders and Stroke-Alzheimer's Disease and Related Disorders Association (NINCDS-ADRDA) ${ }^{13}$ criteria, diagnosis of fronto-temporal criteria according to Neary criteria, diagnosis of vascular dementia according to the National Institute of Neurological Disorders and Stroke and Association Internationale pour la Recherche et l'Enseignement en Neurosciences (NINDS-AIREN) ${ }^{14}$ criteria, or diagnosis of Lewy body disease according to McKeith ${ }^{15}$ criteria. Cognitively healthy control subjects were those aged above 40 years who obtained an overall Clinical Dementia Rating $(C D R)^{16}$ of o, an MMSE score above the $10^{\text {th }}$ percentile for age and education corrected norms, did not fulfill a clinical diagnosis of dementia according to DSMIV criteria, and had no obvious causes of cognitive impairment such as stroke, depression or endocrine disorders. Participants underwent clinical, neurological, neuropsychiatric, neuropsychological and functional assessments at baseline, 9 months and 18 months. Venous blood, CSF samples and MRI scans were available for a subset of participants. The local ethics committee approved the study procedures and all participants gave their informed consent.

\section{Selection of participants}

For the present study, we included 243 participants with available venous blood for DNA extraction and for whom baseline CSF A $\beta_{1-42}$ levels were measured and diagnosis was made. The selection process is shown in Figure 1.

Participants who were genotyped did not differ from those who were not genotyped in terms of age (mean $69.1 \pm 8.6$ vs. $69.3 \pm 9.2$ 
Figure 1 Selection of participants

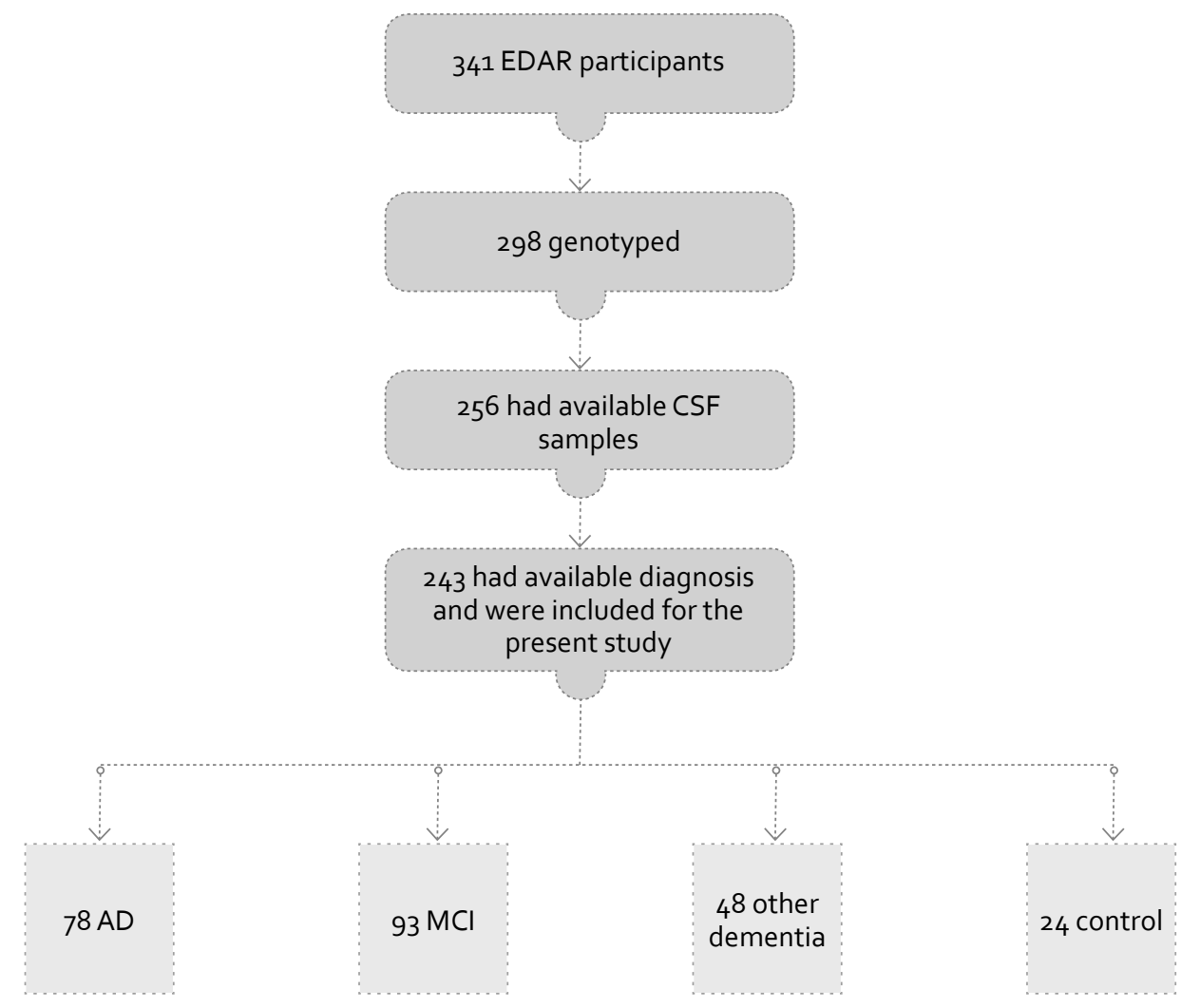

Abbreviations: $\mathrm{CSF}=$ cerebrospinal fluid; $\mathrm{AD}=\mathrm{Alzheimer}$ 's disease; $\mathrm{MCl}=$ mild cognitive impairment

years, $P=0.93$ ) and years of education (mean 10.9 $\pm 4.1 \mathrm{Vs} .10 .0 \pm 4.5$ years, $P=0.33)$. Those who were genotyped scored lower on the MMSE than those who were not genotyped $(25.3 \pm 4.0$ vs. $27.1 \pm 2.9, P=0.02)$. Participants with CSF data did not differ significantly from those who had no available CSF measurements in terms of age, years of education and MMSE score (all $P>0.05$ ). 


\section{Genetic analysis}

We genotyped three SNPs in the MS4A cluster: rs670139 in $M S_{4} A_{4} E_{\text {, }}$ rs610932 in MS4A6A and rs2304933 in MS4A4A. These SNPs are in linkage disequilibrium. ${ }^{2} A P O E$ genotype was determined by a combination of two SNPs, rs7412 and rs429358.

Genomic DNA was extracted from EDTA anticoagulated blood using the polymerase chain reaction technique. DNA samples were randomly placed on 384-well plates. SNPs were genotyped on Sequenom i-Plex platform (Sequenom Inc., Hamburg, Germany). Genotyping was performed blinded to clinical data. Genetic data were subjected to quality control. The SNPs included for the present study were in Hardy-Weinberg equilibrium (Chi-square test, $P>0.05$ ) and had a call rate of $\geq 90 \%$.

\section{CSF collection and analysis}

CSF samples, obtained through lumbar puncture of the $L_{3} / L_{4}$ or $L_{4} / L_{5}$ intervertebral space, were centrifuged and stored in sterile polypropylene tubes at -8o degree Celsius until analyses. All $A \beta_{1-42}$ concentrations were measured using multiplex xMAP Luminex platform (Luminex Corp, Austin, TX) with Innogenetics immunoassays (INNO-BIA AlzBioz Ghent, Belgium) in a laboratory at the Vrije Universiteit Medical Center (VUmc) in Amsterdam, Netherlands. The bioanalysts who performed the analyses were blinded to clinical information.

For the present study, we considered CSF A $\beta_{1-42}$ concentrations below $389 \mathrm{pg} / \mathrm{ml}$ to be abnormal. This cut-off has been determined at the VUmc to best differentiate between patients with subjective cognitive impairment and $A D$, with a sensitivity of $95 \%$ and a specificity of $58 \%$.

\section{Statistical analysis}

We used IBM SPSS Statistics version 19 (IBM Corp., NY, USA) for Mac OS $X$ for the statistical analyses. Group differences in terms of mean age, education and MMSE score were assessed using independent samples t-test.

The distribution of CSF $A \beta_{1-42}$ distribution was skewed (Shapiro Wilk test, $P<0.001)$. We therefore used log-transformed values in the statistical analyses. We assessed the relation between SNPs and CSF 
$A \beta_{1-42}$ in the pooled sample by applying dominant and recessive models. This allowed us to test the effects of heterozygosity and of having two risk alleles. Although an additive model is commonly used in genetic analyses, we did not include this model because it has been shown to have less power in detecting recessive effects, especially when the minor genotype frequency is low, ${ }^{17}$ which was the case in our study. Moreover, a statistically nonsignificant result for an additive model does not preclude association, because in general, genes do not act in a simple additive manner but through complex networks and interactions. ${ }^{18}$

We used mixed models in the statistical analyses. The covariates were age (continuous variable), sex (dichotomized as male vs. female), diagnosis (categorized as control, $\mathrm{MCl}, \mathrm{AD}$ and other dementia) and $A P O E-\varepsilon 4$ status (dichotomized as carriers of at least one $\varepsilon_{4}$ allele vs. noncarriers). Study site was included as a random effect. Given the exploratory nature of the study, we likewise tested whether there was interaction between SNPs and age, sex, APOE- $\varepsilon 4$ status and diagnosis. We corrected for multiple testing using the false discovery rate (FDR) according to the procedure of Benjamini and Hochberg. ${ }^{19}$ An FDR adjusted $P$-value of $P<0.05$ was considered significant.

\section{RESULTS}

The characteristics of the study participants per diagnostic group are summarized in Table 1. The genotype frequencies for the studied SNPs are likewise presented in the table. The group with other dementia consisted of 24 (50\%) participants with frontotemporal dementia, $13(27 \%)$ with dementia of the Lewy body type, $9(19 \%)$ with vascular dementia, $1(2 \%)$ with posterior cortical atrophy, and 1 (2\%) with corticobasal degeneration. Compared to controls, participants with $\mathrm{MCl}$ and other dementia had lower MMSE score and years of education (all $P<0.05$ ) but the three groups did not differ in age $(P>0.05)$. AD cases were older than $\mathrm{MCl}$ and control subjects and had lower MMSE score (all $P<0.05$ ).

Of the 243 participants, abnormal CSF A $\beta_{1-42}$ levels were observed in $48(52 \%)$ with $\mathrm{MCl}, 57(73 \%)$ with $A D$-type dementia, 25 (52\%) with other dementia and $6(25 \%)$ control subjects. Participants with AD had lower CSF A $\beta_{1-42}$ concentration compared to all the other diagnostic groups $(P<0.005)$. MCI participants had lower CSF A $\beta_{1-42}$ levels compared 
Table 1 Characteristics of study participants

\begin{tabular}{|c|c|c|c|c|c|}
\hline Characteristic & All cases & $\begin{array}{l}\text { AD-type } \\
\text { dementia }\end{array}$ & $\mathrm{MCl}$ & $\begin{array}{l}\text { Other } \\
\text { dementia }\end{array}$ & $\begin{array}{l}\text { Control } \\
\text { subjects }\end{array}$ \\
\hline $\mathrm{n}$ & 243 & 78 & 93 & 48 & 24 \\
\hline Age (SD), years & $69(9.2)$ & $72.1(8.7)$ & $69(8.7)$ & $67.6(10.6)$ & $65.5(8.1)$ \\
\hline Female, $\mathrm{n}(\%)$ & $104(43)$ & $35(45)$ & $44(47 \cdot 3)$ & $13(27)$ & $12(50)$ \\
\hline Education (SD), years & $9.8(4.5)$ & $9.3(4.1)$ & $9.7(4 \cdot 3)$ & $9.4(4.7)$ & $11.8(3.7)$ \\
\hline MMSE score (SD) & $25.3(3.8)$ & $22.8(3.6)$ & $27.1(2.2)$ & $23.6(4.3)$ & $29.1(1.0)$ \\
\hline$A \beta_{1-42}$ level (SD), $\mathrm{pg} / \mathrm{ml}$ & $370(152)$ & 308 (139) & $387(140)$ & $392(167)$ & $470(132)$ \\
\hline $\begin{array}{l}A P O E-\varepsilon 4 \text { status, } \mathrm{n}(\%) \text { : } \\
\text { noncarrier } \\
\text { at least } 1 \mathrm{e} 4\end{array}$ & $\begin{array}{l}125(51) \\
103(42)\end{array}$ & $\begin{array}{l}41(53) \\
33(42)\end{array}$ & $\begin{array}{l}46(50) \\
42(45)\end{array}$ & $\begin{array}{l}28(58) \\
18(38)\end{array}$ & $\begin{array}{l}10(42) \\
10(42)\end{array}$ \\
\hline \multicolumn{6}{|c|}{ Genotype frequencies (n), \%: } \\
\hline $\begin{array}{l}\text { MS } 4 A_{4} E \text { rs670139, } \\
\text { CC/CA/AA }\end{array}$ & $\begin{array}{l}(230) \\
32 / 53 / 13\end{array}$ & $\begin{array}{l}(77) \\
30 / 54 / 16\end{array}$ & $\begin{array}{l}(88) \\
28 / 53 / 18\end{array}$ & $\begin{array}{l}(43) \\
39 / 49 / 12\end{array}$ & $\begin{array}{l}(22) \\
36 / 55 / 9\end{array}$ \\
\hline $\begin{array}{l}\text { MS } 4 \text { A6A rs610932, } \\
\text { CC/CA/AA }\end{array}$ & $\begin{array}{l}(230) \\
31 / 50 / 19\end{array}$ & $\begin{array}{l}(74) \\
30 / 53 / 17\end{array}$ & $\begin{array}{l}(91) \\
34 / 45 / 21\end{array}$ & $\begin{array}{l}(43) \\
28 / 49 / 23\end{array}$ & $\begin{array}{l}(22) \\
23 / 50 / 27\end{array}$ \\
\hline $\begin{array}{l}\text { MS4A4A rs2304933, } \\
\text { CC/CA/AA }\end{array}$ & $\begin{array}{l}(231) \\
39 / 51 / 10\end{array}$ & $\begin{array}{l}(77) \\
31 / 61 / 8\end{array}$ & $\begin{array}{l}\text { (90) } \\
40 / 50 / 10\end{array}$ & $\begin{array}{l}(44) \\
50 / 36 / 14\end{array}$ & $\begin{array}{l}(20) \\
40 / 45 / 15\end{array}$ \\
\hline
\end{tabular}

Abbreviations: $\mathrm{AD}=\mathrm{Alzheimer}$ 's disease; $\mathrm{MCl}=$ mild cognitive impairment; $\mathrm{n}=$ sample size; $\mathrm{SD}=$ standard deviation; MMSE= Mini-Mental State Examination Note: All data are means (SD), unless otherwise specified.

to controls $(P=0.01)$, but did not differ with the $A \beta_{1-42}$ levels of those with other type of dementia $(P=0.86)$.

Figure 2 shows that in the pooled sample, the mean CSF A $\beta_{1-42}$ levels of homozygote risk allele carriers are lower compared to other genotypes for MS4A4E rs670139, MS4A6A rs610932 and MS4A4A rs2304933. Using a dominant model, rs610932 showed significant correlation with CSF A $\beta_{1-42}(P=0.001$, FDR adjusted $P<0.05$, Table 2$)$. Its effect on $A \beta_{1-42}$ for each diagnostic group is presented in Figure 3 . A pattern of lower $A \beta_{1-42}$ is seen among homozygous risk allele carriers of rs610932 in all diagnostic groups, except in AD. Using a recessive model, we observed a trend between CSF A $\beta_{1-42^{\prime}}$ and rs670139 $(P=0.12)$ and rs2304933 $(P=0.08)$. We found no interaction with age, sex, $A P O E-\varepsilon 4$ status and diagnosis for all analyses (all $P>0.05$ ). 
Table 2 Influence of MS4A single nucleotide polymorphisms on CSF A $\beta_{1-42}$

\begin{tabular}{|c|c|c|c|c|c|}
\hline Gene & SNP & $\begin{array}{l}\text { Geno- } \\
\text { type }\end{array}$ & $\begin{array}{l}\text { Mean (SD) } A \beta 1-42 \text { level } \\
\text { in } p g / m l, \text { per genotype }\end{array}$ & $\begin{array}{l}\text { Genetic } \\
\text { model }\end{array}$ & $P$-value \\
\hline$M S_{4} A_{4} E$ & rs670139 & $\mathrm{CC} / \mathrm{CA} / \mathrm{AA}$ & $369(151) / 384(149) / 337(150)$ & Recessive & 0.12 \\
\hline$M S_{4} A 6 A$ & rs610932 & $\mathrm{CC} / \mathrm{CA} / \mathrm{AA}$ & $333(151) / 387(150) / 373(150)$ & Dominant & $0.001 *$ \\
\hline$M S_{4} A_{4} A$ & rs2304933 & $\mathrm{CC} / \mathrm{CA} / \mathrm{AA}$ & $376(150) / 370(153) / 350(159)$ & Recessive & 0.08 \\
\hline
\end{tabular}

Abbreviations: $\mathrm{CSF}=$ cerebrospinal fluid; $\mathrm{SNP}=$ single nucleotide polymorphism; $\mathrm{A} \beta=$ amyloid beta; $\mathrm{SD}=$ standard deviation

Note: Risk allele according to AlzGene and other literature underlined and in bold.

* Significant at a false discovery rate adjusted $P<0.05$.

Figure 2 Mean CSFA 1 1-42 concentration of the pooled sample shown per genotype for polymorphisms in three $M S_{4} A$ genes

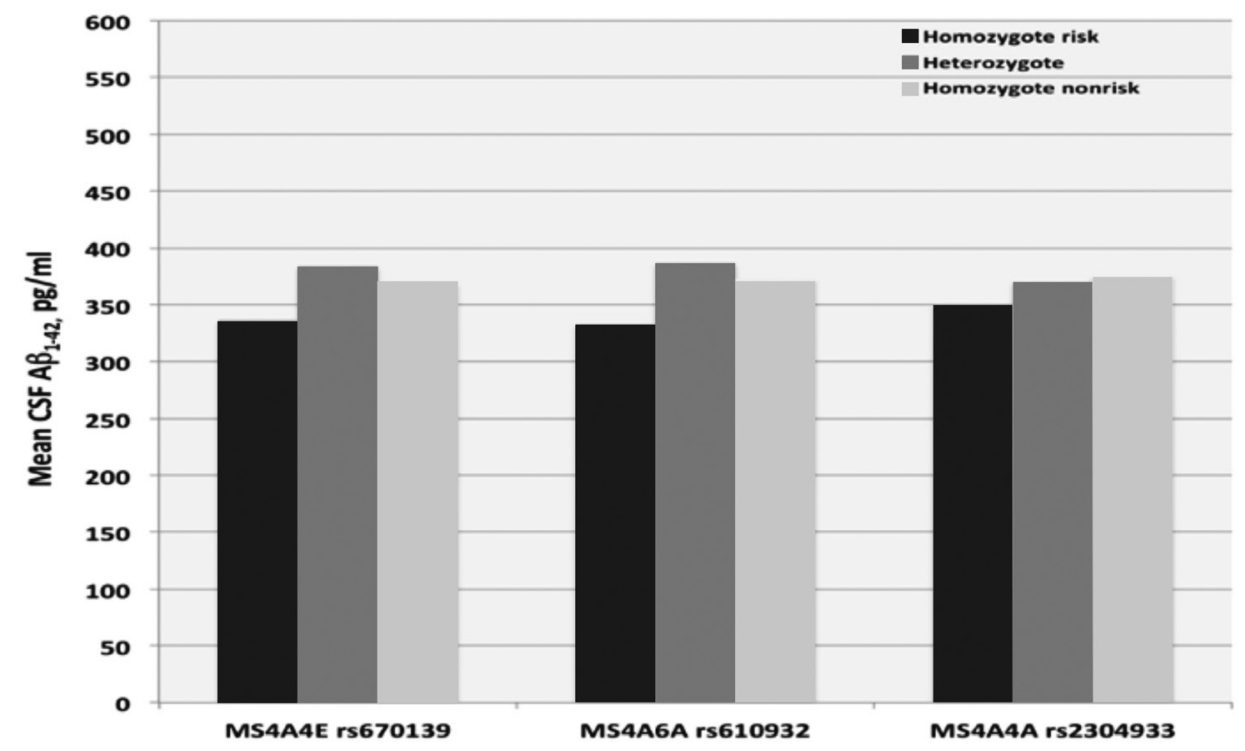


Figure 3 Mean CSF A 1 1-42 concentration per genotype shown per diagnostic group for $M S_{4} A 6 A$ rs610932

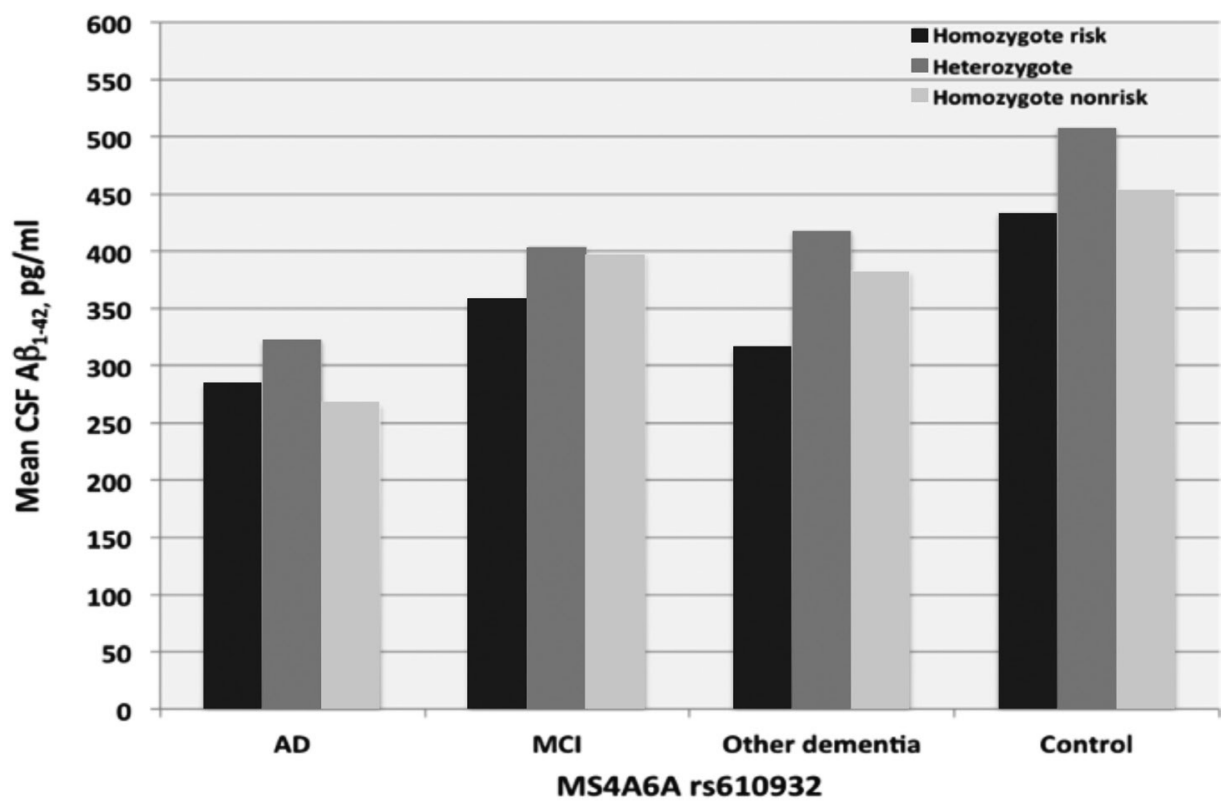

\section{DISCUSSION}

We found that for all SNPs studied, homozygote risk allele carriers had reduced CSF $A \beta_{1-42}$ concentration (rs610932) or showed a trend of lower $A \beta_{1-42}$ levels (rs670139 and rs2304933) compared to heterozygotes and nonrisk allele carriers. Variant rs610932 in MS4A6A significantly correlated to decreased CSF $A \beta_{1-42}$ level in a dominant model. We did not detect this effect in our earlier study with a Finnish AD population. For $M_{4} A_{4} A$ rs2304933, a trend of decreased CSF A $\beta_{1-42}$ levels was observed in a recessive model but not in a dominant model. In our previous study, we found a significant influence of this SNP in a dominant model. For

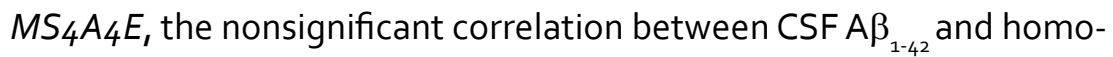
zygous risk allele carriers of rs670139 is consistent with our results in the Finnish AD study. The difference in findings has several possible explanations. One is that the genotypic distribution varied between EDAR and the Finnish cohort. For instance, $31 \%$ of participants in EDAR were homozygous risk allele carriers for rs610932 compared to $53 \%$ in the 
Finnish AD cohort. Another possibility is that the effect of this SNP on CSF A $\beta_{1-42}$ varies with diagnosis. In EDAR, we included participants with a range of diagnoses, of which 78 had $A D$ while in the Finnish cohort, all subjects $(N=222)$ had $A D$. Our discongruent findings may also be caused by the fact that $M S_{4} A_{4} A, M S_{4} A 4 E$ and $M S_{4} A 6 A$ are in linkage disequilibrium. Given our small sample size and the possible weak effects of $M S_{4} A$ loci on $A D$, one SNP may become predictive by chance.

In conclusion, our findings suggest that polymorphisms in the $M S_{4} A$ gene may influence CSF A $\beta_{1-42 .}$ This supports results from GWAS studies that this gene is a genetic risk factor for AD. Replication on a larger scale can further help to determine the influence of this gene on $A D$. There are possibly other genetic risk factors within this linkage disequilibrium block influencing $A D$ pathogenesis, also through pathways other than amyloid metabolism. Further research is needed to discover this.

\section{REFERENCES}

1. Naj AC, Jun G, Beecham GW, Wang LS, Vardarajan BN, Buros J, et al. Common variants at $\mathrm{MS}_{4} \mathrm{~A}_{4} / \mathrm{MS}_{4} \mathrm{~A} 6 \mathrm{E}, \mathrm{CD}_{2} \mathrm{AP}, \mathrm{CD}_{33}$ and EPHA1 are associated with late-onset Alzheimer's disease. Nat Genet 2011; 43(5): 436-41.

2. Hollingworth $P$, Harold $D$, Sims $R$, Gerrish $A$, Lambert JC, Carrasquillo MM, et al. Common variants at $A B C A 7, M S_{4} A 6 A / M S_{4} A_{4} E_{1} E P H A_{1}, C D_{33}$ and $C_{2} A P$ are associated with Alzheimer's disease. Nat Genet 2011; 43(5): 429-35.

3. Antunez C, Boada M, Gonzalez-Perez A, Gayan J, Ramirez-Lorca R, Marin J, et al. The membrane-spanning 4-domains, subfamily $\mathrm{A}\left(\mathrm{MS}_{4} \mathrm{~A}\right)$ gene cluster contains a common variant associated with Alzheimer's disease. Genome Med 2011; 3(5): 33.

4. Liang Y, Buckley TR, Tu L, Langdon SD, Tedder TF. Structural organization of the human MS4A gene cluster on Chromosome 11q12. Immunogenetics 2001; 53(5): 357-68.

5. Carter C. Alzheimer's Disease: APP, Gamma Secretase, APOE, CLU, CR1, PICALM, ABCA7, $\mathrm{BIN}_{1}, \mathrm{CD}_{2} \mathrm{AP}, \mathrm{CD}_{33}$, EPHA1, and MS4A2, and Their Relationships with Herpes Simplex, $\mathrm{C}$. Pneumoniae, Other Suspect Pathogens, and the Immune System. Int J Alzheimers Dis 2011; 2011: 501862.

6. Schellenberg GD, Montine TJ. The genetics and neuropathology of Alzheimer's disease. Acta Neuropathol 2012.

7. Mohandas E, Rajmohan V, Raghunath B. Neurobiology of Alzheimer's disease. Indian J Psy- 
chiatry 2009; 51(1): 55-61.

8. Fiala $\mathrm{M}$, Veerhuis R. Biomarkers of inflammation and amyloid-beta phagocytosis in patients at risk of Alzheimer disease. Exp Gerontol 2010; 45(1): 57-63.

9. Salminen A, Ojala J, Kauppinen A, Kaarniranta K, Suuronen T. Inflammation in Alzheimer's disease: amyloid-beta oligomers trigger innate immunity defence via pattern recognition receptors. Prog Neurobiol 2009; 87(3): 181-94.

10. Sastre M, Klockgether T, Heneka MT. Contribution of inflammatory processes to Alzheimer's disease: molecular mechanisms. Int J Dev Neurosci 2006; 24(2-3): 167-76.

11. Elias-Sonnenschein LS, Helisalmi S, Natunen T, Hall A, Paajanen T, Herukka S-K, et al. Genetic loci associated with Alzheimer's disease and cerebrospinal fluid biomarkers in a Finnish case-control cohort. PLOS ONE 2013 (In press).

12. APA. Diagnostic and statistical manual of mental disorders (4th edition) (DSM-IV). Washington, DC: American Psychiatric Association; 1994.

13. Folstein MF, Folstein SE, McHugh PR. "Mini-mental state". A practical method for grading the cognitive state of patients for the clinician. J Psychiatr Res 1975; 12(3): 189-98.

14. McKhann G, Drachman D, Folstein M, Katzman R, Price D, Stadlan EM. Clinical diagnosis of Alzheimer's disease: report of the NINCDS-ADRDA Work Group under the auspices of Department of Health and Human Services Task Force on Alzheimer's Disease. Neurology 1984; 34(7): 939-44.

15. Roman GC, Tatemichi TK, Erkinjuntti T, Cummings JL, Masdeu JC, Garcia JH, et al. Vascular dementia: diagnostic criteria for research studies. Report of the NINDS-AIREN International Workshop. Neurology 1993; 43(2): 250-60.

16. McKeith IG, Dickson DW, Lowe J, Emre M, O'Brien JT, Feldman H, et al. Diagnosis and management of dementia with Lewy bodies: third report of the DLB Consortium. Neurology 2005; 65(12): 1863-72.

17. Morris JC. The Clinical Dementia Rating (CDR): current version and scoring rules. Neurology 1993; 43(11): 2412-4.

18. Ghebranious N, Ivacic L, Mallum J, Dokken C. Detection of ApoE E2, E3 and E4 alleles using MALDI-TOF mass spectrometry and the homogeneous mass-extend technology. Nucleic Acids Res 2005; 33(17): e149.

19. Lettre G, Lange $C$, Hirschhorn JN. Genetic model testing and statistical power in populationbased association studies of quantitative traits. Genet Epidemiol 2007; 31(4): 358-62.

20. Colhoun HM, McKeigue PM, Davey Smith G. Problems of reporting genetic associations with complex outcomes. Lancet 2003; 361(9360): 865-72.

21. BenjaminiY, Hochberg Y. Controlling the false discovery rate: a practical and powerful approach to multiple testing. Journal of the Royal Statistical Society, Series B 1995; 57: 289-300. 
We assessed the influence of genetic risk factors on key markers of $A D$ pathology in various diagnostic groups. These markers become abnormal at different stages of $A D$. Our findings may serve as a basis for further research. 


\section{CHAPTER 9}

General discussion

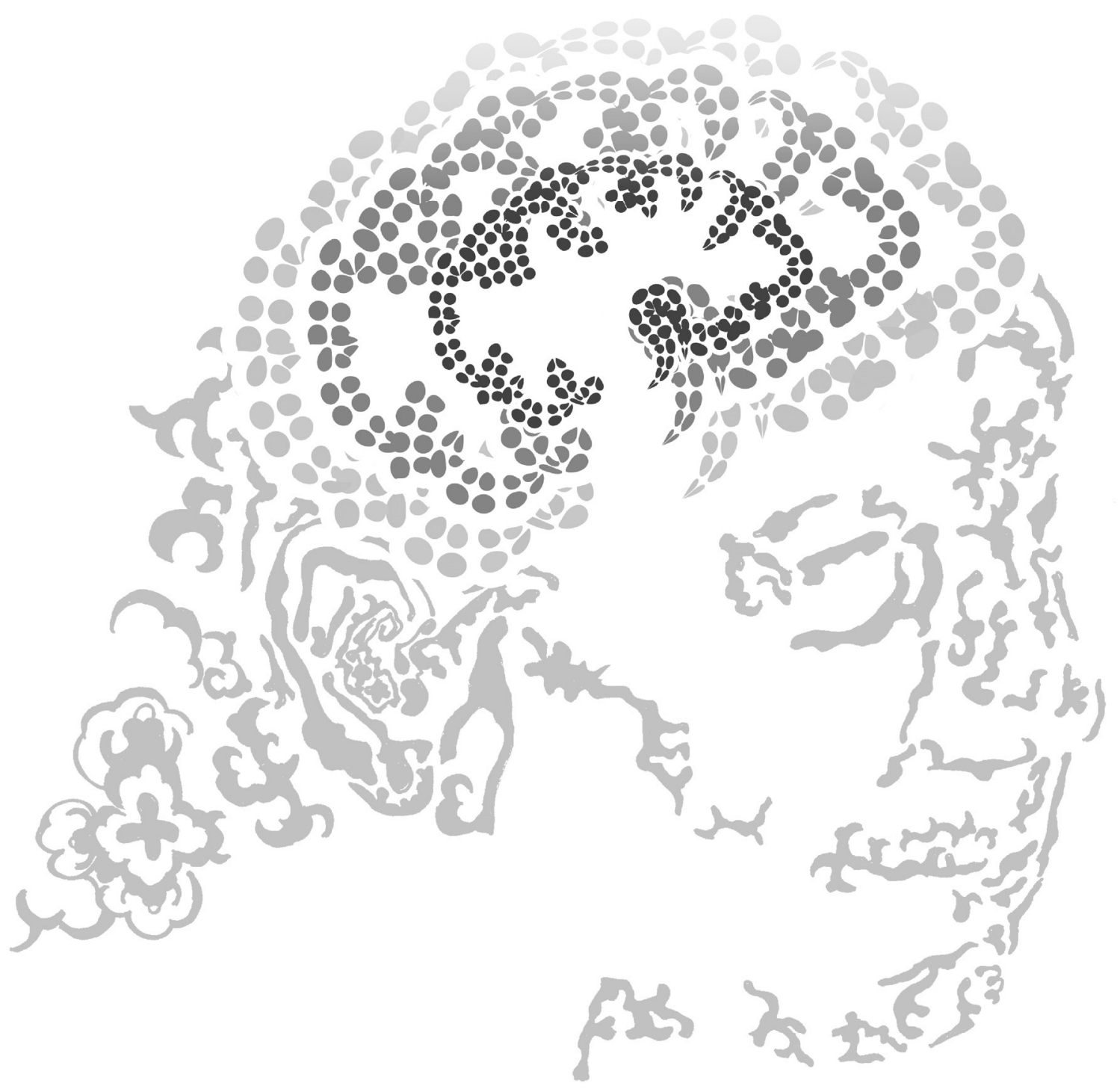




\section{RATIONALE FOR THE THESIS}

The main objective of the thesis was to investigate the influence of genetic risk factors on the pathophysiology and clinical manifestation of Alzheimer's disease (AD). While several AD risk genes have been identified, their effects on AD pathophysiology remain unclear. We examined this by correlating the effects of $A D$ risk genes with key measures of $A D$ pathology, including cerebrospinal fluid (CSF) markers, hippocampal atrophy, memory performance and neuropsychiatric symptoms. As the relation between genetic risk factors and $A D$ may differ depending on the stage of the disease, we used cohorts with different severities of cognitive impairment.

Table 1 Summary of effects of top 10 AlzGene loci on AD risk and key markers of AD pathology

\begin{tabular}{|c|c|c|c|c|c|c|c|}
\hline \multirow{2}{*}{$\begin{array}{l}\text { Chr, Gene } \\
\text { SNP }\end{array}$} & \multicolumn{3}{|l|}{$\operatorname{CSF} A \beta_{1-42}$} & \multicolumn{3}{|c|}{ CSF t-tau } & \\
\hline & $\mathrm{MCl}$ & $A D$ & Other & $\mathrm{MCl}$ & $A D$ & Other & \\
\hline $\begin{array}{l}\text { 1, CR1 } \\
\text { rs } 6656401\end{array}$ & NS & NS & Trend in controls $s^{\mathrm{a}, \mathrm{b}}$ & NS & NS & $\begin{array}{l}\text { NS in } \\
\text { controls }^{\mathrm{a}}\end{array}$ & \\
\hline $\begin{array}{l}\text { 2, BIN1 } \\
\text { rs744373 }\end{array}$ & NS & NS & & NS & NS & & \\
\hline $\begin{array}{l}\text { 6, } C D_{2} A P \\
\text { rs9349407 }\end{array}$ & Trend $^{b}$ & NS & & NS & NS & & \\
\hline $\begin{array}{l}\text { 8, CLU } \\
\text { rs1113600o }\end{array}$ & NS & Significant $^{f}$ & $\begin{array}{l}\text { NS in AD and } \\
\text { controls }^{\mathrm{a}}\end{array}$ & NS & NS & $\begin{array}{l}\text { NS in } \\
\text { AD and } \\
\text { controls }^{a}\end{array}$ & \\
\hline $\begin{array}{l}11, M S_{4} A_{4} E \\
\text { rs670139 }\end{array}$ & NS & NS & $\begin{array}{l}\text { NS in pooled } \\
\text { sample }\end{array}$ & NS & NS & & \\
\hline $\begin{array}{l}11, M S_{4} A 6 A \\
\text { rs610932 }\end{array}$ & NS & NS & $\begin{array}{l}\text { Significant in } \\
\text { pooled sample }\end{array}$ & NS & NS & & \\
\hline $\begin{array}{l}\text { 11, PICALM } \\
\text { rs3851179 }\end{array}$ & Significant ${ }^{\mathrm{e}}$ & NS & & NS & Trend & & \\
\hline $\begin{array}{l}19, A B C A 7 \\
\text { rs } 3764650\end{array}$ & NS & NS & & NS & NS & & \\
\hline $\begin{array}{l}19, C D 33 \\
\text { rs3865444 }\end{array}$ & NS & NS & & NS & NS & & \\
\hline
\end{tabular}


This chapter presents a summary of our main findings in the context of current knowledge, relates these findings to genes in $A D$ pathophysiology, and discusses the implications and methodological considerations.

\section{SUMMARY OF MAIN FINDINGS IN THE CONTEXT OF CURRENT KNOWLEDGE}

Table 1 summarizes our findings of the effects of the top 10 AlzGene loci on key markers in $A D$ pathophysiology and on prediction from $\mathrm{MCl}$ to $A D$. The influence of candidate loci on CSF biomarkers is shown in Table 2.

\begin{tabular}{|c|c|c|c|c|}
\hline $\begin{array}{l}\text { Hippocampal } \\
\text { volume }\end{array}$ & $\begin{array}{l}\text { Delayed } \\
\text { memory }\end{array}$ & \multirow{2}{*}{$\begin{array}{l}\text { Neuropsy- } \\
\text { chiatric } \\
\text { symptoms } \\
\text { in } \mathrm{MCl}\end{array}$} & \multirow{2}{*}{$\begin{array}{l}\text { Association with } \\
\text { clinical AD in Finnish } \\
\text { case-control study }\end{array}$} & \multirow{2}{*}{$\begin{array}{l}\text { Predictive value } \\
\text { for progression } \\
\text { from } \mathrm{MCI} \text { to AD }\end{array}$} \\
\hline $\mathrm{MCl}$ & $\mathrm{MCl}$ & & & \\
\hline Significant $^{a}$ & NS & $--^{c}$ & $\begin{array}{l}\text { Significant in multicenter } \\
\text { GWAS }^{d}\end{array}$ & NS \\
\hline NS & NS & $-{ }^{c} c$ & $\begin{array}{l}\text { Significant in replication } \\
\text { study }^{d}\end{array}$ & NS \\
\hline NS & Significant ${ }^{\mathrm{e}}$ & $-{ }^{c}$ & $\begin{array}{l}\text { Significant in multicenter } \\
\text { GWAS }^{d}\end{array}$ & NS \\
\hline Significant ${ }^{e}$ & NS & $--^{c}$ & $\begin{array}{l}\text { Significant in multicenter } \\
\text { GWAS }^{d}\end{array}$ & NS \\
\hline NS & NS & $\ldots{ }^{c}$ & $\begin{array}{l}\text { Significant in multicenter } \\
\text { GWAS }^{d}\end{array}$ & NS \\
\hline NS & NS & $-c^{c}$ & $\begin{array}{l}\text { Significant in multicenter } \\
\text { GWAS }^{d}\end{array}$ & NS \\
\hline NS & NS & $-{ }^{c}$ & NS & NS \\
\hline NS & Significant ${ }^{\mathrm{e}}$ & $-{ }^{c}$ & $\begin{array}{l}\text { Significant in multicenter } \\
\text { GWAS }^{d}\end{array}$ & NS \\
\hline NS & NS & $--^{c}$ & $\begin{array}{l}\text { Significant in multicenter } \\
\text { GWAS }^{d}\end{array}$ & NS \\
\hline
\end{tabular}


Table 1 Summary of effects of top 10 AlzGene loci on AD risk and key markers of AD pathology Continued

\begin{tabular}{|c|c|c|c|c|c|c|}
\hline \multirow{2}{*}{$\begin{array}{l}\text { Chr, Gene } \\
\text { SNP }\end{array}$} & \multicolumn{3}{|l|}{$\operatorname{CSFA} \beta_{1-42}$} & \multicolumn{3}{|c|}{ CSF t-tau } \\
\hline & $\mathrm{MCl}$ & AD & Other & $\mathrm{MCl}$ & $A D$ & Other \\
\hline $19, A P O E-\varepsilon 4$ & Significant $^{f}$ & Significant $^{f}$ & $\begin{array}{l}\text { Significant in } \\
\text { controls }^{a}\end{array}$ & NS & Trend $^{\mathrm{b}}$ & $\begin{array}{l}\text { Incon- } \\
\text { sistent } \\
\text { effects }^{a}\end{array}$ \\
\hline
\end{tabular}

Abbreviations: $\mathrm{AD}=\mathrm{Alzheimer}$ 's disease; $\mathrm{chr}=$ chromosome; $\mathrm{SNP}=$ single nucleotide polymorphism; $C S F=$ cerebrospinal fluid; $\mathrm{MCl}=$ mild cognitive impairment; $\mathrm{NS}=$ not significant Note: $\mathrm{MCl}$ data from Chapters 2 (meta-analysis), 4 (DESCRIPA and ADNI), and 6 (DESCRIPA); AD data from Chapter 7 (FINN-AD); Other data from Chapters 5 (review) and 8 (EDAR). Analyses for $\mathrm{MCl}$ group adjusted for age and gender; analyses for $A D$ group adjusted for age, gender and $A P O E-\varepsilon 4$ status (except where APOE itself was tested)

${ }^{a}$ Based on systematic review in Chapter 5 .

b Trend defined as $P \geq 0.05$ and $P<0.10$.

c Only APOE was tested for correlation with neuropsychiatric symptoms.

${ }^{d}$ Gene previously genotyped in GWAS or SNP genotyped in genetic association studies that included the Finnish cohort and excluded from the genetic association analysis.

e Significant at an unadjusted $P<0.05$.

f Significant at a false discovery rate adjusted $P<0.05$.

${ }^{g}$ EDAR cohort which consisted of participants with MCl, AD-type dementia, and other dementia in a clinical setting, and cognitively healthy controls.

${ }^{\mathrm{h}}$ Based on meta-analysis in Chapter 2. 


\begin{tabular}{|c|c|c|c|c|}
\hline $\begin{array}{l}\text { Hippocampal } \\
\text { volume }\end{array}$ & $\begin{array}{l}\text { Delayed } \\
\text { memory }\end{array}$ & \multirow{2}{*}{$\begin{array}{l}\text { Neuropsy- } \\
\text { chiatric } \\
\text { symptoms } \\
\text { in } \mathrm{MCl}\end{array}$} & \multirow{2}{*}{$\begin{array}{l}\text { Association with } \\
\text { clinical AD in Finnish } \\
\text { case-control study }\end{array}$} & \multirow{2}{*}{$\begin{array}{l}\text { Predictive value } \\
\text { for progression } \\
\text { from } M C I \text { to } A D\end{array}$} \\
\hline $\mathrm{MCl}$ & $\mathrm{MCl}$ & & & \\
\hline Trend $^{\mathrm{b}}$ & Trend $^{\mathrm{b}}$ & $\begin{array}{l}\text { Increased } \\
\text { agitation, } \\
\text { irritability } \\
\text { and delusion; } \\
\text { decreased } \\
\text { depression }\end{array}$ & $\begin{array}{l}\text { Significant. }{ }^{f} \sim 6 x \text { in- } \\
\text { creased risk }\end{array}$ & $\begin{array}{l}\text { Significant. }{ }^{f, h} \sim 2.5 \\
\text { increased risk }\end{array}$ \\
\hline
\end{tabular}

Table 2 Summary of effects of SNPs in other GWAS and candidate genes on CSF biomarkers in AD

\begin{tabular}{|c|c|c|c|}
\hline Chr, Gene & $A \beta_{1-42}$ & T-tau & P-tau \\
\hline \multicolumn{4}{|c|}{ GWAS not in top 10 AlzGene } \\
\hline 6,MTHFD $1 L$ & NS & NS & NS \\
\hline $11, M S_{4} A_{4} A$ & $\begin{array}{l}\text { Significant for } \\
\text { rs2304933 } \\
\text { NS for A } \beta_{1-42}^{\text {in }} \\
\text { pooled sample }\end{array}$ & NS & NS \\
\hline $19, E X C_{3} L 2$ & NS & NS & NS \\
\hline \multicolumn{4}{|c|}{ GWAS with biomarkers as outcome } \\
\hline $2, E P C_{2}$ & NS & Trend for rs $1374441^{c}$ & NS \\
\hline 7, RELN & NS & NS & NS \\
\hline 15, CYP19A & NS & NS & NS \\
\hline $\begin{array}{l}\text { 19, TOMM40 } \\
\text { (rs157580, rs207565o) }\end{array}$ & NS & NS & NS \\
\hline \multicolumn{4}{|l|}{ Other candidate genes } \\
\hline $2, P P P_{3} R_{1}$ & NS & Trend for rs1868402 ${ }^{c}$ & NS \\
\hline $3, T F$ & NS & NS & NS \\
\hline $10, I D E$ & NS & NS & NS \\
\hline $11, B D N F$ & NS & NS & NS \\
\hline 11, SORL1 & NS & Trend for rs73595277 ${ }^{c}$ & Trend for rs $73595277^{c}$ \\
\hline 14, $\mathrm{CYP}_{4} 6 a$ & NS & NS & NS \\
\hline $17, A C E$ & NS & NS & NS \\
\hline
\end{tabular}


Table 2 Summary of effects of SNPs in other GWAS and candidate genes on CSF biomarkers in AD Continued

\begin{tabular}{|l|l|l|l|}
\hline Chr, Gene & A $\beta_{1-42}$ & T-tau & P-tau \\
\hline 17, MAPT & NS & $\begin{array}{l}\text { Significant for } \mathrm{rs} 2435211^{\mathrm{d}} ; \\
\text { trend for } \mathrm{rs} 16940758^{\mathrm{C}}\end{array}$ & Significant for rs16940758 ${ }^{\mathrm{d}}$ \\
\hline $\begin{array}{l}\text { 19, TOMM40 } \\
\text { (rs8106922) }\end{array}$ & NS & NS & NS \\
\hline
\end{tabular}

Abbreviations: SNPs=single nucleotide polymorphisms; GWAS=genome-wide association study; $\mathrm{CSF}=$ cerebrospinal fluid; $\mathrm{AD}=\mathrm{Alzheimer}$ 's disease

Note: Data from Chapters 7 (FINN-AD) and 8 (EDAR)

a Significant at a false discovery rate adjusted $P<0.05$

${ }^{b}$ EDAR cohort consisting of participants with $\mathrm{MCl}, \mathrm{AD}$-type dementia, other dementia in a clinical setting, and cognitively healthy controls.

c Trend defined as $P \geq 0.05$ and $P<0.10$.

${ }^{d}$ Significant at an unadjusted $P<0.05$.

Predictive value of top AlzGene loci for developing AD-type dementia in individuals with mild cognitive impairment $(\mathrm{MCl})$

We performed analyses in two studies. In the first study (Chapter 2), we assessed the predictive value of $A P O E$ in a large meta-analysis of prospective studies of subjects with $\mathrm{MCl}$. We found an odds ratio (OR) of 2.3, indicating moderate association. The sensitivity and positive predictive value were low, indicating that $A P O E$ genotyping has limited clinical value but is useful for trials aiming to select subjects who are at higher risk for progressing to AD-type dementia. The predictive value of $A P O E$ in our meta-analysis was affected by age and follow-up length. With advancing age, the percentage of $A P O E-\varepsilon_{4}$ carriers among subjects who progressed to $A D$ decreased. This is consistent with previous findings ${ }^{1}$ and could mean that carriers of the $\varepsilon_{4}$ allele may have either progressed to $A D$ or have died at a younger age. ${ }^{2} A$ previous study has shown that there is a North-South gradient in APOE prevalence in Europe. ${ }^{3}$ We modeled this effect using meta-regression and found that the back- 
ground prevalence of $A P O E$ influenced the predictive accuracy. Sensitivity increased while specificity decreased with a higher background prevalence. It is therefore important to take into account the prevalence of $A P O E$ in the population tested when interpreting the results.

In the second study (Chapter 6), we tested the predictive accuracy of the top $10 \mathrm{AlzGene}$ loci in nondemented individuals with cognitive impairment from a memory clinic setting from the DESCRIPA cohort. Only $A P O E$ predicted $A D$-type dementia with an $O R$ very similar to that obtained in our meta-analysis ( $O R=\sim 2.5)$. The other top AlzGene loci showed much weaker risk effects that were not statistically significant. Our results are consistent with those of another study assessing disease progression in $\mathrm{MCl} .{ }^{4}$ Nonetheless, based on AlzGene meta-analyses, it is unlikely that other SNPs would independently exert an effect greater than APOE. A population-based study of nondemented individuals has found that the combined effect sizes of the individual top AlzGene loci only marginally improved prediction of $A D$, but we have not tested this in the present study. ${ }^{5}$

We noted a number of results that were the opposite of AlzGene findings, namely, a seemingly protective effect of $C R 1$ and $B I N 1$ and risk effect of $C D_{33}$ in our cohort. This could be explained by the very small number of risk allele carriers in the SNPs studied in these genes in our cohort.

\section{Genetic association with clinical AD}

We also tested the association of 24 genetic variants with clinical $A D$ in the Finnish population composed of AD patients and age-matched healthy control subjects (Chapter 7). Only APOE and TOMM4O were associated with clinical AD. Carrying at least one $\varepsilon_{4}$ allele increased the risk of $A D$ to more than six times. This result was not affected by age and gender. The high odds ratio we obtained, which was comparable to those reported in other Caucasian populations, ${ }^{6-8}$ could be attributed to the high APOE prevalence in the Finnish population. TOMM4O showed genetic association with $A D$, but this effect disappeared after correction for APOE genotype. TOMM 40 is in linkage disequilibrium with $A P O E$ and our results were in accordance with recent evidence showing that the possibility of finding an effect that was not due to $A P O E$ in the $A P O E$ 
region was unlikely. ${ }^{9}$ Other candidate genes were not associated with $A D$ in the Finnish population, which is in line with AlzGene findings (for genes not included in top list) and the fact that they did not show significant effects in large GWAS.

In multicenter genetic association studies or GWAS involving the Finnish population, associations have been reported for the top AlzGene loci in $A B C A 7, B I N_{1}, C D_{2} A P, C D_{33}, C L U, C R 1, M S_{4} A 4 E$ and MS4A6A. ${ }^{10-12}$

\section{Correlation with CSF biomarkers}

We tested the correlation between CSF markers and top AlzGene loci both in $\mathrm{MCl}$ and $A D$; a range of candidate loci only in $A D$; and variants in the MS4A cluster in a pooled sample consisting of participants with $\mathrm{MCl}$, AD-type dementia, other dementia and cognitively healthy controls. The findings for the top $10 \mathrm{AlzGene}$ loci in $\mathrm{MCl}$ and $A D$ are summarized in Figure 1a-d. The plots also highlight the differences in CSF marker concentrations between $\mathrm{MCl}$ and $\mathrm{AD}$. While CSF $A \beta_{1-42}$ concentrations are in the same range in $\mathrm{MCl}$ and in $A D$, the distribution in $\mathrm{MCl}$ is more spread out. Tau levels are clearly lower in $\mathrm{MCl}$ than in $\mathrm{AD}$. The variation is also smaller.

CSFA $\beta_{1-42}$

Of the top AlzGene, only $A P O E-\varepsilon 4$ is significantly related to reduced CSF A $\beta_{1-42}$ in both $\mathrm{MCl}$ and $\mathrm{AD}$ (Chapters 6 and 7). In $\mathrm{MCl}$ (Chapter 6 ), $A \beta_{1-42}$ concentrations were significantly decreased among APOE $\varepsilon_{4}$ allele carriers whereas marginal reductions at an unadjusted $P$-value were observed among PICALM risk allele carriers. Both genes have been reported to play a role in $A \beta$ aggregation: $A P O E-\varepsilon 4$ through its high avidity binding to $A \beta$ yet less efficient function in $A \beta$ clearance, ${ }^{13-15}$ and PICALM through endocytotic processes. ${ }^{16,17}$ Homozygote risk allele carriers of the other top AlzGene loci tended to have lower $A \beta_{1-42}$ levels, but these effects were not significant.

In AD (Chapter 7), APOE and CLU, which is another apolipoprotein that binds soluble $A \beta$ and is involved in $A \beta$ aggregation, ${ }^{18}$ were significantly related to reduced CSF A $\beta_{1-42}$ concentrations. 
Figure 1a $\mathrm{MCl}$ in DESCRIPA cohort

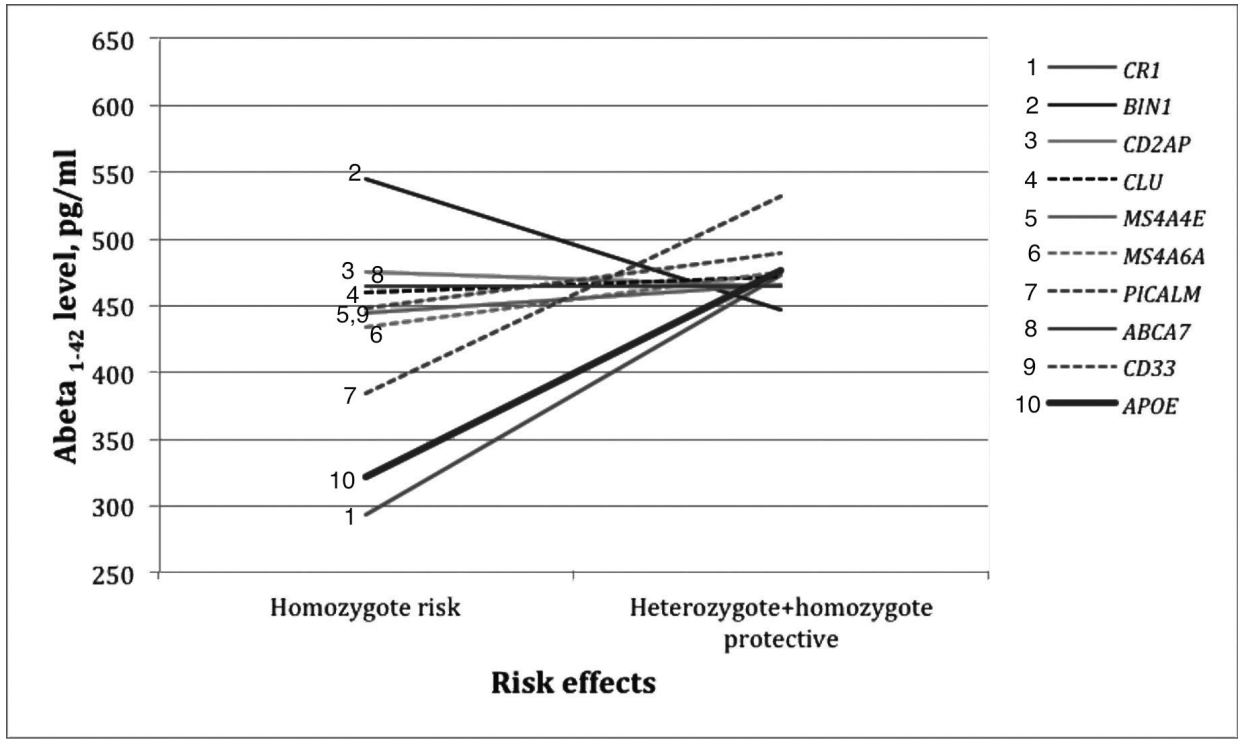

Figure $1 \mathrm{~b} A D$ in FINN-AD cohort

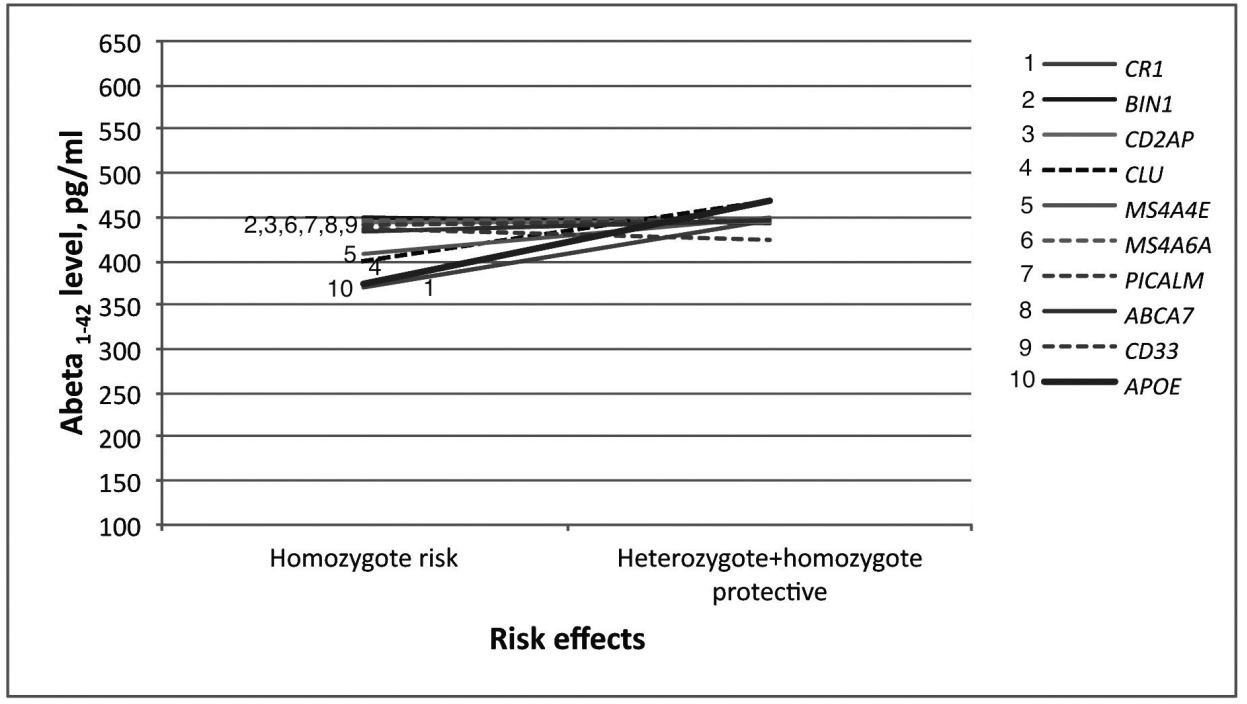

Figure 1a-b The plots show the mean CSF Aß1-42 levels in mild cognitive impairment $(\mathrm{MCl}, 1 \mathrm{a})$ and in Alzheimer's disease (AD, 1 b) for the top 10 AlzGene loci. Genetic variants for which the minor allele is the risk allele are represented by straight lines ( - ) while variants for which the major allele is the risk allele are shown in broken lines (---). 
Figure 1c

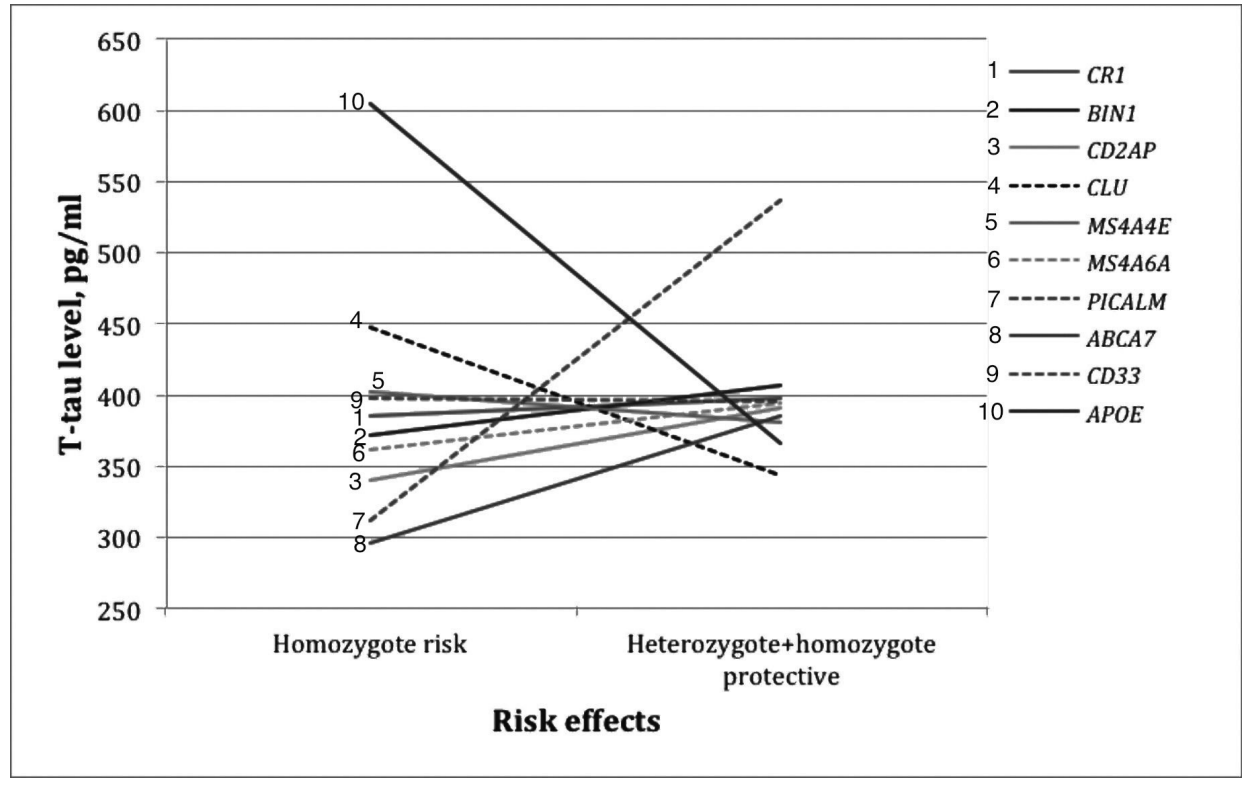

Figure 1d

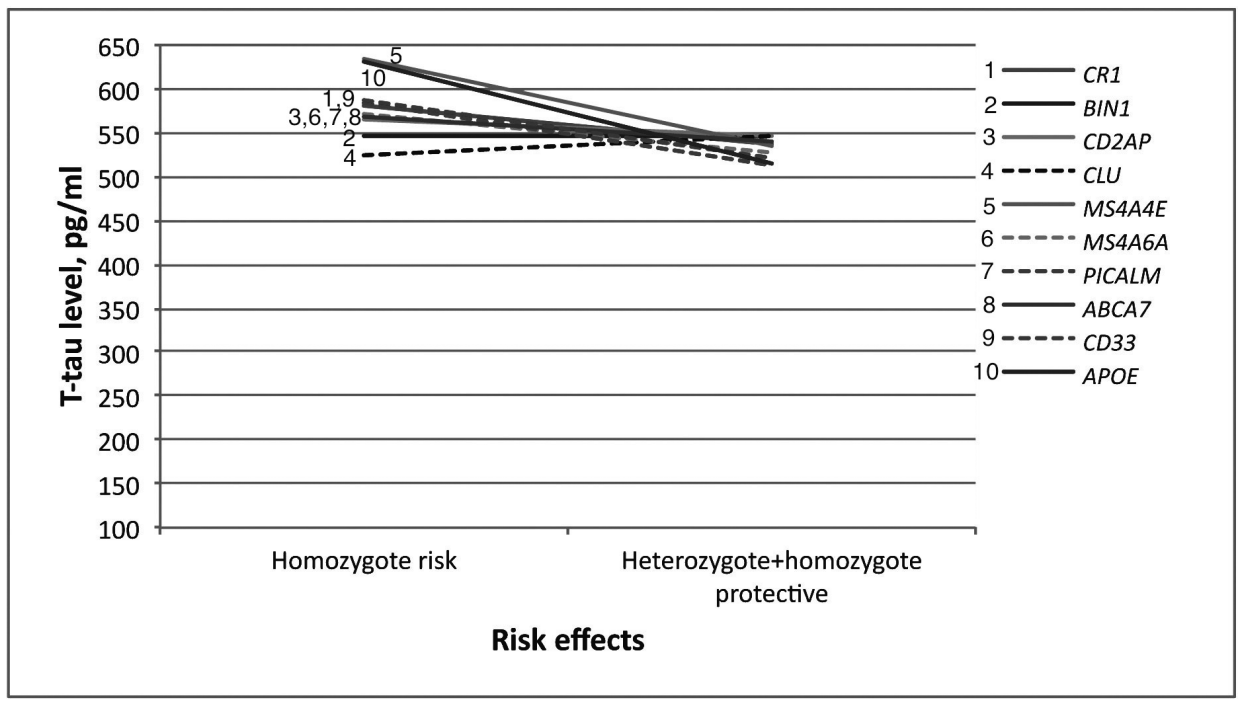

Figure 1c-d The plots show the mean t-tau levels in mild cognitive impairment $(\mathrm{MCl}, 1 \mathrm{C})$ and in Alzheimer's disease (AD, 1d) for the top 10 AlzGene loci. Genetic variants for which the minor allele is the risk allele are represented by straight lines ( - ) while variants for which the major allele is the risk allele are shown in broken lines (---). 
There were few other SNP-related differences because CSF A $\beta$ may already be strongly reduced in demented patients, as indicated by the low variability in CSF A $\beta_{1-42}$ values.

Of the other GWAS SNPS, TOMM 40 and EXOC 322 likewise correlated with decreased $A \beta_{1-42}$ levels in $A D$, but these effects were not independent of $A P O E$.

A notable finding is the relation between SNPs in the MS4A gene family and CSF $A \beta_{1-42}$. Significant reductions in CSF $A \beta_{1-42}$ were found in relation to $M S_{4} A 4 A$ in $A D$ (Chapter 7), and MS $4 A 6 A$ in a pooled sample of $\mathrm{MCl}, A D$, other dementia and cognitively healthy control subjects (Chapter 8 ). The SNPs we studied in MS4A4A and MS4A6A have been identified in GWAS with clinical AD as outcome, ${ }^{19}$ but as far as we know, there has been no studies yet reporting their correlation with $A D$ biomarkers. MS $4 A_{4} A$ and $M S_{4} A 6 A$ are in linkage disequilibrium, and are 2 of the 16 known gene members of the MS4A cluster. The MS4A gene family is poorly characterized. ${ }^{20}$ Other variants of this cluster have been found to be associated with $A D$ in non-Caucasian population. ${ }^{21} A$ role in immunity has been suggested for other variants, ${ }^{2022-25}$ however, it is beyond the scope of the current thesis to investigate this. In the thesis, we showed that MS4A4A and MS $4 A 6 A$, which have been associated with clinical $A D$, also have an effect on CSF A $\beta_{1-42}$.

\section{CSF tau}

The top AlzGene loci were not significantly correlated to CSF tau in both $\mathrm{MCl}$ and $\mathrm{AD}$ (Chapters 6 and 7). Although tau levels among homozygous risk allele carriers in $\mathrm{MCl}$ were generally higher than normal, and were abnormal in $A D$, they were not or were only weakly correlated with the top AlzGene. This suggests that the top AlzGene loci contribute to the development of $A D$ through pathways other than directly affecting tau.

Of interest are the trends we found for polymorphisms in candidate genes, $P P P_{3} R_{1}$ and $M A P T$, in relation to CSF tau in $A D$ (Chapter 7 ). $P P P_{3} R 1$ plays a role in modulating tau phosphorylation via calcineurin. ${ }^{26,27}$ $M A P T$, in turn, codes for tau proteins, ${ }^{28}$ as will be discussed in more detail below. The nonsignificant trends may indicate that the effects of these variants are subtle and requires a much bigger sample in order to attain significance. Our results nevertheless point to the need to further inves- 
tigate the role of candidate genes in tau metabolism, as SNPs in these genes have been previously shown to affect disease progression. ${ }^{29,30}$ Meanwhile, we also observed elevated tau levels in relation to SORL1. This finding may be due to chance as SORL1, which binds to ApoE, is not normally associated with tau.

\section{Correlation with hippocampal volume}

None of the top 10 AlzGene loci significantly correlated with hippocampal volume in $\mathrm{MCl}$ (Chapter 6). The lack of significant correlations with the top AlzGene loci does not necessarily mean that these variants do not affect the hippocampus but more likely that our sample size was too small to detect robust effects on the one hand. On the other hand, hippocampal atrophy is a later event in the pathogenesis of $A D$ and may not yet be evident in our cohort.

We observed nonsignificant associations between hippocampal volume and risk allele carriers of CLU and APOE, and nonrisk allele carriers of $C R 1$. CLU has been associated with brain atrophy in both $\mathrm{MCl}$ and AD. ${ }^{31} C L U$ has also been suggested to affect episodic memory through hippocampal dysfunction. ${ }^{32}$ In our cohort, CLU was related to hippocampal volume and not to memory.

The nonsignificant correlation between hippocampal volume and the $A P O E \varepsilon_{4}$ allele in our cohort is consistent with previous findings. Hippocampal volume loss among APOE $\varepsilon 4$ allele carriers with $\mathrm{MCl}^{33}$ and among cognitively healthy individuals ${ }^{34}$ has been previously reported. $A P O E$ does not directly lead to hippocampal volume loss. Rather, a neuropathologic study has shown that hippocampal atrophy among carriers of the $A P O E \varepsilon 4$ allele occurs through a complex mediation process wherein $A P O E$ affected CSF $A \beta$ that, in turn, resulted in changes in tau, ${ }^{35,}$ ${ }^{36}$ eventually leading to tangle formation and hippocampal atrophy.

The reduced hippocampal volume among homozygous nonrisk allele carriers of $C R 1$ was the opposite of what we expected and not in line with previous studies. It may be due to chance. $C R 1$ has been suggested to play a protective role in $A D$ by binding $A \beta$ oligomers to its $C_{3} b$ complement factor. ${ }^{18,37} \mathrm{~A}$ protective effect of the CR1 SNP (rs6656401) that we studied is not likely based on its effects on CSF A $\beta_{1-42}$ and tau in the present cohort and also in the Finnish AD population. 


\section{Correlation with clinical markers in $\mathrm{MCl}$ Delayed memory}

We tested the top AlzGene loci for influence on delayed memory (Chapter 6). None of the SNPs were significantly related to memory after multiple test correction. $C D_{2} A P$ and $A B C A 7$ showed effects on memory at an unadjusted $P$-value, while a trend was observed for $A P O E$.

$C D_{2} A P$ correlated with worse delayed memory performance. $C D_{2} A P$ has not been shown in a previous study to significantly affect memory, although this study pertained to nondemented individuals in a general population. ${ }^{5} \mathrm{It}$ is conceivable that subtle effects of $C D_{2} A P$ on memory are more detectable in a population of nondemented individuals with cognitive impairment in a clinical setting, such as our cohort. Further research is needed to verify the influence of $C D_{2} A P$ on memory.

The higher delayed memory performance we observed among $A B C A 7$ risk allele carriers compared to noncarriers is apparently the result of the very small number of risk allele carriers in our cohort $1.6 \%$ genotype frequency for homozygous risk allele carriers and $18.3 \%$ for heterozygous carriers). The risk allele of $A B C A 7$ has further not been found to significantly affect memory in the population-based study described above. ${ }^{5}$

We observed a weak correlation between the APOE $\varepsilon_{4}$ allele and delayed memory. Current knowledge suggests that $A P O E$ does not directly affect cognition. Rather, $A P O E$ has been reported to affect $A \beta$ which, through a cascade of events, leads to $A \beta$ deposition, tangle formation and the clinical manifestation of cognitive decline.35, ${ }^{36,38}$ In our study, APOE was significantly related to reduced CSF A $\beta_{1-42 .}$ $A P O E-\varepsilon 4$ carriers had higher tau levels, smaller hippocampal volume and lower delayed memory performance, although the correlation was not significant. These results could be conceived in the context of events shown in Figure 2.

Our results do not rule out the effects of other $A D$ risk genes on cognition. Rather, they suggest that the effects may be subtle, indirect or occur through different pathophysiological mechanisms, as in the case of $A P O E$. 
Figure 2 Schematic diagram of the influence of $A P O E$ on amyloid beta and the series of events that lead to the clinical manifestation of cognitive decline

APOE

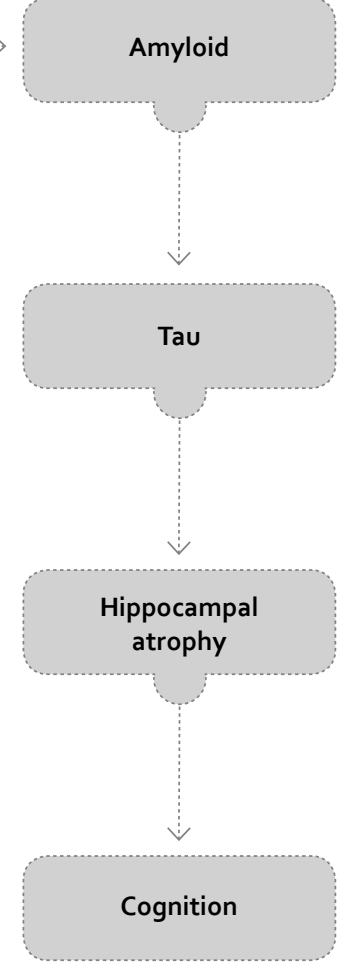

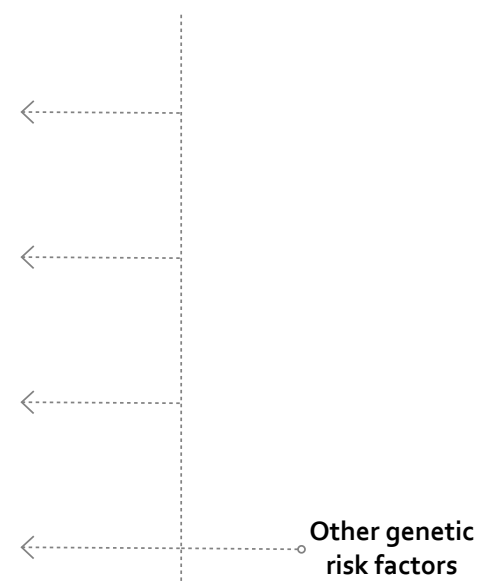

risk factors

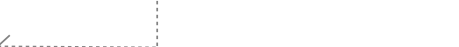

\section{Neuropsychiatric symptoms}

The APOE $\varepsilon_{4}$ allele was significantly related with agitation and irritability, and with clinically significant symptoms of heightened delusions and reduced depression in $\mathrm{MCl}$ (Chapter 4). Clinically significant symptoms are severe enough to disrupt daily functioning and merit treatment. ${ }^{39}$ Agitation and irritability have been reported to be related with reduced CSF A $\beta_{1-42}$ in $\mathrm{MCl} .^{4^{\circ}}$ The correlation we found in our study may very well reflect the effect of $A P O E$ on CSF $A \beta_{1-42,}$ and thus $A D$, rather than directly on agitation. $A P O E-\varepsilon 4$ was related to reduced risk of depression in $\mathrm{MCl}$. 
This is consistent with reported findings in AD. ${ }^{41,42}$ The relation between $A P O E$ and delusion must be interpreted with caution because of the very small number of individuals in our study who had delusions.

\section{GENES IN AD PATHOPHYSIOLOGY}

As discussed in the previous section, we found a number of associations between genetic risk factors and AD biomarkers. In this section, we will discuss how these findings relate to the role of genetic risk factors in $A D$ pathophysiology. As model, we use the amyloid cascade (Figure 2). According to this model, abnormal accumulation of $A \beta$ in plaques triggers a series of responses, including tau phosphorylation and aggregation ${ }^{43}$ that, in turn, lead to the formation of neurofibrillary tangles (NFTs). Cognitive decline, which is a later event in AD pathogenesis, has been shown to correlate with NFTs. ${ }^{36}$

\section{Top 10 AlzGene loci}

Only $A P O E-\varepsilon 4$ consistently showed a relation to the markers we tested. We interpret this in the context of recent in vivo ${ }^{44}, 45$ and neuropathologica| $35,36,38$ findings that $A P O E$ mainly affects amyloid and does not directly affect tau, hippocampal atrophy, memory, and presumably neuropsychiatric symptoms as discussed earlier. We found that indeed, $A P O E-\varepsilon 4$ was strongly correlated with CSF $A \beta_{1-42}$ and showed weaker correlation with the other markers we studied, which are considered as downstream markers. $A P O E-\varepsilon 4$ has been shown to have a high avidity binding to $A \beta,{ }^{14,46}$ to be less efficient in transporting $A \beta$ across the blood-brain barrier, ${ }^{13}$ and to stimulate $A \beta$ aggregation in vitro and amyloid plaque deposition in vivo. ${ }^{13,15,47} A P O E-\varepsilon_{4}$ has also been shown to increase the formation of soluble $A \beta$ oligomers, 48,49 which have been reported to be highly neurotoxic. ${ }^{13,50,51} \mathrm{Abnormal}$ accumulation of $A \beta$ in plaques triggers a series of responses, including tau phosphorylation and aggregation ${ }^{43}$ that, in turn, lead to the formation of neurofibrillary tangles (NFTs). Cognitive decline, which is a later event in AD pathogenesis, has been shown to correlate with $\mathrm{NFTs},{ }^{36}$ as previously discussed and summarized in Figure 2.

$C L U$ correlated with reduced CSF A $\beta_{1-42}$ level in AD and reduced hippocampal volume in $\mathrm{MCl}$ in the present thesis. Previous studies 
have not found a relation between $C L U$, and $A \beta$ and tau in $\mathrm{CSF}^{52-54}$ or in plaques and tangles. ${ }^{55}, 5^{6}$ No common coding variant in $C L U$ has been found to date that could explain the genetic association with AD. 57,58 Instead, genetic variations that affect expression levels of clusterin have been suggested to influence the risk of developing AD. ${ }^{18,57,59}$ We did not measure clusterin levels in the current thesis, but we explain our findings in view of this knowledge. CLU has generally been reported to exert a protective role in $A D .{ }^{58,60,61} C L U$ codes for multifunctional proteins that among others, act as chaperone of $A \beta$ in the brain. ${ }^{80,62}$ Clusterin is involved in lipid transport, guards against $A \beta$ aggregation through mechanisms that include binding to soluble $A \beta$ in $C S F$, stabilizing $A \beta$ peptides, inhibiting formation of $A \beta$ oligomers and amyloid fibrils, mediating $A \beta$ clearance from the brain through endocytosis and transporting $A \beta$ across the blood- brain barrier. ${ }^{18,58,61-63}$ However, in the presence of excessive $A \beta$ peptides or oligomers, clusterin has been shown to increase $A \beta$ aggregation..$^{8}$ While this is on the one hand detrimental for the brain, on the other hand, it has also been reported to prevent excessive neuroinflammation,,$^{58}$ thus conferring to a certain extent a protective effect. Elevated clusterin levels have been found to correlate with reduced CSF $A \beta_{1-42}$ in AD but not in controls, suggesting that clusterin levels are related to neuritic plaques. ${ }^{64}$ In a clinicopathological study, increased clusterin levels in the hippocampus of AD patients have been reported, but this did not correlate with neuritic plaque density, and thereby not with $A \beta .{ }^{65}$ Meanwhile, other studies have provided in vivo and in vitro evidence that $A \beta$ enhanced clusterin expression. ${ }^{59,}{ }^{66}$ Increased clusterin levels in $\mathrm{MCl}$ has been suggested as neuroprotective in that it corresponded to slower brain atrophy rates; whereas in $A D$, the correlation between elevated clusterin levels and brain atrophy has been attributed to failure of neuroprotection. ${ }^{67}$ Based on the aforementioned studies, we conclude that clusterin appears to be an indicator, rather than an initiator, of AD pathology.

PICALM in the present thesis decreased CSF A $\beta_{1-42}$ concentration in $\mathrm{MCl}$ and showed a trend of increased tau level in AD. The influence of PICALM on $A \beta$ in CSF and on neuritic plaques upon neuropathological examination has been confirmed by other studies. ${ }^{54-56}$ PICALM is involved in clathrin-mediated endocytosis. It has been shown to 
influence $A \beta$ neurotoxicity by regulating endocytosis. ${ }^{16}$ It has also been suggested to indirectly increase $A \beta$ production by modifying $A \beta$ precursor protein or its proteases through altered trafficking of vesicle-associated membrane protein 2 (VAMP2). ${ }^{17}$ Previous studies have reported that VAMP 2 trafficking is critical for synaptic integrity. ${ }^{68,69}$ PICALM has been posited to influence $A D$ risk through synaptic dysfunction. ${ }^{70}$ Synaptic dysfunction has been related to tau aggregation and hyperphosphorylation. ${ }^{71}$ While it is conceivable that the trend we observed for CSF tau in the current thesis could be explained by the indirect role of PICALM on synaptic integrity, other studies showed no relation between PICALM and tau in $\mathrm{CSF}^{53,54}$ and NFTs upon neuropathological examination. ${ }^{55,56}$

$C D_{2} A P$ was related to decreased delayed memory in $\mathrm{MCl}$ in our study. In addition, we observed a trend of reduced CSF A $\beta_{1-42}$ level in $\mathrm{MCl}$. To our knowledge, no literature to date has linked $C D_{2} A P$ with cognition and $A \beta$. A previous study found no correlation between cognition and the combined risk of top GWAS SNPs including CD2AP. ${ }^{5}$ Like PICALM , CD2AP is involved in clathrin-mediated endocytosis, ${ }^{72}$ and has a suggested role in synaptic dysfunction and cell membrane processes. ${ }^{70}$ $C D_{2} A P$ functions as a scaffold adaptor protein ${ }^{10}$ and as such has a role in regulating signal transduction. The involvement of $C D_{2} A P$ in $A \beta$ processing is not straightforward but has been posited to occur within the complex complement cascade network. ${ }^{25} C_{2} A P$ has been described as forming part of the complement system and an immune network through its association with $C D 2$, which is a T-lymphocyte marker protein, that facilitates communication between cells. ${ }^{25}$ In addition, $C D_{2} A P$ has been linked with atherosclerosis, which is an AD risk factor, via its binding with other proteins that are exploited by bacterial pathogens. ${ }^{25}$

$C R 1$ was related to increased hippocampal volume in $\mathrm{MCl}$ in the present thesis. We attributed this result to chance given that the rest of our findings did not support a protective effect of the SNP we studied. A different variant in $C R 1$ has been suggested to be neuroprotective. ${ }^{73}$ Meanwhile, a trend of decreased $A \beta_{1-42}$ concentration among control subjects has been reported in previous research. ${ }^{54}$ The precise nature of how $C R 1$ contributes to $A D$ risk has been the subject of numerous studies. $C R 1$, with as complement factors $C_{3} b$ and $C_{4} b$, is a member of the complement system receptors. ${ }^{18,25}$ The complement system is part 
of the innate immune system ${ }_{1}^{74}$ which is the body's first line of defense against pathogens. Complement activation has been reported as an early event in the development of $A D$ pathology. ${ }^{75} C R 1$ aids in eliminating immune complexes containing $C_{3} b$ and $C_{4} b$, and in clearing $A \beta$ by binding $A \beta$ oligomers to its $C_{3} b$ complement factor. ${ }^{18} A \beta_{1-42}$ in plasma has also been reported to adhere to $C_{3} b .{ }^{76} A$ part from being actively involved in clearing pathogens, $C R 1$ also plays a role in complement inhibition, thereby subduing the inflammatory response and limiting the damage to surrounding tissues. ${ }^{74}$ Excessive and chronic activation of the complement system is detrimental as it damages surrounding tissues. ${ }^{74}$ Moreover, it has been reported to lead to neuropathological changes that increase the phosphorylation of tau and ultimately leads to neuronal death. ${ }^{74,77}$ In this sense, $C R 1$ appears to have a protective role in $A D$, although this needs to be verified by further research. Previous work has shown reduced complement inhibitors in AD. ${ }^{77}$ Furthermore, it has been suggested that in $A D$, disruptive complement signaling and the presence of $A \beta$ leads to a series of events wherein more complement factors are secreted which, in turn, results in chronic inflammatory reaction. ${ }^{77}$

The $A B C A 7$ risk allele correlated with better memory in the current thesis. We explained this finding as probably due to the very small number of risk allele carriers in our study. $A B C A 7$ has not been shown in previous work to be associated with cognition. ${ }^{5} A B C A 7$ has also not been reported to be involved in $A \beta$ metabolism, ${ }^{70}$ although it has been shown to inhibit the secretion of $A \beta$ in vitro. ${ }^{78}$ Several studies have suggested that $A B C A 7$ possibly contributes to $A D$ pathophysiology by its involvement in the complement system and lipoprotein-related mechanisms. ${ }^{19}, 25,70,79 A B C A 7$ codes an ATP-binding cassette (ABC) transporter mainly found in immune network cells. ${ }^{25}$ One of its substrates is ApoE. The main function of $A B C A 7$ appears to be phagocytosis of apoptotic cells, thereby serving as defense mechanism against pathogens. ${ }^{25}$ It has been reported to be involved in the efflux of lipids from cells to lipoprotein particles, ${ }^{79}$ but not in the efflux of cholesterol. ${ }^{80}$ However, it has been shown to mediate efflux of cholesterol to lipid-laden $\mathrm{ApoE}_{,}{ }^{25}$ which opens further research possibilities for understanding the contribution of $A B C A 7$ and its interaction with other risk factors to $A D$ pathophysiology. 
We studied polymorphisms in three $M S_{4} A$ genes, of which two are included in the top $10 \mathrm{AlzGene}\left(M S_{4} A_{4} E\right.$ and $\left.M S_{4} A 6 A\right)$ and another $\left(M S_{4} A_{4} A\right)$ has been identified in GWAS to be associated with clinical AD. We will discuss these three genes, which are in linkage disequilibrium, together in this section. $M S_{4} A_{4} A$ and $M S_{4} A 6$ reduced $C S F A \beta_{1-42}$ concentrations respectively in $A D$ and in a pooled sample of cognitively healthy controls, $\mathrm{MCl}, \mathrm{AD}$ and other dementia cases in the present thesis. To our knowledge, $M S_{4} A$ has not been previously reported to affect CSF A $\beta$. Previous studies of $M S_{4} A$ genes have been in relation to immunity. ${ }^{22-25}$ The $M S_{4} A$ family consists of at least 16 known genes ${ }^{10}$ clustered along chromosome 11q12. All MS4A family members code for proteins with multiple membrane-spanning domains, ${ }^{81}$ form part of oligomeric cell surface proteins and play a role in cellular signal transduction. ${ }^{22}$ $M S_{4} A_{4} A, M S_{4} A_{4} E$ and $M S_{4} A 6 A$ have been reported to play a role in immunity, being structurally related to the immunoglobulin $E$ receptor and to $C D 20,{ }^{25}$ which is a B-lymphocyte cell surface molecule. ${ }^{18}$ These studies suggest a role of immunity mediated by MS $4 A$ in AD pathophysiology. The precise mechanisms by which this occurs, and how this may have affected CSF A $\beta$ in our study, deserve further investigation.

$B I N 1$ has been established in various GWAS as a genetic risk factor for $A D,{ }^{10,19,82-84}$ but showed no effect on the AD markers we studied. Previous studies likewise found no correlation between $B I N_{1}$ and CSF $A \beta$ and tau, ${ }^{53}$ or with cognition. ${ }^{5}{ }^{85}$ The involvement of $B I N_{1}$ in clathrinmediated endocytosis and apoptosis provides a possible explanation how $B I N 1$ contributes to $A D$ pathophysiology. $B I N 1$ encodes proteins belonging to the Bin/Amphyphisin/Rvs (BAR) family adapter that form complexes acting in clathrin-mediated endocytosis. ${ }^{18}$ In this process, proteins from the plasma membrane are transported via clathrincoated vesicles from the cell surface to inside the cell, where they are sorted and targeted to different destinations.$^{86}$ The manner in which the amyloid precursor protein (APP) is processed has been reported to be dependent on endocytosis and intracellular sorting which, in turn, influences $A \beta$ production. ${ }^{86}$ Other explanations are the involvement of $B I N 1$ in synaptic formation, neuronal membrane organization and stress signaling ${ }^{18,70,84}$ which could be disrupted in AD. 
$C D_{33}$ also did not influence any of the $A D$ markers we tested. $C D_{33}$ has previously been studied in relation to cognition, but this likewise did not yield significant result. ${ }^{5} C_{33}$ has been posited to contribute to $A D$ risk via the immune network. ${ }^{25} C_{33}$ belongs to the sialic acid binding Ig-like lectin (Siglec) family that binds sialic acid and has been reported to regulate both innate ${ }^{79}$ as well as adaptive ${ }^{25}$ immune responses. Further, $C D_{33}$ has been suggested to contribute to the development of $A D$ through synaptic dysfunction and cell membrane processes..$^{70}$

\section{GWAS SNPs not in top $10 \mathrm{AlzGene}$}

$E X O C_{3} L 2$ in our study was related to reduced CSF $A \beta_{1-42}$ levels in $A D$, but this result became nonsignificant when we corrected for $A P O E-\varepsilon_{4}$ status. $E X O C_{3} L_{2}$ is in linkage disequilibrium with $A P O E .{ }^{87}$ Previous studies have shown that the association between $E X O C_{3} L 2$ and clinical $A D$ was not independent of $A P O E .^{12,87} E X O C_{3} L_{2}$ has been shown to facilitate correct vesicle targeting of proteins and lipids during exocytosis, thereby playing a role in neuronal outgrowth and integrity. ${ }^{88,89}$ $E_{X O C_{3} L 2}$ has been associated with rapid disease progression in AD. ${ }^{90}$ MTHFD 1 L showed no correlation to CSF $A \beta_{1-42}$ and tau in our study. MTHFD $1 L$ has been suggested to affect $A D$ risk through folaterelated pathways. ${ }^{91} M T F H D_{1} L$ encodes a protein that synthesizes tetrahydrofolate in the mitochondria. This folate-pathway has been reported to be involved in the synthesis of homocysteine..$^{92}$ Elevated homocysteine levels have been associated with increased AD risk, ${ }^{93-95}$ but also with cardiovascular diseases ${ }^{96,97}$ that are also risk factors for $A D$. The influence of MTHFD $1 L$ on AD risk is therefore possibly mediated by cardiovascular factors. We did not test this in our study, and its ascertainment deserves further research.

\section{GWAS SNPs with biomarkers as outcome}

We observed a trend between $E P C 2$ and increased CSF tau concentration in $A D$ but $E P C 2$ did not affect $A \beta_{1-42}$. This confirms previous GWAS findings with CSF tau and $A \beta_{1-42^{.9}}$ Other $E P C 2$ variants in GWAS also mainly affected CSF tau and not $A \beta . .^{8}$ The known functions of $E P C_{2}$ do not directly link to tau metabolism or $A D$. One of the possibilities as to 
how $E P C 2$ contributes to $A D$ pathology is through epigenetics. $E P C 2$, which is a member of the polycomb family, is involved in heterochromatin formation, modification of chromatin, and dysregulation of epigenetic mechanisms and has also been implicated in mental retardation..$^{98}$ Further research would help better characterize the relation between $E P C_{2}$ and $A D$.

$R E L N$ was not significantly related to CSF biomarkers in the current thesis. A previous clinicopathological study showed that RELN was associated with abnormal tau concentration in NFT, particularly in the hippocampus, in $A D$ and interestingly also in cognitively healthy controls. ${ }^{99}$ This suggests that RELN is a potential indicator of AD pathology before the onset of dementia. RELN codes for reelin, which is part of the ApoE pathway, and which is involved in directing the migration of neurons and their positioning, and in forming and maintaining synapses.99-101 Previous studies have indicated that $R E L N$ plays a protective role in AD by (1) increasing long-term potentiation (LTP), which has been suppressed by $A \beta$ oligomers; and (2) inhibiting tau phosphorylation. ${ }^{99},{ }^{101}$ RELN has been shown to compensate for $A \beta$ induced LTP suppression by increasing the receptor activity of NMDA, thereby reversing the effect of $A \beta$ and preventing synaptic dysfunction. ${ }^{101}$ This compensatory mechanism fails at high concentrations of $A \beta$.

We studied three polymorphisms in TOMM40, of which two (rs157580 and rs2075650) have been identified in GWAS with biomarkers as outcome, and one (rs8106922) is a candidate SNP. In this section, we will discuss all three variants. All TOMM40 SNPs were related to reduced CSF A $\beta_{1-42}$ but not tau levels in the present thesis, in accordance with GWAS findings. The GWA studies reported associations that were uncorrected for APOE. ${ }^{98,102}$ As TOMM 40 is in linkage disequilibrium with $A P O E$, we repeated our analyses with adjustment for $A P O E-\varepsilon 4$ status and found that indeed, the effects of TOMM 40 SNPs on CSF biomarkers were not independent of APOE. TOMM 40 has been suggested to influence $A D$ pathophysiology through mitochondrial dysfunction. ${ }^{103}$ TOMM $_{40}$ functions to control the outer mitochondrial membrane pore subunit, through which proteins enter the mitochondria. ${ }^{103}$ Mitochondrial dysfunction has been reported to lead to the 
accumulation of APP and the cellular influx of $A \beta .^{103-105}$ The contribution of TOMM 40 to AD pathophysiology is likely to be influenced by $A P O E$ or reflects the effects of $A P O E$.

CYP19A did not affect CSF biomarkers in AD in our study. This is consistent with GWAS results, which interestingly found an association between $C Y P_{19} A$ and $C S F A \beta_{1-42}$ in control subjects but not in $A D$ and $\mathrm{MCl}^{102}{ }^{102} \mathrm{CP}_{19} \mathrm{~A}$ encodes cytochrome $\mathrm{P} 450$ aromatase, which catalyzes the formation of estrogens from androgens. ${ }^{106}$ Aromatase has a neuroprotective role and functions to regulate neural differentiation, plasticity and, through the synthesis of estrogen, also sexual behavior. ${ }^{107-109}$ Impaired aromatase expression and estrogen deficiency have been suggested to contribute to AD risk, which has been shown in animal studies to increase the formation of $A \beta$ plaques. ${ }^{110}$ As estrogen is involved in modulating kinase and phosphatase activities, it also has a suggested role in inhibiting tau hyperphosphorylation. ${ }^{111}$ The role of estrogen, and consequently gender, as risk factors for $A D$ remain controversial. Longitudinal studies of estrogen therapy among postmenopausal women showed an increased risk of AD. ${ }^{112,133} \mathrm{~A}$ gender-specific effect of $C Y P_{1} g$ has been suggested, ${ }^{106}$ but another study found no effect of gender on aromatase-related AD risk. ${ }^{114}$

\section{SNPs from candidate genes}

$P P P_{3} R 1$ showed a weak association with $A D$ risk and a trend of elevated tau concentration in $A D$ in our study. $A$ correlation between $P P P_{3} R 1$ and tau in individuals with $A \beta$ deposition has been previously reported and found to be associated with disease progression. ${ }^{29} P P P_{3} R_{1}$ appears to contribute to $A D$ pathophysiology via calcineurin, which modulates the phosphorylation of tau. ${ }^{27} P P P_{3} R 1$, which is a protein phosphatase, is the calcium binding regulatory subunit of calcineurin. ${ }^{26}$

MAPT was related to increased tau in AD and was also weakly associated with $A D$ risk in the current thesis. Previous studies have shown conflicting evidence linking MAPT with tau. ${ }^{29,115-117}$ In one study, a MAPT haplotype $\left(\mathrm{H}_{1}\right)$ has been correlated with reduced $A D$ pathology independent of $A P O E_{1}^{116}$ whereas another study found the same variant to be associated with risk of developing $\mathrm{MCl} .{ }^{117}$ What is known is that tauopathy is a feature of $A D$ and that tau dysfunction leads to 
neurodegeneration. MAPT plays a role in this in that it codes for the microtubule-associated protein tau, which functions to promote and stabilize microtubule assembly, as well as maintain neuronal integrity, axonal transport and polarity. ${ }^{28} \operatorname{In} A D$, this protein has been reported to be abnormally expressed. ${ }^{118} \mathrm{Tau}$, which is normally bound to microtubules, has been described to disengage from microtubules and to disassemble during abnormal hyperphosphorylation. ${ }^{118}$ Moreover, the disengaged tau has been reported to capture normal tau, thus preventing microtubule assembly. ${ }^{118}$ Aside from these, hyperphosphorylated tau protein is a main component of NFTs, as discussed earlier.

$S O R L 1$ was related to increased tau in $A D$ in the present thesis. We attributed this findings to chance because previous correlational studies of individual SNPs in SORL1 and CSF biomarkers have yielded either conflicting or inconclusive results. ${ }^{19}$ The influence of SORL1 on AD risk appears to be very small that detection is likely only by performing haplotype analyse ${ }^{120}$ or by pooling samples in a mega-analysis. ${ }^{121}$ Different mechanisms have been suggested by which SORL1 contributes to AD pathophysiology. One is though APP processing. SORL1 encodes the vacuolar protein-sorting 10 (VPS10) domain, which is part of a group of protein-trafficking molecules that guide APP into recycling pathways. ${ }^{122}$ Underexpression of SORL1 has been reported to result in APP being sorted into sites for $A \beta$ production, wherein APP cleavage by presenilin 1 occurs and $A \beta$ peptides are produced. ${ }^{122-125}$ Another mechanism by which SORL1 may influence AD pathogenesis is through cholesterol metabolism and its associated cerebrovascular diseases. ${ }^{125}$ SORL1 likewise encodes a protein belonging to the low-density lipoprotein (LDL) receptor family, which binds ApoE and transports LDL into cells via endocytosis. ${ }^{125}$

TF did not correlate to CSF biomarkers in our study. Previous work has shown that $T F$ reduced CSF $A \beta_{1-42} / A \beta_{1-40}$ ratio. ${ }^{115} T F$ has been suggested to influence $A D$ risk by modulating $A \beta$ and through iron overload. ${ }^{126} \mathrm{TF}$ encodes transferrin, a plasma glycoprotein that binds and transports iron across the blood brain barrier to the brain. ${ }^{127} A \beta$, and also tau, have metal binding sites. Metal ions have been reported to foster the aggregation of $A \beta .{ }^{128} \mathrm{Via}$ another mechanism, iron overload due to disrupted iron metabolism has been shown to contribute 
to AD pathogenesis by oxidative damage which, in turn, results in reduced protein synthesis in the brain ${ }^{129}$ and ultimately cell death.

$B D N F$ in the current thesis showed no correlation to CSF biomarkers. A correlation between $B D N F$ and reduced CSF A $\beta$ concentration has been previously reported. ${ }^{115} B D N F$ encodes the brain-derived neurotrophic factor (BDNF) protein, which is a member of the neurotrophin nerve growth factor family, that is involved in multiple functions, including promoting neuronal survival and differentiation, axonal and dendritic growth, as well as synaptic transmission and plasticity. ${ }^{130} \mathrm{BDNF}$ has a neuroprotective function. It is abundantly expressed in the hippocampus, neocortex and hypothalamus, ${ }^{131,132}$ which are specific areas affected in AD. Decreased BDNF protein levels have been reported to influence $A D$ pathophysiology by means of insufficient trophic support that may lead to regional neuronal degeneration, as has been observed in AD. ${ }^{133}$ Alternately, reduced BDNF levels has also been suggested to reflect overall synaptic loss and amyloid deposition in AD. ${ }^{132}$

$C_{4 P} 6 A_{1}$ was not related to CSF biomarkers in the present thesis. In previous studies, $C Y P_{4} 6 A_{1}$ has been shown to affect $A \beta_{1-42^{\prime}}$ and interestingly also tau, ${ }^{134}$ both in CSF and upon neuropathological examination. ${ }^{134,135} \mathrm{CYP}_{4} 6 \mathrm{~A}_{1}$ has been posited to contribute to the pathogenesis of AD through cholesterol metabolism. CYP46A1 encodes the enzyme, cholesterol $24 \mathrm{~S}$-hydroxylase (CYP46), which is brain-specific. CYP46 functions to make cholesterol more soluble and easier to eliminate through the blood-brain barrier by hydroxylation of cholesterol into 24-hydroxycholesterol. ${ }^{136,137}$ Deficits in Cyp 46 has been suggested to result in increased brain cholesterol. ${ }^{136} \mathrm{~A}$ cholesterol-rich environment has been reported to be favorable for the activities of $b$-secretase and g-secretase, ${ }^{136}$ which cleave APP, resulting in the production of $A \beta$ isoforms.

IDE did not correlate to CSF biomarkers in our study. Past research has correlated IDE amyloid deposition and NFT in AD. ${ }^{138}$ IDE codes for zinc metallopeptidase and is involved in the degradation of intracellular insulin and $A \beta{ }^{139}$ It has also been shown to play a role in $A \beta$ clearance. ${ }^{140}$ One of the ways in which deficiencies in the insulin-degrading enzyme, IDE, could contribute to $A D$ pathology is by failing to clear $A \beta .^{141}$ Another is by failing to degrade $A \beta$. This has been observed in cases of 
hyperinsulinaemia, wherein insulin competes with $A \beta$ for IDE. ${ }^{141,142}$ In both instances, $A \beta$ can accumulate and aggregate.

$A C E$ in our study marginally correlated with $A D$ risk but showed no effect on CSF biomarkers. While the association between $A C E$ and $A D$ risk has been confirmed by several studies, ${ }^{143-145}$ results of other studies on the effects of $A C E$ risk variants on biomarkers of $A D$ have been inconclusive. ${ }^{115,146} A C E$ encodes angiotensin I converting enzyme (ACE) 1, and is associated with hypertension and cerebrovascular diseases. ${ }^{144} A C E$ mediates the degradation of the more toxic $A \beta_{1-42}$ isoform to $A \beta_{1-40}{ }^{147}$ The use of $A C E$ inhibitors has been shown to lead to $A \beta$ accumulation and deposition, ${ }^{147,148}$ thereby possibly contributing to AD pathophysiology.

\section{METHODOLOGICAL CONSIDERATIONS}

\section{Study design}

The main objective of the thesis was to examine the influence of genetic risk factors on clinical and biomarker correlates of $A D$. As such, the cross-sectional design we used was sufficient. We were able to test the prognostic value of $A P O E$ for progression to $A D$ through a meta-analysis. Based on the limited follow-up information on clinical outcome for one of the cohorts we studied, we were also able to test the risk associated with developing AD for the top AlzGene loci. For one of the studies, we employed a case-control design, which allowed us to perform genetic association analyses.

In Chapter 6, we used a cohort comprised of SCl and $\mathrm{MCl}$.

Excluding $\mathrm{SCl}$ cases from the analyses yielded similar results. This suggests that at baseline, differences between the two diagnostic groups in terms of the markers studied were not evident. However, as $\mathrm{SCl}$ and $\mathrm{MCI}$ may represent heterogeneous etiologies, a longitudinal design would help determine whether there are differential effects of the $A D$ susceptibility genes. We were not able to examine the effects of the $A D$ risk genes on biomarkers and clinical markers longitudinally because data on these were not available at the time of the study. 


\section{Sample population and setting}

The population in our studies included patients with $\mathrm{MCl}, \mathrm{AD}$-type dementia, non-AD type dementia and cognitively healthy controls. This has the advantage of testing the effects of AD susceptibility genes on the selected markers in different diagnostic groups. Given the multicenter composition of the cohorts used in the thesis, we included study site as a random effect in the statistical analyses.

\section{Sample size}

The sample sizes limited the interpretation of results for some of the studies in the thesis. Our sample size was sufficiently powered for the correlational study with neuropsychiatric symptoms in $\mathrm{MCl}$ in Chapter 4, the correlational study with memory in $\mathrm{MCl}$ in Chapter 6, and the genetic association and biomarker correlation analyses in AD in Chapter 7. The sample size for the correlational analyses with CSF biomarker and imaging marker in $\mathrm{MCl}$ was relatively small, which reduced statistical power and can explain why findings were not significant after multiple test correction. Nevertheless, results were often consistent with those reported in studies using larger samples. This suggests that exploratory studies such as ours could still provide useful information, although replication in larger samples is needed.

\section{Multiple testing}

Multiple testing in genetic studies is inevitable. While this guards to a certain extent against false positive findings, it may have resulted in conservative interpretations of results, given that the genes we tested, with the exception of candidate genes, are established AD risk genes which justify independent hypothesis testing. For this reason, some

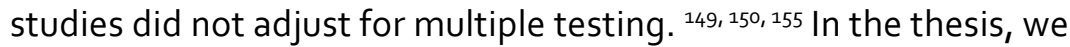
chose to correct for multiple testing but also to discuss results that were significant at an unadjusted $P$-value or showed notable trends.

\section{Gene selection}

A SNP does not necessarily indicate that the gene in which the SNP is found is actually involved in the pathopphysiology of a disease. It could also be nearby genes in linkage disequilibrium that could be involved. 
In the present thesis, we selected SNPs from genes that have been associated with AD as established in GWAS and AlzGene meta-analyses, or based on their effects on $A \beta$ and tau as reported in GWAS or previous candidate gene studies. There is nonetheless a wide range of other genes that have been studied in relation to $A D$ and are of interest for clinical and biomarker studies, but this was outside the scope of the current thesis.

\section{Genetic model}

We used a dominant genetic model in the analyses for two studies because of the very low minor genotype frequencies $(<20 \%$ for $90 \%$ of SNPs in Chapter 6 , and $\leqq 15 \%$ for $\sim 50 \%$ of SNPs in Chapter 7 ) in combination with the relatively small sample size. While it is not unusual to assume a dominant model in this case, ${ }^{151}$ it may have nonetheless masked the effects of some SNPs. As guide in interpreting the results, we have provided continuous data per genotype on CSF biomarkers and hippocampal volume measure, and memory. This enabled qualitative interpretation of the relation between markers and each genotype.

\section{Comparability of measurement instruments}

As we made use of different cohorts, measurement instruments differed. This may have influenced the comparison of results between these cohorts, although this may not be a major issue as discussed below.

\section{Genetic analyses}

For DESCRIPA, FINN-AD and EDAR, genotyping of genomic DNA from venous blood was done on Sequenom i-Plex MassARRAY platform and subjected to similar quality measures, i.e., filters for call rate, minor allele frequency and Hardy-Weinberg equilibrium. We did not use imputed SNP values. The SNPs in our analyses were genotyped, which optimizes accuracy of data used.

ADNI made use of Illumina 610 Quad array. Information on $A P O E$ genotype was procured from their database. In Chapter 4, we pooled APOE data from ADNI and DESCRIPA. As far as we know, there are no conflicting issues between Sequenom and Illumina platforms. 


\section{CSF biomarker analyses}

CSF was obtained through lumbar puncture in all cohorts. $A \beta$ and tau levels in DESCRIPA and FINN-AD were measured using commercially available INNOTEST enzyme-linked immunosorbent assays (ELISAs). For DESCRIPA, measurements were performed in one laboratory. But because CSF was obtained from various sites, we adjusted for the possible effect of study site in our statistical analyses. For FINN-AD, CSF collection and measurements were performed in one laboratory following routine protocol, thus minimizing variations in results.

For EDAR, another platform, Luminex, was used. Measurements were centralized in one laboratory. Measurements obtained via Luminex require statistical transformations to make them comparable to ELISA-based systems.

In the thesis, we pooled CSF data only for study sites in the same cohort and did not combine data from different cohorts.

\section{MRI imaging analyses}

MRI data was available only for one cohort (DESCRIPA). MRI scans were made following the routine protocol of the study centers. This may have introduced variability. In our multilevel statistical model, we were not able to correct for the possible effect of study site because of the small number of participants per site. Hippocampal volume was measured using automated learning embeddings atlas propagation (LEAP) with corrections for intracranial volume. This, in turn, minimized variability in measurement.

\section{Cognitive measures}

We used delayed memory as a clinical marker. Memory performance was assessed according to the neuropsychological protocol at each center. Consequently, the tests used varied. To pool the data, raw scores were transformed into z-scores adjusted for age, gender and education using normative data that were locally collected or were published. ${ }^{152}$ We used z-scores in the analyses. 


\section{Assessment of neuropsychiatric symptoms}

We used the Neuropsychiatric Inventory (NPI), which is a well-validated instrument, to assess neuropsychiatric symptoms in two independent cohorts. DESCRIPA used the full NPI scale that assessed both presence and severity of symptoms, whereas ADNI used the shorter $\mathrm{NPI}$ questionnaire (NPI-Q) that only indicated presence of symptoms. As the NPI-O has been cross-validated with the NPI and has been shown to have good test-retest reliability, ${ }^{153}$ we were able to assess neuropsychiatric symptoms in the pooled cohort using NPI items that only assessed presence of symptoms.

The NPI is an informant-rated instrument. Interpreting the results obtained in this manner must therefore take into consideration that they may reflect the informant's subjective experience.

\section{IMPLICATIONS}

The findings of the current thesis have allowed us to gain better understanding of the influence of genetic risk factors on key markers of $A D$ pathology, and to draw several conclusions.

First, compared to $A P O E$, the other variants we studied conferred much smaller or no effects on $A D$ risk. They currently have limited diagnostic and predictive value. Only $A P O E \varepsilon_{4}$ allele was a significant predictor for progression from $\mathrm{MCl}$ to $A D$-type dementia. $A P O E-\varepsilon 4$, however, has low sensitivity and positive predictive value, which makes genotyping of limited value for predicting AD-type dementia in clinical practice. APOE genotyping may be of value in selecting subjects for trials that aim to prevent progression to dementia, as it helps select subjects with a higher risk for progression to AD-type dementia. In turn, in a population where the prevalence of $A P O E-\varepsilon_{4}$ is high, such as in Chapter 7, APOE genotyping is clinically useful in identifying those who have AD-type dementia. Testing APOE in combination with other $A D$ risk genes may increase predictive accuracy.

Second, $A P O E-\varepsilon_{4}$ mainly affects $A \beta$ and is thus useful in assessing $A D$ risk but not progression, which is associated with tau. The relation between $A P O E-\varepsilon 4$ and the clinical markers cognition and neuropsychiatric symptoms in $\mathrm{MCl}$ may very well reflect underlying $A \beta$ abnormalities. 
Third, we presented evidence that $C L U$ and $M S_{4} A$ correlated with CSF A $\beta_{1-42}$. Both have been established as AD risk genes in GWAS and in the 10 top AlzGene. Replication on a larger scale is needed to assess the clinical utility of our findings.

Fourth, CSF A $\beta_{1-42}$ appears to be a stronger correlate of AD genetic risk factors, compared to the other biomarker and clinical markers we assessed. However, different SNPs exert their influence at different stages of $A D$ pathogenesis. It is thus of clinical relevance to take into consideration the temporal order of pathogenic events and determine appropriate genetic variants to test, if the functions of these variants are known.

Fifth, we included three multicenter studies that had as participants nondemented individuals with cognitive impairment or $\mathrm{MCl}$ in a clinical setting. We were particularly interested in this population because they have an increased risk of progressing to $A D$, although not all of them will develop $A D$ pathology. The effects of $A D$ susceptibility genes on $A D$ risk may differ for other diagnostic groups in a different setting. Moreover, the loci identified in GWAS were associated with clinical AD. These genes may exert effects in $A D$ that are not evident in $\mathrm{MCl}$.

Finally, the clinical utility of genetic risk factors with smaller effects in our study lies in understanding the different mechanisms by which they contribute to $A D$ risk and pathophysiology. In the present thesis, we used the amyloid cascade hypothesis as a model. However, the majority of the variants we tested may have contributed to AD risk via other pathways, notably, immune network, complement system, clathrin-mediated endocytosis, cholesterol and lipid metabolism, as well as tau metabolism. While this does not relegate the role of $A \beta$ in $A D$ pathogenesis, it emphasizes the need to explore other factors and mechanisms that lead to AD.

\section{FUTURE RESEARCH DIRECTIONS}

We assessed the influence of genetic risk factors on key markers of $A D$ pathology in various diagnostic groups. These markers become abnormal at different stages of AD. Our findings may serve as basis for further 
research. Replication on a larger scale is needed in order to test the robustness of our results.

The trends or small effects we found for a number of SNPs strongly indicates the need to pool data and perform studies on a much larger scale. As we mentioned in Chapter 5 , this requires collaborating at national and international levels to allow sharing, pooling, harmonizing raw data, and when feasible, harmonizing techniques for genetic and phenotypic analyses. Databases that are accessible for scientific research are another excellent means of performing studies with a larger sample size.

Our limited follow-up data did not allow us to assess changes in the $A D$ markers in relation to genetic risk factors. A longitudinal design would be more informative, and may possibly yield causal relations. Studies of genetic risk factors known to affect disease progression, such as SNPs involved in tau metabolism, require a longitudinal design. Ideally, such as design includes neuropathologic confirmation. Furthermore, ascertaining genotype may not be sufficient when studying disease progression. Measuring gene expression or protein levels, such as in the case of clusterin, is one way of determining the extent of pathogenesis.

Exploring other markers, such as those pertaining to inflammation or lipid metabolism, in relation to AD susceptibility genes in predementia would further the understanding of $A D$ pathophysiology. Moreover, as genes interact with other genes and with the environment, it is of relevance to perform research as to how this may contribute to $A D$ risk and what intervention strategies could be formulated. 


\section{REFERENCES}

1. Farrer LA, Cupples LA, Haines JL, Hyman B, Kukull WA, Mayeux R, et al. Effects of age, sex, and ethnicity on the association between apolipoprotein $E$ genotype and Alzheimer disease. A meta-analysis. APOE and Alzheimer Disease Meta Analysis Consortium. JAMA 1997; 278(16): 1349-56.

2. Tilvis RS, Kahonen-Vare MH, Jolkkonen J, Valvanne J, Pitkala KH, Strandberg TE. Predictors of cognitive decline and mortality of aged people over a 10-year period. $J$ Gerontol $A$ Biol Sci Med Sci 2004; 59(3): 268-74.

3. Norberg J, Graff C, Almkvist O, Ewers M, Frisoni GB, Frolich L, et al. Regional differences in effects of APOE epsilon 4 on cognitive impairment in non-demented subjects. Dement Geriatr Cogn Disord 2011; 32(2): 135-42.

4. HuX, Pickering EH, Hall SK, Naik S, LiuYC, Soares H, et al. Genome-wide association study identifies multiple novel loci associated with disease progression in subjects with mild cognitive impairment. Transl Psychiatry 2011; 1: e54.

5. Verhaaren BF, Vernooij MW, Koudstaal PJ, Uitterlinden AG, Duijn CM, Hofman A, et al. Alzheimer's Disease Genes and Cognition in the Nondemented General Population. Biol Psychiatry 2012.

6. Frisoni GB, Geroldi C, Bianchetti A, Trabucchi M, Govoni S, Franceschini G, et al. Apolipoprotein $\mathrm{E}$ epsilon 4 allele frequency in vascular dementia and Alzheimer's disease. Stroke 1994; 25(8): 1703-4.

7. Benjamin R, Leake A, Ince PG, Perry RH, McKeith IG, Edwardson JA, et al. Effects of apolipoprotein $E$ genotype on cortical neuropathology in senile dementia of the Lewy body and Alzheimer's disease. Neurodegeneration 1995; 4(4): 443-8.

8. Harrington CR, Louwagie J, Rossau R, Vanmechelen E, Perry RH, Perry EK, et al. Influence of apolipoprotein $\mathrm{E}$ genotype on senile dementia of the Alzheimer and Lewy body types. Significance for etiological theories of Alzheimer's disease. Am J Pathol 1994; 145(6): 147284 .

9. Jun G, Vardarajan BN, Buros J, Yu CE, Hawk MV, Dombroski BA, et al. Comprehensive Search for Alzheimer Disease Susceptibility Loci in the APOE Region. Arch Neurol 2012: 1-10.

10. Hollingworth $P$, Harold D, Sims R, Gerrish A, Lambert JC, Carrasquillo MM, et al. Common variants at $A B C A 7, M S_{4} A 6 A / M S_{4} A_{4} E_{1}, E P H A 1, C D_{33}$ and $C D_{2} A P$ are associated with Alzheimer's disease. Nat Genet 2011; 43(5): 429-35.

11. Lambert JC, Heath S, Even G, Campion D, Sleegers K, Hiltunen M, et al. Genome-wide association study identifies variants at CLU and CR1 associated with Alzheimer's disease. Nat Genet 2009; 41(10): 1094-9. 
12. Lambert JC, Zelenika D, Hiltunen M, Chouraki V, Combarros O, Bullido MJ, et al. Evidence of the association of BIN1 and PICALM with the AD risk in contrasting European populations. Neurobiol Aging 2011; 32(4): 756 e11-5.

13. Bu G. Apolipoprotein E and its receptors in Alzheimer's disease: pathways, pathogenesis and therapy. Nat Rev Neurosci 2009; 10(5): 333-44.

14. Strittmatter WJ, Saunders AM, Schmechel D, Pericak-Vance M, Enghild J, Salvesen GS, et al. Apolipoprotein E: high-avidity binding to beta-amyloid and increased frequency of type 4 allele in late-onset familial Alzheimer disease. Proc Natl Acad SciU S A 1993; 90(5): 197781.

15. Leoni V. The effect of apolipoprotein $E$ (ApoE) genotype on biomarkers of amyloidogenesis, tau pathology and neurodegeneration in Alzheimer's disease. Clin Chem Lab Med 2011; 49(3): 375-83.

16. Maritzen T, Koo SJ, Haucke V. Turning CALM into excitement: AP180 and CALM in endocytosis and disease. Biol Cell 2012.

17. Miller SE, Sahlender DA, Graham SC, Honing S, Robinson MS, Peden AA, et al. The molecular basis for the endocytosis of small R-SNAREs by the clathrin adaptor CALM. Cell 2011; 147(5): 1118-31.

18. Schellenberg GD, Montine TJ. The genetics and neuropathology of Alzheimer's disease. Acta Neuropathol 2012.

19. Naj AC, Jun G, Beecham GW, Wang LS, Vardarajan BN, Buros J, et al. Common variants at $\mathrm{MS}_{4} \mathrm{~A}_{4} / \mathrm{MS}_{4} \mathrm{~A} 6 \mathrm{E}, \mathrm{CD}_{2} \mathrm{AP}, \mathrm{CD}_{33}$ and EPHA1 are associated with late-onset Alzheimer's disease. Nat Genet 2011; 43(5): 436-41.

20. Antunez C, Boada M, Gonzalez-Perez A, Gayan J, Ramirez-Lorca R, Marin J, et al. The membrane-spanning 4-domains, subfamily $\mathrm{A}\left(\mathrm{MS}_{4} \mathrm{~A}\right)$ gene cluster contains a common variant associated with Alzheimer's disease. Genome Med 2011; 3(5): 33.

21. Logue MW, Schu M, Vardarajan BN, Buros J, Green RC, Go RC, et al. A comprehensive genetic association study of Alzheimer disease in African Americans. Arch Neurol 2011; 68(12): 1569-79.

22. Liang Y, Buckley TR, Tu L, Langdon SD, Tedder TF. Structural organization of the human MS4A gene cluster on Chromosome 11q12. Immunogenetics 2001; 53(5): 357-68.

23. Zuccolo J, Bau J, Childs SJ, Goss GG, Sensen CW, Deans JP. Phylogenetic analysis of the MS4A and TMEM176 gene families. PLoS One 2010; 5(2): e9369.

24. Kim SH, Bae JS, Holloway JW, Lee JT, Suh $\mathrm{CH}_{1}, \mathrm{Nahm} \mathrm{DH}$, et al. A polymorphism of MS4A2 $(-109 \mathrm{~T}>\mathrm{C})$ encoding the beta-chain of the high-affinity immunoglobulin $\mathrm{E}$ receptor (FcepsilonRıbeta) is associated with a susceptibility to aspirin-intolerant asthma. Clin Exp Allergy 2006; 36(7): 877-83. 
25. Carter C. Alzheimer's Disease: APP, Gamma Secretase, APOE, CLU, CR1, PICALM, ABCA7, $B I N_{1}, C D_{2} A P, C D_{33}, E P H A_{1}$, and MS4A2, and Their Relationships with Herpes Simplex, C. Pneumoniae, Other Suspect Pathogens, and the Immune System. Int J Alzheimers Dis 2011; 2011: 501862.

26. Karch CM, Jeng AT, Goate AM. Calcium phosphatase calcineurin influences tau metabolism. Neurobiol Aging 2012.

27. Reese LC, Taglialatela G. A role for calcineurin in Alzheimer's disease. Curr Neuropharmacol 2011; 9(4): 685-92.

28. Heutink P. Untangling tau-related dementia. Hum Mol Genet 2000; 9(6): 979-86.

29. Cruchaga C, Kauwe JS, Mayo K, Spiegel N, Bertelsen S, Nowotny P, et al. SNPs associated with cerebrospinal fluid phospho-tau levels influence rate of decline in Alzheimer's disease. PLoS Genet 2010; 6(9).

30. Bekris LM, Millard S, Lutz F, Li G, Galasko DR, Farlow MR, et al. Tau phosphorylation pathway genes and cerebrospinal fluid tau levels in Alzheimer's disease. Am J Med Genet $B$ Neuropsychiatr Genet 2012; 159B(7): 874-83.

31. Thambisetty M, Simmons A, Velayudhan L, Hye A, Campbell J, Zhang Y, et al. Association of plasma clusterin concentration with severity, pathology, and progression in Alzheimer disease. Arch Gen Psychiatry 2010; 67(7): 739-48.

32. Erk S, Meyer-Lindenberg A, Opitz von Boberfeld C, Esslinger C, Schnell K, Kirsch P, et al. Hippocampal function in healthy carriers of the CLU Alzheimer's disease risk variant. J Neurosci 2011; 31(49): 18180-4.

33. Goni J, Cervantes S, Arrondo G, Lamet I, Pastor P, Pastor MA. Selective Brain Gray Matter Atrophy Associated with APOE epsilon 4 and MAPT $\mathrm{H}_{1}$ in Subjects with Mild Cognitive Impairment. J Alzheimers Dis 2012.

34. O'Dwyer L, Lamberton F, Matura S, Tanner C, Scheibe M, Miller J, et al. Reduced Hippocampal Volume in Healthy Young ApoE4 Carriers: An MRI Study. PLoS One 2012; 7(11): e48895.

35. Bennett DA, Wilson RS, Schneider JA, Evans DA, Aggarwal NT, Arnold SE, et al. Apolipoprotein $E$ epsilon 4 allele, $A D$ pathology, and the clinical expression of Alzheimer's disease. Neurology 2003; 60(2): 246-52.

36. Bennett DA, Schneider JA, Wilson RS, Bienias JL, Arnold SE. Neurofibrillary tangles mediate the association of amyloid load with clinical Alzheimer disease and level of cognitive function. Arch Neurol 2004; 61(3): 378-84.

37. Sleegers K, Lambert JC, Bertram L, Cruts M, Amouyel P, Van Broeckhoven C. The pursuit of susceptibility genes for Alzheimer's disease: progress and prospects. Trends Genet 2010; 26(2): 84-93. 
38. Bennett DA, Schneider JA, Wilson RS, Bienias JL, Berry-Kravis E, Arnold SE. Amyloid mediates the association of apolipoprotein $E \varepsilon_{4}$ allele to cognitive function in older people. $J$ Neurol Neurosurg Psychiatry 2005; 76(9): 1194-9.

39. Caputo M, Monastero R, Mariani E, Santucci A, Mangialasche F, Camarda R, et al. Neuropsychiatric symptoms in 921 elderly subjects with dementia: a comparison between vascular and neurodegenerative types. Acta Psychiatr Scand 2008; 117(6): 455-64.

40. Ramakers IH, Verhey FR, Scheltens $P$, Hampel $H$, Soininen $H$, Aalten $P$, et al. Anxiety is related to Alzheimer cerebrospinal fluid markers in subjects with mild cognitive impairment. Psychol Med 2012: 1-10.

41. Lyketsos CG, Baker L, Warren A, Steele C, Brandt J, Steinberg M, et al. Depression, delusions, and hallucinations in Alzheimer's disease: no relationship to apolipoprotein $\mathrm{E}$ genotype. J Neuropsychiatry Clin Neurosci 1997; 9(1): 64-7.

42. Ballard C, Massey $\mathrm{H}$, Lamb H, Morris C. Apolipoprotein E: non-cognitive symptoms and cognitive decline in late onset Alzheimer's disease. J Neurol Neurosurg Psychiatry 1997; 63(2): $273-4$.

43. Jack CR, Jr. Alzheimer disease: new concepts on its neurobiology and the clinical role imaging will play. Radiology 2012; 263(2): 344-61.

44. Desikan RS, McEvoy LK, Holland D, Thompson WK, Brewer JB, Aisen PS, et al. Apolipoprotein $\mathrm{E}$ \{varepsilon\}4 Does Not Modulate Amyloid-beta-Associated Neurodegeneration in Preclinical Alzheimer Disease. AJNR Am J Neuroradiol 2012.

45. Kantarci K, Lowe V, Przybelski SA, Weigand SD, Senjem ML, Ivnik RJ, et al. APOE modifies the association between Abeta load and cognition in cognitively normal older adults. Neurology 2012; 78(4): 232-40.

46. Strittmatter WJ, Weisgraber KH, Huang DY, Dong LM, Salvesen GS, Pericak-Vance M, et al. Binding of human apolipoprotein $E$ to synthetic amyloid beta peptide: isoform-specific effects and implications for late-onset Alzheimer disease. Proc Natl Acad Sci U S A 1993; 9o(17): 8098-102.

47. Holtzman DM, Herz J, Bu G. Apolipoprotein e and apolipoprotein e receptors: normal biology and roles in Alzheimer disease. Cold Spring Harb Perspect Med 2012; 2(3): a006312.

48. Hashimoto T, Serrano-Pozo A, HoriY, Adams KW, Takeda S, Banerji AO, et al. Apolipo-

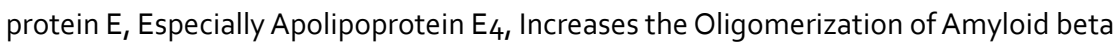
Peptide. J Neurosci 2012; 32(43): 15181-92.

49. Cerf E, Gustot A, Goormaghtigh E, Ruysschaert JM, Raussens V. High ability of apolipoprotein $\mathrm{E}_{4}$ to stabilize amyloid-beta peptide oligomers, the pathological entities responsible for Alzheimer's disease. FASEB J 2011; 25(5): 1585-95. 
50. Nimmrich V, Ebert U. Is Alzheimer's disease a result of presynaptic failure? Synaptic dysfunctions induced by oligomeric beta-amyloid. Rev Neurosci 2009; 20(1): 1-12.

51. Kayed R, Head E, Thompson JL, McIntire TM, Milton SC, Cotman CW, et al. Common structure of soluble amyloid oligomers implies common mechanism of pathogenesis. Science 2003; 300(5618): 486-9.

52. Kauwe JS, Cruchaga C, Karch CM, Sadler B, Lee M, Mayo K, et al. Fine mapping of genetic variants in $\mathrm{BIN}_{1}, \mathrm{CLU}, \mathrm{CR} 1$ and PICALM for association with cerebrospinal fluid biomarkers for Alzheimer's disease. PLoS One 2011; 6(2): e15918.

53. Schott JM. Using CSF biomarkers to replicate genetic associations in Alzheimer's disease. Neurobiol Aging 2012; 33(7): 1486 e9-15.

54. Schjeide BM, Schnack C, Lambert JC, Lill CM, Kirchheiner J, Tumani H, et al. The role of clusterin, complement receptor 1 , and phosphatidylinositol binding clathrin assembly protein in Alzheimer disease risk and cerebrospinal fluid biomarker levels. Arch Gen Psychiatry 2011; 68(2): 207-13.

55. Kok EH, Luoto T, Haikonen S, Goebeler S, Haapasalo H, Karhunen PJ. CLU, CR1 and PICALM genes associate with Alzheimer's-related senile plaques. Alzheimers Res Ther 2011; 3(2): 12.

56. Chibnik LB, Shulman JM, Leurgans SE, Schneider JA, Wilson RS, Tran D, et al. CR1 is associated with amyloid plaque burden and age-related cognitive decline. Ann Neurol 2011; 69(3): 560-9.

57. Guerreiro RJ, Beck J, Gibbs JR, Santana I, Rossor MN, Schott JM, et al. Genetic variability in CLU and its association with Alzheimer's disease. PLoS One 2010; 5(3): e9510.

58. Nuutinen T, Suuronen T, Kauppinen A, Salminen A. Clusterin: a forgotten player in Alzheimer's disease. Brain Res Rev 2009; 61(2): 89-104.

59. Hardy J, Guerreiro R, Lovestone S. Clusterin as an Alzheimer biomarker. Arch Neurol 2011; 68(11): 1459-60.

6o. Narayan P, Meehan S, Carver JA, Wilson MR, Dobson CM, Klenerman D. Amyloid-beta Oligomers are Sequestered by both Intracellular and Extracellular Chaperones. Biochemistry 2012; 51(46): 9270-6.

61. Bhamra MS, Ashton NJ. Finding a pathological diagnosis for Alzheimer's disease: Are inflammatory molecules the answer? Electrophoresis 2012.

62. Calero M, Rostagno A, Matsubara E, Zlokovic B, Frangione B, Ghiso J. Apolipoprotein J (clusterin) and Alzheimer's disease. Microsc ResTech 2000; 50(4): 305-15.

63. Yerbury JJ, Poon S, Meehan S, Thompson B, Kumita JR, Dobson CM, et al. The extracellular chaperone clusterin influences amyloid formation and toxicity by interacting with prefibrillar structures. FASEB J 2007; 21(10): 2312-22. 
64. Nilselid AM, Davidsson P, Nagga K, Andreasen N, Fredman P, Blennow K. Clusterin in cerebrospinal fluid: analysis of carbohydrates and quantification of native and glycosylated forms. Neurochem Int 2006; 48(8): 718-28.

65. Lidstrom AM, Bogdanovic N, Hesse C, Volkman I, Davidsson P, Blennow K. Clusterin (apolipoprotein J) protein levels are increased in hippocampus and in frontal cortex in Alzheimer's disease. Exp Neurol 1998; 154(2): 511-21.

66. Nuutinen T, Huuskonen J, Suuronen T, Ojala J, Miettinen R, Salminen A. Amyloid-beta 1-42 induced endocytosis and clusterin/apoJ protein accumulation in cultured human astrocytes. Neurochem Int 2007; 50(3): 540-7.

67. Thambisetty M, An Y, Kinsey A, Koka D, Saleem M, Guntert A, et al. Plasma clusterin concentration is associated with longitudinal brain atrophy in mild cognitive impairment. Neuroimage 2012; 59(1): 212-7.

68. Harel A, Wu F, Mattson MP, Morris CM, Yao PJ. Evidence for CALM in directing VAMP2 trafficking. Traffic 2008; 9(3): 417-29.

69. Olgiati P, Politis AM, Papadimitriou GN, De Ronchi D, Serretti A. Genetics of late-onset Alzheimer's disease: update from the alzgene database and analysis of shared pathways. Int J Alzheimers Dis 2011; 2011: 832379.

70. Morgan K. The three new pathways leading to Alzheimer's disease. Neuropathol Appl Neurobiol 2011; 37(4): 353-7.

71. Sheng M, Sabatini BL, Sudhof TC. Synapses and Alzheimer's disease. Cold Spring Harb Perspect Biol 2012; 4(5).

72. Monzo P, Gauthier NC, Keslair F, Loubat A, Field CM, Le Marchand-BrustelY, et al. Clues to CD2-associated protein involvement in cytokinesis. Mol Biol Cell 2005; 16(6): 2891-902.

73. Brouwers N, Cauwenberghe CV, Engelborghs S, Lambert JC, Bettens K, Bastard NL, et al. Alzheimer risk associated with a copy number variation in the complement receptor 1 increasing $\mathrm{C}_{3} \mathrm{~b} / \mathrm{C}_{4} \mathrm{~b}$ binding sites. Mol Psychiatry 2012; 17(2): 223-33.

74. Aiyaz M, Lupton MK, Proitsi P, Powell JF, Lovestone S. Complement activation as a biomarker for Alzheimer's disease. Immunobiology 2012; 217(2): 204-15.

75. Eikelenboom P, van Exel E, Veerhuis R, Rozemuller AJ, van Gool WA, Hoozemans JJ. Innate immunity and the etiology of late-onset Alzheimer's disease. Neurodegener Dis 2012; 10(14): 271-3.

76. Rogers J, Li R, Mastroeni D, Grover A, Leonard B, Ahern G, et al. Peripheral clearance of amyloid beta peptide by complement $\mathrm{C}_{3}$-dependent adherence to erythrocytes. Neurobiol Aging 2006; 27(12): 1733-9.

77. Crehan $\mathrm{H}$, Hardy J, Pocock J. Microglia, Alzheimer's disease, and complement. Int J Alzheimers Dis 2012; 2012: 983640 . 
78. Chan SL, Kim WS, Kwok JB, Hill AF, Cappai R, Rye KA, et al. ATP-binding cassette transporter $\mathrm{A} 7$ regulates processing of amyloid precursor protein in vitro. J Neurochem 2008; 106(2): 793-804.

79. Guerreiro RJ, Hardy J. Alzheimer's disease genetics: lessons to improve disease modelling. Biochem Soc Trans 2011; 39(4): 910-6.

8o. Wang N, Lan D, Gerbod-Giannone M, Linsel-Nitschke P, Jehle AW, Chen W, et al. ATPbinding cassette transporter $A_{7}(A B C A 7)$ binds apolipoprotein $A-I$ and mediates cellular phospholipid but not cholesterol efflux. J Biol Chem 2003; 278(44): 42906-12.

81. Schellenberg GD, Montine TJ. The genetics and neuropathology of Alzheimer's disease. Acta Neuropathol 2012; 124(3): 305-23.

82. Harold D, Abraham R, Hollingworth P, Sims R, Gerrish A, Hamshere ML, et al. Genomewide association study identifies variants at CLU and PICALM associated with Alzheimer's disease. Nat Genet 2009; 41(10): 1088-93.

83. HuX, Pickering E, LiuYC, Hall S, Fournier H, Katz E, et al. Meta-analysis for genome-wide association study identifies multiple variants at the BIN 1 locus associated with late-onset Alzheimer's disease. PLoS One 2011; 6(2): e16616.

84. Seshadri S, Fitzpatrick AL, Ikram MA, DeStefano AL, Gudnason V, Boada M, et al. Genome-wide analysis of genetic loci associated with Alzheimer disease. JAMA 2010; 303(18): 1832-40.

85. Hamilton G, Harris SE, Davies G, Liewald DC, Tenesa A, Starr JM, et al. Alzheimer's disease genes are associated with measures of cognitive ageing in the lothian birth cohorts of 1921 and 1936. Int J Alzheimers Dis 2011; 2011: 505984.

86. Wu F, Yao PJ. Clathrin-mediated endocytosis and Alzheimer's disease: an update. Ageing Res Rev 2009; 8(3): 147-9.

87. Carrasquillo MM, Belbin O, HunterTA, Ma L, Bisceglio GD, Zou F, et al. Replication of BIN1 association with Alzheimer's disease and evaluation of genetic interactions. J Alzheimers Dis 2011; 24(4): 751-8.

88. Barkefors I, Fuchs PF, Heldin J, Bergstrom T, Forsberg-Nilsson K, Kreuger J. Exocyst complex component 3 -like 2 ( $\mathrm{EXOC}_{3} \mathrm{~L} 2$ ) associates with the exocyst complex and mediates directional migration of endothelial cells. J Biol Chem 2011; 286(27): 24189-99.

89. Vega IE, Hsu SC. The exocyst complex associates with microtubules to mediate vesicle targeting and neurite outgrowth. J Neurosci 2001; 21(11): 3839-48.

90. Schmidt C, Wolff M, von Ahsen N, Zerr I. Alzheimer's disease: genetic polymorphisms and rate of decline. Dement Geriatr Cogn Disord 2012; 33(2-3): 84-9. 
91. Naj AC, Beecham GW, Martin ER, Gallins PJ, Powell EH, Konidari I, et al. Dementia revealed: novel chromosome 6 locus for late-onset Alzheimer disease provides genetic evidence for folate-pathway abnormalities. PLoS Genet 2010; 6(9).

92. Ramirez-Lorca R, Boada M, Antunez C, Lopez-Arrieta J, Moreno-Rey C, Hernandez I, et al. The MTHFD1L gene rs11754661 marker is not associated with Alzheimer's disease in a sample of the Spanish population. J Alzheimers Dis 2011; 25(1): 47-50.

93. Seshadri S, Beiser A, Selhub J, Jacques PF, Rosenberg IH, D'Agostino RB, et al. Plasma homocysteine as a risk factor for dementia and Alzheimer's disease. N Engl J Med 2002; 346(7): 476-83.

94. Van Dam F, Van Gool WA. Hyperhomocysteinemia and Alzheimer's disease: A systematic review. Arch Gerontol Geriatr 2009; 48(3): 425-30.

95. Hooshmand B, Solomon A, Kareholt I, Leiviska J, Rusanen M, Ahtiluoto S, et al. Homocysteine and holotranscobalamin and the risk of Alzheimer disease: a longitudinal study. Neurology 2010; 75(16): 1408-14.

96. Wald DS, Law M, Morris JK. Homocysteine and cardiovascular disease: evidence on causality from a meta-analysis. BMJ 2002; 325(7374): 1202.

97. Refsum H, Ueland PM, Nygard O, Vollset SE. Homocysteine and cardiovascular disease. Annu Rev Med 1998; 49: 31-62.

98. Kim S, Swaminathan S, Shen L, Risacher SL, Nho K, Foroud T, et al. Genome-wide association study of CSF biomarkers Abeta1-42, t-tau, and p-tau181p in the ADNI cohort. Neurology 2011; 76(1): 69-79.

99. Kramer PL, Xu H, Woltjer RL, Westaway SK, Clark D, Erten-Lyons D, et al. Alzheimer disease pathology in cognitively healthy elderly: a genome-wide study. Neurobiol Aging 2011; 32(12): 2113-22.

100. Bar I, Lambert de Rouvroit C, Goffinet AM. The evolution of cortical development. An hypothesis based on the role of the Reelin signaling pathway. Trends Neurosci 2000; 23(12): $633-8$.

101. Durakoglugil MS, Chen Y, White CL, Kavalali ET, Herz J. Reelin signaling antagonizes betaamyloid at the synapse. Proc Natl Acad SciU S A 2009; 106(37): 15938-43.

102. Han MR, Schellenberg GD, Wang LS. Genome-wide association reveals genetic effects on human Abeta 42 and tau protein levels in cerebrospinal fluids: a case control study. BMC Neurol 2010; 10: 90.

103. Ferencz B, Karlsson S, Kalpouzos G. Promising Genetic Biomarkers of Preclinical Alzheimer's Disease: The Influence of APOE and TOMM 40 on Brain Integrity. Int J Alzheimers Dis 2012; 2012: 421452. 
104. Mancuso M, Calsolaro V, Orsucci D, Carlesi C, Choub A, Piazza S, et al. Mitochondria, cognitive impairment, and Alzheimer's disease. Int J Alzheimers Dis 2009; 6.

105. Devi L, Prabhu BM, Galati DF, Avadhani NG, Anandatheerthavarada HK. Accumulation of amyloid precursor protein in the mitochondrial import channels of human Alzheimer's disease brain is associated with mitochondrial dysfunction. J Neurosci 2006; 26(35): 9057-68.

106. Corbo RM, Gambina G, Ulizzi L, Moretto G, Scacchi R. Genetic variation of CYP19 (aromatase) gene influences age at onset of Alzheimer's disease in women. Dement Geriatr Cogn Disord 2009; 27(6): 513-8.

107. Garcia-Segura LM, Veiga S, Sierra A, Melcangi RC, Azcoitia I. Aromatase: a neuroprotective enzyme. Prog Neurobiol 2003; 71(1): 31-41.

108. Azcoitia I, Sierra A, Veiga S, Honda S, Harada N, Garcia-Segura LM. Brain aromatase is neuroprotective. J Neurobiol 2001; 47(4): 318-29.

109. Iivonen S, Corder E, Lehtovirta M, Helisalmi S, Mannermaa A, Vepsalainen S, et al. Polymorphisms in the CYP19 gene confer increased risk for Alzheimer disease. Neurology 2004; 62(7): 1170-6.

110. Yue $X$, Lu M, Lancaster T, Cao P, Honda S, Staufenbiel M, et al. Brain estrogen deficiency accelerates Abeta plaque formation in an Alzheimer's disease animal model. Proc Natl Acad SciU SA 2005; 102(52): 19198-203.

111. Carroll JC, Rosario ER. The potential use of hormone-based therapeutics for the treatment of Alzheimer's disease. Curr Alzheimer Res 2012; 9(1): 18-34.

112. Maki PM, Henderson VW. Hormone therapy, dementia, and cognition: the Women's Health Initiative 10 years on. Climacteric 2012; 15(3): 256-62.

113. Shao H, Breitner JC, Whitmer RA, Wang J, Hayden K, Wengreen $\mathrm{H}$, et al. Hormone therapy and Alzheimer disease dementia: New findings from the Cache County Study. Neurology 2012; 79(18): 1846-52.

114. Huang R, Poduslo SE. CYP19 haplotypes increase risk for Alzheimer's disease. J Med Genet 2006; 43(8): e42.

115. Kauwe JS, Wang J, Mayo K, Morris JC, Fagan AM, Holtzman DM, et al. Alzheimer's disease risk variants show association with cerebrospinal fluid amyloid beta. Neurogenetics 2009; 10(1): 13-7.

116. Wider C, Ross OA, Nishioka K, Heckman MG, Vilarino-Guell C, Jasinska-Myga B, et al. An evaluation of the impact of MAPT, SNCA and APOE on the burden of Alzheimer's and Lewy body pathology. J Neurol Neurosurg Psychiatry 2012; 83(4): 424-9.

117. Di Maria E, Cammarata S, Parodi MI, Borghi R, Benussi L, Galli M, et al. The H1 haplotype of the tau gene (MAPT) is associated with mild cognitive impairment. $J$ Alzheimers Dis 2010; 19(3): 909-14. 
118. Alonso A, Zaidi T, Novak M, Grundke-lqbal I, Iqbal K. Hyperphosphorylation induces selfassembly of tau into tangles of paired helical filaments/straight filaments. Proc Natl Acad SciUS A 2001; 98(12): 6923-8.

119. Elias-Sonnenschein LS, Bertram L, Visser PJ. Relationship between genetic risk factors and markers for Alzheimer's disease pathology. Biomark Med 2012; 6(4): 477-95.

120. Cuenco KT, Lunetta KL, Baldwin CT, McKee AC, Guo J, Cupples LA, et al. Association of distinct variants in SORL1 with cerebrovascular and neurodegenerative changes related to Alzheimer disease. Arch Neurol 2008; 65(12): 1640-8.

121. Olgiati P, Politis A, Albani D, Rodilossi S, Polito L, Ateri E, et al. Association of SORL1 alleles with late-onset Alzheimer's disease. findings from the GIGAS_LOAD study and mega-analysis. Curr Alzheimer Res 2012; 9(4): 491-9.

122. Rogaeva E, Meng Y, Lee JH, GuY, Kawarai T, Zou F, et al. The neuronal sortilin-related receptor SORL1 is genetically associated with Alzheimer disease. Nat Genet 2007; 39(2): 168-77.

123. Reitz C, Cheng R, Rogaeva E, Lee JH, Tokuhiro S, Zou F, et al. Meta-analysis of the association between variants in SORL1 and Alzheimer disease. Arch Neurol 2011; 68(1): 99-106.

124. Pottier C, Hannequin D, Coutant S, Rovelet-Lecrux A, Wallon D, Rousseau S, et al. High frequency of potentially pathogenic SORL1 mutations in autosomal dominant early-onset Alzheimer disease. Mol Psychiatry 2012.

125. Cuenco K, Lunetta KL, Baldwin CT, McKee AC, Guo J, Cupples LA, et al. Association of distinct variants in SORL1 with cerebrovascular and neurodegenerative changes related to Alzheimer disease. Arch Neurol 2008; 65(12): 1640-8.

126. Kauwe JS, Bertelsen S, Mayo K, Cruchaga C, Abraham R, Hollingworth P, et al. Suggestive synergy between genetic variants in TF and HFE as risk factors for Alzheimer's disease. Am $J$ Med Genet B Neuropsychiatr Genet 2010; 153B(4): 955-9.

127. Huebers HA, Finch CA. The physiology of transferrin and transferrin receptors. Physiol Rev $1987 ; 67(2): 520-82$.

128. Casadesus G, Smith MA, Zhu X, Aliev G, Cash AD, Honda K, et al. Alzheimer disease: evidence for a central pathogenic role of iron-mediated reactive oxygen species. J Alzheimers Dis 2004; 6(2): 165-9.

129. Lehmann DJ, Schuur M, Warden DR, Hammond N, Belbin O, Kolsch $H$, et al. Transferrin and HFE genes interact in Alzheimer's disease risk: the Epistasis Project. Neurobiol Aging 2012; 33(1): 202 e1-13.

130. Bramham CR, Messaoudi E. BDNF function in adult synaptic plasticity: the synaptic consolidation hypothesis. Prog Neurobiol 2005; 76(2): 99-125. 
131. Boiocchi C, Maggioli E, Zorzetto M, Sinforiani E, Cereda C, Ricevuti G, et al. Brain-derived neurotrophic factor gene (BDNF) variants and Alzheimer's disease: an association study in an AD Italian population. Rejuvenation Res 2012.

132. Lee J, Fukumoto H, Orne J, Klucken J, Raju S, Vanderburg CR, et al. Decreased levels of BDNF protein in Alzheimer temporal cortex are independent of BDNF polymorphisms. Exp Neurol 2005; 194(1): 91-6.

133. Hock C, Heese K, Hulette C, Rosenberg C, Otten U. Region-specific neurotrophin imbalances in Alzheimer disease: decreased levels of brain-derived neurotrophic factor and increased levels of nerve growth factor in hippocampus and cortical areas. Arch Neurol 2000; 57(6): 846-51.

134. Papassotiropoulos A, Streffer JR, Tsolaki M, Schmid S, Thal D, Nicosia F, et al. Increased brain beta-amyloid load, phosphorylated tau, and risk of Alzheimer disease associated with an intronic CYP46 polymorphism. Arch Neurol 2003; 60(1): 29-35.

135. Johansson A, Katzov H, Zetterberg H, Feuk L, Johansson B, Bogdanovic N, et al. Variants of CYP $46 A_{1}$ may interact with age and APOE to influence CSF Abeta 42 levels in Alzheimer's disease. Hum Genet 2004; 114(6): 581-7.

136. Wolozin B. Cyp46 (24S-cholesterol hydroxylase): a genetic risk factor for Alzheimer disease. Arch Neurol 2003; 60(1): 16-8.

137. Helisalmi S, Vepsalainen S, Koivisto AM, Mannermaa A, livonen S, Hiltunen M, et al. Association of CYP 46 intron 2 polymorphism in Finnish Alzheimer's disease samples and a global scale summary. J Neurol Neurosurg Psychiatry 2006; 77(3): 421-2.

138. Blomqvist ME, Chalmers K, Andreasen N, Bogdanovic N, Wilcock GK, Cairns NJ, et al. Sequence variants of IDE are associated with the extent of beta-amyloid deposition in the Alzheimer's disease brain. Neurobiol Aging 2005; 26(6): 795-802.

139. Im H, Manolopoulou M, Malito E, Shen Y, Zhao J, Neant-Fery M, et al. Structure of substrate-free human insulin-degrading enzyme (IDE) and biophysical analysis of ATPinduced conformational switch of IDE. J Biol Chem 2007; 282(35): 25453-63.

140. Vekrellis K, Ye Z, Qiu WQ, Walsh D, Hartley D, Chesneau V, et al. Neurons regulate extracellular levels of amyloid beta-protein via proteolysis by insulin-degrading enzyme. $J$ Neurosci 2000; 20(5): 1657-65.

141. Qiu WQ, Folstein MF. Insulin, insulin-degrading enzyme and amyloid-beta peptide in Alzheimer's disease: review and hypothesis. Neurobiol Aging 2006; 27(2): 190-8.

142. Schuh AF, Rieder CM, Rizzi L, Chaves M, Roriz-Cruz M. Mechanisms of brain aging regulation by insulin: implications for neurodegeneration in late-onset Alzheimer's disease. ISRN Neurol 2011; 2011: 306905. 
143. Belbin O, Brown K, Shi H, Medway C, Abraham R, Passmore P, et al. A multi-center study of ACE and the risk of late-onset Alzheimer's disease. J Alzheimers Dis 2011; 24(3): 587-97.

144. Ning M, Yang Y, Zhang Z, Chen Z, Zhao T, Zhang D, et al. Amyloid-beta-Related Genes SORL1 and ACE are Genetically Associated With Risk for Late-onset Alzheimer Disease in the Chinese Population. Alzheimer Dis Assoc Disord 2010.

145. Kehoe PG, Katzov H, Andreasen N, Gatz M, Wilcock GK, Cairns NJ, et al. Common variants of ACE contribute to variable age-at-onset of Alzheimer's disease. Hum Genet 2004; 114(5): 478-83.

146. Sarajarvi T, Helisalmi S, Antikainen L, Makinen P, Koivisto AM, Herukka SK, et al. An association study of 21 potential Alzheimer's disease risk genes in a Finnish population. $J$ Alzheimers Dis 2010; 21(3): 763-7.

147. Zou K, Yamaguchi H, Akatsu H, Sakamoto T, Ko M, Mizoguchi K, et al. Angiotensin-converting enzyme converts amyloid beta-protein 1-42 (Abeta(1-42)) to Abeta(1-40), and its inhibition enhances brain Abeta deposition. J Neurosci 2007; 27(32): 8628-35.

148. Hemming ML, Selkoe DJ. Amyloid beta-protein is degraded by cellular angiotensinconverting enzyme (ACE) and elevated by an ACE inhibitor. J Biol Chem 2005; 280(45): 37644-50.

149. Rodriguez-Rodriguez E, Sanchez-Juan P, Vazquez-Higuera JL, Mateo I, Pozueta A, Berciano J, et al. Genetic risk score predicting accelerated progression from mild cognitive impairment to Alzheimer's disease. J Neural Transm 2012.

150. Feulner TM, Laws SM, Friedrich P, Wagenpfeil S, Wurst SH, Riehle C, et al. Examination of the current top candidate genes for $A D$ in a genome-wide association study. Mol Psychiatry 2010; 15(7): 756-66.

151. Salanti G, Southam L, Altshuler D, Ardlie K, Barroso I, Boehnke M, et al. Underlying genetic models of inheritance in established type 2 diabetes associations. Am J Epidemiol 2009; 170(5): 537-45.

152. Visser PJ, Verhey FRJ, Boada M, Bullock R, De Deyn PP, Frisoni GB, et al. Development of Screening Guidelines and Clinical Criteria for Predementia Alzheimer's Disease: The DESCRIPA Study. Neuroepidemiology 2008; 30(4): 254-65.

153. Kaufer DI, Cummings JL, Ketchel P, Smith V, MacMillan A, Shelley T, et al. Validation of the NPI-Q, a brief clinical form of the Neuropsychiatric Inventory. J Neuropsychiatry Clin Neurosci 2000; 12(2): 233-9. 



\section{SUMMARY SAMENVATTING}

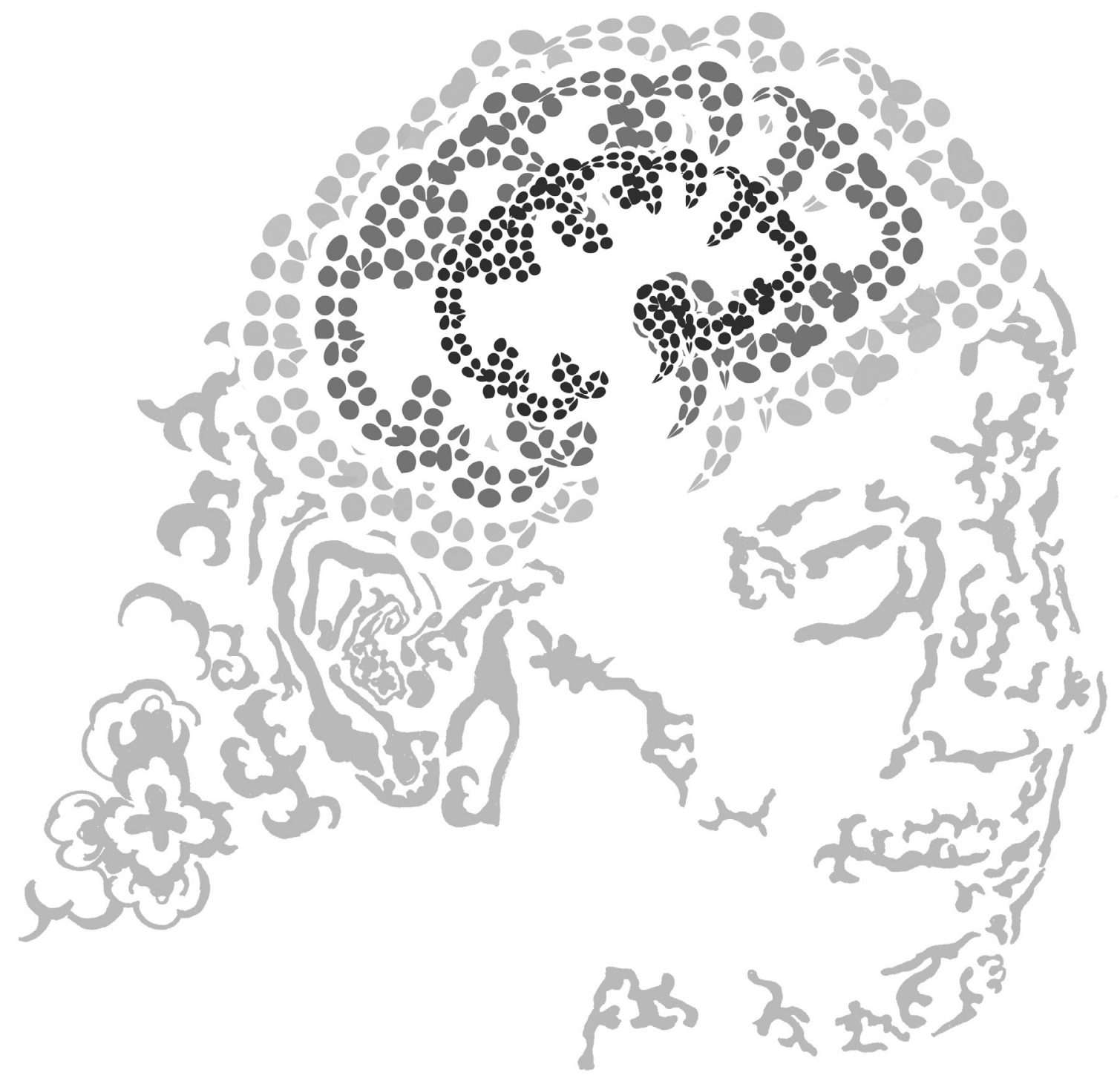




\section{Summary}

Alzheimer's disease (AD) is the most common cause of dementia. It is characterized by progressive neuronal death, memory loss, behavioral and affective changes, and impairments in activities of daily living. It culminates in dementia.

There is currently no cure for AD-type dementia. Available treatments are aimed at slowing the progression of the disease and address its associated symptoms. Often, treatment is sought when the disease is already at an advanced phase because only then do clinical symptoms become evident. Early diagnosis of AD is important, as drugs with disease-delaying potentials are most effective at the predementia stage.

Early detection of $A D$ entails understanding the complex relationship between risk factors and AD pathophysiology. Recent technological advances have shown the increasing role of genetics in $A D$ susceptibility. In this dissertation, we investigated the influence of genetic risk factors on the pathophysiology and clinical manifestation of Alzheimer's disease (AD). While several AD risk genes have been identified, their effects on AD pathophysiology remain unclear. We examined this by testing the correlations between genetic risk factors for $A D$, in particular, single nucleotide polymorphisms (SNPs), and key measures of AD pathology, including cerebrospinal fluid (CSF) markers $A \beta$ and tau, hippocampal atrophy, memory performance and neuropsychiatric symptoms. As the relation between genetic risk factors and $A D$ may differ depending on the stage of the disease, we used cohorts with different severities of cognitive impairment. The specific objectives, methods used and general information on the cohorts are described in Chapter 1.

In Chapter 2, using meta-analysis, we assessed the usefulness of $A P O E$ genotyping in predicting progression to AD-type dementia among patients with mild cognitive impairment $(\mathrm{MCl})$ and in selecting subjects for clinical trials aimed at preventing progression to dementia. We found that the $A P O E \& 4$ allele carriers have more than twice the 
risk of developing $A D$ compared to noncarriers. The low sensitivity and positive predictive value indicate that $A P O E$ genotyping has limited clinical value but is useful for trials aiming to select subjects who are at higher risk for progressing to AD-type dementia.

Chapter 3 is closely related to Chapter 2. It contains the protocol for the diagnostic test accuracy of $A P O E$ for dementia in the primary care setting. The protocol is written for the Cochrane Collaboration, is meant to serve as guide for similar reviews, and is a prerequisite for the conduct of full reviews.

In Chapter 4, we studied the relation between APOE \&4 allele and neuropsychiatric symptoms in people with $\mathrm{MCl}$. We found that the $A P O E \& 4$ allele was significantly related with agitation and irritability, and with reduced depression.

Chapter 5 is a qualitative literature review in various ways: (1) of the possible role of $A D$ genetic risk variants on $A \beta$ and tau were measured in vivo in CSF or by positron emission tomography (PET), or (2) upon neuropathological examination. Of the almost 50 genetic variants in 26 genes we included in the review, only APOE and PICALM showed consistent effects on $A \beta$ but not on tau.

In Chapter 6, we investigated the association between the top 10 AlzGene loci, which are considered as established AD risk genes; and key markers of $A D$ pathology in $C S F$, magnetic resonance imaging and cognition in nondemented individuals with cognitive impairment. Only $A P O E$ predicted progression to $A D$, showed a consistent effect on $A D$ markers, and correlated significantly with CSF A $\beta_{1-42}$.

Chapter 7 presents the findings of a case-control genetic association study of 25 SNPs, and correlational study of 36 SNPs with CSF biomarkers in a Finnish cohort. We provide evidence that $A P O E-\varepsilon_{4}, C L U$ and $M S_{4} A 4 A$, which have been identified in GWAS to be associated with $A D$, also significantly reduced CSF $A \beta_{1-42}$ in AD. None of the other AlzGene and GWAS loci showed significant effects on CSF tau. The effects of other SNPs on CSF biomarkers and clinical AD diagnosis did not reach statistical significance. Our findings suggest that $A P O E-\varepsilon 4, C L U$ and $M S_{4} A 4 A$ influence both $A D$ risk and CSF $A \beta_{1-42}$. 
Chapter 8 aimed to replicate the findings in Chapter 7, and further investigated the effects of variants in the MS4A gene cluster on CSF A $\beta$. The study was performed in a cohort consisting of patients with $A D, M C l$ and cognitively healthy individuals. Our findings suggest that polymorphisms in the $M S_{4} A$ gene may influence CSF A $\beta_{1-42}$. This supports results from GWAS studies that $M S_{4} A$ is a genetic risk factor for AD.

Chapter 9 presents a general summary and discussion of our main findings and their role in the context of current knowledge, relates the findings to genes in AD pathophysiology, their implications and the methodological considerations. We conclude with suggestions for future research directions. 


\section{Samenvatting}

De ziekte van Alzheimer (AD) is de meest voorkomende oorzaak van dementie en wordt gekenmerkt door het progressief afsterven van neuronen, geheugenverlies, veranderingen in gedrag, stemmingswisselingen en toenemende problemen in het dagelijks functioneren. De ziekte leidt uiteindelijk tot dementie.

Op dit moment is er nog geen behandeling om dementie als gevolg van $A D$ te genezen. Beschikbare behandelmethoden zijn erop gericht om de progressie van de ziekte te vertragen en de symptomen te bestrijden. Vaak start de behandeling pas als de ziekte al in een gevorderd stadium is, omdat de klinische symptomen dan pas herkend worden. Vroege diagnostiek van dementie is belangrijk omdat medicijnen die de potentie hebben om de ziekte te kunnen vertragen het meest effectief zijn als het stadium van dementie nog niet is bereikt.

Om AD in een vroeg stadium vast te kunnen stellen, is het noodzakelijk om inzicht te hebben in de complexe relatie tussen risicofactoren en de pathofysiologie van $A D$. Recente technologische ontwikkelingen hebben de rol van genen op de vatbaarheid voor $A D$ aan het licht gebracht. In deze proefschrift hebben we de invloed onderzocht van genetische risicofactoren, met name 'single nucleotide polymorphisms' (SNPs), op de pathofysiologie en klinische manifestaties van $A D$. Hoewel er verschillende risicogenen van $A D$ zijn geïdentificeerd, is hun effect op de pathofysiologie van AD nog steeds onduidelijk. We hebben dit onderzocht door de effecten van $A D$ risicogenen te correleren met sleutelindicatoren van $A D$ pathologie, waaronder hersenvocht (cerebrospinal fluid oftewel CSF) markers bèta amyloïde (A $\beta$ ) en tau, hippocampus atrofie, geheugenprestaties en neuropsychiatrische symptomen. Aangezien de relatie tussen genetische risicofactoren en AD kan verschillen tussen ziektestadia, hebben we cohorten gebruikt die verschillen in de mate van cognitieve achteruitgang. De specifieke doelen van het onderzoek, de gebruikte methoden en algemene informatie over de cohorten, staan beschreven in Hoofdstuk 1. 
In Hoofdstuk 2 hebben we een meta-analyse uitgevoerd om te onderzoeken hoe bruikbaar APOE genotypering is bij het voorspellen van AD-dementie in patiënten met milde cognitief stoornis (mild cognitive Impairment), oftewel $\mathrm{MCl}$. Ook hebben we onderzocht hoe bruikbaar APOE genotypering is voor het selecteren van deelnemers aan klinische trials die gericht zijn op het voorkomen van progressie naar AD-dementie. Wij vonden dat het risico op AD meer dan verdubbeld is in dragers van het $A P O E \& 4$ allel in vergelijking met mensen zonder dit allel. De lage sensitiviteit en positieve voorspellende waarde vormen een indicatie dat $A P O E$ genotypering van beperkte waarde is voor klinische doeleinden, maar wel bruikbaar is om mensen te selecteren die een hoger risico lopen om $A D$ te ontwikkelen ten behoeve van trials.

Hoofdstuk 3 is nauw verbonden aan Hoofdstuk 2. Het bevat het protocol hoe wij kunnen testen hoe nauwkeurig $A P O E$ is voor een diagnose dementie in de eerstelijnszorg. Het protocol is geschreven voor de Cochrane Collaboration en is bedoeld als gids voor vergelijkbare reviews. Het is een eerste vereiste voor het uitvoeren van volledige reviews.

In Hoofdstuk 4, hebben we de relatie onderzocht tussen het $A P O E \& 4$ allel en neuropsychiatrische symptomen in mensen met $\mathrm{MCl}$. We vonden dat het $A P O E \& 4$ allel significant gerelateerd is aan agitatie en prikkelbaarheid, evenals aan verminderde depressie.

Hoofdstuk 5 beschrijft een kwalitatief literatuuronderzoek naar de mogelijke rol van genetische risicofactoren voor $A D$ op $A ß$ en tau. $A ß$ en tau werden op verschillende manieren gemeten: (1) $i$ in vivo in CSF of met behulp van positron emissie tomografie (PET); of (2) door neuropathologisch onderzoek. Van de bijna 50 genetische variaties in 26 genen die wij in deze review hebben geïncludeerd, vertoonden alleen APOE en PICALM consistente effecten op A $\beta$, maar niet op tau.

In Hoofdstuk 6 hebben wij onderzoek gedaan naar de relatie tussen de top 10 AlzGene loci - die worden beschouwd als gevestigde risicogenen voor $A D$ en key markers van $A D$ pathologie in $C S F, M R I$ en cognitie in niet demente individuen met cognitieve stoornissen. Alleen $A P O E$ bleek een voorspeller te zijn voor de ontwikkeling naar AD. Het 
vertoonde een consistent effect op AD-markers en vertoonde een significante correlatie met CSF A $\beta_{1-42}$.

In Hoofdstuk 7 presenteren wij de bevindingen van een casecontrol genetische associatie studie van 25 SNPs, en een correlatie studie van 36 SNPs met CSF biomarkers in een Fins cohort. Wij tonen aan dat $A P O E-\varepsilon 4, C L U$ en MS4A4A, die in GWAS zijn geïdentificeerd als $A D$-gerelateerd, ook samenhangen met een significante reductie van CSF A $\beta_{1-42}$ in AD. Geen van de andere AlzGene en GWAS loci vertoonden significante effecten op CSF tau. De effecten van andere SNPs op CSF biomarkers en klinische $A D$ diagnoses waren statistisch niet significant. Onze bevindingen wijzen erop dat $A P O E-\varepsilon 4, C L U$ en $M S_{4} A_{4} A$ invloed hebben op zowel het risico op AD als op CSF $A \beta_{1-42}$

Het doel van Hoofdstuk 8 was om de bevindingen van Hoofdstuk 7 te repliceren en om de effecten van varianten in het MS4A gen-cluster op CSF A $\beta$ te onderzoeken. Het onderzoek werd uitgevoerd in een cohort dat bestond uit patiënten met $A D, M C l$ en cognitief gezonde individuen. Onze bevindingen suggereren dat polymorphismen in het MS 4 A gen van invloed kunnen zijn op CSF A $\beta_{1-42 .}$ Dit ondersteunt de resultaten van GWAS studies die aangeven dat dit gen een genetische risicofactor is voor AD.

Hoofdstuk 9 geeft eerst een samenvatting en beschouwing van onze belangrijkste bevindingen in de context van de huidige stand van zaken in de wetenschap. Wij relateren de bevindingen aan genen en hun rol in AD pathofysiologie, en gaan in op de implicaties van onze bevindingen. In dit hoofdstuk gaan wij ook in op methodologische overwegingen. Wij sluiten af met suggesties voor toekomstig onderzoek. 


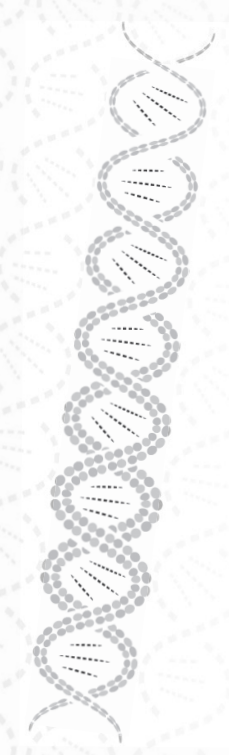




\section{ACKNOWLEDGMENTS}

In June 2008, I started my PhD research in Maastricht. In December 2012, I submitted my dissertation. I travelled more than 200,000 kilometers by train between Delft and Maastricht during these years. In a way, doing a PhD and taking the Dutch trains are the same: In cases of delays, try to find alternatives. Each alternative brought its own challenges. Is it then a wonder that I need 6 pages for my acknowledgments? 
I would like to thank the many people who contributed to my fascinating journey to understanding Alzheimer and life.

First of all, my thanks to all the research participants of the 10-year $\mathrm{MCI}$ follow-up study, the DESCRIPA study and the EDAR study. You have given your time and effort to undergo our numerous tests. Some of you gave blood and repeatedly underwent lumbar puncture, all for research purposes. Without you, our research would not exist.

My deepest thanks to my supervisors. In no time, it has become clear that the first thing a supervisor says when he sees me tells a lot. One asks, 'How are you?' Another, 'How are the analyses?' Still another, 'How is the weather there?'

Prof. Verhey, Frans, thank you for the opportunity to do a PhD under your supervision. You have given me space to explore. At the same time, you readily provided support when asked. When it became definite that I would be spending several months abroad for my internship, you asked how it would be with my husband. That was really thoughtful! Léon appreciated your asking.

Dr. Visser, Pieter Jelle, the statistics test you gave as part of my application for a PhD position was alluring. Develop an algorithm for predicting Alzheimer! It got me very interested, and I was quite excited to proceed with the job. My research project took a different twist. I believe that in the end, things happen for a good reason. You are the most exceptional scientist I know, and I learned a lot from you. I think people in our department would immediately recognize the students you supervised by the lengthy tables in their papers!

I was fortunate to work with a close team in Kuopio. Prof. Soininen, Hilkka, your encouraging words, also when you comment on DESCRIPA papers, work like magic. Dr. Hiltunen, Mikko, your energy and enthusiasm are contagious. Together with the whole team there, we produced a nice paper. It has been a pleasure working on it.

Dr. Helisalmi, Seppo, you have always found it important that things go well with the research and with the researcher. Having lunch is equally important as genotyping SNPs. I went to your lab as a neuropsychologist. I came out totally fascinated with this barely visible thing called DNA. 
Prof. Marc De Baets, Prof. Christine de Die, Prof. Cornelia van Duijn, Prof. Erik Scherder, Prof. Rudolf Ponds, Dr. Bart Rutten and Dr. Mikko Hiltunen, thank you for finding the time to participate in my defense panel.

The months I spent in Kuopio were literally the darkest and coldest moment of my life, but the people I met were warmhearted.

Marjo, you were, as it is said in Dutch, my steun en toeverlaat in Kuopio, my mainstay. You patiently explained the $A B C s$ of $P C R$, how to find the lunch menu on a Finnish website, introduced me to GeoCatching, showed what the Finnish sisu is about, and took me to the next warmest place to a sauna: Kasinharju 309. Matti, you literally brought me warmth by placing an extra heater in my room. Antonio and Aleksi, it was an honor to meet you! The tastes of kalakukko and mämmi will stay forever in my mind.

Lakku and Lakshmi, your hospitality and generosity are heartwarming. Our weekend away in a cottage with Lilli, Maria, Gagos, Arto and Andrea was an adventure! Never thought I'd do it but did it: plunge in the freezing water after the heat of the sauna. Jaya and Heramb, we had so much fun during our Viking evening that I ended up with stomach cramps from all our laughter. The tar ice cream for dessert worked like a laughing gas! Ashik, your Indian cuisine was the best I ever had! I guess the restaurants here do not follow the strict protocol you use when cooking.

Irina, my saunamate, a dear friend, the only other person who dared wake me up in the middle of the night and before the break of dawn just because. It was nice to cross the Arctic Circle line with you, and to see you with Fusako and Natalya in Delft. I think, saying 'nice' is an understatement.

Annika, thanks for our memorable Smoke Sauna visits! With you, it was just letting go without going loose. It was not so crazy after all, to swing from scorching heat to the numbing snow, and start all over again. Terhi, it was a pleasure to see you once more. The pies at Kahvila Kaneli were absolutely delicious! Anette, thanks for lending your expertise in biostatistics and sharing your thoughts on our paper. 
Maria Pikkarainen, your friendly and welcoming smile immediately put me to ease. Thanks for giving me a very practical item: a map.

Markku, our coffee break discussions together with Seppo and Marjo were always interesting. I wish you a good flight and a safe landing.

Aruna and Hannu, you always prepared a full feast for me that I almost didn't dare come for a visit anymore, thinking that it would be such a bother for you. But then I realized that I would have done the same for you. Hope to see you again someday, somewhere. Lorena, Joey and Tanja, it was a pleasant surprise to get to know you and be invited to a Filipino-Finnish home. Mango cake and bagoong were something I never expected to eat there!

My thanks to colleagues in Maastricht. If I fail to include some names, fear not! It's not my memory but just the space in this paper that is constrained.

Els, you were my first contact person in Maastricht. I admire how you manage to accommodate everyone in Frans' agenda. Thanks for always finding a slot for me.

Carla Brandts, in all my years at our department, you were the only one who spoke my name as it is meant to be spoken. That was special.

Nico and Ron Mengelers, you are indispensable! You were always ready to help whenever my mini Mac did something strange. What would have taken me forever to figure out, took you only a couple of minutes to fix. Ron, I find it fascinating how you sometimes took over my computer via team viewer to install something. High tech!

Elsa, your spontaneity and concern for everyone are unmissable! I think that I am not the only one in our department who come to you when we don't know where else to go or who else to ask. I enjoyed preparing sushi for the sushi club.

Inez, Anja and Olga, without you as office roommates, I would be talking to the plants. Inez, I will think of you for the one moment that you baked a cake and saved a piece for me to take in the train on my journey back to Delft. Anja, it was nice talking with you over everyday things, including carnival costumes. Olga, the most important thing I 
learned from you when preparing a manuscript is how to remove field codes. It sure kept my references from getting mixed up.

Martin, your thoroughness in going through our intern's thesis was something I appreciated. If I would write another paper, I would subject it to your scrutiny. Susanne, thank you for your assistance in collecting data for EDAR. It has really been fine working with you. Saartje, Heidi and Lies, we shared a common room, an apartment for the first time, in Paris for de AAIC. It worked out well and I found it gezellig. Ankie, Laurent and Marco, thank you for all the administrative support. Tanja, it was such an ease to share an exam room at B1 with you. Martie, thanks for guiding me through.

Wil, you stood by me during a most challenging period, and supported me in looking after my interests. It meant a lot to me.

Reem, from Vienna to Oxford-that was how far you got me to go. You, Guy and Helena. Anna, how can I ever not think of you whenever I see a doorless room? I'm looking forward to further working with you on those Cochrane reviews. Lena, our meetings for the EDAR study monitor always went like a breeze. It has been a real pleasure working with you.

Rob, you literally gave my years of work its form. I wanted it to be just simple but elegant. It was amazing how you transformed what I wanted to something much more than I expected. Thanks so much to you and Anita!

Gerald and Rita, my paranymphs, and Mette, our lunch breaks were often consumed by passionate discussions about the academe, food, life and many, many more. Gerald, buddy, finding you was like partly being home. Rita, we'll still have that Portuguese dinner one of these days. Mette, from Switzerland, you travelled all the way to Kuopio to see me, and will now be travelling to Maastricht to be with me on my defense. Come over and let me just give you a hug! Eka and Antwan, madalot! Your support for my PhD work right from the start got me this far.

Mitzi, Adam, Agi, Morie, Cherie, Benjamin, Rowena, Ian, Kristel and kids, you have always been an inspiration for me. Miriam, 
Henri, Bert, Berry, Marij and Emmy, thanks for your encouragement and support. Jannah, in honor of your birthday, I am defending years of scientific work on this day, the $24^{\text {th }}$ of April.

Ma Mariets, vanaf het begin was jij een grote steun voor mij. Als ik soms tot laat of juist heel vroeg in Maastricht moest zijn, stond jouw huis in Heerlen altijd open. En ondanks jouw conditie stond er altijd een maaltijd op tafel en een ontbijt. Met jou kon ik alles delen, mijn ups en mijn downs. Jouw lieve zorgen, belangstelling en jouw vechtlust inspireerden mij steeds om door te gaan. Ik ben blij dat je nu hier bij mijn promotie kunt zijn. Zorg dat je nog lang bij ons blijft!

Mommy, inaalay ko sa iyo ang librong ito. Mula pagkabata, ang pangarap mo para sa akin ay maging doktor. Sa wakas, naging doktor na ako—ng pilosopiya! Mahal na mahal kita mommy. Wala kang kapantay at katulad para sa akin. Sa iyo, natutunan kong magtiyaga, manalig sa Diyos at huwag kailanman susuko. Dad, muchisimas gracias, por todo. I miss you.

Léon, mijn lieve man, dank je dat je altijd bij mij bent. Kom, houd mijn hand vast. Wij gaan verder! 



\section{CURRICULUM VITAE AND PUBLICATIONS}

Lyzel Samaniego Elias-Sonnenschein was born on August 25, 1970 in Manila, Philippines. She completed her high school at the Dominican St. James Academy. She earned her bachelor and masteral degrees in psychology, with specializations in clinical and experimental psychology, at the University of the Philippines (UP) in Diliman. As a student, she co-founded an organization for street children, and was engaged in charitable activities and medical missions.

While studying for her master's, Lyzel worked in the academe and at several health institutions. Among others, she was an editor at the Ateneo de Manila University, a lecturer in psychology at UP Manila and a psychologist in a private clinic. In 1998, she started working as a researcher for ECPAT International, which is a global network against the commercial sexual exploitation of children. As part of a training team, her work brought her to Africa, Central America and Europe. In 2000, she decided to work as a psychologist in a clinical setting, and joined the memory center of St. Luke's Medical Center. Trained to perform neuropsychological assessments, she became part of a multidisciplinary team that mainly saw patients who had memory complaints. This was the start of her professional interest in Alzheimer.

In 2002, she married Léon Sonnenschein, whom she met in Delft during her trip to Europe for ECPAT. A year later, she came to live in the Netherlands. After learning Dutch, she proceeded to obtaining a master's degree in clinical neuropsychology at the Vrije Universiteit in Amsterdam. For her thesis, she set up a joint research with the Department of Neurology, Academic Medical Center, University of Amsterdam to study cognition in Dutch patients with LGMD2A, a 
progressive muscular disease caused by mutations in the CAPN3 gene. She earned her degree cum laude in 2007. During her studies, she was a board member of Alzheimer Nederland-Delft, Westland and Oostland region. In her portfolio were the Alzheimer Café's in this region.

In 2008, Lyzel joined the Department of Psychiatry and Neuropsychology of Maastricht University to do PhD research on early markers and predictors of Alzheimer's disease. Her research focused on genetic risk factors. As part of her $\mathrm{PhD}$, she went to Kuopio, Finland in 2011 and worked for three months as a visiting researcher at the Institute of Clinical Medicine-Neurology, University of Eastern Finland. This resulted in a collaborative project that is still ongoing. In 2012, she returned twice to Kuopio for work visits.

As part of her interest in education, Lyzel also started a project to develop together with foreign students internationalized tutor material tasks for selected courses in medicine. She is currently working as a researcher at the Department of Psychiatry and Neuropsychology at Maastricht University. 


\section{Publications}

Elias-Sonnenschein LS, Helisalmi S, Natunen T, Hall A, Paajanen

T, Herukka S-K, Laitinen M, Remes AM, Koivisto AM, Mattila KM, Lehtimäki T, Verhey FRJ, Visser PJ, Soininen $\mathrm{H}$, Hiltunen M.

Genetic variants associated with Alzheimer's disease and cerebrospinal fluid biomarkers in a Finnish case-control cohort. PLOS ONE, 2013 (In Press).

Elias-Sonnenschein LS, Bertram L, Visser PJ.

Relationship between genetic risk factors and markers for Alzheimer's disease pathology. Biomarkers in Medicine, 2012, 6(4):477-495.

Elias-Sonnenschein LS, Viechtbauer W, Ramakers IHGB, Verhey FRJ, Visser PJ.

Predictive value of $A P O E-\varepsilon 4$ allele for conversion from $\mathrm{MCl}$ to AD-type dementia: a meta-analysis. Journal of Neurology, Neurosurgery and Psychiatry, 2011, Oct;82(10):1149-56.

Vermeiren APA, Bosma H, Visser PJ, Zeegers MP, Graff C, Ewers M, Frisoni GB, Frolich L, Hampel $H$, Jones RW, Kehoe PG, Lenoi $H$, Minthon $L$, Nobili F, Olde Rikkert M, Rigaud A-S, Scheltens P, Soininen H, Spiru L, Tsolaki M, Wahlund L-O, Vellas B, Wilcock G, Elias-Sonnenschein LS, Verhey FRJ.

The association between $A P O E-\varepsilon 4$ and Alzheimer type dementia among memory clinic patients is confined to those with a higher education: the DESCRIPA study. Journal of Alzheimer's Disease, 2013, doi:10.3233.

Norberg J, Graff C, Almkvist O, Ewers M, Frisoni GB, Frolich L, Hampel $H$, Jones RW, Kehoe PG, Lenoir $H$, Minthon L, Nobili F, Olde Rikkert M, Rigaud AS, Scheltens $P$, Soininen $H$, Spiru L, Tsolaki M, Wahlund LO, Vellas B, Wilcock G, Elias-Sonnenschein LS, Verhey FR, Visser PJ. Regional differences in effects of $A P O E-\varepsilon 4$ on cognitive impairment in non-demented subjects. Dementia and Geriatric Cognitive Disorders, 2011, 32(2):135-42. 


\section{Submitted papers}

Elias-Sonnenschein LS, Viechtbauer W, Ramakers IHGB, Verhey FRJ, and Visser PJ.

Presence of $A P O E-\varepsilon 4$ allele for the longitudinal diagnosis of Alzheimer's and other dementia disorders in people with cognitive impairment but no dementia in a primary care setting. Revision submitted to the Cochrane Collaboration (2013).

Elias-Sonnenschein LS, Viechtbauer W, Ramakers IHGB, Verhey FRJ, and Visser PJ.

Presence of $A P O E-\varepsilon 4$ allele for the longitudinal diagnosis of Alzheimer's and other dementia disorders in people with cognitive impairment but no dementia in a secondary care setting. Revision submitted to the Cochrane Collaboration (2013).

Elias-Sonnenschein LS, Viechtbauer W, Ramakers IHGB, Verhey FRJ, and Visser PJ.

Presence of $A P O E-\varepsilon 4$ allele for the longitudinal diagnosis of Alzheimer's and other dementia disorders in people with cognitive impairment but no dementia in a community care setting. Revision submitted to the Cochrane Collaboration (2013).

Elias-Sonnenschein LS, Kenis G, Graff C, Jones RW, Kehoe PG, Minthon L, Nobili F, Olde Rikkert M, Scheltens P, Spiru L, Wilcock G, Blennow K, Wolz R, Verhey FRJ, Visser PJ.

Biomarker and cognitive correlates of $A D$ risk genes in nondemented individuals with cognitive impairment. Under review (2013).

Elias-Sonnenschein LS, Ramakers IHGB, Verhey FRJ, Graff C, Frisoni G, Scheltens P, Nobili FM, Damian M, Hilkka S, Spiru L, Jones R, Olde-Rikkert M, Wilcock G, Hampel H, Aalten P, Shaw LM, Trojanowski JQ, Visser PJ. Neuropsychiatric symptoms associated with the $A P O E-\varepsilon_{4}$ allele in subjects with mild cognitive impairment in the DESCRIPA and ADNI cohorts. Submitted (2013).

Elias-Sonnenschein LS, Verhey FRJ, Visser PJ for the EDAR study. Effects of MS4A variants on cerebrospinal fluid abeta 1-42. Submitted (2013). 
